Prepared for the U.S. Department of Energy

Under Contract DE-AC05-76RL01830

\title{
Three-Dimensional Groundwater Models of the 300 Area at the Hanford Site, Washington State
}

\author{
MD Williams $\quad$ PD Thorne \\ ML Rockhold Y Chen
}

September 2008

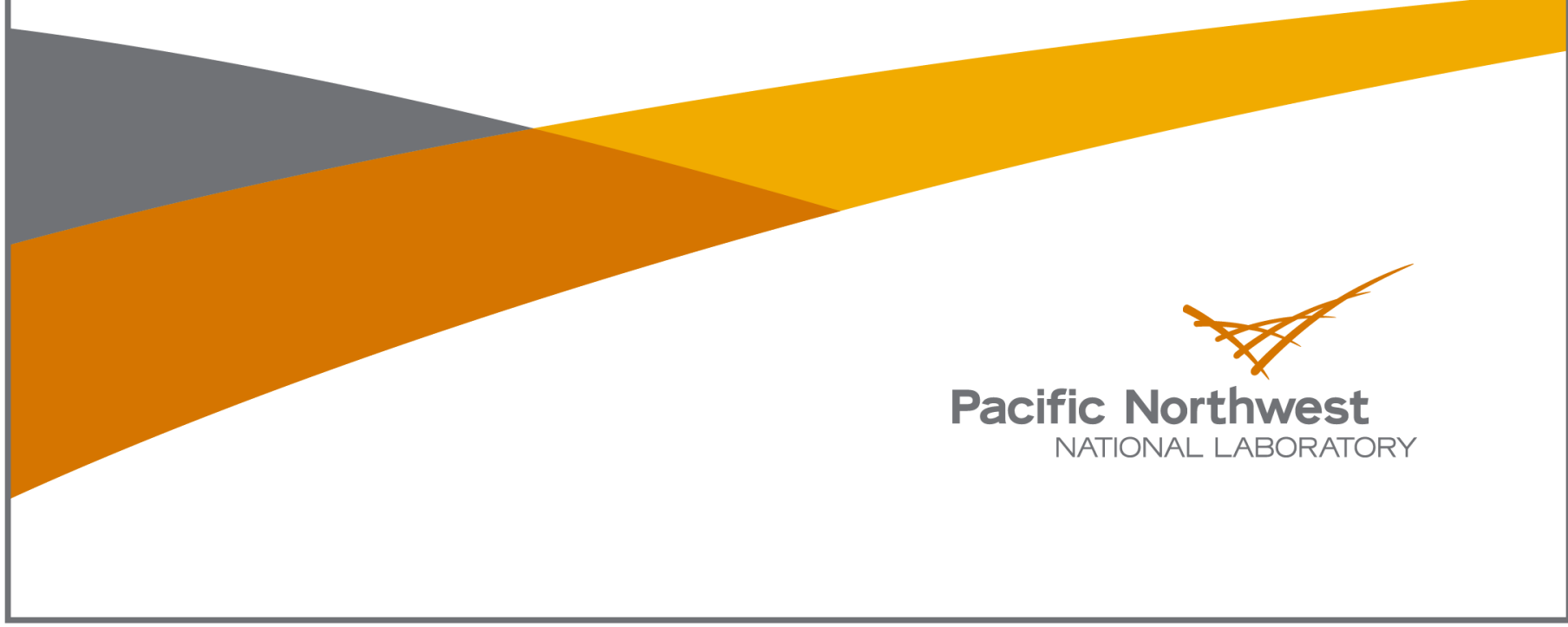




\title{
DISCLAIMER
}

This report was prepared as an account of work sponsored by an agency of the United States Government. Neither the United States Government nor any agency thereof, nor Battelle Memorial Institute, nor any of their employees, makes any warranty, express or implied, or assumes any legal liability or responsibility for the accuracy, completeness, or usefulness of any information, apparatus, product, or process disclosed, or represents that its use would not infringe privately owned rights. Reference herein to any specific commercial product, process, or service by trade name, trademark, manufacturer, or otherwise does not necessarily constitute or imply its endorsement, recommendation, or favoring by the United States Government or any agency thereof, or Battelle Memorial Institute. The views and opinions of authors expressed herein do not necessarily state or reflect those of the United States Government or any agency thereof.

\author{
PACIFIC NORTHWEST NATIONAL LABORATORY \\ operated by \\ BATTELLE \\ for the \\ UNITED STATES DEPARTMENT OF ENERGY \\ under Contract DE-AC05-76RL01830
}

Printed in the United States of America
Available to DOE and DOE contractors from the
Office of Scientific and Technical Information,
P.O. Box 62, Oak Ridge, TN 37831-0062;
ph: (865) 576-8401
fax: $(865) 576-5728$
email: reports@adonis.osti.gov

\author{
Available to the public from the National Technical Information Service, \\ U.S. Department of Commerce, 5285 Port Royal Rd., Springfield, VA 22161 \\ ph: (800) 553-6847 \\ fax: $(703) 605-6900$ \\ email: orders@ntis.fedworld.gov \\ online ordering: http://www.ntis.gov/ordering.htm
}




\title{
Three-Dimensional Groundwater Models of the 300 Area at the Hanford Site, Washington State
}

\author{
MD Williams PD Thorne \\ ML Rockhold \\ Y Chen
}

September 2008

Prepared for

the U.S. Department of Energy

under Contract DE-AC05-76RL01830

Pacific Northwest National Laboratory

Richland, Washington 99352 



\section{Executive Summary}

The purpose of this research is to develop and maintain numerical groundwater flow and transport models that can be used to refine the conceptual site model for groundwater beneath the 300 Area, and to assist in evaluating alternative remediation technologies focused on the 300 Area uranium plume. Groundwater flow rates and directions in the 300 Area are very dynamic because of the high hydraulic conductivities, along with the large daily, weekly, and seasonal fluctuations in the Columbia River stage. Quantifying the dynamics of groundwater flow and transport in the 300 Area aquifer will help understand the significant seasonal variability of uranium plume concentrations seen in biannual groundwater monitoring, and will help evaluate remediation options. Groundwater flow rates are very high in the upper portion of the 300 Area unconfined aquifer (within the Hanford formation), with velocities up to 10 to $15 \mathrm{~m} / \mathrm{d}$ ( 35 to $50 \mathrm{ft} / \mathrm{d}$ ) based on a tracer test and limited plume-migration data. Variability in the groundwater-flow directions is apparent from analysis of hourly and subhourly automated water-level measurements from monitoring networks established in the 300 Area. Generalized flow directions in the area between the north and south process ponds are toward the east to south, with the directions changing toward the south and west during periods of increases in the river stage (daily and seasonal).

High-resolution water level and river stage data were required to simulate the dynamics of the 300 Area aquifer. Two scales of groundwater flow and transport models were developed based on the availability of high-resolution water-level monitoring data. A larger-domain model was developed that includes the 300 Area and extends north and south using data from the early 1990s water-level monitoring network. A smaller domain model was developed for a portion of the large scale model domain in the north of the 300 Area that used water-level data from another smaller monitoring well network that was established in 2004. These models focus on the highly permeable upper portion of the unconfined aquifer within the Hanford formation that has hydraulic conductivity values 2 to 3 orders of magnitude higher than the underlying Ringold Formation aquifers. These models simulate saturated and unsaturated groundwater flow and transport with the STOMP code, which was developed at Pacific Northwest National Laboratory. ${ }^{1}$ The model domains include the lower portion of the vadose zone to encompass the range of river stage and water-table elevation variations seen during the simulation periods.

The hydrostratigraphy, topography, and bathymetry for the three-dimensional models used a consistent framework using EarthVision ${ }^{\circledR}$ software. ${ }^{2}$ The hydrostratigraphic units were determined from previously published interpretations of the 300 Area, along with data from additional wells installed since those studies. A reanalysis of some of the older geologic unit picks from well logs in the area, along with using geophysical logs, was conducted based on the detailed knowledge gained from the 300 Area limited field investigation boreholes. The primary hydrostratigraphic units within the model domain were the Hanford formation gravels, a fine-grained Ringold Formation unit that was encountered in many of the wells (although not completely continuous) in the 300 Area immediately below the Hanford and Ringold contact, and the underlying Ringold gravels. The three-dimensional hydrostratigraphy in the EarthVision database was sampled at the model finite difference node locations.

\footnotetext{
${ }^{1}$ Subsurface Transport Over Multiple Phases (numerical code).

${ }^{2}$ EarthVision ${ }^{\circledR}$ is a registered trademark of Dynamic Graphics, Inc.
} 
Recent studies of the hyporheic zone in the 300 Area have shown the importance of a layer of river alluvium with lower hydraulic conductivity (relative to the Hanford formation) that is dampening the response of wells near the river to river-stage fluctuations, and limiting the aquifer flux to and from the river. Downhole probe measurements of electrical conductivity and temperature of the aquifer in wells near the Columbia River have been interpreted to estimate the extent of the groundwater/river water mixing zone. For example, downhole probe measurements in 2006 revealed that river water entered the aquifer to a distance of more than $188 \mathrm{~m}(617 \mathrm{ft})$ inland when the river stage was high. Limited data on specific conductance (from biannual groundwater monitoring events) indicate the inland extent of river water could be much greater in places.

A number of large- and small-scale model simulations were run focusing on the hydraulic conductivity values and distribution within the Hanford formation and river alluvium zone. Simulations were run with uniform hydraulic conductivity values for the Hanford formation and with the Hanford formation subdivided into two zones with different hydraulic conductivity values. Heterogeneous hydraulic properties in the Hanford formation were also developed from stochastic hydraulic properties developed for the large-scale model. The hydraulic conductivity of the Hanford formation in the 300 Area was difficult to determine through common methods used for aquifer testing, such as slug tests and limited duration pumping tests, because of its very high permeability $(>1000 \mathrm{~m} / \mathrm{d}[3,280 \mathrm{ft} / \mathrm{d}])$ and the fluctuating water table induced by changes in the river stage. Hydraulic conductivities for the Ringold Formation were not varied and were established based on slug testing results. A simulation matrix was developed to bracket hydraulic conductivity values for the Hanford formation and to evaluate the different property distributions. The number of simulations that could be run was limited by the computational requirements of the runs and available resources. This precluded a rigorous inverse process for parameter estimation within the scope of this effort. However, this research did include some limited trial and error fitting of hydraulic conductivity.

Simulation results were assessed by a number of metrics, including calculating the difference between simulated and measured water levels for wells from the automated water-level monitoring network within the model domain; simulated tracer plume drift directions and $x-y$ velocities calculated from changes in center of mass of the tracer plumes compared to the limited field tracer test results; and comparison of the arrivals and inland extent of a simulated river water tracer (for the small-scale model only) with downhole measurements of specific conductance from the automated monitoring well network. Additionally, water fluxes are calculated for the model boundaries (north, south, east, and Columbia River) for evaluation in comparison with independent estimates and to show the range in simulated values for the different cases that were run. Recommendations for additional conceptual and numerical model development based on the results of this study are also described in this report. 


\section{Acknowledgments}

The authors would like to acknowledge the helpful support of the following individuals: Duane Ward for GIS, testing, and archiving; Ray Clayton, Darrell Newcomer, and Robert Edrington (at Fluor Hanford, Inc.) for collecting and processing water level data; Bruce Bjornstad and Bruce Williams assisted in the hydrostratigraphic interpretation; Brad Fritz and Rob Mackley for their insight on the 300 Area hyporheic zone; and Yi-Ju Bott for preliminary exploratory data analyses. We also acknowledge the guidance and contributions of Vicky Freedman and Fred Zhang for developing and implementing the configuration management system. Hope Matthews provided the text editing with text processing provided by Lila Andor and Stacy Larsen. We acknowledge John Smoot (Fluor Hanford, Inc) for his the review and recommendations. Finally, the authors would like to thank Chris Johnson for his thorough and thoughtful review. 



\section{Acronyms and Abbreviations}

$\begin{array}{ll}\text { AWLN } & \text { Automated Water Level Network Data Module } \\ \text { BHI } & \text { Bechtel Hanford, Inc. } \\ \text { BWTF } & \text { Buried Waste Test Facility } \\ \text { DOE } & \text { U.S. Department of Energy } \\ \text { DOE-RL } & \text { U.S. Department of Energy, Richland Operations Office } \\ \text { FY } & \text { fiscal year } \\ \text { gpd } & \text { gallons per day } \\ \text { gpm } & \text { gallons per minute } \\ \text { GSLIB } & \text { Geostatistical Software Library } \\ \text { LFI } & \text { limited field investigation } \\ \text { Lpd } & \text { liters per day } \\ \text { Lpm } & \text { liters per minute } \\ \text { MMT } & \text { Multicomponent Mass Transfer } \\ \text { PNNL } & \text { Pacific Northwest National Laboratory } \\ \text { PTF } & \text { pedotransfer functions } \\ \text { RACS } & \text { Remediation and Closure Science Project } \\ \text { RESRAD } & \text { residual radioactivity code } \\ \text { RI/FS } & \text { remedial investigation feasibility study } \\ \text { RMSE } & \text { root mean squared error } \\ \text { SGSIM } & \text { sequential Gaussian simulation program } \\ \text { STOMP } & \text { Subsurface Transport Over Multiple Phases (numerical code) } \\ \text { VTT } & \text { Variable Thickness Transient (numerical code) } \\ & \end{array}$





\section{Contents}

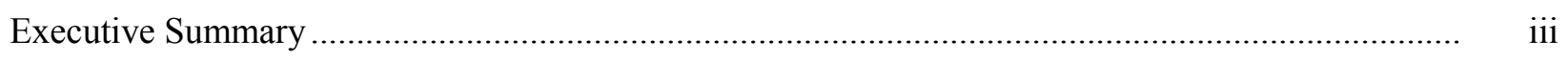

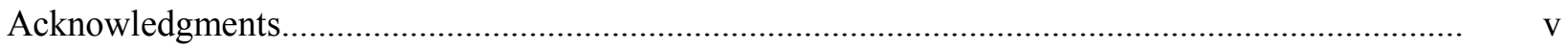

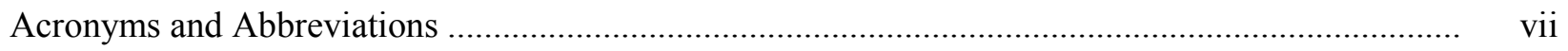

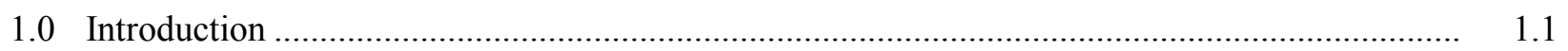

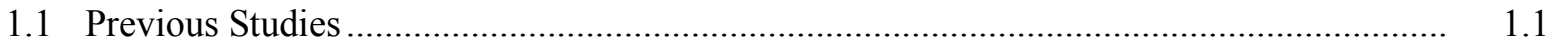

1.1.1 Site Characterization Studies..................................................................... 1.4

1.1.2 Previous Modeling Studies.............................................................................. 1.5

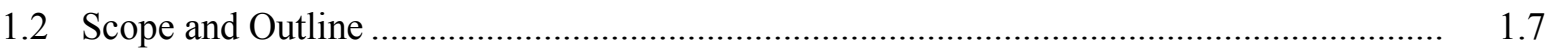

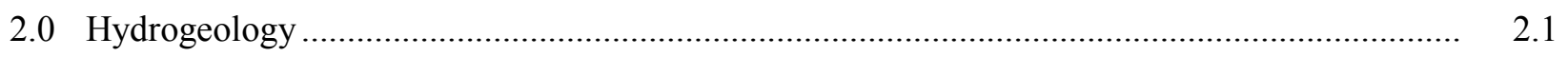

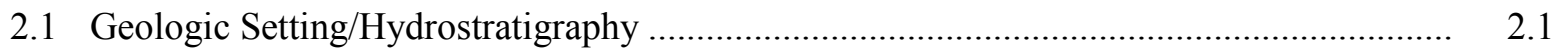

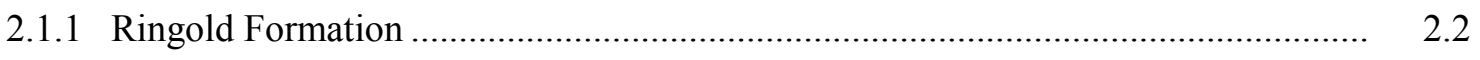

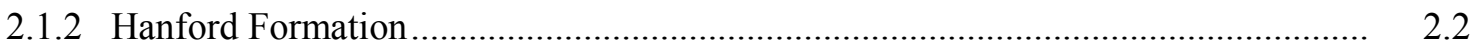

2.1.3 Recent Eolian Deposits and Backfill ............................................................... 2.3

2.1.4 Hydrogeologic Unit Designations for Groundwater Modeling ............................... 2.3

2.1.5 Revision of Hanford and Ringold Formations Contact Surface............................. 2.4

2.1.6 Spatial Data Management (EarthVision Database) ............................................. 2.6

2.1.7 Uncertainties in Defining the Hydrogeologic Framework ................................... 2.7

2.2 Aquifer Hydraulic Properties .................................................................................... 2.13

2.3 Water Table and Groundwater Flow Directions ............................................................ 2.14

2.3.1 Current (2004+) Water-Level Monitoring Network............................................ 2.18

2.3.2 Early 1990s Water-Level Monitoring Network …................................................. 2.34

2.3.3 Polyphosphate Treatability Test Flow Rates and Directions ................................ 2.37

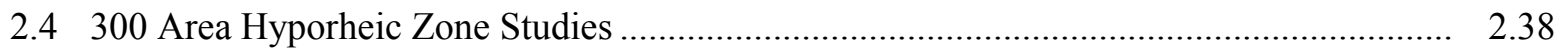

2.4.1 Drive-Point Penetration................................................................................. 2.39

2.4.2 Piezometer Head Measurements and Slug Tests ..................................................... 2.39

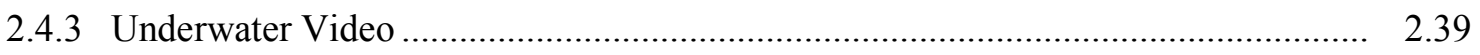

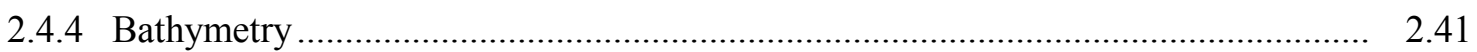

2.4.5 Sub-Bottom Profiling .............................................................................. 2.41

2.4.6 Sediment Sampling ................................................................................. 2.42

3.0 Large-Scale 300 Area Groundwater Flow and Transport Model ........................................... 3.1

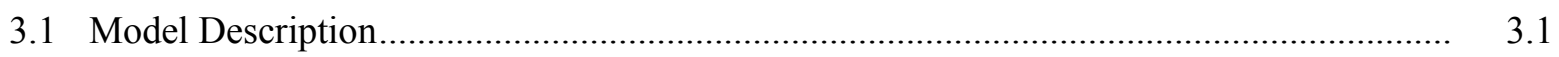

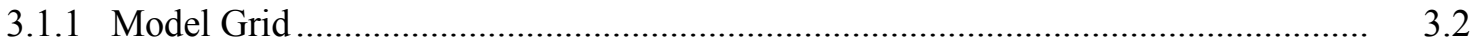

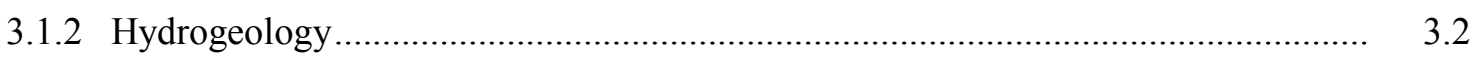

3.1.3 Boundary Conditions................................................................................. 3.5

3.1.4 Water Sources and Sinks.......................................................................... 3.6

3.1.5 Hydraulic Property Distributions ……................................................................ 3.7

3.1.6 Spatial Moment Calculations ....................................................................... 3.24 
3.2 Simulation Results................................................................................................. 3.25

3.2.1 Example Simulation Detailed Results ............................................................ 3.27

3.2.2 Large-Scale 300 Area Model Cases .................................................................... 3.41

4.0 Small-Scale North 300 Area Flow and Transport Model .....................................................

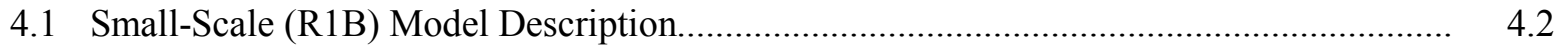

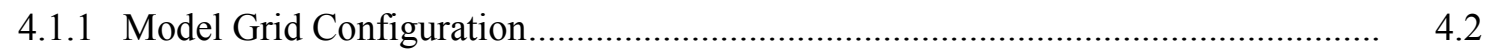

4.1.2 Model Boundary Conditions ............................................................................ 4.2

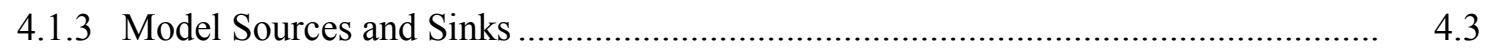

4.1.4 Model Hydrostratigraphy .................................................................................. 4.4

4.1.5 Model Material Properties...................................................................... 4.7

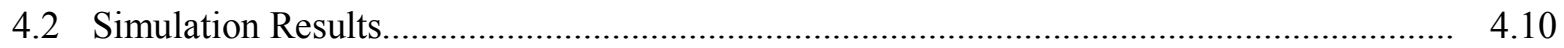

4.2.1 Detailed Example Simulation Case - r1b2-e ................................................... 4.11

4.2.2 Comparison of Hydraulic Property Cases ................................................................ 4.26

4.2.3 Refined Vertical Node Grid Spacing Model - R1C ........................................... 4.31

5.0 Summary and Recommendations ............................................................................. 5.1

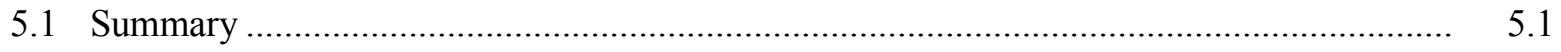

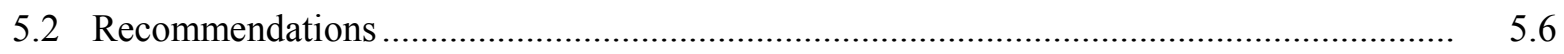

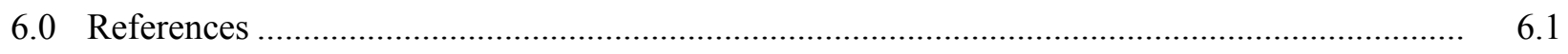

Appendix A - Hanford Site 300 Area Porosity Data ..................................................................... A.1

Appendix B - Hanford Site 300 Area Gamma Log Data ............................................................ B.1

Appendix C - Whole Sediment Grain-Size Distribution Data and Metrics for Selected LFI Core Samples ................................................................................. C. C.

Appendix D - Tests for Statistical Significance of Differences Between Mean Values ..................... D.1 


\section{Figures}

1.1 Map of the Hanford Site with the 300 Area Location...........................................................

1.2 Locations of Monitoring Wells and Facilities at the 300 Area ............................................. 1.3

2.1 Hydrogeologic Stratigraphic Column for the 300 Area ....................................................... 2.1

2.2 Contour Map of Contact Elevation Between the Ringold and Overlying Hanford

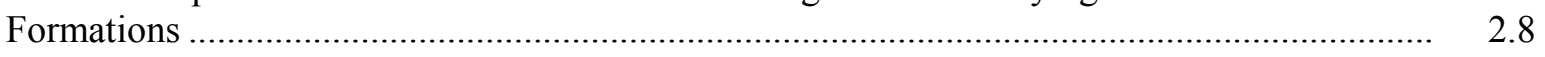

2.3 Cross Section A-A' Showing Hydrogeologic Units and Seasonal Water-Table

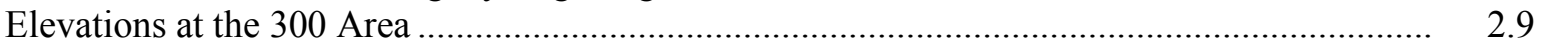

2.4 Cross Section B-B' Showing Hydrogeologic Units and Seasonal Water-Table Elevations at the 300 Area

2.5 Cross Section C-C' Showing Hydrogeologic Units and Seasonal Water-Table Elevations at the 300 Area

2.6 Cross Section D-D' Showing Hydrogeologic Units and Seasonal Water-Table Elevations at the 300 Area

2.7 Cross Section E-E' Showing Hydrogeologic Units and Seasonal Water-Table Elevations at the 300 Area

2.8 Map Showing Locations of Cross Sections ................................................................. 2.12

2.9 Three-Dimensional View of the Top of the Ringold Formation Showing Boreholes Defining the Fine-Grained Subunit.

2.10 Location and Hydraulic Conductivity Values for Pumping Tests with Results Considered Reliable.

2.11 Columbia River Stage from the 300 Area Gauging Station for 2006 and 2007

2.12 Water-Table Elevations and Uranium Concentrations in Upper Part of Unconfined Aquifer Beneath 300 Area, December 2005.

2.13 Water-Table Elevations and Uranium Concentrations in Upper Part of Unconfined Aquifer Beneath the 300 Area, June 2006

2.14 The 2004+ Water-Level Monitoring Network for the 300 Area - Initial High-River Stage Example.

2.15 The 2004+ Water-Level Monitoring Network for the 300 Area - Sustained High-River Stage Example.

2.16 The 2004+ Water-Level Monitoring Network for the 300 Area - Initial Lower River Stage Following High-River Stage Example

2.17 The 2004+ Area Water-Level Monitoring Network in the 300 Area - Sustained LowRiver Stage - Inflow Example.

2.18 The 2004+ Water-Level Monitoring Network for the 300 Area - Sustained Low-River Stage - Outflow Example.

2.19300 Area Water-Level Monitoring Network - Hydraulic Gradient Rose Diagrams for Mid-October, 2006, Through July 26, 2007

2.20 300 Area Water-Level Monitoring Network - Hydraulic Gradient Rose Diagrams for July 26, 2006, Through July 26, 2007. 
2.21 300 Area Water-Level Monitoring Network - Hydraulic Gradient Rose Diagrams for July 26, 2006, Through July 26, 2007.

2.22 Hydraulic Gradient Directions for August 2006 Through January 2007 Calculated from 300 Area Automated Water-Level Network for Well Cluster 399-1-16a, 399-2-2, and 399-1-7.

2.23 Hydraulic Gradient Directions for February 2007 Through July 2007 Calculated from 300 Area Automated Water-Level Network for Well Cluster 399-1-16a, 399-2-2, and 399-1-7.....

2.24 Temperature Measurements from Wells in the 2004+ 300 Area Monitoring Network for 2006

2.25 Electrical Conductivity Measurements from Wells in the 2004+ 300 Area Monitoring Network for 2006

2.26 Columbia River Stage from the 300 Area Gauging Station for 1992 and Early 1993

2.27 Wells in the Early 1990s Water-Level Monitoring Network

2.28 Wells in the Early 1990s Water-Level Monitoring Network 2.36

2.29 Monitoring Well Network for the Polyphosphate Treatability Test Site 2.37

2.30 Locations of the Drive-Point Penetrations and the "Depth of Refusal" Results 2.40

2.31 Hydraulic Conductivity Measured in Piezometers in the Hyporheic Zone Near Spring 9 Along the Columbia River Shoreline.

2.32 Transects for Acoustic Profiles of the River Bed Shown in Figure 2.33

2.33 Example Acoustic Profiles of the River Bed Along the Transects Shown in Figure 2.32.

2.34 Locations of Sediment Samples Collected from the River Bed and Sediment Photos

2.35 Area Where Saturated Hanford Formation Sediment is in Contact With the River Channel Based on the Current Hydrogeologic Model .

3.1 Plan View of Large-Scale 300 Area STOMP Model Grid with Selected Wells.

3.2 Three-Dimensional View of STOMP Model Grid R5B with the Top of the Model Domain in the Vadose Zone at an Elevation of 109 m NAVD88

3.3 Plan-View Zonations of the Hanford Formation at 106-m Elevation and 102-m Elevation

3.4 Locations of Boreholes from Which Core Porosity and Gross Gamma Log Data Were Collected

3.5 Directional Experimental and Model Variograms for Total Porosity and Gross Gamma Log Data in the 300 Area...

3.6 Cross-Plot of Co-Located Porosity and Gamma Log Data for 300 Area Wells

3.7 Gamma Log - Grain Size Correlation Functions Representing Selected Samples from LFI Boreholes

3.8 Oblique Views of Three Stochastic Realizations of $d_{\mathrm{g}}$ Generated Using SGSIM with Gamma Log Data and Gamma Log-Grain Size Correlation Functions

3.9 Oblique Views of Three Stochastic Realizations of Total Porosity Generated Using SGSIM with Simulated dg fields as Soft Data.....

3.10 Oblique Views of Three Stochastic Realizations of x-Direction Hydraulic Conductivity

3.11 Oblique Views of Three Stochastic Realizations of Porosity 
3.12 Oblique Views of Three Stochastic Realizations of x-Direction Hydraulic Conductivity Generated Using Smoothed Contours.

3.13 River Stage During Simulation Period Showing Times of Tracer Pulses and Drift.....

3.14 Comparison of Simulated Hydraulic Heads and Measured Water Levels for Boundary Wells

3.15 Comparison of Simulated Hydraulic Heads and Measured Water Levels for Selected Near-River Wells

3.16 Comparison of Simulated Hydraulic Heads and Measured Water Levels for Selected Inland Wells

3.17 Calculated Head Residuals for Large-Scale 300 Area Model Example Case...

3.18 Simulated Instantaneous Water Fluxes Calculated for Model Boundaries

3.19 Simulated Cumulative Net Water Fluxes Calculated for Model Boundaries

3.20 Simulated Annual Cumulative Water Flux for Period from February 1, 1992, to February 1, 1993

3.21 Simulated Conservative Tracer- April 20, 1992 Pulse; Initial High-River Stage Period

3.22 Simulated Conservative Tracer- June 22, 1992 Pulse; High- to Low-River Stage Period. Plots show the plumes at the end of the 1-day pulse and at 5, 10, 15, 20, and 25 elapsed days.

3.23 Simulated Conservative Tracer- October 6, 1992, Pulse; Low-River Stage Period.

3.24 Plume Center-of-Mass Horizontal Velocity Magnitudes for April, June, and October 1992 Conservative Tracer Pulses

3.25 Comparison of Sum-of-Squared Hydraulic Head Residuals for Large-Scale 300 Area Model Simulations.....

3.26 Comparison of Sum-of-Squared Hydraulic Head Residuals for All Stochastic LargeScale 300 Area Model Simulations.

3.27 Summary of Simulated Cumulative Annual Water Fluxes for Large-Scale 300 Area Model Simulations

4.1 Plan View of Small-Scale Model Grid with Selected Wells.

4.2 Hydraulic Property Zonation at 103-m Elevation for the Small-Scale 300 Area Model.

4.3 Hydraulic Property Zonation at 102-m Elevation for the Small-Scale 300 Area Model

4.4 Three-Dimensional View of Hydraulic Property Zonation for the Small-Scale 300 Area Model ......

4.5 River Stage and Timing of Tracer Pulses

4.6 Comparison of Simulated Hydraulic Heads and Measured Water Levels for Boundary Wells

4.7 Comparison of Simulated Hydraulic Heads and Measured Water Levels for Near-River Wells Within the Model Domain .

4.8 Comparison of Simulated Hydraulic Heads and Measured Water Levels for Inland Wells within the Model Domain.

4.9 Calculated Head Residuals for Small-Scale 300 Area Model Example Case..

4.10 Simulated Instantaneous Water Fluxes Calculated for Model Boundaries

4.11 Simulated Net Cumulative Water Fluxes Calculated for the Small-Scale Model Boundaries 
4.12 Simulated Annual Cumulative Water Flux for 2006 for the Small-Scale Model Example Case.

4.13 Simulated Conservative Tracer Pulse for Small-Scale Model Case r1b2-e During the Initial Seasonal River Stage Increase in March 2007

4.14 Simulated Conservative Tracer Pulse for Small-Scale Model Case r1b2-e During High-River Stage Period in June 2006 Followed by Lower Stage in July 2006

4.15 Simulated Conservative Tracer Pulse for Small-Scale Model Case r1b2-e During Low-River Stage Period in December 2006 and January 2007

4.16 Weekly Average Simulated Tracer Horizontal Velocities from Calculated Center of Mass Positions of Tracer Pulses for Case r1b2-e.

4.17 Simulated Conservative River Tracer for Small-Scale Model Case r1b2-e During HighRiver Stage Period in 2006

4.18 Comparison of Simulated River Tracer with Electrical Conductivity Measurements for 2006.

4.19 Comparison of Water-Level Measurement Fit of Small-Scale 300 Area Model Cases.

4.20 Comparison of Weekly Average Tracer Simulated Velocities from Calculated Center of Mass Positions of Tracer Pulses for Selected Cases.

4.21 Simulated Conservative Tracer Pulse for Case r1b2-g During the Low-River Stage Period in December 2006 and January 2007.

4.22 Comparison of Simulated Conservative River Tracer Maximum Inland Extent for Selected Cases During the High-River Stage Period in 2006

4.23 Comparison of Simulated Cumulative Net Annual Water Fluxes for the Small-Scale 300 Area Model Cases for 2006.

4.24 Three Dimensional View of the Hydraulic Property Zonation for the Refined Vertical Node Spacing Small-Scale 300 Area Model.

4.25 Comparison of Water-Level Measurement Fit for the Small-Scale 300 Area Model Cases With Refined Vertical Grid and Standard Grid ...

4.26 Comparison of Cumulative Net Annual Water Fluxes for the Small-Scale 300 Area Model Cases With Refined Vertical Grid and Standard Grid 


\section{Tables}

2.1 Revised Elevation Picks for Top of Ringold and Fine-Grained Subunit ................................ 2.6

2.2 Summary of Aquifer Pumping Tests Results for the 300 Area............................................. 2.15

2.3 Well Names with Hourly and Sub-Hourly Temperature and Electrical Conductivity Measurements in the 2004+ 300 Area Monitoring Network ................................................ 2.32

3.1 Parameters of Nested Spherical Variogram Models for 300 Area Porosity and Gamma

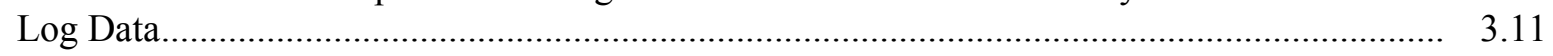

3.2 Parameters of Gamma Log - Grain Size Correlation Functions Shown in Figure 3.7 ............. 3.14

3.3 Common Parameters for Large-Scale 300 Area Model Runs................................................ 3.25

3.4 Large-Scale 300 Area Simulations - Hydraulic Conductivity Cases ...................................... 3.26

3.5 Detailed Hydraulic Head Residuals Calculated for the Example Case..................................... 3.32

4.1 Common Material and Transport Properties Used for the Smaller-Scale 300 Area

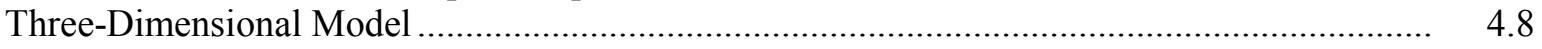

4.2 Hydraulic Property Values for the Small-Scale 300 Area Three-Dimensional Model Cases.

4.3 Detailed Hydraulic Head Residuals Calculated for the Small-Scale Model Example Case.

5.1 Net Aquifer Water Flux Estimates to the Columbia River Along the Hanford Site................. 5.6 



\subsection{Introduction}

Researchers at Pacific Northwest National Laboratory (PNNL) have developed field-scale groundwater flow and transport simulations for the aquifer beneath the 300 Area. The research was conducted as part of the 300-FF-5 Operable Unit Phase III Feasibility Study (DOE-RL 2005) and will also support upcoming activities associated with new records of decision for the region. The 300 Area is located in the southeast portion of the U.S. Department of Energy's (DOE) Hanford Site in Washington State (Figure 1.1). Historical operations involving uranium fuel fabrication and research activities at the 300 Area have contaminated engineered liquid-waste disposal facilities, the underlying vadose zone, and the uppermost aquifer with uranium (Peterson et al. 2008a). The purpose of this research is to develop and maintain numerical groundwater flow and transport models that can be used to refine the conceptual site model for groundwater beneath the 300 Area, and to assist in evaluating alternative remediation technologies focused on the 300 Area uranium plume.

The unconfined aquifer system beneath the 300 Area is very dynamic because of the influence of fluctuations in the Columbia River stage (daily, weekly, and seasonal) and the high permeability of the Hanford formation, which is the uppermost hydrologic unit. To simulate the dynamics of this system for this study, two groundwater flow and transport models were developed based on the availability of hourly water-level data for multiyear periods from 1) networks of wells around the 300 Area, and 2) the Columbia River stage. The plan view domains of these models were determined by the well coverage in these water-level monitoring networks as shown in Figure 1.2. These models used a common three-dimensional hydrostratigraphic framework developed from extensive site characterization studies (discussed below), and encompass the upper portion of the unconfined aquifer and the lower portion of the vadose zone. The first model has a larger domain (see Figure 1.2) and was based on a water-level monitoring network operated during the early to mid-1990s (Campbell 1994, Campbell and Newcomer 1992). The second, smaller-scale model focused on the northern portion of the 300 Area (see Figure 1.2) and was based on the current water-level monitoring network established in 2004 by the Remediation and Closure Science (RACS) Project. This water-level monitoring network has been supplemented by other projects in subsequent years. These models used the Subsurface Transport Over Multiple Phases (STOMP) code, a general-purpose tool for simulating subsurface flow and transport developed at PNNL (White and Oostrom 2000, 2004).

\subsection{Previous Studies}

Prior site characterization and groundwater modeling studies of the 300 Area are briefly described in the following subsections. Important processes and dynamics identified in these previous studies need to be incorporated into the site conceptual model and implemented in the numerical models. Specific site characterization studies are described in more detail in Sections 1.1.1 and 2.0; these studies relate to the development of the hydrogeologic framework used in constructing the 300 Area groundwater models. 


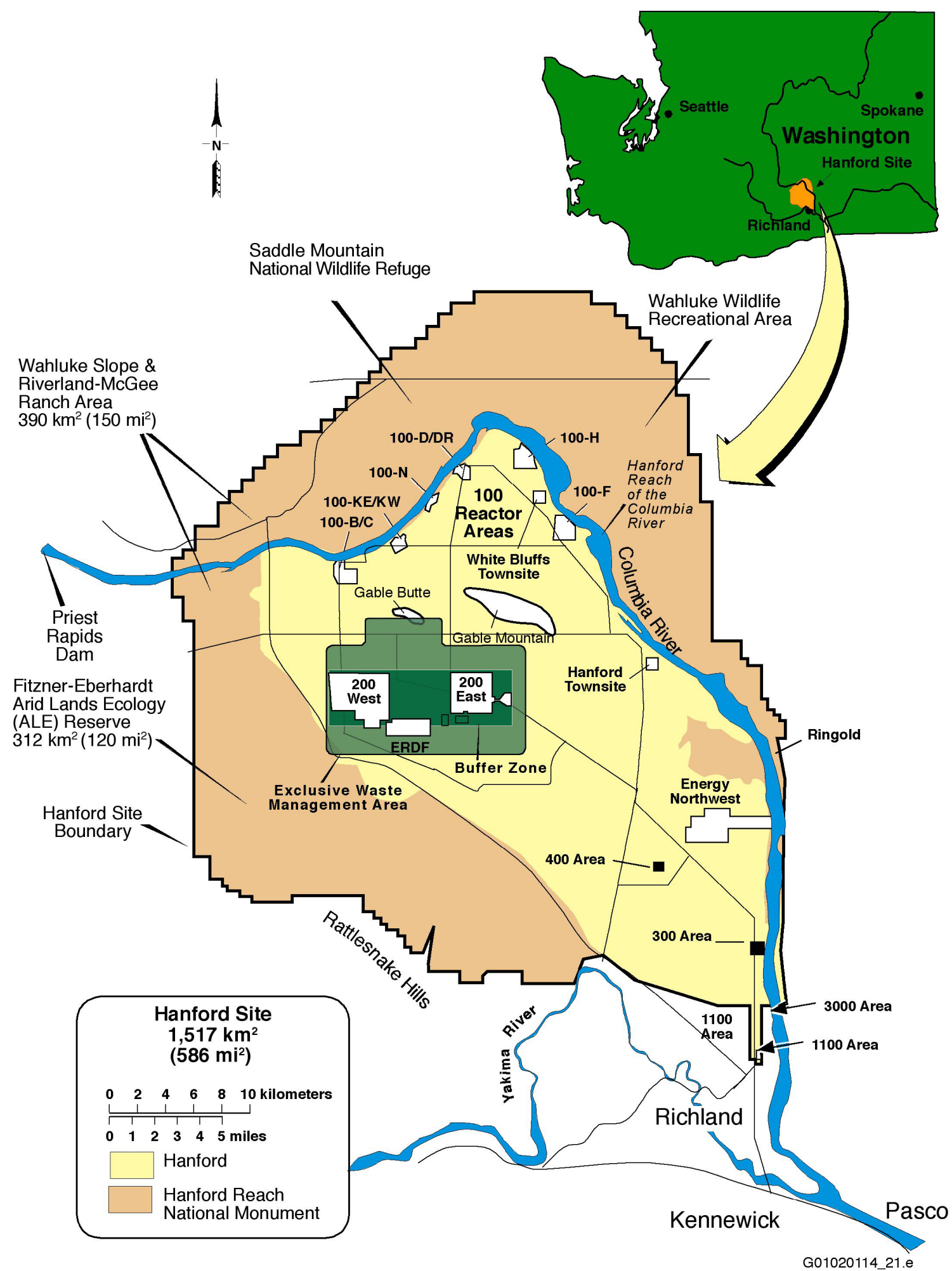

Figure 1.1. Map of the Hanford Site with the 300 Area Location 


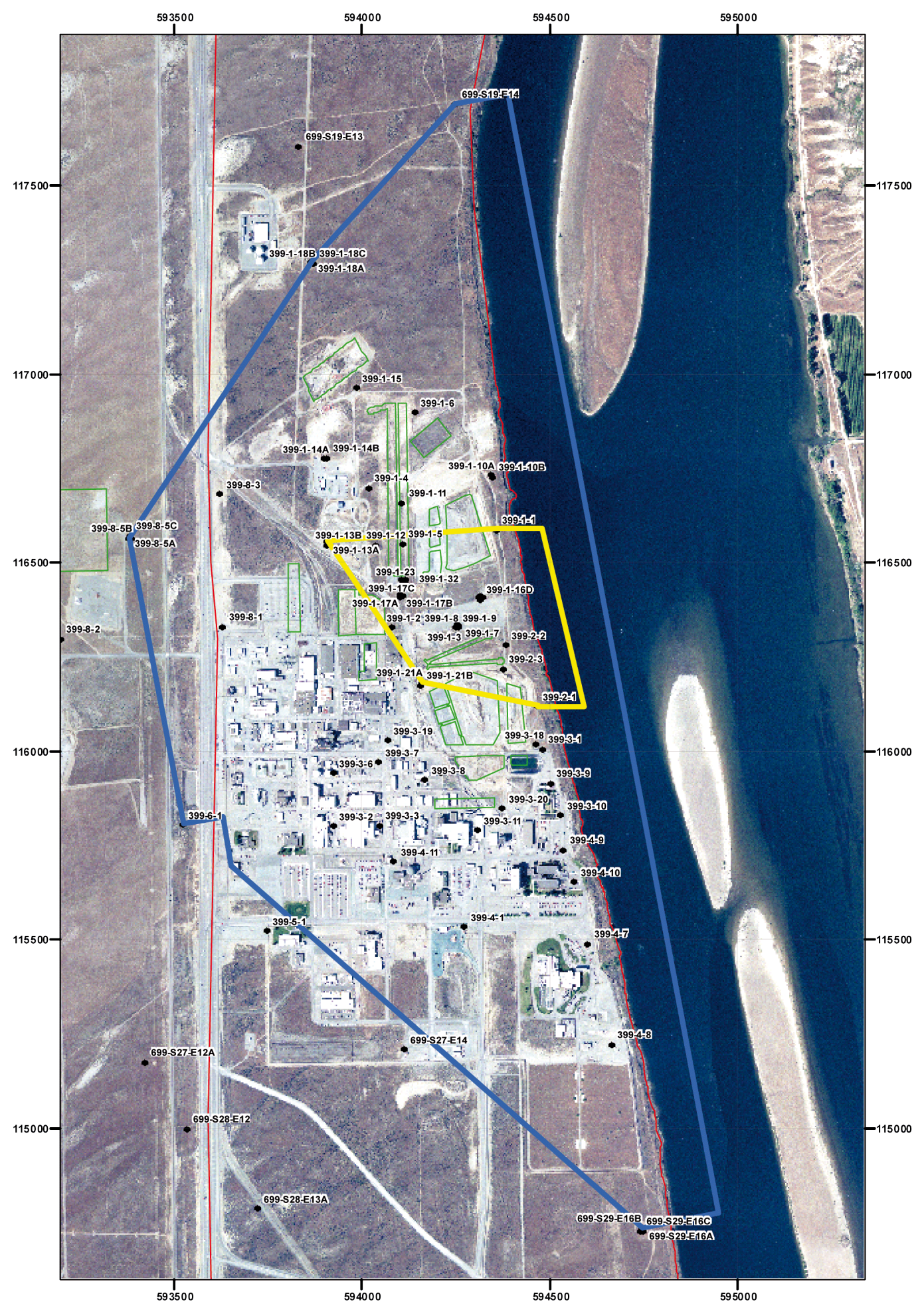

Figure 1.2. Locations of Monitoring Wells and Facilities at the 300 Area. Blue lines show the larger-scale groundwater model boundaries and the yellow lines show the smaller-scale model boundaries. The green lines show the outlines of the major waste disposal sites. 


\subsubsection{Site Characterization Studies}

Lindberg and Bond (1979), Schalla et al. (1988), Gaylord and Poeter (1991), and Swanson et al. (1992) performed early studies on the hydrogeologic characterization of the 300 Area. The hydrogeologic framework of the 300 Area was recently updated in a limited field investigation (LFI) of the 300 Area performed in fiscal years (FY) 2006 and 2007 (Williams et al. 2007).

Four new wells were installed as part of the LFI. The installation process included collection of continuous core samples and geophysical logging. Physical and chemical properties were measured on many of the samples in the laboratory. Results from the LFI helped refine the hydrogeologic unit contacts, sediment characteristics, and the distribution of uranium in vadose zone and aquifer sediments. In addition to the LFI wells, a new characterization well was installed recently in an area of sparse well coverage northwest of the 300 Area (Williams et al. 2006 [see Figure 1.2, well 699-S20-E10]). Depth-discrete hydraulic testing that used slug interference tests, conducted as part of the LFI borehole characterization, showed that the Hanford formation sediment in the upper portion of the 300 Area unconfined aquifer had a much greater hydraulic conductivity than the Ringold Formation sediment in the deeper portion of the unconfined aquifer; i.e., 100 to 1000 times greater. Specific hydraulic conductivity values for most slug tests conducted in the Hanford formation during the LFI could not be determined using this test method because of the very high permeability, so minimum values were reported. Depth-discrete soil and water sampling was also conducted for uranium analysis as part of the LFI. Almost all the uranium-contaminated water and soil samples were from the Hanford formation, with only one contaminated sample from the deeper Ringold Formation that was just below the Hanford and Ringold Formation contact.

Uranium concentration trends were recently compiled for 300 Area groundwater in an update to the conceptual model for uranium (Peterson et al. 2008a) and also an earlier expanded groundwater monitoring report for the 300-FF-5 Operable Unit (Peterson et al. 2005). Samples for monitoring uranium in groundwater from wells in the 300 Area are collected during the low-to-average water table/river stage conditions in December, and again at high-river stage/water-table conditions in June. Uranium concentrations above background levels are detected only from wells completed in upper portion of the unconfined aquifer within the Hanford formation. While the overall extent and concentration levels of the uranium plume have not changed appreciably over the past few years, significant seasonal trends are apparent during the high and low water-table conditions. During low water-table conditions in December, peak uranium concentrations, ranging from 100 to $200 \mu \mathrm{g} / \mathrm{L}$, are measured from wells near the shoreline of the 300 Area with lower concentrations around the waste site farther inland. During high water-table conditions in June, higher uranium concentrations are measured from wells inland around the waste sites with lower concentrations along the river shoreline. Uranium concentrations are also higher during years with very high Columbia River stage/water-table conditions.

Studies on the dynamics and uranium contamination in the hyporheic zone - the zone of mixing between the aquifer and Columbia River in the 300 Area - have been ongoing for the past few years; results are reported in Fritz et al. (2007). These studies describe the spatial and temporal variations in the uranium plume in the aquifer, along with uranium concentrations measured at the shoreline and in the Columbia River bed. Detailed pressure and uranium measurements in the hyporheic zone were used to estimate water and uranium fluxes to the river that vary significantly with river stage. Hydraulic tests conducted in the riverbed showed significantly lower hydraulic conductivities relative to the upper 
portion of the unconfined aquifer with the hydraulic conductivities increasing with depth. These dynamics need to be captured by the numerical implementation of the site conceptual model.

A 300 Area treatability test for stabilization of uranium in groundwater using polyphosphate was started in FY 2006, with major site characterization and field injection activities conducted in FY 2007 (Vermeul et al. 2007). These activities focused around LFI well 399-1-23 (see Figure 1.2). A network of 15 monitoring wells was installed around well 399-1-23 at distances up to $30 \mathrm{~m}$ (100 ft). In addition to borehole characterization and aquifer tests, a sodium-bromide tracer test was conducted in December 2006 (injection of 552,600 L [146,000 gal] of solution into the aquifer at well 399-1-23 at a rate of 757 liters per minute (Lpm) [200 gal per min (gpm)]. Polyphosphate injection was conducted in June 2007 (approximately 3,800,000-L [1 million gal] of reagent injected into well 399-1-23 at 757 Lpm [200 gpm]). Preliminary monitoring results of the tracer test showed the tracer drifted with ambient groundwater flow after the injection at a velocity of up to $15 \mathrm{~m} / \mathrm{d}(50 \mathrm{ft} / \mathrm{d})$ southeast from the injection well during late December 2006 and early January 2007. Groundwater flow directions during the June 2007 treatability test were oriented more toward the south (compared to the southeast during December 2006 and January 2007).

\subsubsection{Previous Modeling Studies}

The earliest numerical 300 Area groundwater modeling study was published by Lindberg and Bond (1979). Lindberg and Bond (1979) developed a Variable Thickness Transient (VTT) groundwater flow model of the 300 Area from a sub-region within the larger Hanford Project VTT model (Kipp et al. 1972). These VTT models were two-dimensional (x-y) transmissivity finite difference models. Lindberg and Bond (1979) developed a calibrated flow model that specified transmissivity distributions to fit weekly water-level measurements collected from 29 wells in the 300 Area in 1977. Transmissivities for the final calibrated model ranged from $1,900,000$ to $250,000,000 \mathrm{Lpd} / \mathrm{m}(150,000$ to $20,000,000 \mathrm{gpd} / \mathrm{ft})$ with the highest values in the central portion of the model. The transient flow model included water sources/sinks from the 300 Area operations. Average groundwater velocities from selected streamlines (using steadystate flow fields at selected times with an assumed porosity of $10 \%)$ were $5.4 \mathrm{~m} / \mathrm{d}(18 \mathrm{ft} / \mathrm{d})$ with a range from 0.3 to $43 \mathrm{~m} / \mathrm{d}$ ( 1 to $142 \mathrm{ft} / \mathrm{d}$ ). Pathlines were calculated using the transient flow field and compared to a steady-state streamline at the same starting location and time that showed the travel time to the Columbia River was longer in the transient path line. Transport calculations for a number of radionuclides were conducted using the VTT velocity field with the Multicomponent Mass Transfer (MMT) model for a test case based on a spill from the 325 Building in 1979. Radionuclide transport was simulated using linear isotherms with distribution coefficients $\left(\mathrm{K}_{\mathrm{d}}\right)$.

A three-dimensional numerical model was developed for the Phase I remedial investigation of the 300-FF-5 Operable Unit in 1993 (DOE-RL 1994a). This model used the PORFLO-3 code, a saturated/unsaturated finite difference flow and transport code (Runchal et al. 1992). The model contained four types of hydrofacies zones (developed for the 300 Area by Gaylord and Poeter [1991]) of gravel, sandy gravel, sand, and mud/silt. These hydrofacies were applied to the grid to create 17 separate zones in the model. Flow calibration runs were conducted with limited monthly steel-tape water-level measurements, along with a short period for which hourly water-level data were available. Final hydraulic conductivity for the model "ranged from $0.2 \mathrm{~m} / \mathrm{d}(0.65 \mathrm{ft} / \mathrm{d})$ for $\mathrm{mud} / \mathrm{silt}$ to $7500 \mathrm{~m} / \mathrm{d}$ for gravel" (DOE-RL 1994a, pg. D-4). Flow and transport simulations were conducted with multiple $\mathrm{K}_{\mathrm{d}}$ values for uranium $(0,1,10$, and $25 \mathrm{~mL} / \mathrm{g})$ with initial uranium concentrations in the aquifer based on contoured 
measured concentrations from the first quarter of 1992. There were no additional sources of uranium from the vadose zone. Because there were no additional uranium sources for the model, simulated uranium concentrations decreased from the initial concentrations through time for all cases. Results from the $\mathrm{K}_{\mathrm{d}}=1 \mathrm{~mL} / \mathrm{g}$ case, starting with the 1992 uranium concentrations, showed simulated uranium concentrations decreased to less than $10 \mathrm{pCi} / \mathrm{L}$ by the year 2000 . For the $\mathrm{K}_{\mathrm{d}}=25 \mathrm{~mL} / \mathrm{g}$ case, maximum simulated concentrations were $23 \mathrm{pCi} / \mathrm{L}$ at the year 2018. This model was also used to investigate possible remediation scenarios (e.g., the impact of extraction wells). Simple one-dimensional analytic models were also developed based on the travel times from the three-dimensional model results. Model results were used for the remedial investigation feasibility study (RI/FS) for the 300-FF-5 Operable Unit in 1995 (DOE-RL 1994b).

A Residual Radiation (RESRAD) model (ANL 1993) was used in the 300 Area to evaluate and help determine the uranium soil cleanup levels for the 300-FF-1 and 300-FF-2 soil operable units (BHI 2002). The RESRAD simulations in this Bechtel Hanford, Inc. (BHI 2002) study were designed to represent future conditions at the 300 Area site with a vegetated cover and natural recharge. Simulations were conducted to determine soil uranium concentrations in the upper $4 \mathrm{~m}(13 \mathrm{ft})$ of the soil zone that would not exceed the $30 \mu \mathrm{g} / \mathrm{L}$ maximum contaminant level for uranium in the aquifer immediately downgradient of the contaminated soil site. The simulations in the BHI report (BHI 2002) only addressed the transport of uranium from initial residual contamination in the upper portion of the vadose zone ( $4 \mathrm{~m}[13 \mathrm{ft}])$. The lower vadose zone (below $4 \mathrm{~m}$ [13 ft] depth) and aquifer were not represented as contaminated for initial conditions in this modeling effort. The aquifer was treated as being a constant thickness with a hydraulic conductivity of $673,846 \mathrm{~m} / \mathrm{yr}(1845 \mathrm{~m} / \mathrm{d})$ and a hydraulic gradient of $5 \times 10^{-4}$. The result of this study was a revision in the prior soil cleanup standard from $350 \mathrm{pCi} / \mathrm{g}$ total uranium concentrations to $267 \mathrm{pCi} / \mathrm{g}$. This RESRAD study included uranium leaching and sorption studies with contaminated 300 Area sediments under various water chemistries using bench-scale column and batch studies (BHI 2002, Serne et al. 2002). Based on these bench-scale studies, a $K_{d}$ of $8.9 \mathrm{~mL} / \mathrm{g}$ was selected for the uppermost 4-m (13-ft) contaminated zone, and a $\mathrm{K}_{\mathrm{d}}$ of $0 \mathrm{~mL} / \mathrm{g}$ was used for the lower vadose zone and aquifer to provide a conservative estimate within the RESRAD model.

Waichler and Yabusaki (2005) developed a two-dimensional (x-z) model of the aquifer and vadose zone, using the STOMP code, along the transect between well 399-6-1 and the Columbia River (oriented perpendicular to the river). This model used hourly water-level data from the 300 Area and hourly river stage data measured at the 300 Area in the early 1990s (see Section 2.4) to provide boundary conditions for the two-dimensional model and for comparison with model predictions. Cases were run with the vertical domain extending down to the top of the basalt and a shallower domain down to the top of the Ringold Formation mud unit. Simulated fluxes from the deeper model that extended to the basalt were increased by only a small amount relative to fluxes calculated for the shallower domain. Thus, the shallower domain was used for the study. Cases were also run with different hydraulic conductivities (K) specified for the Hanford formation, the most permeable unit located at the top of the unconfined aquifer in the 300 Area. Hydraulic conductivities ranging from $1500 \mathrm{~m} / \mathrm{d}(4921 \mathrm{ft} / \mathrm{d})$ to $15,000 \mathrm{~m} / \mathrm{d}(49,212 \mathrm{ft} / \mathrm{d})$ were used. Solute transport simulations were conducted to illustrate the mixing zone between the Columbia River and the aquifer. The mixing zone, simulated by a river tracer, extended up to $150 \mathrm{~m}$ $(492 \mathrm{ft})$ inland for the base case $(1500 \mathrm{~m} / \mathrm{d}[4921 \mathrm{ft} / \mathrm{d}$ ] Hanford formation $\mathrm{K})$ and extended further inland for the higher $\mathrm{K}$ cases. The study showed large reductions in the extent of the simulated mixing zone using boundary conditions (i.e., Columbia River stage) that averaged daily or monthly compared to simulated results using hourly forcing; however, the study also stated that a 2- to 12-hr forcing may be acceptable. 
Meyer et al. (2007) provides a description of the development of a comprehensive methodology for combined estimation of hydrogeologic conceptual models, parameter, and scenario uncertainty, and its application to uranium transport at the 300 Area. The methodology is based on an extension of a maximum likelihood implementation of Bayesian model averaging. For application at the 300 Area, eight alternative three-dimensional models representing uncertainty in hydrogeologic and geochemical properties, as well as the temporal variability, were considered. Two alternative scenarios representing alternative future behavior of the Columbia River were also considered. The alternative models developed used MODFLOW and MT3DMS modeling codes, which were calibrated using hydraulic head and uranium concentration observations over a 7-year period. Uranium concentrations within each scenario were then predicted over a 20 -year period. The research in this report represents the first successful attempt at joint calibration of groundwater flow and transport models for the 300 Area using hydraulic head and uranium concentration data. More importantly, this research demonstrates the feasibility of applying a comprehensive uncertainty assessment to large-scale, detailed groundwater flow and transport modeling. Some limitations of this modeling effort include the following:

- Meyer et al. (2007) did not address continuing sources of uranium in the vadose zone, primarily because uranium concentration distribution in the vadose zone is largely unknown.

- Monthly average river stages were used for boundary conditions on the Columbia River side of the model domain, and constant head conditions were assumed for the inland side of the model domain.

- Relatively coarse spatial discretization was used.

Selections of the temporal frequency of river stage forcing, constant head inland boundary conditions, and coarse spatial discretization were based primarily on computational considerations and constraints associated with inverse modeling.

\subsection{Scope and Outline}

Groundwater flow and transport models were developed for the 300 Area based on the previous studies briefly discussed in Section 1.1. Important processes and features identified in these studies are part of the conceptual model used for developing and implementing the numerical groundwater model. This includes constructing three-dimensional hydrostratigraphy of the site based on site characterization efforts focused primarily on the very high-permeability upper portion of the unconfined aquifer (Hanford formation), along with a river alluvium zone. Additionally, the models included hourly river stage and water-table fluctuations through annual time periods to simulate important seasonal trends. This research is limited to three-dimensional groundwater flow and conservative tracer transport simulations; it does not include uranium transport simulations, which should be implemented in future three-dimensional modeling efforts.

Section 2.0 describes the 300 Area site hydrogeology. Groundwater flow and transport models are described in Section 3.0 that used the early 1990s water-level monitoring network. Section 4.0 describes the smaller-scale groundwater flow and transport models that used the 2004+ water-level monitoring network. Section 5.0 provides a summary of the results of these modeling efforts. Appendices A, B, and $\mathrm{C}$ describe the porosity data, gross-gamma log data, and some of the grain-size distribution data, respectively, that were used for parameterization of the heterogeneous models. 



\subsection{Hydrogeology}

This section describes the 300 Area hydrogeology, high-resolution water-level monitoring networks, preliminary results of treatability tests in the 300 Area related to groundwater flow rates and directions, and hyporheic zone studies conducted along the 300 Area Columbia River shoreline. These studies were incorporated into the site conceptual model used to develop the three-dimensional numerical groundwater flow and transport models.

\subsection{Geologic Setting/Hydrostratigraphy}

The unconfined aquifer at the 300 Area is within sediments deposited on top of a thick $(>3000 \mathrm{~m}$ [9842 ft]) sequence of basalt flows. At the 300 Area, these sediments range in total thickness from 40 to $60 \mathrm{~m}$ (131 to $196 \mathrm{ft}$ ). The principal sedimentary units consist of, from lower to upper: the fluvial and lacustrine sediments of the Ringold Formation, the glaciofluvial Hanford formation, and a relatively thin layer of eolian sand and silt at the surface. However, the surface eolian deposits were removed by

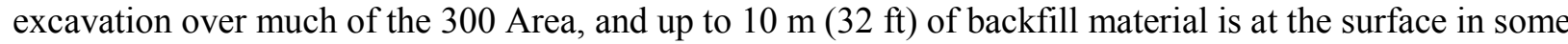
areas. The Cold Creek unit, which lies between the Hanford and Ringold Formations in other portions of the Hanford Site, has not been identified beneath the 300 Area. A schematic representation of the 300 Area hydrogeologic column is shown in Figure 2.1.

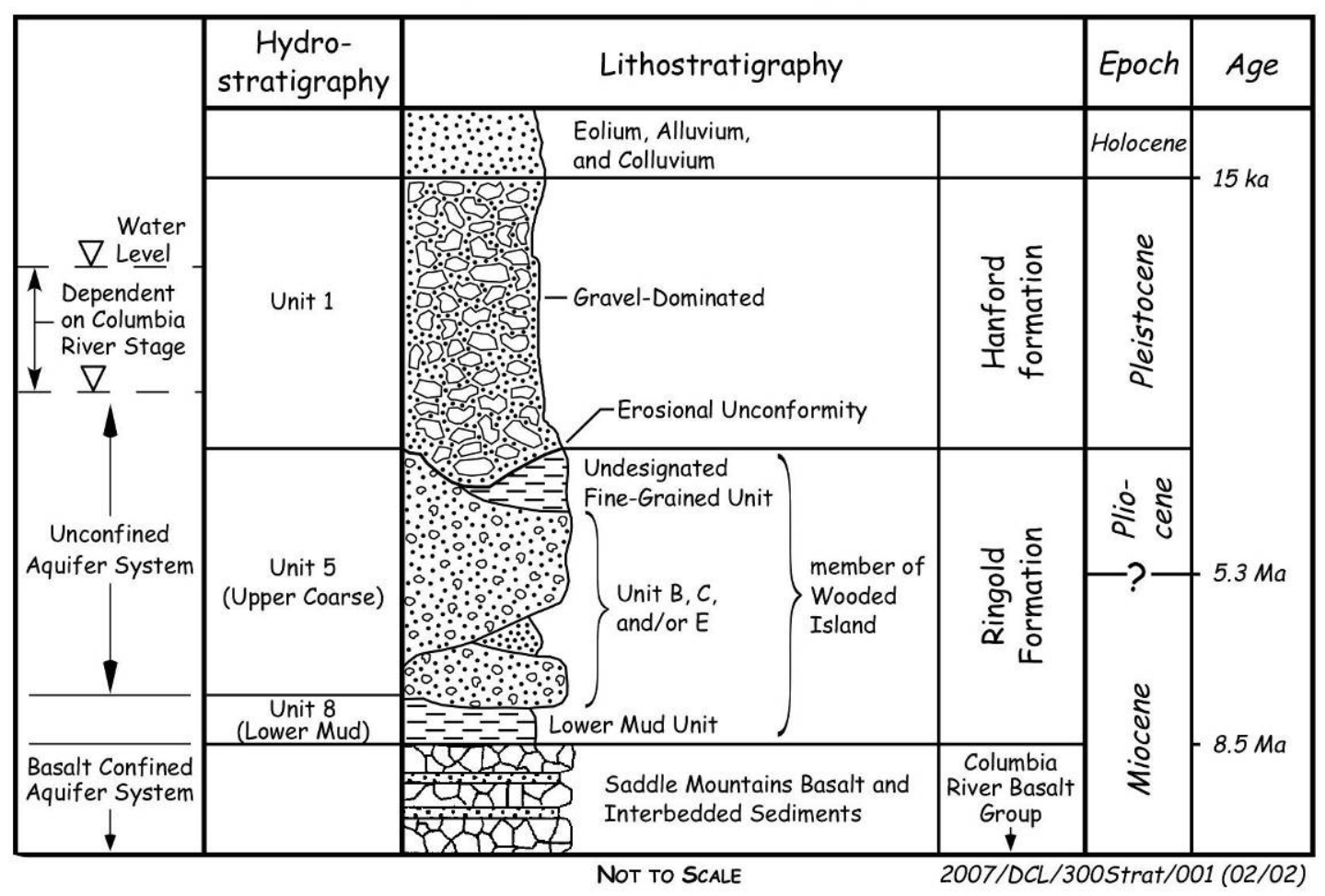

Figure 2.1. Hydrogeologic Stratigraphic Column for the 300 Area (modified from Reidel et al. [1992], Lindsey [1995], Williams et al. [2000] and DOE-RL [2002]) 


\subsubsection{Ringold Formation}

The Ringold Formation was deposited on top of the basalt by the ancestral Columbia River and its tributaries. Because of uplift of the basalts and overlying sediments, the Columbia River eventually began to erode, rather than deposit, sediments in the Pasco Basin. As a result, the upper portion of the Ringold Formation was eroded from the 300 Area.

Lindsey (1995) defined three informal members of the Ringold Formation based on dominant sediment facies types. Only the lowermost member, Wooded Island, exists at the 300 Area. The overlying Ringold Formation sediments comprised of the Taylor Flat and Savage Island members were removed by erosion.

The Wooded Island member is divided into five gravel-dominated units (designated A, B, C, D, and E) separated by mud-dominated over bank and lacustrine deposits (Lindsey 1995). The lowermost Ringold unit A sand and gravel was deposited on top of the basalt bedrock, and is discontinuous beneath the 300 Area. The Ringold lower-mud unit, a relatively thick and continuous lacustrine mud comprised of silty clay to silty sand, forms a confining aquitard above the unit A gravel or lies directly on top of basalt where unit A is missing. Above the lower-mud unit are the combined Ringold Formation units $\mathrm{B}$ and $\mathrm{C} / \mathrm{E}$ sand and gravel, which are indistinguishable except on the western side of the 300 Area where they are separated by a discontinuous Ringold Formation overbank deposit. Unit D is not found in the vicinity of the 300 Area.

A previously undesignated fine-grained subunit has been identified in several boreholes at the top of the Ringold Formation sand and gravel sequence. This subunit is composed of low-permeability silty sand to sandy sediment. This subunit was identified at three of the four new boreholes described in Williams et al. (2007), indicating it is more continuous than previously estimated. The fine-grained subunit is relatively consolidated and characterized by alternating layers of oxidized and reduced finegrained sediment. Although it has primarily been found near the top of the Ringold Formation sequence in the 300 Area, boreholes in other areas indicate the subunit may sometimes be overlain by more typical Ringold sand and gravel. This fine-grained sediment is not part of the member of Taylor Flat (upper Ringold) that is found above the Ringold unit E in some parts of the Hanford Site.

\subsubsection{Hanford Formation}

The informally named Hanford formation was deposited by cataclysmic glacial floods that inundated the Pasco Basin a number of times during the Pleistocene, approximately 1 million to 13,000 years ago (DOE-RL 2002). The floods caused massive erosion of older sediments and basalt bedrock, which resulted in deposition of sediments in low-lying areas.

The Hanford formation has been divided into three major facies: 1) gravel dominated, 2) sand dominated, and 3) silt dominated. These facies generally correspond to coarse gravels, laminated sands, and graded rhythmites, respectively (DOE-RL 2002). Gravel-dominated strata consist of coarse-grained sand, and granule-to-boulder sized clast-supported gravel. The gravel can have an open matrix structure with large pore spaces and high permeability. The sand-dominated facies consists of fine- to coarsegrained sand. Small pebbles and pebbly interbeds $(<20-\mathrm{cm}$ [8-in.] thick) may be encountered. The siltdominated facies consist of silt and fine- to coarse-grained sand forming normally graded rhythmites. Plane lamination and ripple cross-lamination is common in outcrops in these facies. Hanford formation 
sediments tend to have a large proportion of basaltic fragments because of the upstream erosion of basalt bedrock in the channeled scablands of eastern Washington during the glacial floods (see Bretz 1969 and Bjornstad 2007 for descriptions of the channeled scablands).

At the 300 Area, the Hanford formation is approximately up to $30-\mathrm{m}$ (98-ft) thick and comprised primarily of gravel-dominated and sand-dominated facies. Because of their coarse texture and lack of consolidation/cementation, Hanford formation sediments are much more permeable than the Ringold Formation sediments and tend to dominate groundwater flow in the 300 Area vicinity.

Williams et al. (2007) describe Hanford formation sediments encountered at the four new LFI boreholes as unconsolidated boulder-to-pebble-gravel with coarse- to fine-sand and minor amounts of silt. Most often, Hanford formation sediments exhibit a clast-support structure with a matrix of poorly sorted sand and silt. Occasionally, the matrix is missing, which produces an open framework with large pores between the clasts. Reworked Ringold Formation sediment, which was eroded by the cataclysmic floods and redeposited, was found within the Hanford formation during pit excavations at the 300 Area (Bjornstad 2004). These Ringold Formation sediments sometimes include reworked Ringold mud either as rounded clasts up to $1-\mathrm{m}(3.2-\mathrm{ft})$ in diameter, or as localized mud matrix deposited along with the Hanford formation cataclysmic flood gravel. The mud clasts were eroded from upstream Ringold Formation deposits that are similar to those exposed across the Columbia River from the 300 Area. The reworked Ringold Formation sediments, randomly deposited within the Hanford formation, may create localized zones of lower permeability that affect water movement through the vadose zone and the aquifer.

\subsubsection{Recent Eolian Deposits and Backfill}

A thin layer, generally less than 3-m (10-ft) thick, of wind-deposited sand and silt originally covered the Hanford formation in the vicinity of the 300 Area. However, most of this material has been removed by excavation. In some places, up to $6-\mathrm{m}(20-\mathrm{ft})$ of backfill material is on the surface. The backfill is comprised of reworked sand and gravel from Hanford formation or eolian deposits, or of coal plant ash in and around the south process ponds where the coal-fired Power House (384 Building) waste was disposed (Young and Fruchter 1991).

\subsubsection{Hydrogeologic Unit Designations for Groundwater Modeling}

In developing a Hanford Site groundwater flow model, Cole et al. (2001) delineated hydrogeologic units to reflect differences in hydraulic properties of sediments, such as effective porosity and hydraulic conductivity. These hydrogeologic units generally correspond to geologic units (Figure 2.1) but sometimes differ when geologic units with similar hydraulic properties are grouped together, or when hydrogeologic subunits are delineated based on differences in texture or cementation within a geologic unit.

At the 300 Area, the Hanford formation corresponds to model unit 1 (u1) in this study and is the same as hydrostratigraphic unit 1 defined across the Hanford Site in Cole et al. (2001) as shown in Figure 2.1. Overlying eolian sediment and backfill is also included in model unit 1 . However, these are generally above the water table and do not affect saturated zone groundwater models. Model units 2 and 3 correspond to the Cold Creek subunits that are missing at the 300 Area. 
Model unit 4 (u4), defined by Cole et al. (2001) as the fine-grained mud portion of the member of Taylor Flat (also called upper Ringold), is also missing in the 300 Area vicinity. However, the previously undifferentiated fine-grained subunit of the Ringold E sand and gravel has been designated as unit 4 in the 300 Area groundwater model. This fine-grained subunit is stratigraphically in the same position, between the underlying Ringold unit E sand and gravel, and the overlying Hanford formation, as model unit 4 of Cole et al. (2001).

Model units 5, 8, and 9 (u5, $\mathrm{u} 8$, and $\mathrm{u} 9$, respectively) correspond to geologic units of the Ringold Formation. Unit 8 is the lower Ringold mud unit that separates the Ringold sand and gravel of overlying model unit 5 and underlying model unit 9. Cole et al. (2001) designated model unit 6 as the discontinuous over-bank and/or lacustrine mud that separates the Ringold unit $\mathrm{C} / \mathrm{E}$ sand and gravel from the underlying unit B sand and gravel in some areas of the Hanford Site. However, because these overbank deposits only exist on the western side of the 300 Area and are not expected to have much impact on groundwater flow, the discontinuous overbank sediments have been combined with Ringold units $\mathrm{C} / \mathrm{E}$ and $\mathrm{B}$ to create model unit 5 .

To support 300 Area groundwater modeling for this and other related research, a hydrogeologic framework model was created using the geologic modeling software EarthVision ${ }^{\circledR}{ }^{1}$ The EarthVision model was developed by fitting surfaces to elevation data points representing the top of each of the model hydrogeologic units. Control points were defined in areas where a unit was known to be missing. Surface topography in the model area was defined based on the U.S. Geological Survey (10-m [32-ft]) resolution digital elevation models that were derived from 7.5-minute quadrangle sheets (last edited in 1992 for the 300 Area portion). ${ }^{2}$ Bathymetry of the Columbia River channel was based on data collected by the U.S. Fish and Wildlife Service as part of its program to study fall Chinook salmon in the Hanford Reach (Anglin et al. 2006).

\subsubsection{Revision of Hanford and Ringold Formations Contact Surface}

Elevation of the contact between the Hanford and Ringold Formations was extremely important for groundwater modeling at the 300 Area. The Hanford formation, comprised predominantly of unconsolidated sand and gravel, is significantly more permeable than the underlying and older Ringold Formation, which includes more compacted and variably cemented fine-grained to gravelly sediment. A revised interpretation of the geometry of the contact surface between the Hanford and Ringold Formations (bottom of model unit 1) was completed in September 2006. This reinterpretation was based on recent information acquired from four characterization boreholes drilled as part of the LFI for uranium in 2006 (Williams et al. 2007). Data from continuous core samples and characterization activities associated with the four new boreholes provided new details on the subsurface stratigraphy that led to a revised interpretation of data from previously drilled boreholes and a substantial update of the 300 Area hydrogeologic framework. The characterization information from the LFI boreholes included sediment sample analyses, spectral gamma logging, neutron moisture logging, and depth-discreet slug testing to estimate hydraulic conductivity. Comparing the correspondence between gamma logs and lithologic interpretations from the LFI boreholes with the gamma logs from older boreholes assisted in reinterpretation of the Hanford and Ringold Formation contact at the older boreholes. In addition to

\footnotetext{
${ }^{1}$ EarthVision ${ }^{\circledR}$ is a registered trademark of Dynamic Graphics, Inc.

${ }^{2}$ Website address: rocky.ess.washington.edu/data/raster/tenmeter/byquad/index.html. Last accessed on June 12, 2008 .
} 
revising the Hanford and Ringold Formation contact surface, the discontinuous fine-grained subunit of the Ringold C/E gravel (Figure 2.1) was delineated at the top of the Ringold Formation.

The process for developing the revised Hanford and Ringold Formation contact consisted of the following steps:

- A hydrogeologist identified Hanford and Ringold Formation contact elevations and the thickness of the fine-grained Ringold subunit in the four LFI boreholes.

- A team of hydrogeologists evaluated and, in some cases, reinterpreted the available information from other boreholes to determine the Ringold Formation contact elevation and thickness of the finegrained Ringold subunit at each borehole location.

- A hand-drawn contour map of the Hanford and Ringold Formation contact surface was created based on the selected borehole contact elevations and knowledge of the depositional and erosional history of the site.

- The borehole elevations and hand-drawn contours were used to create a digital grid of the contact surface in the EarthVision software using minimum-tension gridding.

- Thickness data from borehole interpretations for the fine-grained Ringold Formation subunit were used with information on where the unit was missing to create a thickness grid for this subunit.

The revised hydrogeologic configuration described in this report is an update of the hydrogeologic framework described in Peterson et al. (2005). Table 2.1 lists the elevation picks for the Hanford and Ringold Formation contact, and the thickness and bottom elevation for the fine-grained Ringold subunit. There were additional boreholes where the fine-grained subunit was known to be missing. A contour map of the top of the Ringold Formation elevation is provided in Figure 2.2; the contours on this map match those in the hand-drawn contour map for this surface. The borehole elevation picks used in defining the top of the Ringold Formation are also plotted on the map. A northwest-southeast trending paleochannel in the surface of the Ringold Formation can be seen as a relatively lower elevation area on the contour plot. The paleochannel is filled with the more recent Hanford formation sediment and provides a preferential pathway for groundwater movement because of greater transmissivity.

Five cross-sections (Figures 2.3, 2.4, 2.5, 2.6, and 2.7) were created to illustrate the relative positions and thickness of the principal hydrogeologic units. Nearby monitoring wells are also shown on the cross sections, which are shown in Figure 2.8. Total drilled-depth of the wells is indicated by a vertical line, and the position of screened or perforated open intervals is represented by a series of horizontal lines.

The fine-grained subunit of the Ringold Formation lies at the top of the Ringold unit C/E sand and gravel. Figure 2.9 shows a three-dimensional view of the top of the Ringold surface, with the finegrained subunit shown in a lighter color. Blue squares indicate the points where the top of the finegrained subunit was identified at a borehole. Boreholes where the fine-grained subunit appears to be missing are denoted as a red vertical line. There is uncertainty in the extent of the fine-grained unit because information from many of the older boreholes is too limited to reveal its presence. At some boreholes, the subunit may have been missed because sediment samples were only collected every $1.5 \mathrm{~m}$ $(5 \mathrm{ft})$. It also may be difficult to recognize the fine-grained unit in cuttings from cable-tool drilled boreholes. 


\subsubsection{Spatial Data Management (EarthVision Database)}

The conceptual model of the hydrogeologic framework for the 300 Area is maintained using the EarthVision geologic modeling software. Hydrogeologic information is transferred from the threedimensional EarthVision model to a numerical model-grid structure by querying the EarthVision model at each of the model nodes. These are represented by a set of X, Y, and Z coordinates. The output is a label for the hydrogeologic unit that exists at that point. For some model grids, it is useful to know if the node is beyond a specified average river boundary in $\mathrm{X}, \mathrm{Y}$ coordinate space. A utility feature within EarthVision that provides a method for assigning a label to points within a polygon is used to label points within the specified Columbia River boundary.

Table 2.1. Revised Elevation Picks for Top of Ringold and Fine-Grained Subunit. Elevations are NAVD88 vertical datum.

\begin{tabular}{|c|c|c|c|c|c|}
\hline Borehole & $\begin{array}{l}\text { Ground } \\
\text { Surface } \\
\text { Elevation } \\
\text { (m) }\end{array}$ & $\begin{array}{l}\text { Depth to Top } \\
\text { of Ringold } \\
\text { Formation } \\
\text { (m) }\end{array}$ & $\begin{array}{l}\text { Elevation Top of } \\
\text { Ringold } \\
\text { Formation (m) }\end{array}$ & $\begin{array}{l}\text { Thickness of Fine- } \\
\text { Grained Subunit of } \\
\text { Ringold Formation } \\
\text { (m) }\end{array}$ & $\begin{array}{l}\text { Elevation Top of } \\
\text { Ringold Formation } \\
\text { Sand and Gravel (m) }\end{array}$ \\
\hline $399-1-10 \mathrm{~B}$ & 114.5 & 16.9 & 97.6 & 0 & 97.6 \\
\hline $399-1-11$ & 115.7 & 13.1 & 102.6 & Unknown & Not deep enough \\
\hline $399-1-13 \mathrm{~A}$ & 118.6 & 15.2 & 103.4 & Unknown & Not deep enough \\
\hline 399-1-14A & 117.0 & 13.8 & 103.2 & Unknown & Not deep enough \\
\hline $399-1-15$ & 116.2 & 13.4 & 102.8 & $>1.2$ & $<101.6$ \\
\hline $399-1-17 C$ & 115.5 & 15.2 & 100.3 & 0 & 100.3 \\
\hline $399-1-18 C$ & 118.5 & 15.5 & 103 & 0 & 103 \\
\hline $399-1-2$ & 118.2 & 19.2 & 99 & 0 & 99 \\
\hline $399-1-20$ & 117.8 & 15.2 & 102.6 & Unknown & Not deep enough \\
\hline $399-1-21 B$ & 117.0 & 20.9 & 96.1 & 6.1 & 90 \\
\hline $399-1-23$ & 115.47 & 15.1 & 100.4 & 0 & 100.4 \\
\hline $399-1-4$ & 116.6 & 13.4 & 103.2 & 0 & 103.2 \\
\hline $399-1-6$ & 114.2 & 12.8 & 101.4 & $>0.6$ & $<100.8$ \\
\hline $399-2-1$ & 114.7 & 14.4 & 100.3 & 1.5 & 98.8 \\
\hline $399-2-3$ & 115.1 & 18.3 & 96.8 & $>1.5$ & $<95.3$ \\
\hline $399-3-1$ & 117.5 & 14.3 & 103.2 & 7 & 96.2 \\
\hline $399-3-10$ & 117.7 & 16.8 & 100.9 & $>3.7$ & $<97.2$ \\
\hline $399-3-12$ & 118.5 & 19.5 & 99 & $>0.3$ & $<98.7$ \\
\hline $399-3-18$ & 117.68 & 14.1 & 103.6 & 10.7 & 92.9 \\
\hline $399-3-19$ & 120.65 & 25.3 & 95.4 & $>0.6$ & $<94.8$ \\
\hline $399-3-20$ & 120.45 & 24.7 & 95.8 & $>4$ & $<91.8$ \\
\hline $399-3-9$ & 118.6 & 16.5 & 102.1 & $>4.6$ & $<97.5$ \\
\hline $399-4-1$ & 120.8 & 25.6 & 95.2 & 1.5 & 93.7 \\
\hline $399-4-11$ & 123.8 & 26.5 & 97.3 & Unknown & Not deep enough \\
\hline $399-4-5$ & 123.6 & 25.9 & 97.7 & 0.9 & 96.8 \\
\hline $399-4-7$ & 115.7 & 26.0 & 89.7 & 0 & 89.7 \\
\hline $399-5-1$ & 121.0 & 18.9 & 102.1 & 3.7 & 98.4 \\
\hline $399-5-2$ & 119.7 & 14.6 & 105.1 & 0 & 105.1 \\
\hline
\end{tabular}


Table 2.1. (contd.)

\begin{tabular}{lccccc}
\hline \multicolumn{1}{c}{ Borehole } & $\begin{array}{c}\text { Ground } \\
\text { Surface } \\
\text { Elevation } \\
(\mathrm{m})\end{array}$ & $\begin{array}{c}\text { Depth to Top } \\
\text { of Ringold } \\
\text { Formation } \\
(\mathrm{m})\end{array}$ & $\begin{array}{c}\text { Elevation Top of } \\
\text { Ringold } \\
\text { Formation }(\mathrm{m})\end{array}$ & $\begin{array}{c}\text { Thickness of Fine- } \\
\text { Grained Subunit of } \\
\text { Ringold Formation } \\
(\mathrm{m})\end{array}$ & $\begin{array}{c}\text { Elevation Top of } \\
\text { Ringold Formation } \\
\text { Sand and Gravel }(\mathrm{m})\end{array}$ \\
\hline 399-6-1 & 118.8 & 17.1 & 101.7 & 0 & 101.7 \\
$399-8-1$ & 121.0 & 20.7 & 100.3 & 3 & 97.3 \\
$399-8-2$ & 121.6 & 21.4 & 100.2 & 8.8 & 91.4 \\
399-8-3 & 120.6 & 18.0 & 102.6 & $<9.8$ & $<92.8$ \\
399-8-5C & 122.2 & 22.4 & 99.8 & 7 & 92.8 \\
699-S11-E12A & 111.7 & 18.3 & 93.4 & Unknown & Not deep enough \\
699-S11-E12B & 112.3 & 16.8 & 95.5 & Unknown & Not deep enough \\
699-S12-3 & 133.3 & 13.4 & 119.9 & 0 & 119.9 \\
699-S18-E2A & 133.0 & 22.8 & 110.2 & 0 & 110.2 \\
699-S19-E13 & 120.3 & 23.1 & 97.2 & 0 & 97.2 \\
699-S20-E10 & 119.7 & 14.4 & 105.3 & Unknown & Not deep enough \\
699-S22-E9C & 114.1 & 7.3 & 106.8 & Unknown & 101.3 \\
699-S27-E14 & 122.7 & 21.4 & 101.3 & 0 & 110.4 \\
699-S27-E9C & 119.3 & 8.9 & 110.4 & Unknown & Not deep enough \\
699-S29-E12 & 118.5 & 13.8 & 104.7 & 0 & 99.5 \\
699-S29-E16C & 115.9 & 16.4 & 99.5 & Unknown & Not deep enough \\
699-S30-E15A & 122.4 & 19.8 & 102.6 & & \\
\hline & & & & & 0
\end{tabular}

\subsubsection{Uncertainties in Defining the Hydrogeologic Framework}

Uncertainty in the hydrogeologic framework arises from the possibility of misinterpretation and from actual spatial variability of the physical system. Uncertainty from misinterpretation can arise from the incorrect identification of a unit at a borehole or a unit being missed in the borehole interpretation. Samples are often logged only every 1.5 to $3 \mathrm{~m}$ (4.9 to $9.8 \mathrm{ft}$ ), which may not be sufficient to reveal a relatively thin unit. Incomplete descriptions or errors in descriptions and field interpretations can also lead to misinterpretation of units at a borehole location.

However, even if the interpretation of units at boreholes were $100 \%$ accurate, unit continuity and elevation between boreholes would be uncertain because of the variability of the aquifer system between boreholes. For example, erosional channels may exist within the Ringold Formation surface and not be represented in the model because no boreholes are located in the channel area. Additionally, a unit may be present in an area where no boreholes exist and not be represented in the model. Elevations of hydrogeologic units in the model are interpolated and extrapolated by the EarthVision gridding utility in areas where there are no data. Control points are used to control the extrapolation in accordance with geologic interpretations and knowledge of the depositional environment. 


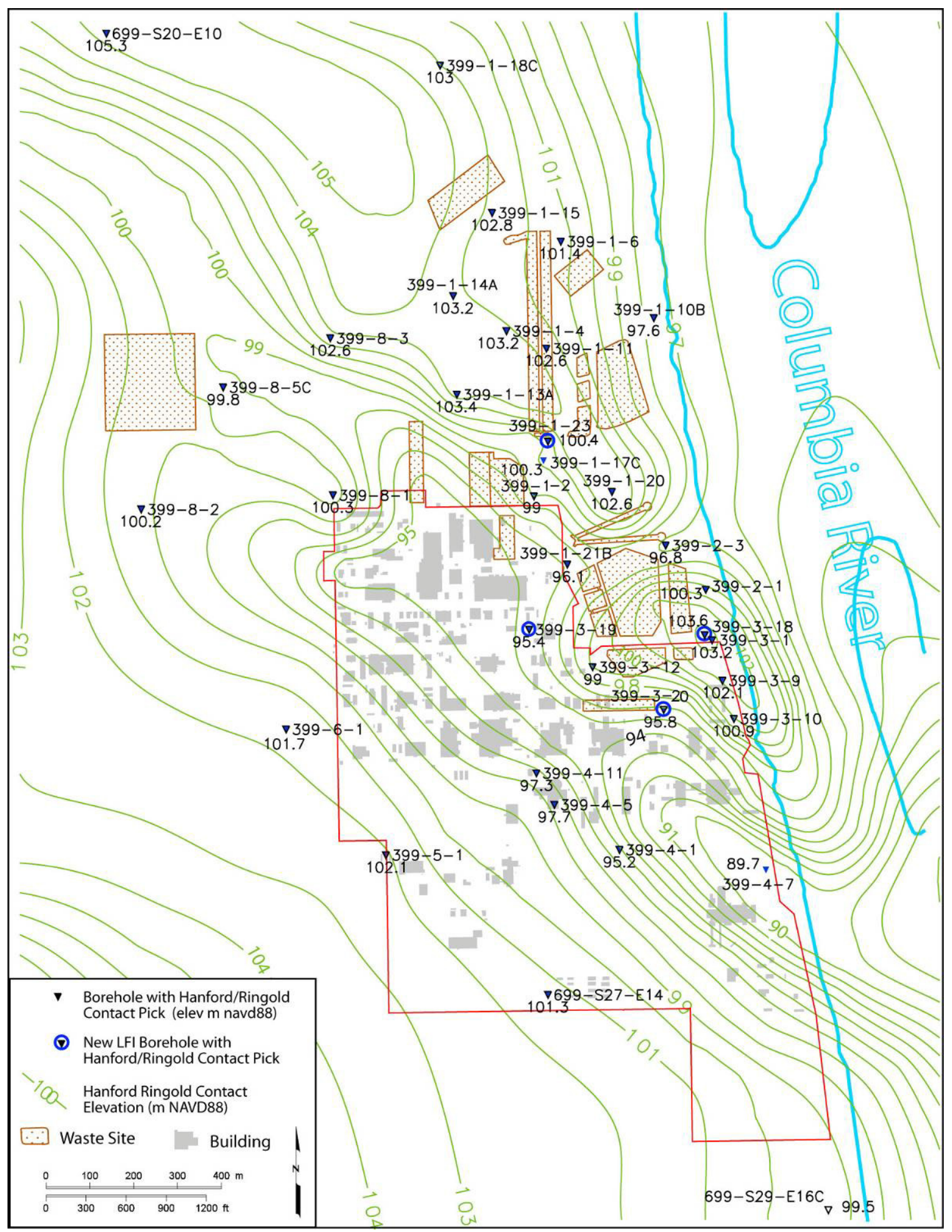

Figure 2.2. Contour Map of Contact Elevation Between the Ringold and Overlying Hanford Formations. The red line shows the outline of the 300 Area. 


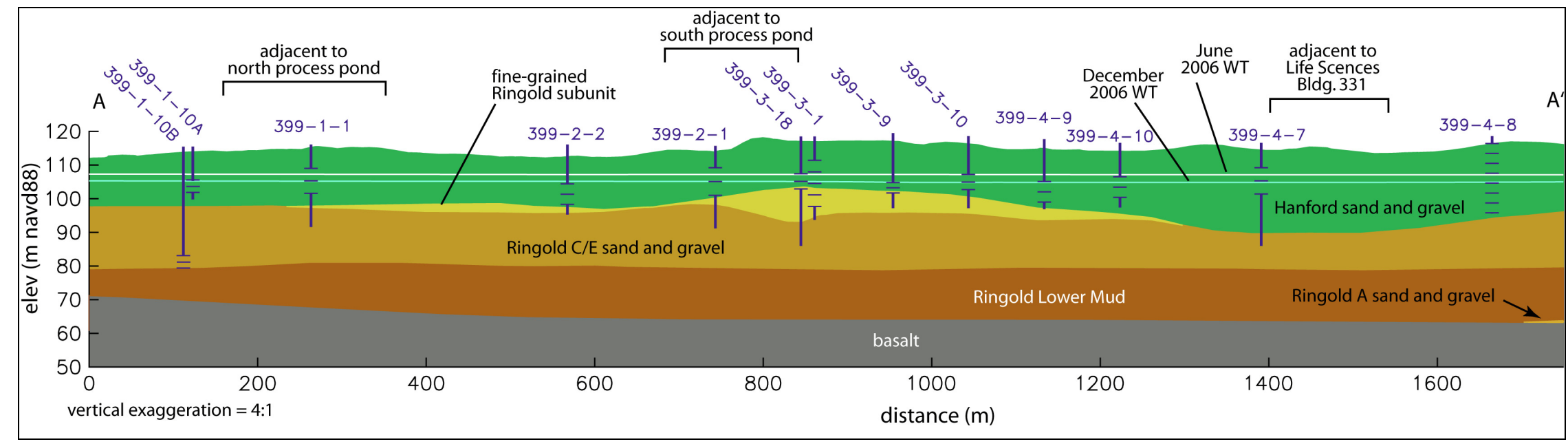

Figure 2.3. Cross Section A-A' Showing Hydrogeologic Units and Seasonal Water-Table Elevations at the 300 Area

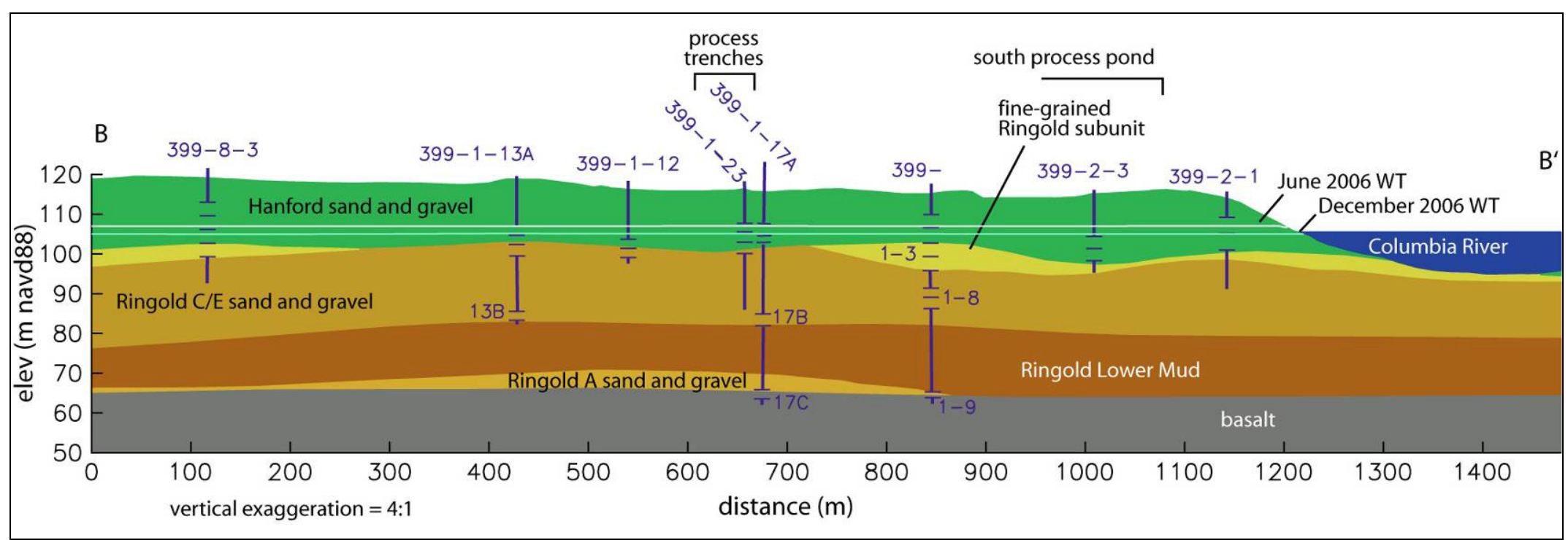

Figure 2.4. Cross Section B-B' Showing Hydrogeologic Units and Seasonal Water-Table Elevations at the 300 Area 


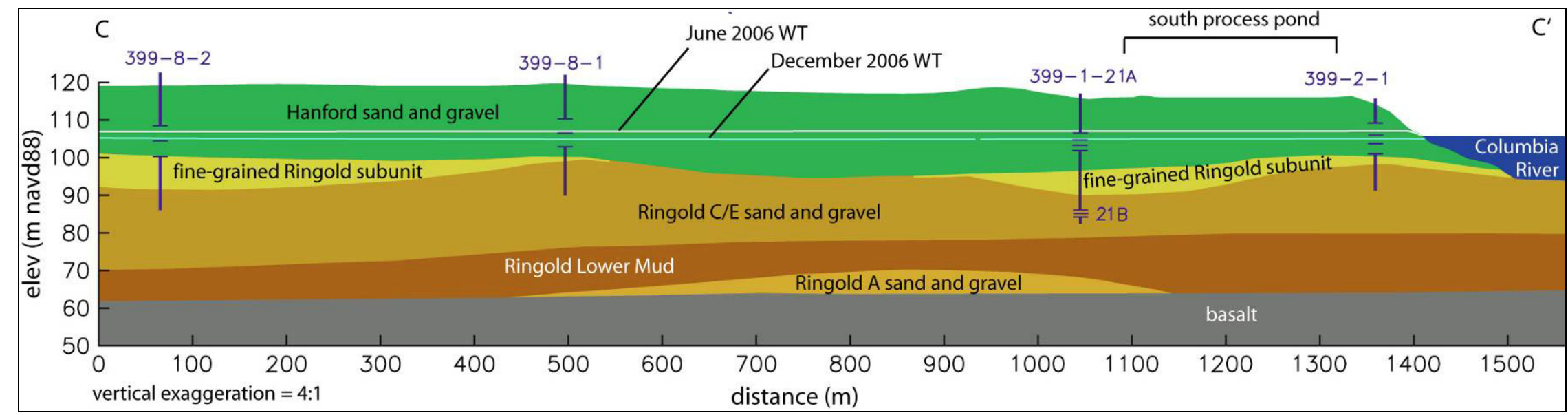

Figure 2.5. Cross Section C-C' Showing Hydrogeologic Units and Seasonal Water-Table Elevations at the 300 Area

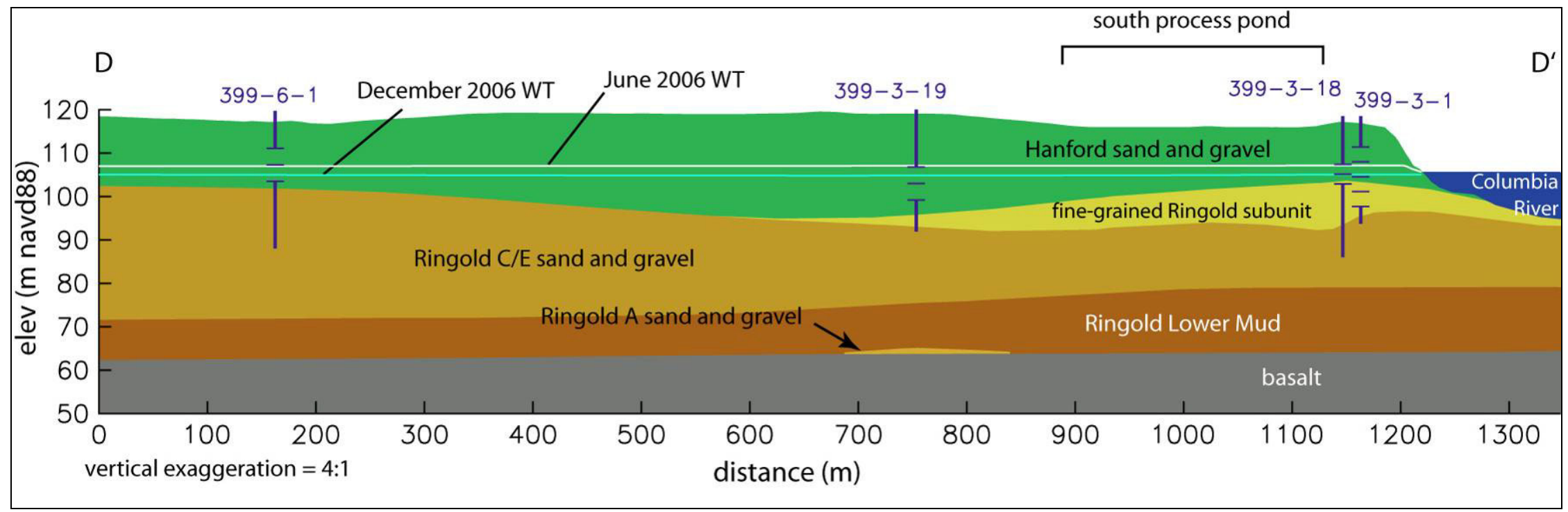

Figure 2.6. Cross Section D-D' Showing Hydrogeologic Units and Seasonal Water-Table Elevations at the 300 Area 


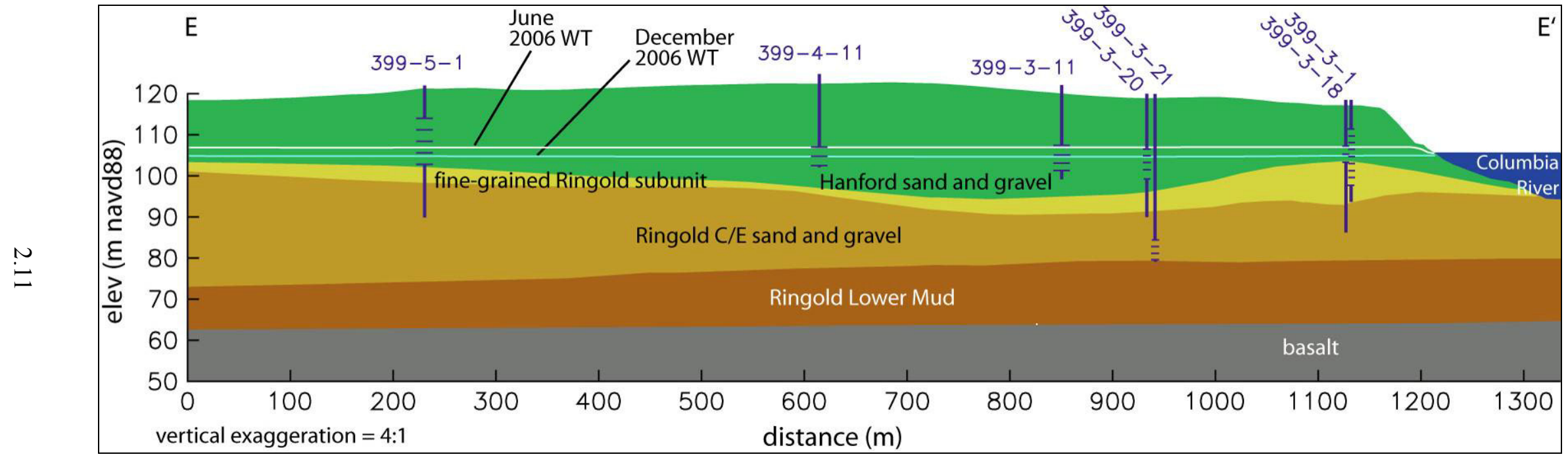

Figure 2.7. Cross Section E-E' Showing Hydrogeologic Units and Seasonal Water-Table Elevations at the 300 Area 


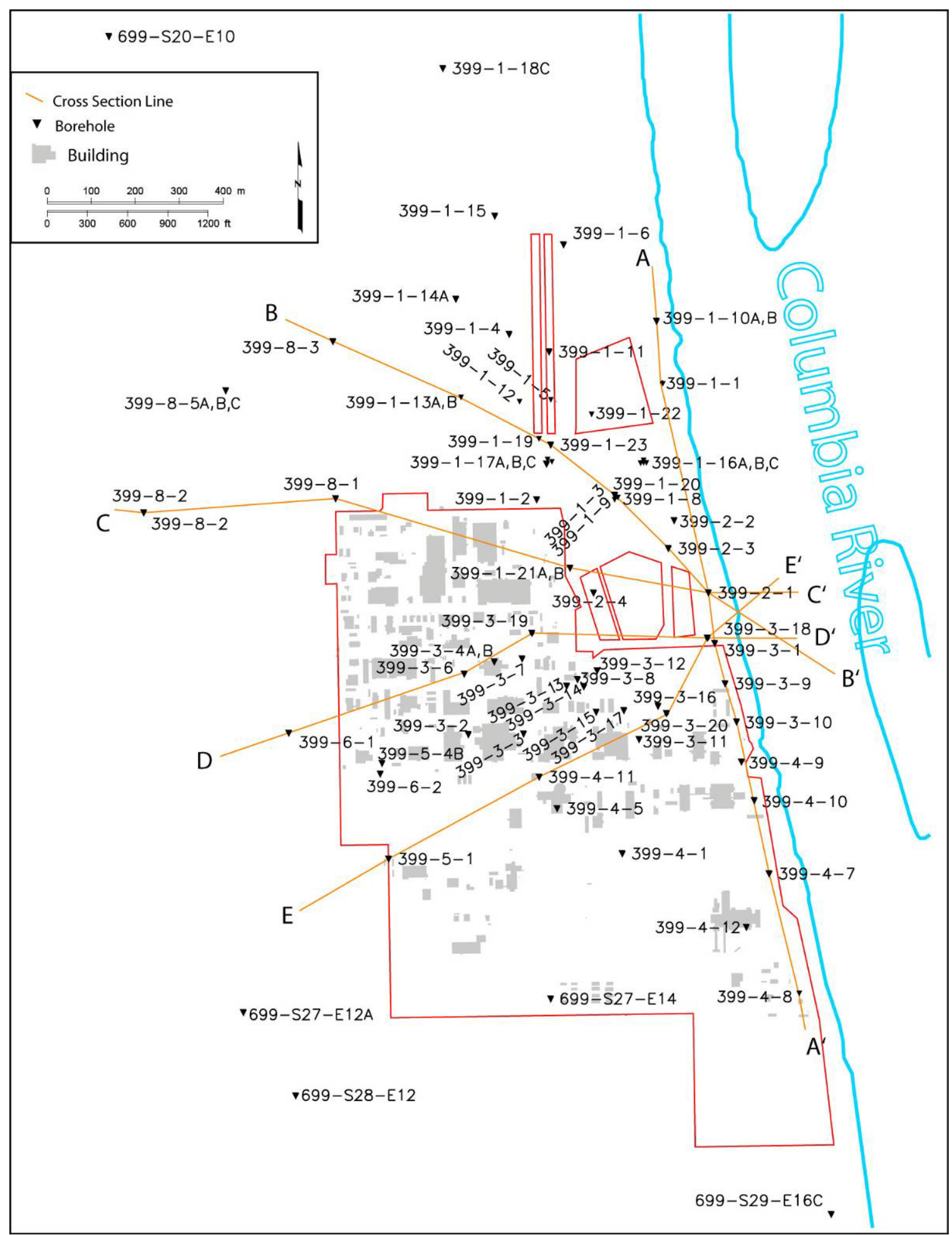

Figure 2.8. Map Showing Locations of Cross Sections 


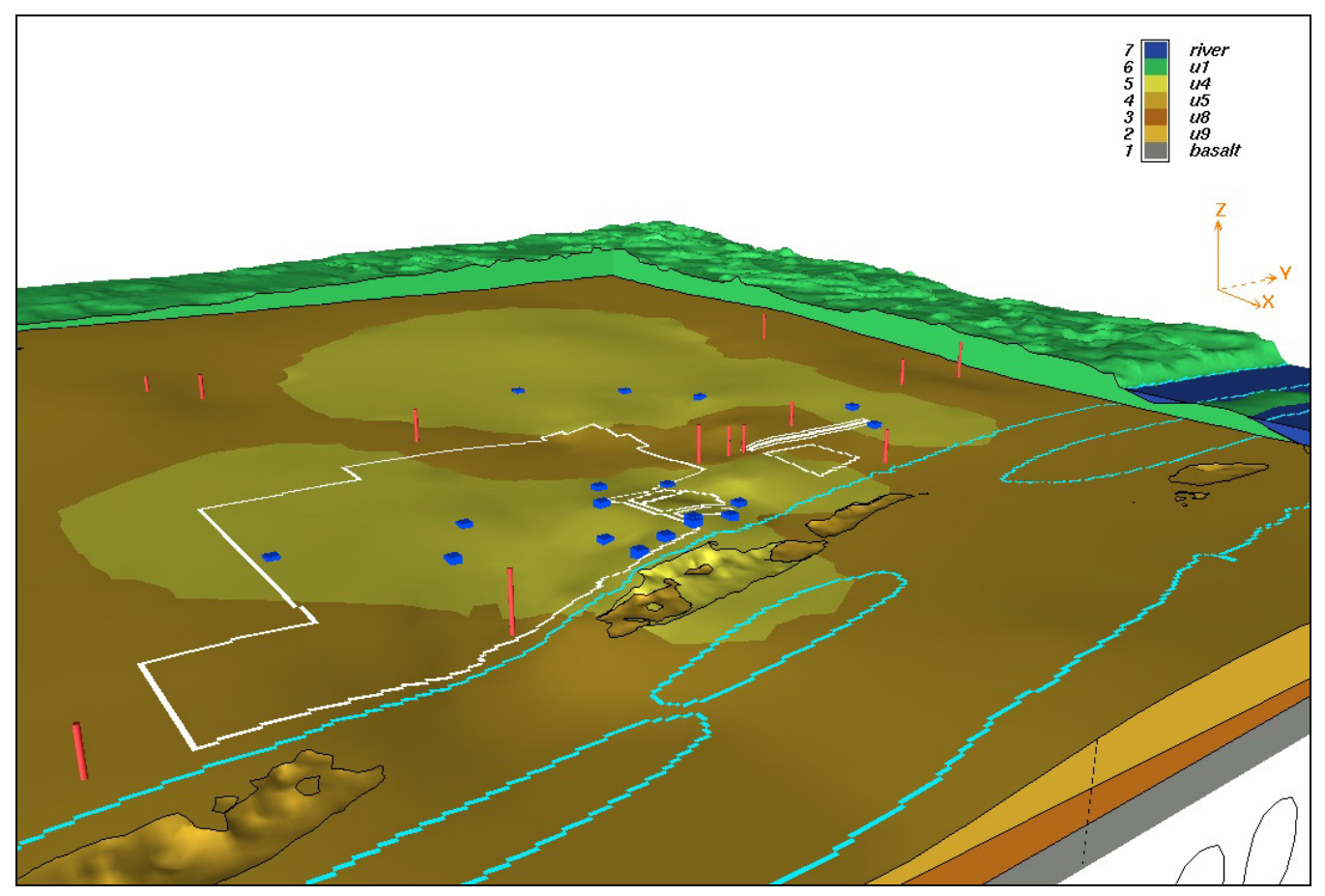

Figure 2.9. Three-Dimensional View of the Top of the Ringold Formation Showing Boreholes Defining the Fine-Grained Subunit

Specific uncertainties that may be particularly important in the 300 Area hydrogeologic conceptual model include the following:

- Geometry of the Hanford and Ringold Formation contact

- Lateral extent of the Ringold Formation fine-grained subunit

- Mixtures of Hanford formation and reworked Ringold Formation sediment with elevated hydraulic conductivity being identified as native Ringold Formation

- Configuration of the Hanford and Ringold Formation contact at the Columbia River interface

- Presence and thickness of a recent (late Holocene period) alluvial layer in the Columbia River bed.

\subsection{Aquifer Hydraulic Properties}

Several pumping tests and slug tests were conducted at 300 Area wells within the unconfined aquifer. The pumping test results were evaluated to determine the reliability of the reported values; in a few cases, reanalysis of test data was required to ensure the results were reliable. Results of this evaluation are shown in Table 2.2, and Figure 2.10 shows the location and calculated hydraulic conductivity values for pumping tests that were determined to be reliable. Hydraulic conductivity values from slug tests conducted at the recently installed LFI wells (Williams 2007) are also shown in Figure 2.10. For some pumping tests where very small drawdown was observed, it was not possible to determine a precise hydraulic conductivity value. However, it was possible to determine the conductivity is probably greater than $5000 \mathrm{~m} / \mathrm{d}(16,404 \mathrm{ft} / \mathrm{d})$. 
Available pumping test results were evaluated to determine the reliability of values reported in Figure 2.10 and a few tests were reanalyzed. Evaluation results are shown in Table 2.2. The presence of a recharge boundary may cause the well response to deviate from the infinite-aquifer radial-flow that is assumed by the applied analysis methods of Cooper and Jacob (1946) and Theis (1935). The Columbia River is a potential recharge boundary for many of the tests in the 300 Area. However, a recharge boundary may also be caused in an unconfined aquifer by discharge of water from the pumping test to an area that is too near to the pumped well, particularly where the depth of the water table is relatively shallow. The pumping test data were evaluated by plotting both the drawdown and the derivative of drawdown for aquifer tests reported in Schalla et al. (1988) to identify recharge boundary effects.

Table 2.2 includes tests identified as being invalid because a recharge boundary affected the results prior to the establishment of infinite-acting radial flow conditions. Results are not provided for these wells. In addition, because of the high permeability of the Hanford formation sediments, it was determined that values of hydraulic conductivity $(\mathrm{K})$ greater than $5000 \mathrm{~m} / \mathrm{d}(16,404 \mathrm{ft} / \mathrm{d})$ could not be precisely measured with the applied pumping test methods. For four of the five tests with $\mathrm{K}>5000 \mathrm{~m} / \mathrm{d}(>16,404 \mathrm{ft} / \mathrm{d})$, the maximum draw downs are $0.1 \mathrm{~m}(0.3 \mathrm{ft})$ or less. The potential effects of well inefficiency, water-level trends, and delayed yield from the unconfined aquifer could all have a similar magnitude effect on the drawdown during a pumping test. The mean hydraulic conductivity value for Hanford formation tests is shown in Figure 2.10 (assuming the minimum value for those marked $>$ ) is $3098 \mathrm{~m} / \mathrm{d}(10,164 \mathrm{ft} / \mathrm{d}$ ). The average for Ringold Formation sediments is $36 \mathrm{~m} / \mathrm{d}(118 \mathrm{ft} / \mathrm{d})$. This large contrast in ability to transmit groundwater and contaminant plumes illustrates why the principal focus for the uranium plume is the saturated portion of the Hanford formation.

\subsection{Water Table and Groundwater Flow Directions}

The 300 Area water table is very dynamic because of fluctuations in the Columbia River stage (see Figure 2.11) and the very high permeability of the Hanford formation sediments that comprise the uppermost part of the unconfined aquifer. Large hourly, daily, weekly, and seasonal fluctuations in the Columbia River stage are caused by the operation of hydroelectric dams on the river and seasonal trends (i.e., spring freshet). The dynamics of Columbia River stage fluctuations and the water-table elevation cause a mixing zone of river water and groundwater within the aquifer. During periods of relatively high-river stage periods, river water enters the aquifer. Measurements of specific conductance and temperature, for which there is a large contrast between groundwater and river water, in 300 Area wells show that river water can encroach more than $190 \mathrm{~m}(623 \mathrm{ft})$ inland in the aquifer during a high-river stage period. During periods of relatively low-river stage, groundwater discharges to the river, as indicated by measurements of specific conductance and other analytes in aquifer tubes installed below the river bed and in springs along the shoreline (Fritz et al. 2007). 
Table 2.2. Summary of Aquifer Pumping Tests Results for the 300 Area

\begin{tabular}{|c|c|c|c|c|c|c|c|c|c|c|c|}
\hline \multirow[b]{2}{*}{ Well Name } & \multirow[b]{2}{*}{$\begin{array}{c}\mathrm{K}(\mathrm{m} / \mathrm{d}) \\
\text { Hanford } \\
\text { Formation }\end{array}$} & \multirow[b]{2}{*}{$\begin{array}{l}\mathrm{K}(\mathrm{m} / \mathrm{d}) \\
\text { Ringold } \\
\text { Unit E/C }\end{array}$} & \multirow[b]{2}{*}{$\begin{array}{l}\text { Hanford } \\
\text { Thickness } \\
\text { (m) }\end{array}$} & \multirow[b]{2}{*}{$\begin{array}{l}\text { Ringold } \\
\text { Thickness } \\
\text { (m) }\end{array}$} & \multirow[b]{2}{*}{$\begin{array}{l}\text { Test Start } \\
\text { Date }\end{array}$} & \multirow[b]{2}{*}{ Test Type } & \multicolumn{2}{|c|}{$\begin{array}{l}\text { Constant Rate Test } \\
\text { Information }\end{array}$} & \multirow[b]{2}{*}{$\begin{array}{l}\text { Maximum Head } \\
\text { Change at Well } \\
\text { (m) }\end{array}$} & \multirow[b]{2}{*}{ Analysis Method } & \multirow[b]{2}{*}{ Reference/Source } \\
\hline & & & & & & & $\begin{array}{l}\text { Pumping } \\
\text { Duration } \\
\text { (min) }\end{array}$ & $\begin{array}{l}\text { Flow Rate } \\
\text { (L/min) }\end{array}$ & & & \\
\hline $399-1-10 \mathrm{~A}$ & 980 & & 7.7 & 18.2 & $11 / 25 / 1986$ & $\begin{array}{l}\text { Constant } \\
\text { Rate }\end{array}$ & 240 & 2385 & 0.7 & Theis Type-Curve & Schalla et al. 1988 \\
\hline $399-1-13 \mathrm{~A}$ & 3800 & & 2.3 & 20.0 & $11 / 05 / 1986$ & $\begin{array}{l}\text { Constant } \\
\text { rate }\end{array}$ & 132 & 2498 & 0.3 & Theis Type-Curve & Schalla et al. 1988 \\
\hline $399-1-18 \mathrm{~A}$ & $>5000$ & & 2.3 & 19.8 & $11 / 11 / 1986$ & $\begin{array}{l}\text { Constant } \\
\text { rate }\end{array}$ & 120 & 2574 & 0.1 & Theis Type-Curve & Schalla et al. 1988 \\
\hline $399-1-2$ & $>5000$ & & 5.8 & 18.6 & $12 / 07 / 1977$ & $\begin{array}{l}\text { Constant } \\
\text { rate }\end{array}$ & 150 & 2460 & $<0.1$ & $\begin{array}{l}\text { Minimal } \\
\text { Drawdown }\end{array}$ & New analysis \\
\hline $399-1-4$ & 3800 & & 1.5 & 19.7 & $12 / 05 / 1977$ & $\begin{array}{l}\text { Constant } \\
\text { rate }\end{array}$ & 465 & 1264 & 2.1 & $\begin{array}{l}\text { Cooper and Jacob } \\
\text { Straight-line } \\
\text { Semilog Method } \\
\text { (Recovery) }\end{array}$ & $\begin{array}{l}\text { Lindberg and Bond } \\
1979\end{array}$ \\
\hline $399-8-1$ & $>5000$ & & 4.7 & 24.7 & $12 / 01 / 1977$ & $\begin{array}{l}\text { Constant } \\
\text { rate }\end{array}$ & 480 & 1800 & 0.1 & Theis Type-Curve & New analysis \\
\hline $399-8-2$ & 1100 & & 2.7 & 30.1 & $12 / 15 / 1977$ & $\begin{array}{l}\text { Constant } \\
\text { rate }\end{array}$ & 480 & 473 & 0.4 & $\begin{array}{l}\text { Radflow } \\
\text { Composite }\end{array}$ & New analysis \\
\hline $399-1-16 \mathrm{~A}$ & & 42 & 0 & 22.2 & $02 / 26 / 1987$ & $\begin{array}{l}\text { Constant } \\
\text { rate }\end{array}$ & 180 & 114 & 0.5 & $\begin{array}{l}\text { Cooper and } \\
\text { Jacob Straight- } \\
\text { line Semilog } \\
\text { Method } \\
\text { (Drawdown) }\end{array}$ & Schalla et al. 1988 \\
\hline 699-S22-E9A & & 49 & 0 & 5.5 & 03/30/1992 & $\begin{array}{l}\text { Constant } \\
\text { rate -obs }\end{array}$ & 2880 & $93 a$ & $0.8 \mathrm{~b}$ & $\begin{array}{l}\text { Newman Type- } \\
\text { curve }\end{array}$ & Swanson 1992 \\
\hline 699-S22-E9D & & 51 & 0 & 5.5 & 03/30/1992 & $\begin{array}{l}\text { Constant } \\
\text { rate }\end{array}$ & 2880 & 93 & 2.1 & $\begin{array}{l}\text { Cooper and Jacob } \\
\text { Straight-line } \\
\text { Semilog Method } \\
\text { (Drawdown) }\end{array}$ & Swanson 1992 \\
\hline 699-S27-E9A & & 37 & 0 & 10.3 & 03/10/1992 & $\begin{array}{l}\text { Constant } \\
\text { rate -obs }\end{array}$ & 2880 & $510 \mathrm{a}$ & $0.63 b$ & $\begin{array}{l}\text { Newman Type- } \\
\text { Curve }\end{array}$ & Swanson 1992 \\
\hline 699-S27-E9d & & 36 & 0 & 10.3 & 03/10/1992 & Const-Mult & 2880 & 510 & 2.2 & $\begin{array}{l}\text { Cooper and Jacob } \\
\text { Straight-line } \\
\text { Semilog Method } \\
\text { (Drawdown) }\end{array}$ & Swanson 1992 \\
\hline
\end{tabular}


Table 2.2. (Cont)

\begin{tabular}{|c|c|c|c|c|c|c|c|c|c|c|c|}
\hline Well Name & $\begin{array}{c}\mathrm{K}(\mathrm{m} / \mathrm{d}) \\
\text { Hanford } \\
\text { Formation }\end{array}$ & $\begin{array}{l}\mathrm{K}(\mathrm{m} / \mathrm{d}) \\
\text { Ringold } \\
\text { Unit E/C }\end{array}$ & $\begin{array}{l}\text { Hanford } \\
\text { Thickness } \\
\text { (m) }\end{array}$ & $\begin{array}{l}\text { Ringold } \\
\text { Thickness } \\
\text { (m) }\end{array}$ & $\begin{array}{l}\text { Test Start } \\
\text { Date }\end{array}$ & Test Type & $\begin{array}{c}\text { Pumping } \\
\text { Duration } \\
\text { (min) }\end{array}$ & $\begin{array}{l}\text { Flow Rate } \\
\text { (L/min) }\end{array}$ & $\begin{array}{l}\text { Maximum Head } \\
\text { Change at Well } \\
\text { (m) }\end{array}$ & Analysis Method & Reference/Source \\
\hline $399-1-16 b$ & \multicolumn{4}{|c|}{$\begin{array}{l}\text { Unreliable (recharge boundary } \\
\text { effect) }\end{array}$} & $02 / 19 / 1987$ & $\begin{array}{l}\text { Constant } \\
\text { rate }\end{array}$ & 800 & 45 & 4.4 & & Schalla et al. 1988 \\
\hline $399-1-16 c$ & \multicolumn{4}{|c|}{$\begin{array}{l}\text { Unreliable (recharge boundary } \\
\text { effect) }\end{array}$} & 02/17/1987 & $\begin{array}{l}\text { Constant } \\
\text { rate }\end{array}$ & 480 & 11 & 12.81 & & Schalla et al. 1988 \\
\hline $399-1-17 b$ & \multicolumn{4}{|c|}{$\begin{array}{l}\text { Unreliable (recharge boundary } \\
\text { effect) }\end{array}$} & 02/09/1987 & $\begin{array}{l}\text { Constant } \\
\text { rate }\end{array}$ & 315 & 87 & 12.81 & & Schalla et al. 1988 \\
\hline $399-1-17 c$ & \multicolumn{4}{|c|}{$\begin{array}{l}\text { Unreliable (recharge boundary } \\
\text { effect) }\end{array}$} & 02/11/1987 & $\begin{array}{l}\text { Constant } \\
\text { rate }\end{array}$ & 360 & 106 & 6.3 & & Schalla et al. 1988 \\
\hline $399-1-18 c$ & \multicolumn{4}{|c|}{$\begin{array}{l}\text { Unreliable (recharge boundary } \\
\text { effect) }\end{array}$} & 02/03/1987 & $\begin{array}{l}\text { Constant } \\
\text { rate }\end{array}$ & 480 & 15 & 10.4 & & Schalla et al. 1988 \\
\hline
\end{tabular}

(a) Flow rate at pumping well 699-S22-E9D.

(b) Drawdown at observation well. 


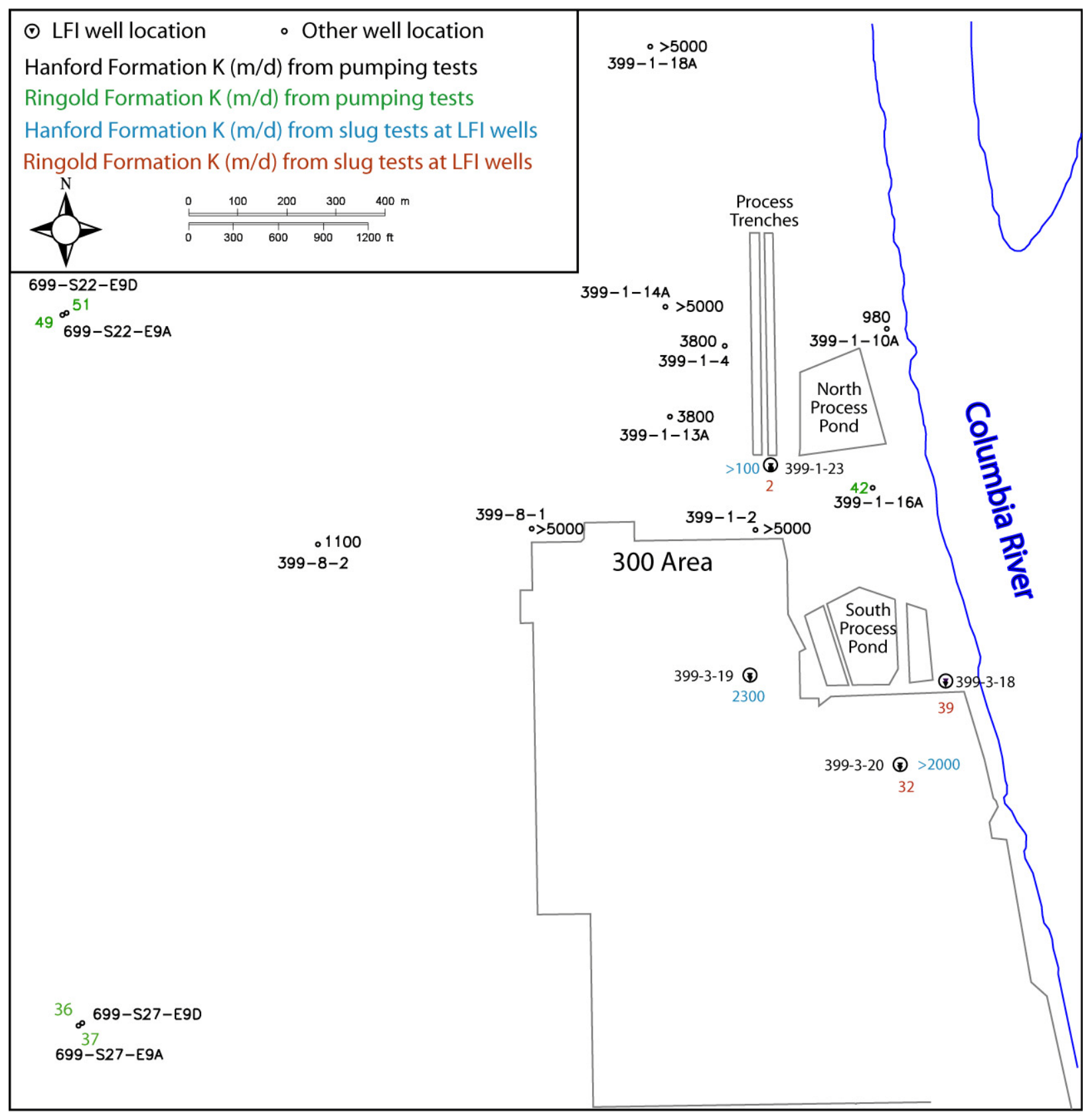

Figure 2.10. Location and Hydraulic Conductivity Values for Pumping Tests with Results Considered Reliable (slug test results from Williams et al. 2007) 


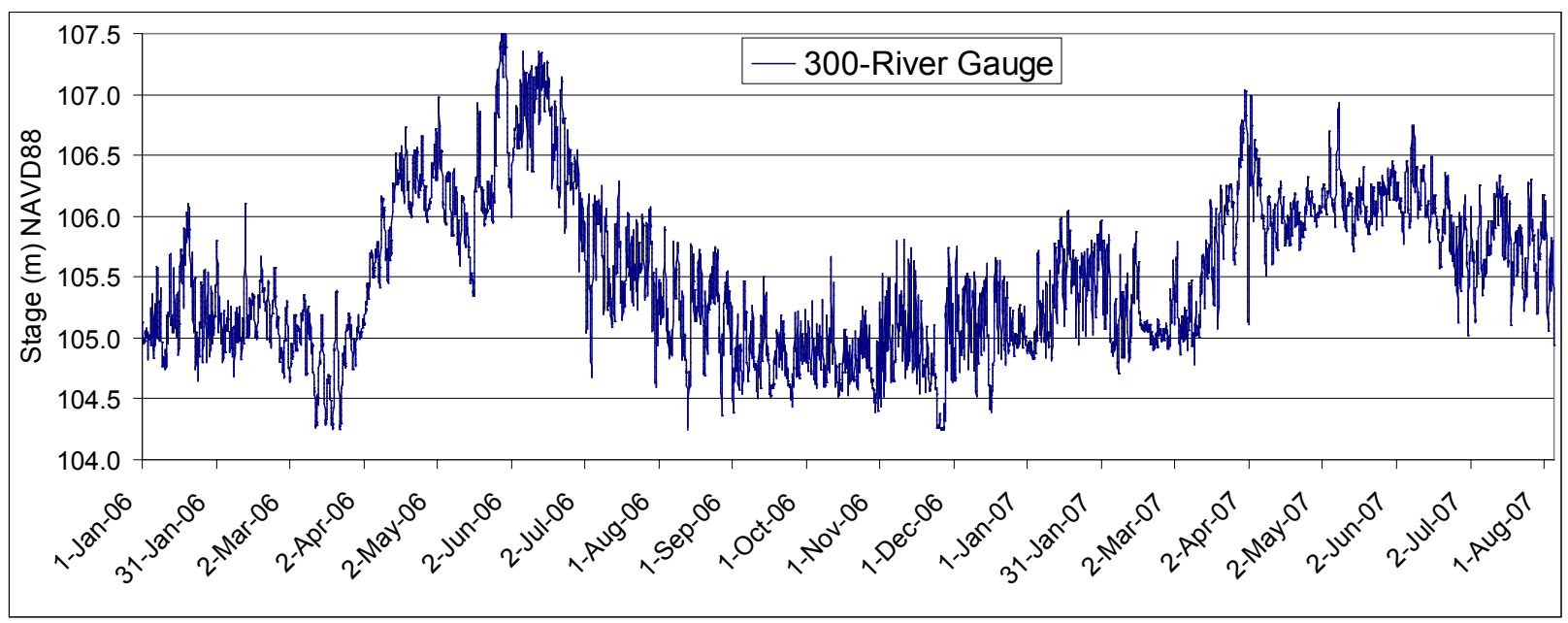

Figure 2.11. Columbia River Stage from the 300 Area Gauging Station for 2006 and 2007 (partial)

The water table is relatively flat in the 300 Area (i.e., very small hydraulic gradients) because of the extremely high permeability of the Hanford formation that comprises the uppermost portion of the unconfined aquifer. The water-table elevation contours from the Hanford Site Groundwater Monitoring Program (Hartman et al. 2007) for a high-river stage period (June) and low-river stage period (December) are shown in Figures 2.12 and 2.13, respectively. These figures show that the water table, along with the uranium concentrations, is distinctly different during these periods. During low water-table conditions in December, peak uranium concentrations ranging from 100 to $200 \mu \mathrm{g} / \mathrm{L}$, were measured from wells near the 300 Area shoreline with lower concentrations around the waste site farther inland. During high watertable conditions in June, higher uranium concentrations are measured from wells inland around the waste sites with lower concentrations along the river shoreline.

Two separate high-resolution water-level monitoring networks were set up in the 300 Area to investigate the water-table dynamics through collection of water-level data at an hourly and/or sub-hourly frequency over multiyear periods. The current network consists of 13 wells and was established in 2004 (Fritz et al. 2007). An earlier network was established in the early 1990s and operated until the mid-1990s (Campbell 1994, Campbell and Newcomer 1992). These networks and data analysis are discussed in Sections 2.3.1 and 2.3.2.

\subsubsection{Current (2004+) Water-Level Monitoring Network}

An automated water-level monitoring network was installed in 2004 by the RACS Project in the 300 Area (Fritz et al. 2007). Nine wells were initially included in this network that collected water levels on hourly and sub-hourly intervals and was expanded to include 13 wells in 2006 (see Figure 2.14). This monitoring network is focused between the north and south process ponds and extends westward past the southern portion of the north process trenches (see Figure 2.12 for waste site locations). Six of these wells were also used to monitor groundwater temperature and electrical conductivity. The 300 Area water-level monitoring network was supplemented in July 2006 with the addition of the polyphosphate injection well (399-1-23) and well 399-1-16A to refine the well coverage from the original network. 
Two additional wells, 399-1-11 and 399-1-10A, were added in October 2006 to increase the northern extent of the well coverage. The addition of wells 399-1-23 and 399-1-16A to this network resulted in significant variations in the computed gradient direction compared to the results from the coarser water-level network.

Contoured hydraulic head data and calculated hydraulic gradients for selected time periods in 2006 and 2007 are shown in Figures 2.14 through 2.18. The specific times for these plots were selected to illustrate distinct periods during the yearly river stage cycle. The hydraulic gradient vectors in these figures were calculated from triangular groups of wells. Hydraulic gradients were calculated from a plane that was fit to the three water-level elevations at each time period for each well group. Figure 2.14 shows a time with high inland-directed gradients during the initial high-river stage of the year following sustained lower-river stages during the winter. Figure 2.15 shows inland-directed hydraulic gradients during the sustained period of high-river stage in June 2007. High-hydraulic gradients directed toward the river occur during the significant drop in the river stage (typically in late June or early July) following the period of sustained high-river stage as shown in Figure 2.16. Figures 2.17 and 2.18 show two cases where the predominant gradient direction changed during the sustained low-river stage period.

The contoured hydraulic head data in Figures 2.14 through 2.18 show generally higher gradients in the north and east portion of this monitoring well network, particularly during the low-river stage, as illustrated in Figure 2.17. This indicates lower hydraulic conductivity for the Hanford formation unconfined aquifer at the northeastern part of this region compared to the southwestern portion of the monitoring network.

Monthly rose diagrams showing the groundwater flow direction from this network using measurements every 2 hours for the period July 2006 to July 2007 are shown in Figures 2.19 to 2.21. These stacked rose diagrams are grouped by month to show the seasonal variations in hydraulic gradients for each of these well clusters. The bi-hourly data are split out on separate plots for each month in Figures 2.22 and 2.23 for one specific well cluster located near the river. This cluster was selected for separate monthly plots in Figures 2.22 and 2.23 based on the two predominant flow directions seen in the stacked rose diagrams in Figure 2.21. The monthly plots for this cluster show the flow direction is predominantly east-northeast during the late summer and fall (low-river stage period) and predominantly southsouthwest during the spring and early summer (high-river stage period). 


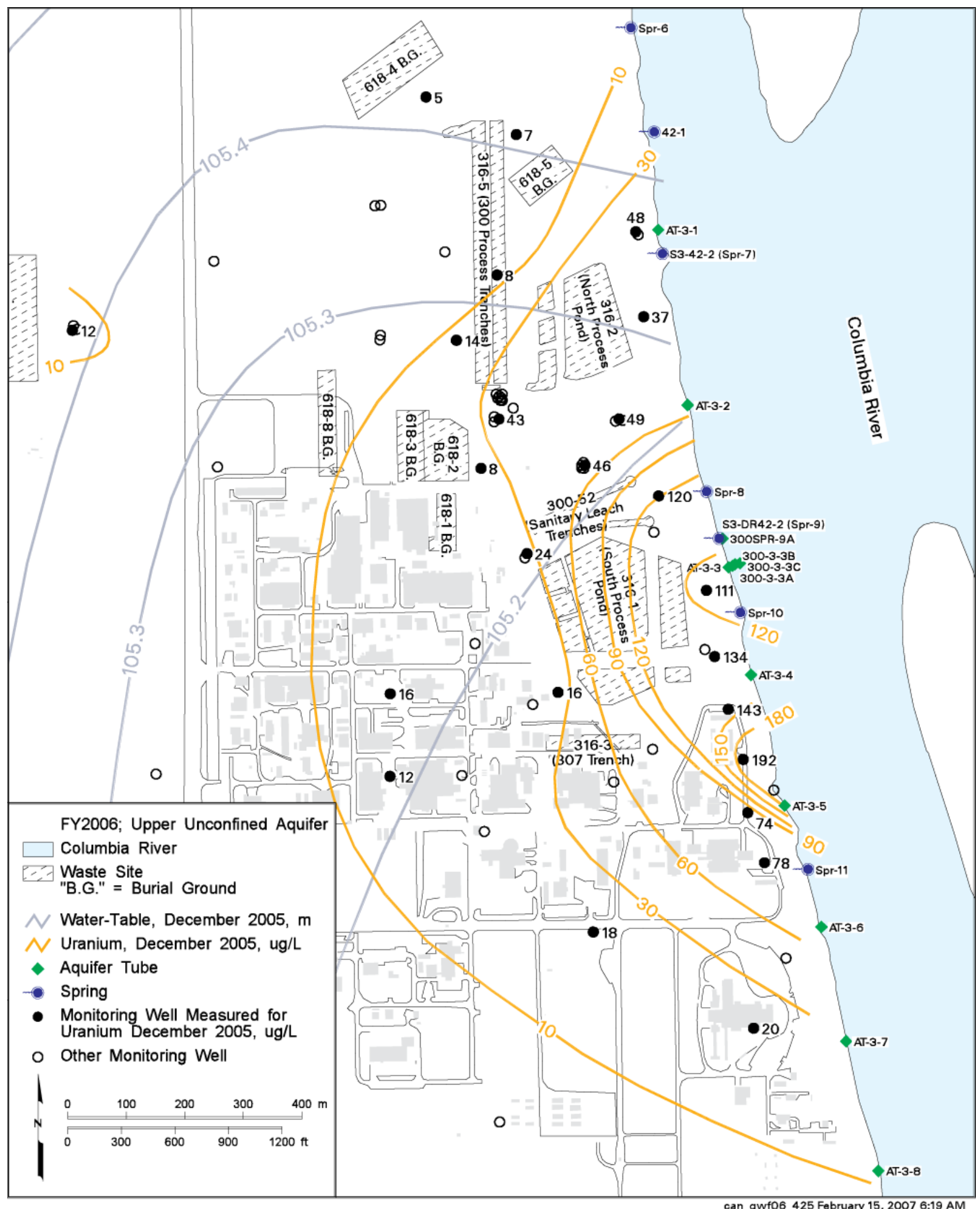

Figure 2.12. Water-Table Elevations and Uranium Concentrations in Upper Part of Unconfined Aquifer Beneath 300 Area, December 2005 (Source: Hartman et al. 2007) 


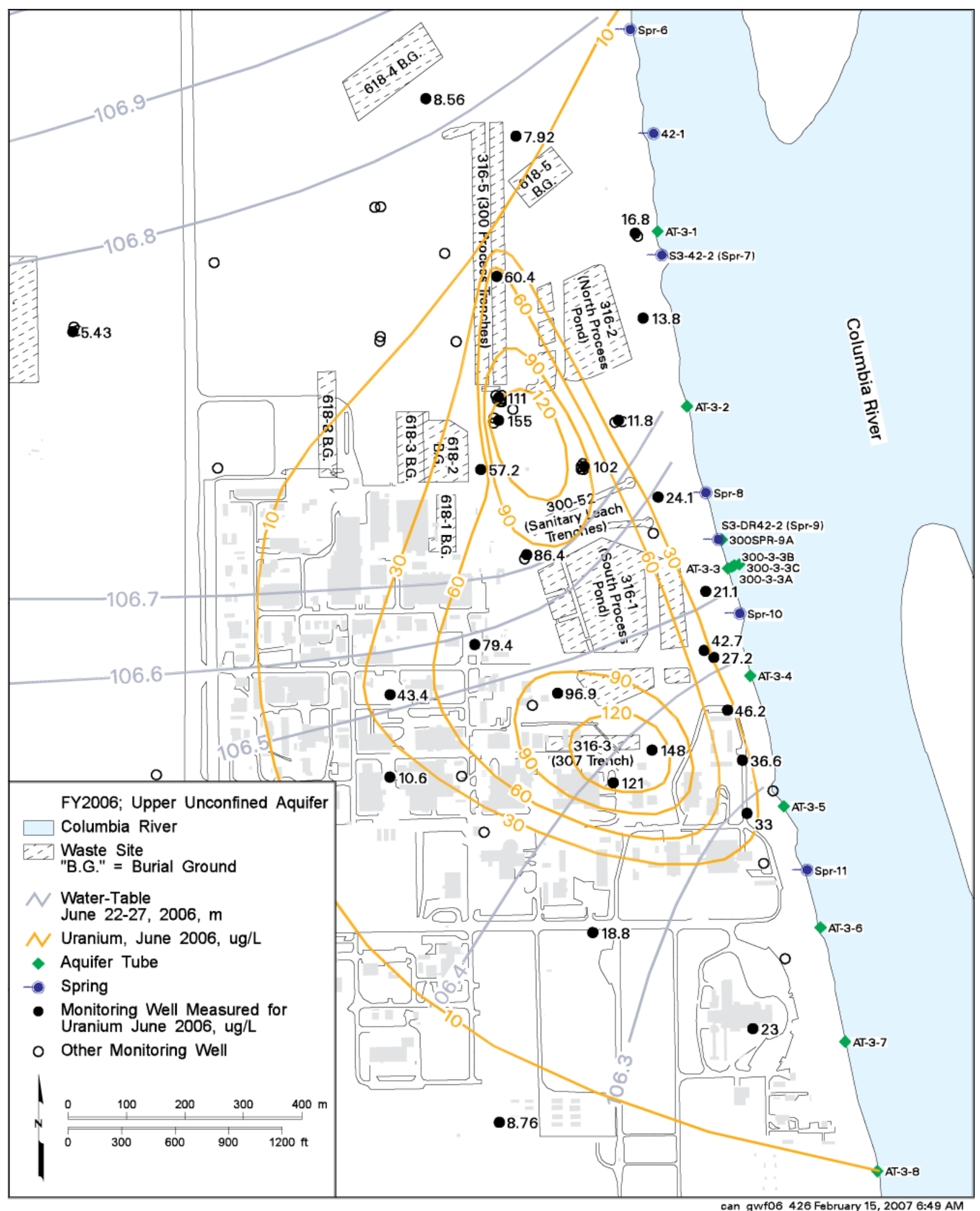

Figure 2.13. Water-Table Elevations and Uranium Concentrations in Upper Part of Unconfined Aquifer Beneath the 300 Area, June 2006 (Source: Hartman et al. 2007) 


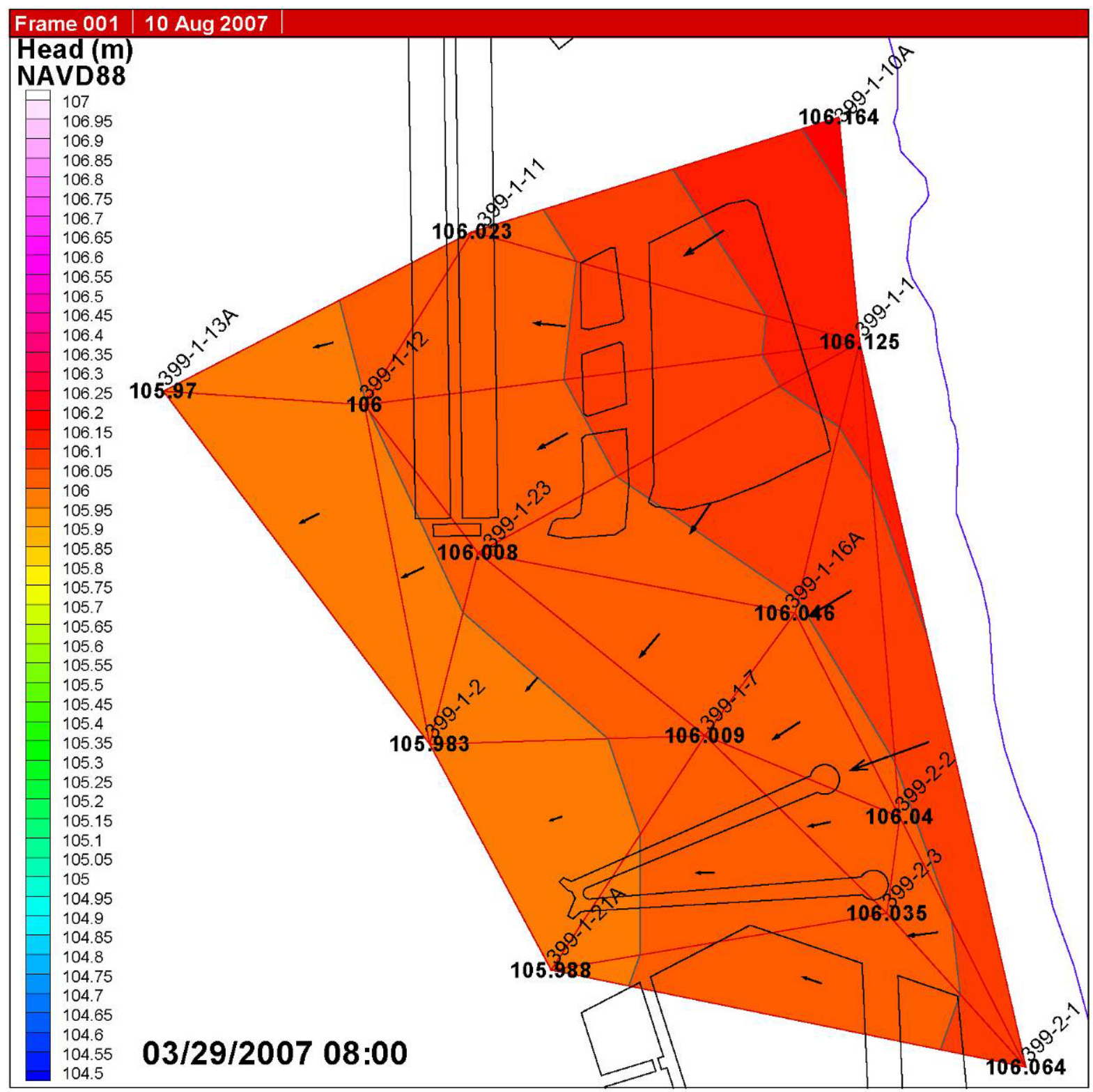

Figure 2.14. The 2004+ Water-Level Monitoring Network for the 300 Area - Initial High-River Stage Example 


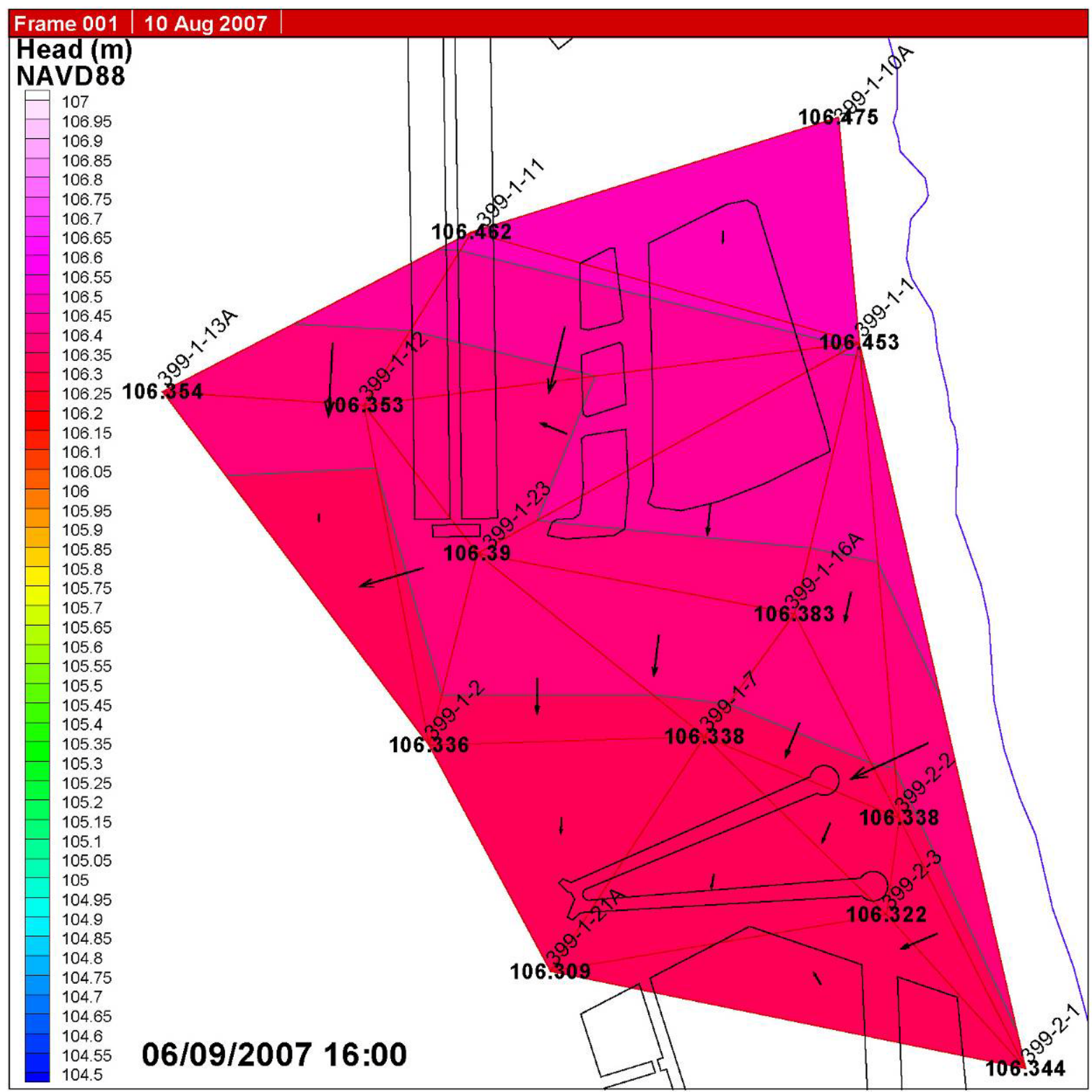

Figure 2.15. The 2004+ Water-Level Monitoring Network for the 300 Area - Sustained High-River Stage Example 


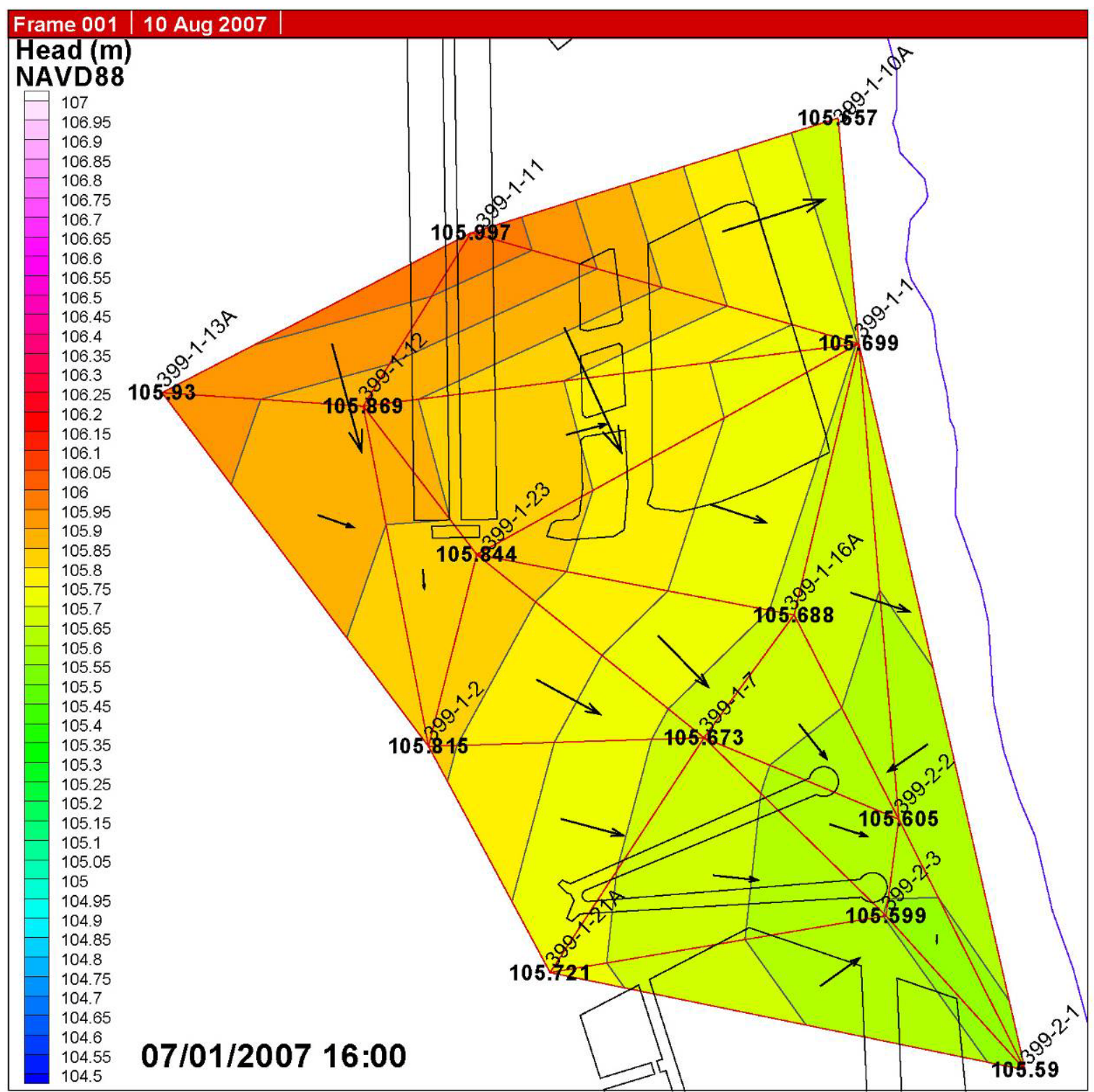

Figure 2.16. The 2004+ Water-Level Monitoring Network for the 300 Area - Initial Lower River Stage Following High-River Stage Example 


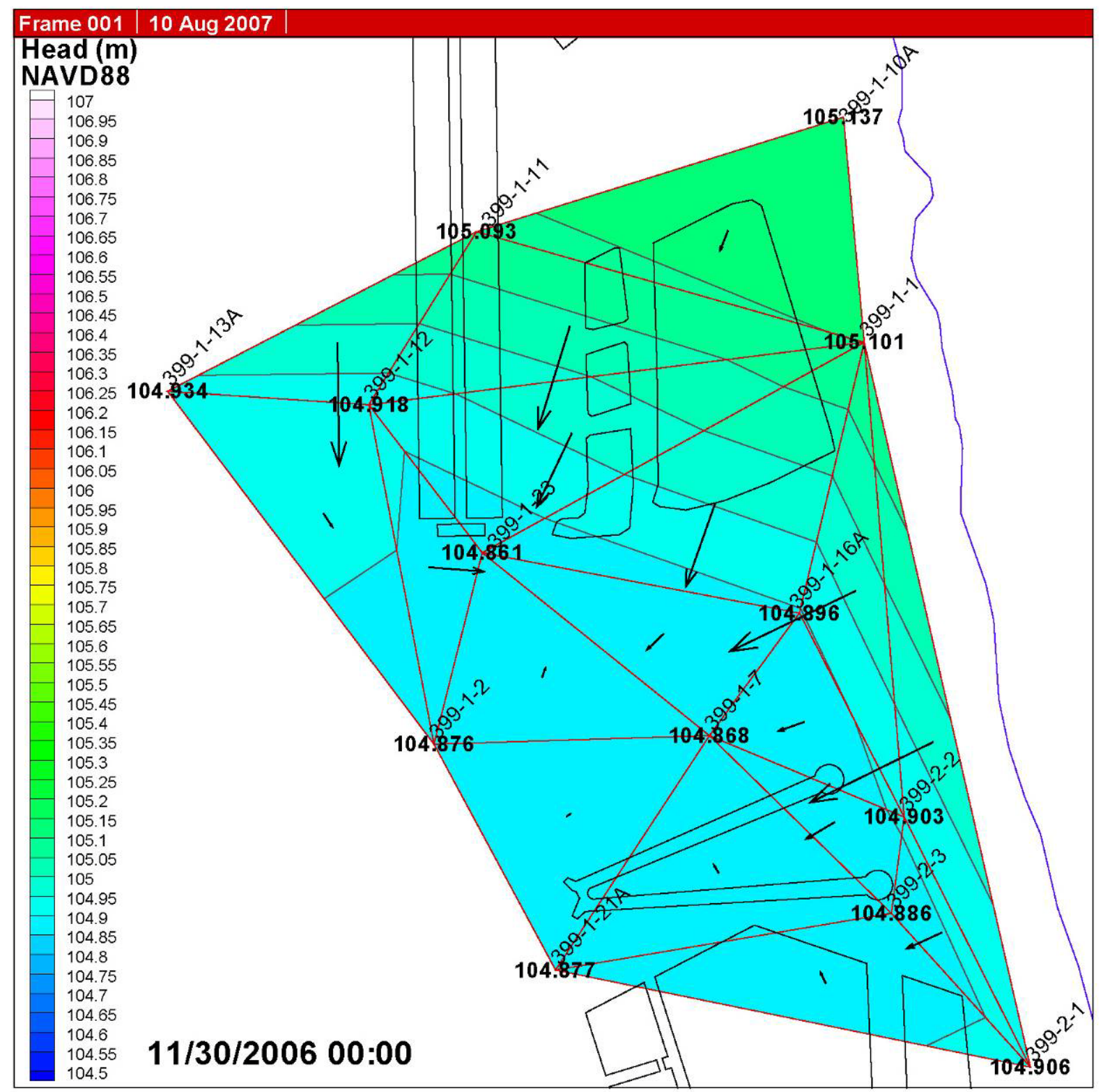

Figure 2.17. The 2004+ Area Water-Level Monitoring Network in the 300 Area - Sustained Low-River Stage - Inflow Example 


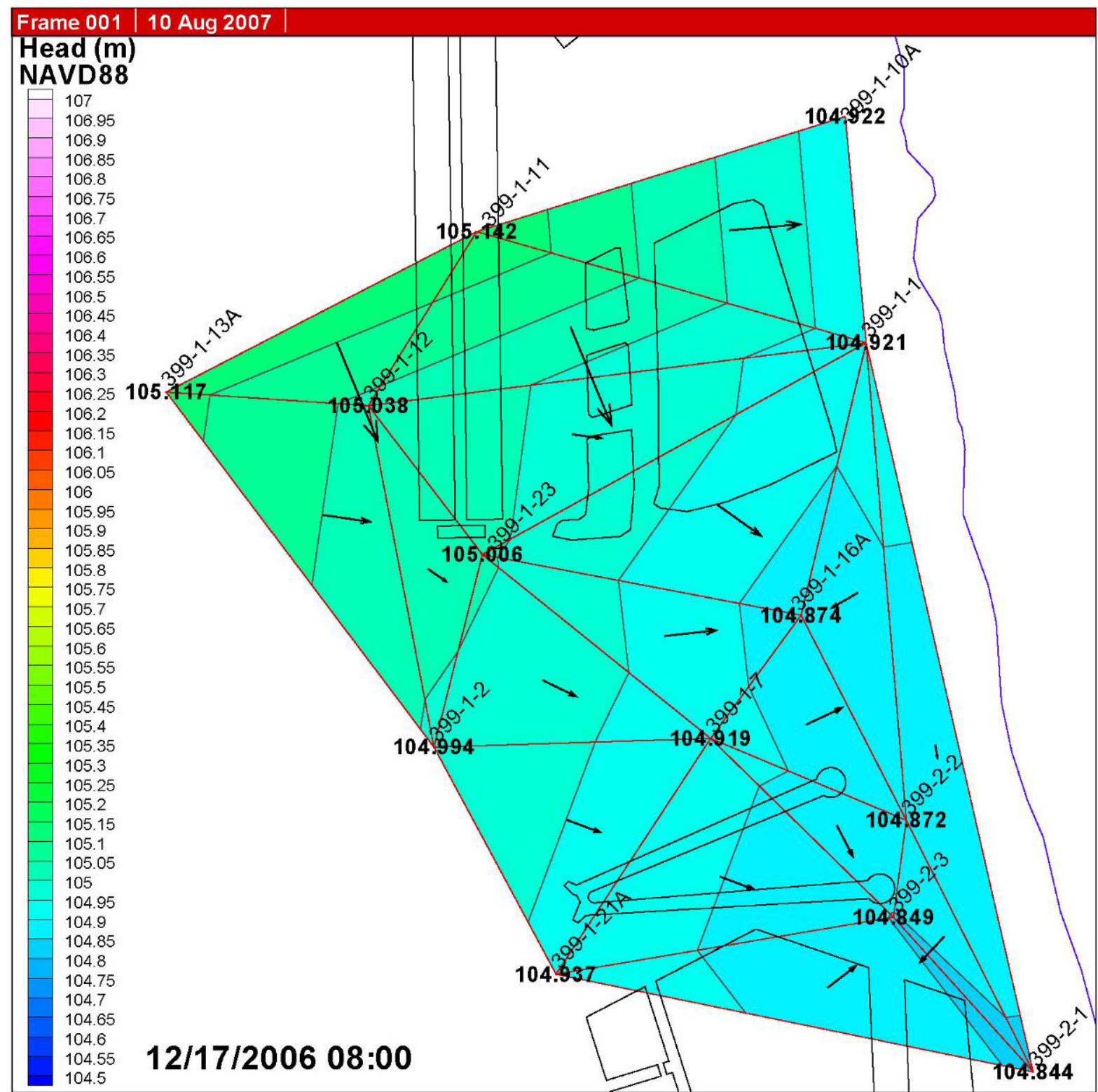

Figure 2.18. The 2004+ Water-Level Monitoring Network for the 300 Area - Sustained Low-River Stage - Outflow Example 

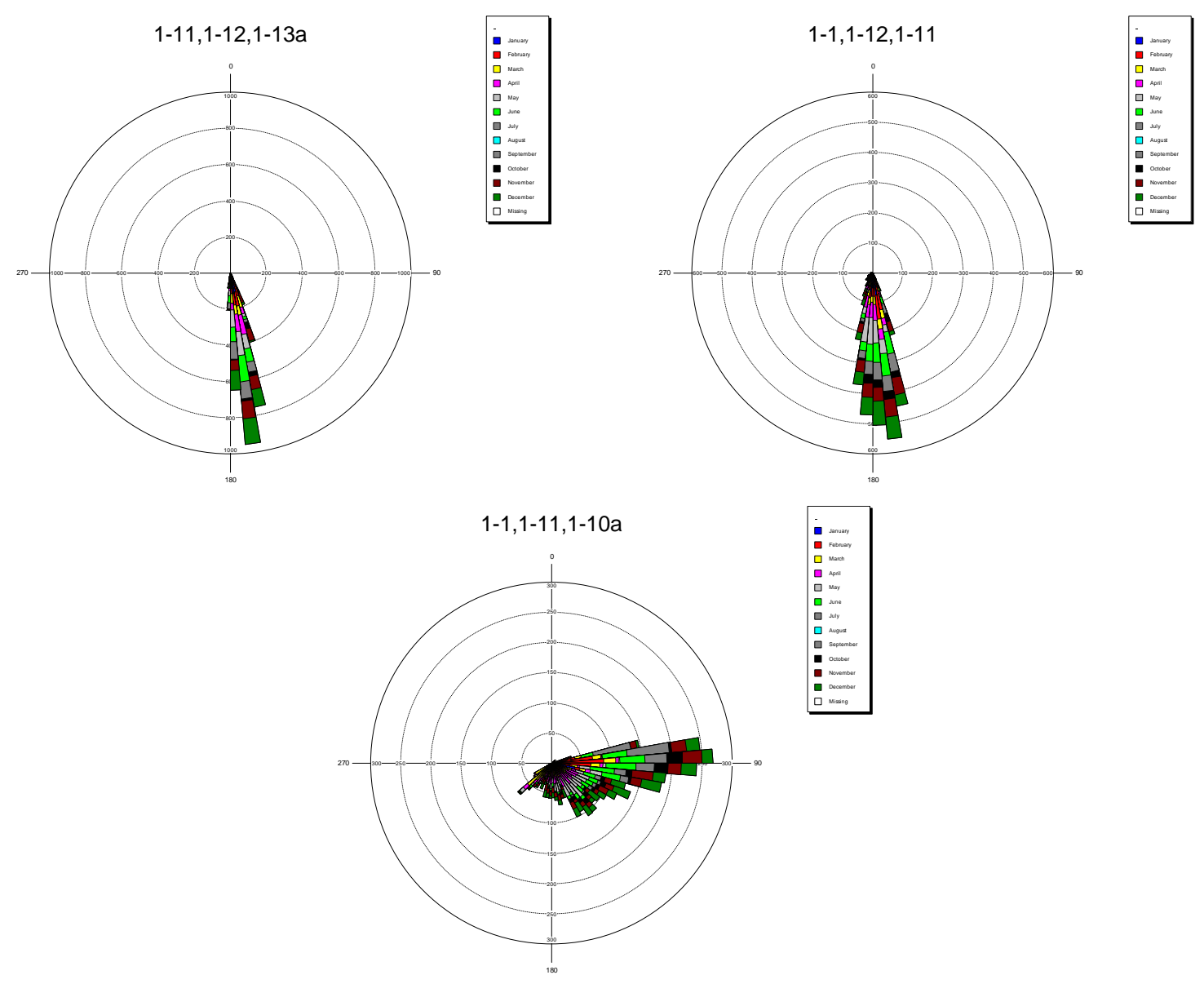

Figure 2.19. 300 Area Water-Level Monitoring Network - Hydraulic Gradient Rose Diagrams for Mid-October, 2006, Through July 26, 2007 (bi-hourly data; partial year). Data for northern portion of monitoring network. Azimuth shows direction of flow. The radius is scaled to the count of gradient directions within 5-degree classes. 399-prefix removed from well names. Note: Some data are missing from well 399-1-1 in August and September 2006. 

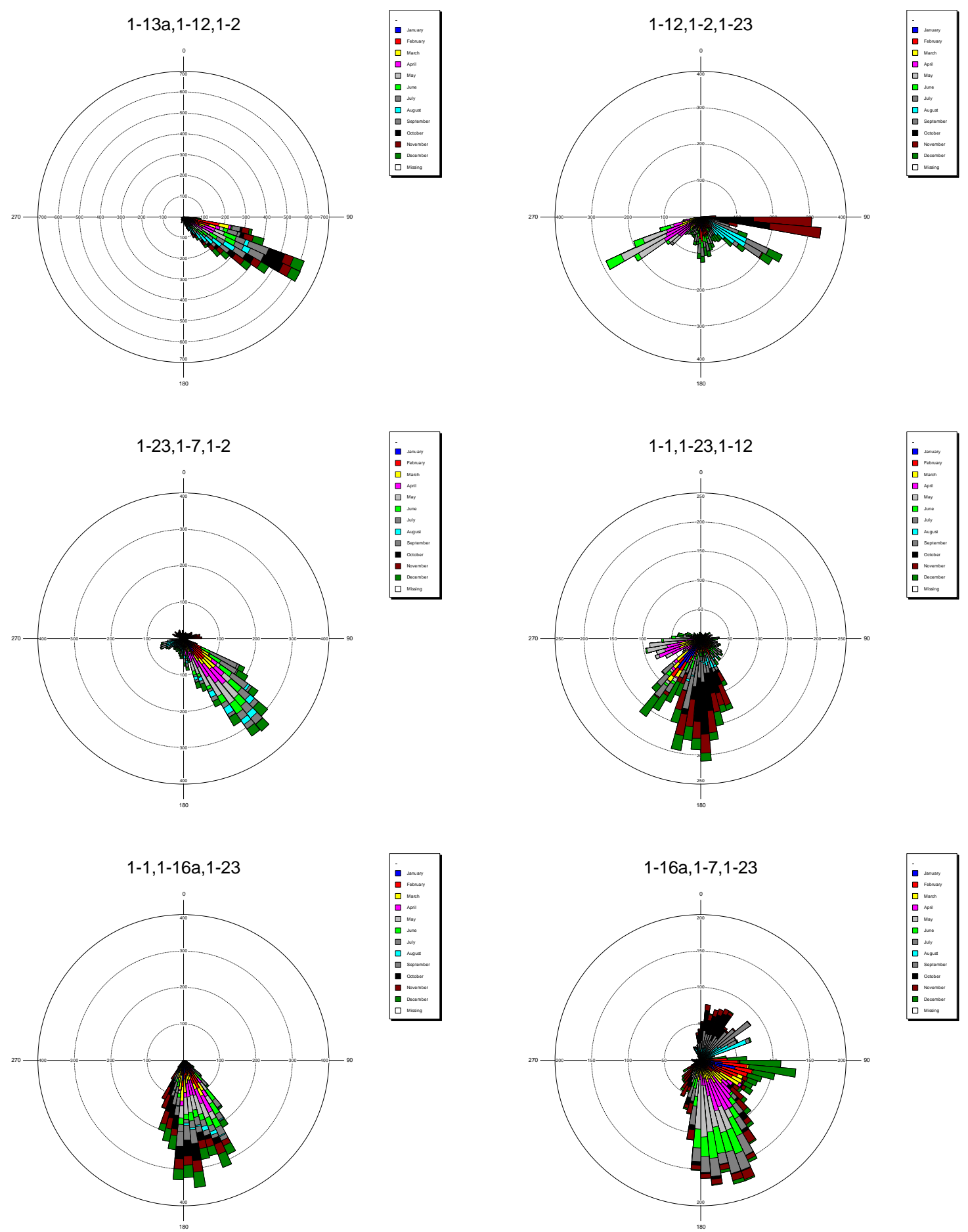

Figure 2.20. 300 Area Water-Level Monitoring Network - Hydraulic Gradient Rose Diagrams for July 26, 2006, Through July 26, 2007 (bi-hourly data). Data for central portion of monitoring network. Azimuth shows direction of flow. The radius is scaled to the count of gradient directions within 5-degree classes. 399- prefix removed from well names. Note: Some data are missing from well 399-1-1 in August and September 2006. 

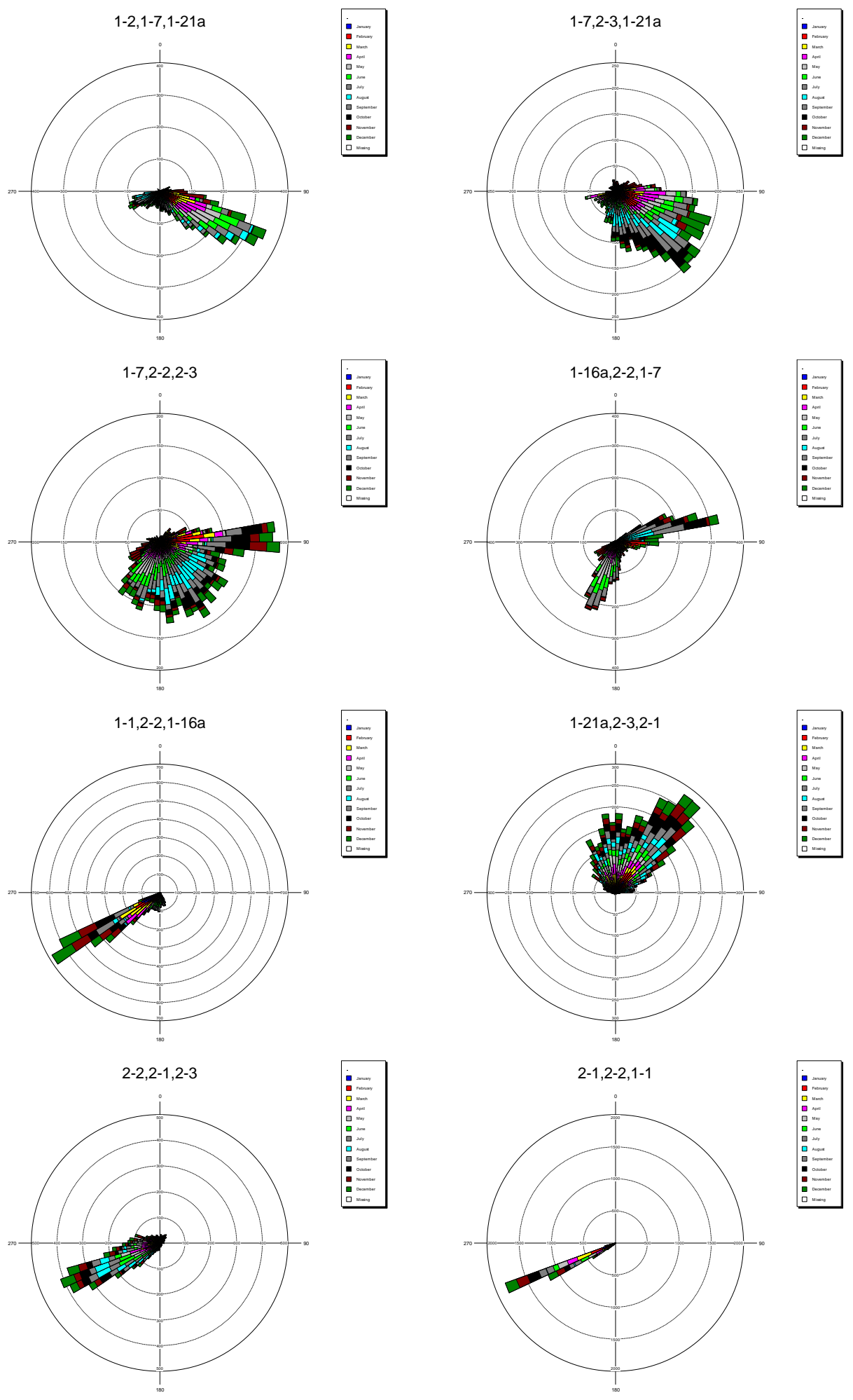

Figure 2.21. 300 Area Water-Level Monitoring Network - Hydraulic Gradient Rose Diagrams for July 26, 2006, Through July 26, 2007 (bi-hourly data). Data for southern portion of monitoring network. Azimuth shows direction of flow. The radius is scaled to the count of gradient directions within 5-degree classes. 399- prefix removed from well names. Note: Some data are missing from well 399-1-1 in August and September 2006. 

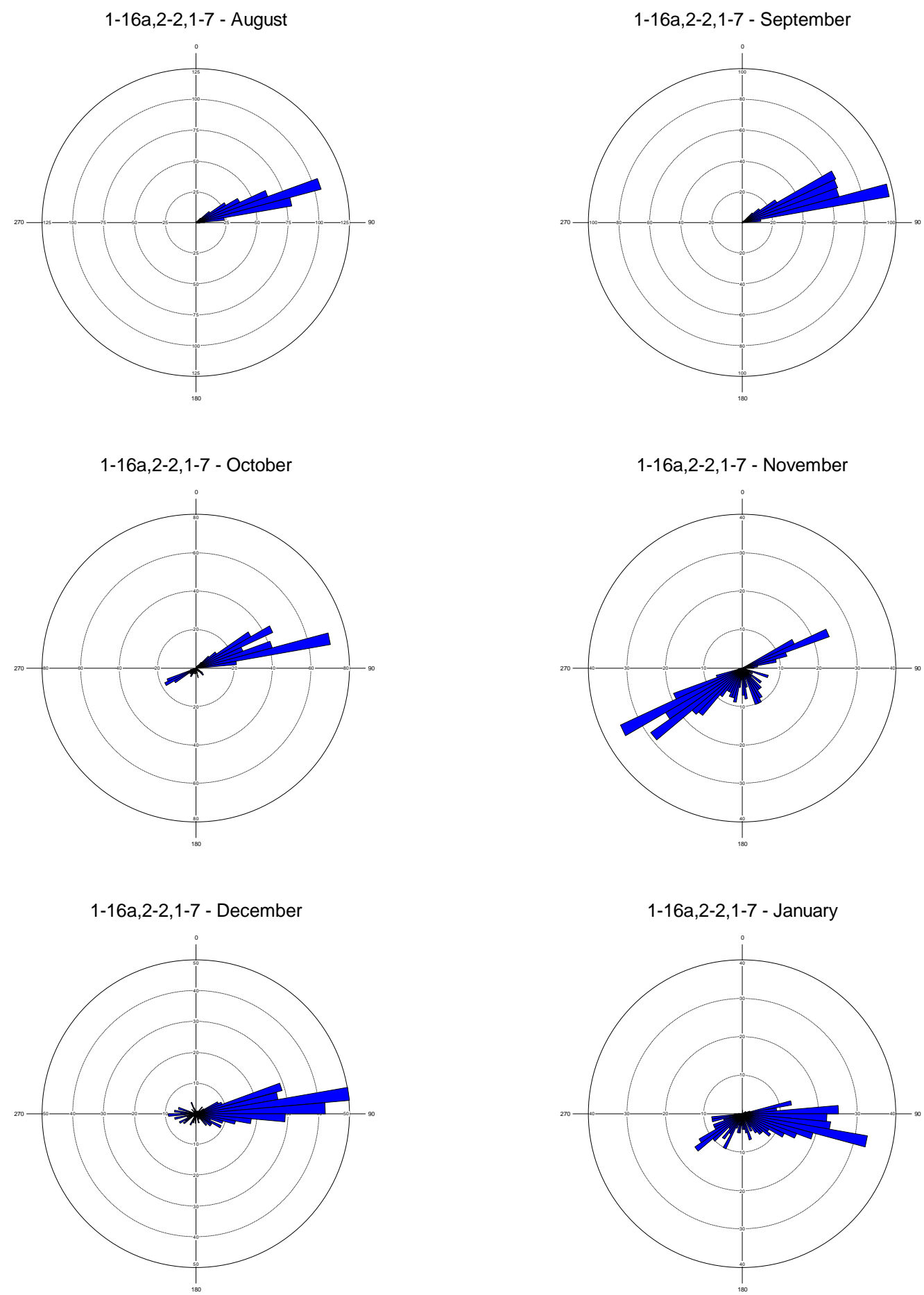

Figure 2.22. Hydraulic Gradient Directions for August 2006 Through January 2007 Calculated from 300 Area Automated Water-Level Network (bi-hourly data) for Well Cluster 399-1-16a, 399-2-2, and 399-1-7. Azimuth shows direction of flow. The radius is scaled to the count of gradient directions within 5-degree classes. 
1-16a,2-2,1-7 - February
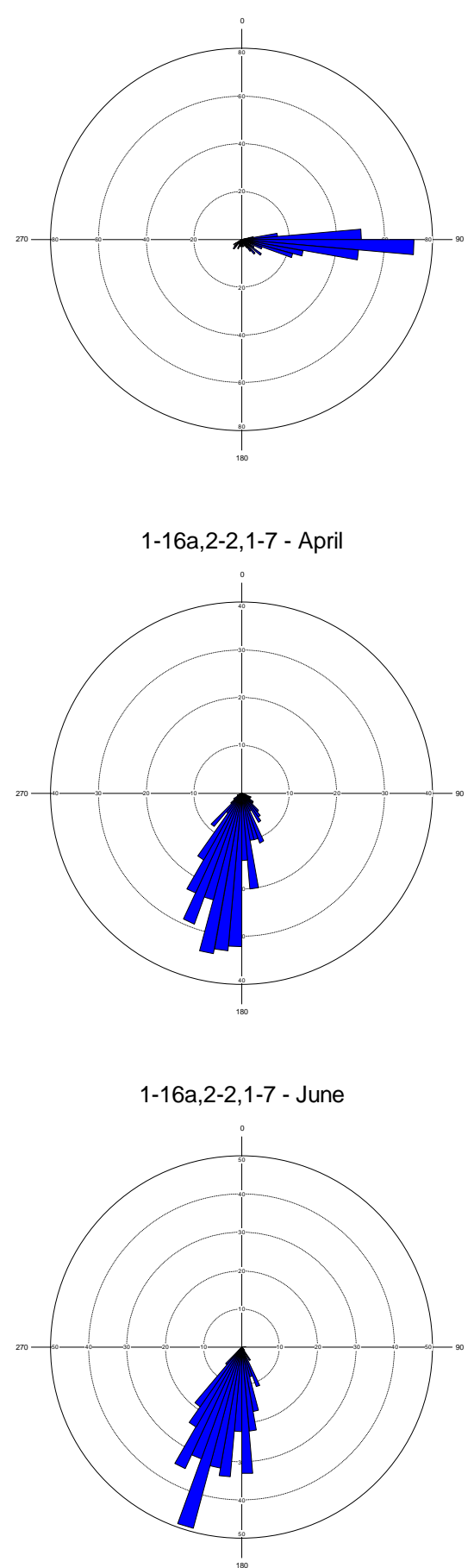

1-16a,2-2,1-7 - March

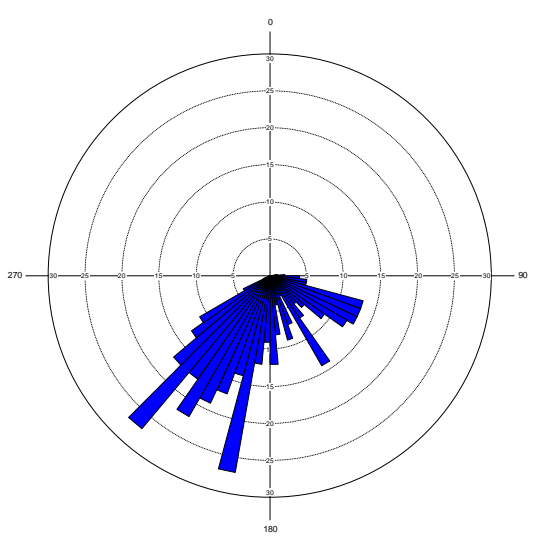

1-16a,2-2,1-7 - May

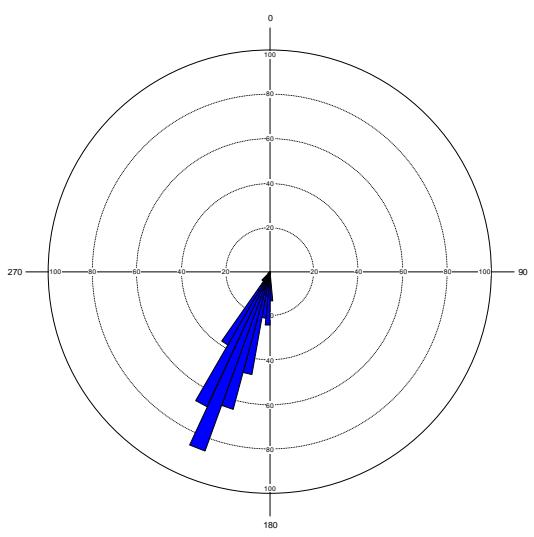

1-16a,2-2,1-7 - July

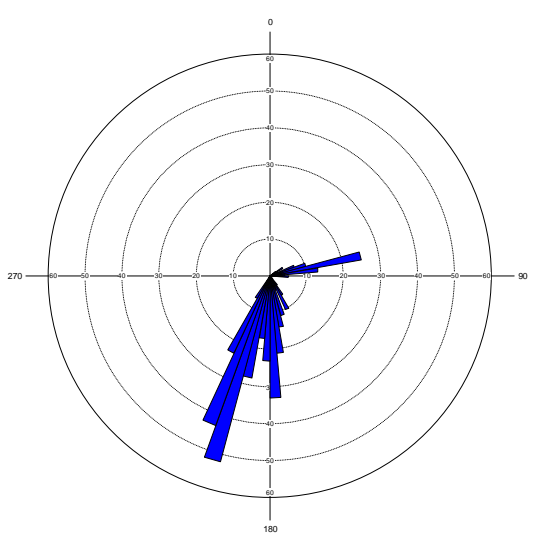

Figure 2.23. Hydraulic Gradient Directions for February 2007 Through July 2007 Calculated from 300 Area Automated Water-Level Network (2-hour data intervals used) for Well Cluster 399-1-16a, 399-2-2, and 399-1-7. Azimuth shows direction of flow. The radius is scaled to the count of gradient directions within 5-degree classes. Note: Some July data from 2006 are included (July 26, 2006 through July 31, 2006). 
Analysis of the gradient directions calculated from the data from the automated water-level monitoring network were used to select the predominant downgradient direction for the downgradient monitoring well location for a tracer test around well 399-1-23 in December 2006 at the Polyphosphate Treatability Test site. The higher-resolution water-level monitoring network that includes the polyphosphate injection well (399-1-23) was not operational during a high-river stage period, so the coarser dataset that included only 9 wells was used to guide downgradient directions for this period. Based on this gradient direction analysis, a southeastern direction was selected for downgradient monitoring. Results of the tracer test (discussed in Section 2.3.3) confirmed this direction during December 2006 and January 2007 based on the measured tracer breakthrough curves from the monitoring well network. An additional set of downgradient wells were installed at the polyphosphate treatability test site in May 2007 and were oriented toward the south-southwest, south, and south-southeast of the injection well (399-1-23) based on the predominant downgradient directions during the high-river stage periods (April, May, and June) calculated from the water-level monitoring network in this area.

Preliminary results of the polyphosphate treatability test injection test conducted in early June 2007 showed that the predominant groundwater flow direction during the test was toward the south (as compared to the southeast during the December 2006 tracer test). There was good agreement with the predominant groundwater flow directions measured during these field tests, and the predicted gradients using these analyses with automated hourly water-level measurement data collected during prior years.

\subsubsection{Temperature and Electrical Conductivity Measurements}

Along with water-level measurements, temperature and electrical conductivity were measured hourly and sub-hourly in six of the wells in the 2004+ water-level monitoring network (Fritz et al. 2007). These wells are shown in Table 2.3, along with the distance from the Columbia River (see Figure 2.14 for locations). Temperature data for these wells in 2006 are shown in Figure 2.24 and electrical conductivity is shown in Figure 2.25. During relatively high-river stage periods, river water enters into the aquifer (i.e., bank storage), influencing the groundwater temperature and electrical conductivity. In addition to the differences in temperature between river water and the aquifer (river water is significantly colder than the aquifer), the electrical conductivity of these two waters is also distinctly different. These two parameters can be used as indicators for the groundwater/river water mixing zone. Ambient groundwater electrical conductivity measurements (i.e., away from the river or during low-river stage periods) in the upper portion of the 300 Area unconfined aquifer (in the Hanford formation) are approximately 0.40 $\mathrm{mS} / \mathrm{cm}$ to $0.45 \mathrm{mS} / \mathrm{cm}$. Electrical conductivity measurements of river water in this area are approximately $0.14 \mathrm{mS} / \mathrm{cm}$.

Table 2.3. Well Names with Hourly and Sub-Hourly Temperature and Electrical Conductivity Measurements in the $2004+300$ Area Monitoring Network

\begin{tabular}{cc}
\hline Well Name & Distance to Columbia River \\
\hline $399-1-1$ & $49.6 \mathrm{~m}(163 \mathrm{ft})$ \\
$399-1-7$ & $188 \mathrm{~m}(617 \mathrm{ft})$ \\
$399-1-12$ & $363 \mathrm{~m}(1190 \mathrm{ft})$ \\
$399-2-1$ & $46.9 \mathrm{~m}(154 \mathrm{ft})$ \\
$399-2-2$ & $77.9 \mathrm{~m}(256 \mathrm{ft})$ \\
$399-2-3$ & $105 \mathrm{~m}(345 \mathrm{ft})$ \\
\hline
\end{tabular}


These data (Figures 2.24 and 2.25) show the extent of the groundwater/river water mixing zone during the high-river stage of 2006 (see Figure 2.11) was at least $188 \mathrm{~m}(617 \mathrm{ft}$ ) inland (based on the responses at well 399-1-7). No impact was seen in the next farthest well inland (well 399-1-12), which is $363 \mathrm{~m}$ (1190 ft) from the Columbia River. Of these two parameters (electrical conductivity and temperature), electrical conductivity provides a stronger signal and is more conservative than temperature due to the heat capacity and thermal conductivity of the aquifer solids that dampens the temperature impact.

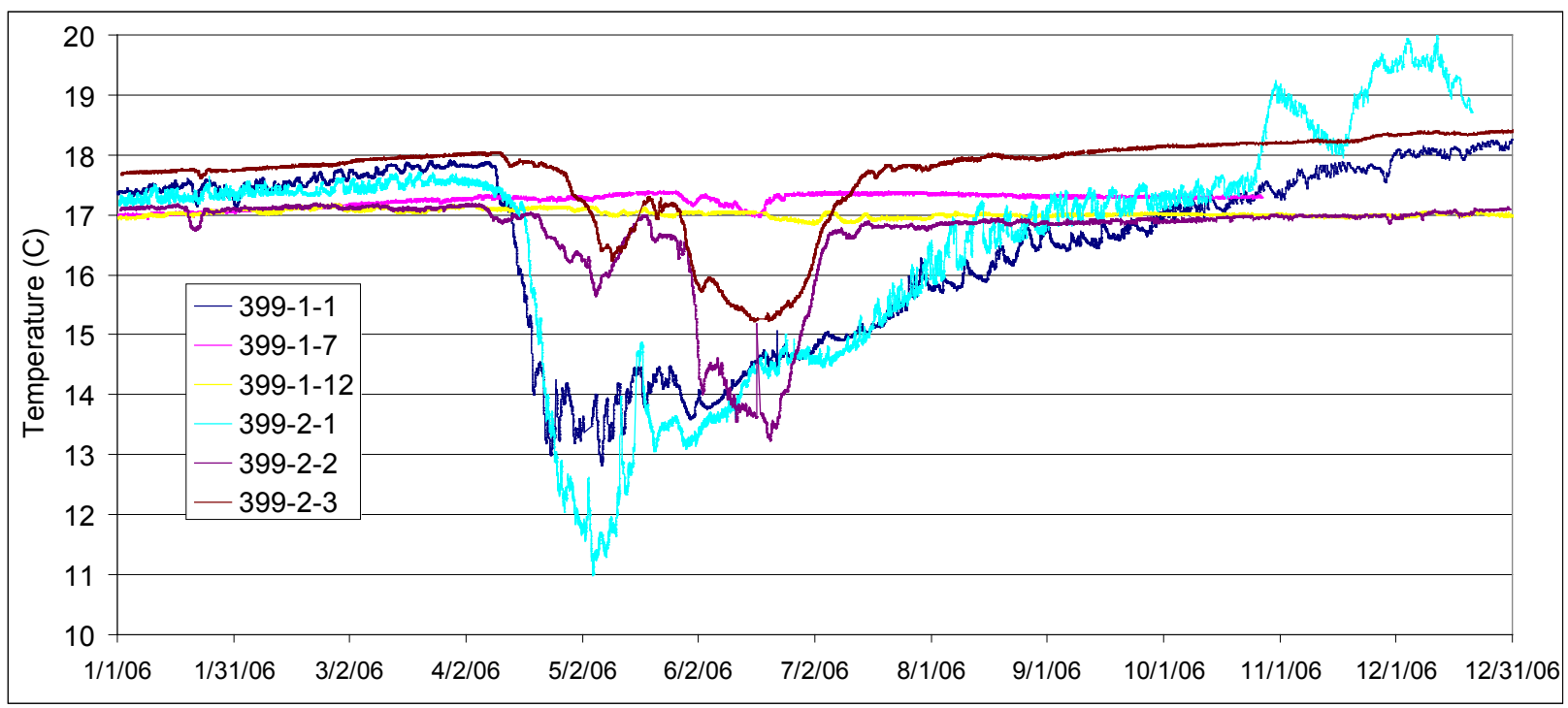

Figure 2.24. Temperature Measurements from Wells in the 2004+ 300 Area Monitoring Network for 2006

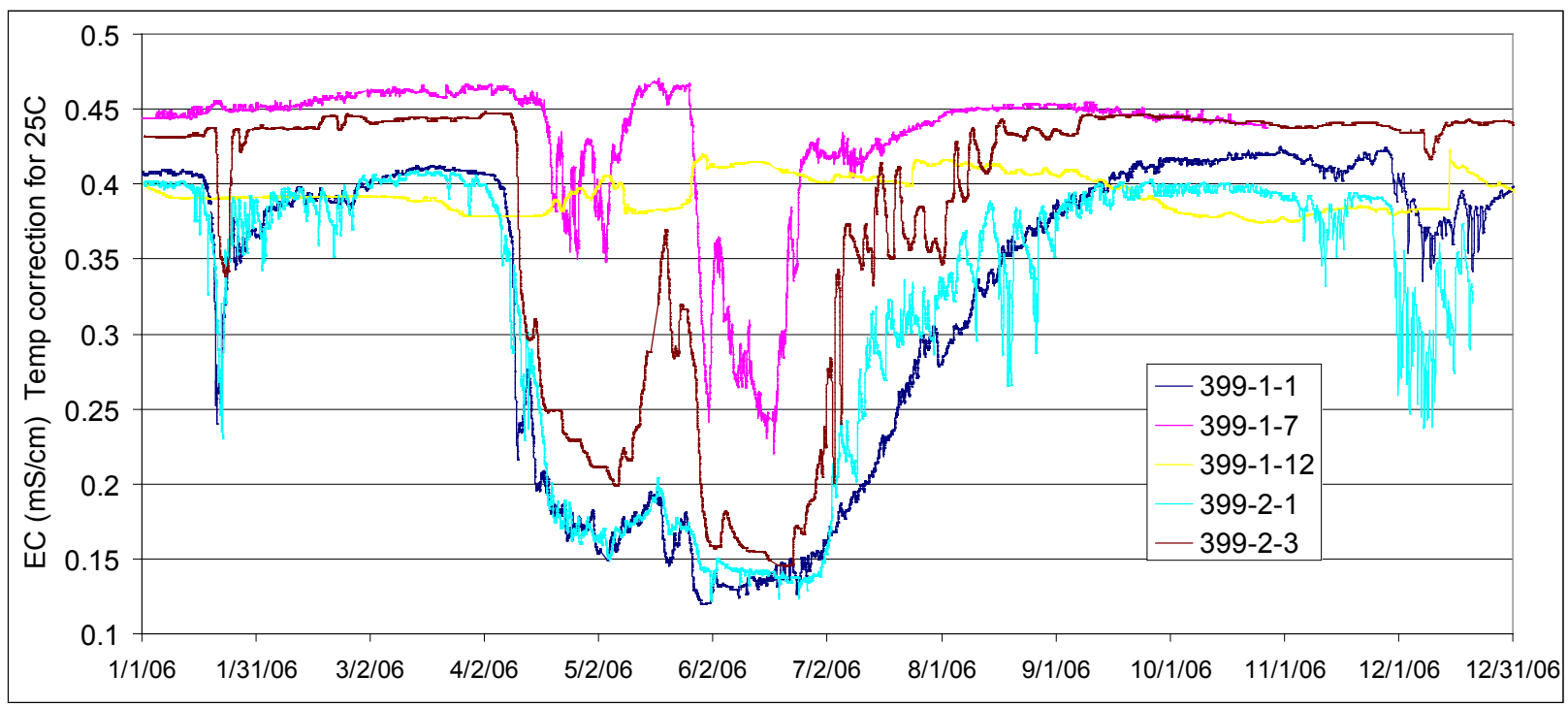

Figure 2.25. Electrical Conductivity Measurements from Wells in the 2004+ 300 Area Monitoring Network for 2006. Note: Data for well 399-2-2 are not shown due to problems with this sensor in 2006. 


\subsubsection{Early 1990s Water-Level Monitoring Network}

In the early to mid-1990s, a water-level monitoring network was established in the 300 Area as part of 300 Area aquifer characterization and feasibility studies. The network included 32 wells and the Columbia River stage adjacent to the 300 Area; however, the monitoring periods for specific wells during this time were variable. Water levels were monitored in these wells on an hourly interval via pressure transducers and dataloggers. Pressure transducer data were checked periodically with manual water-level measurements for these wells. These data, which are maintained by Fluor Hanford, Inc. (Richland, Washington), are described in Campbell (1994) and Campbell and Newcomer (1992).

A time period from early 1992 to early 1993 was selected from this water-level monitoring network dataset for analysis because this period had the greatest number of wells (20) with hourly water-level measurements monitoring the uppermost portion of the unconfined aquifer. The 300 Area river stage is shown in Figure 2.26 for this period. Water-level contours (based on triangulation of available well locations) and the associated hydraulic gradients are shown in Figures 2.27 and 2.28 for low- and high-river stages, respectively. The early 1990s network covered a larger area and had greater spacing between wells (i.e., coarser) than the 2004+ network (compare Figures 2.27 and 2.14).

Spatial differences in the calculated hydraulic gradients shown in Figure 2.27 can provide information on relative hydraulic conductivities of the uppermost portion of the unconfined aquifer. The highhydraulic gradients (as indicated by the closely spaced contour lines and larger vector magnitudes) on the western portion of the area in Figure 2.27 are the result of the relatively lower hydraulic conductivity of the Ringold Formation at the water table in these wells (e.g., wells 699-s27-e9a and 699-s22-e9a) compared to the much higher hydraulic conductivity of the Hanford formation at the water table in the rest of the area (see structure contour map in Figure 2.2 and water-table map in Figure 2.12). Relative differences within the Hanford formation can also be seen in the steeper gradients in the northeastern portion of Figure 2.27 as compared to the flatter hydraulic gradient in the central and southeastern portions.

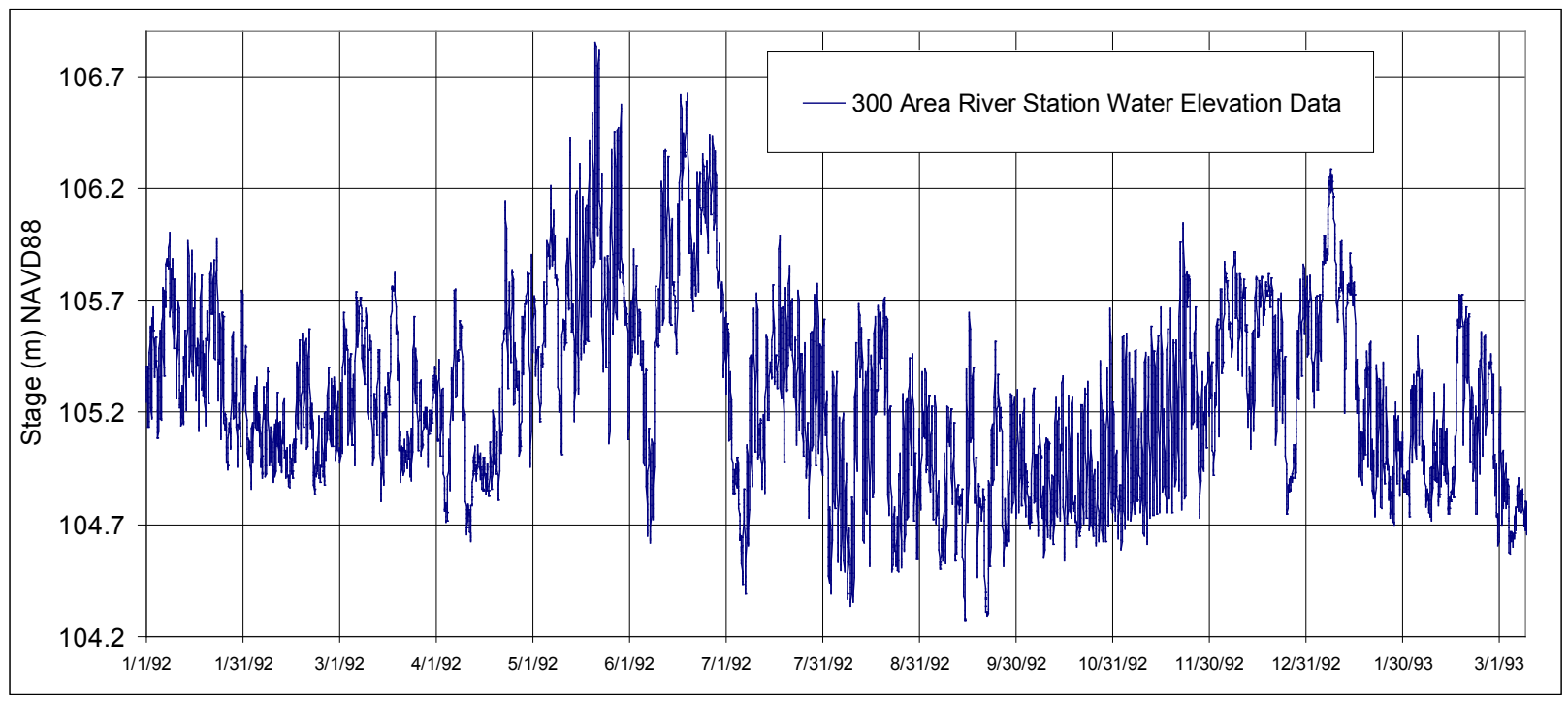

Figure 2.26. Columbia River Stage from the 300 Area Gauging Station for 1992 and Early 1993 


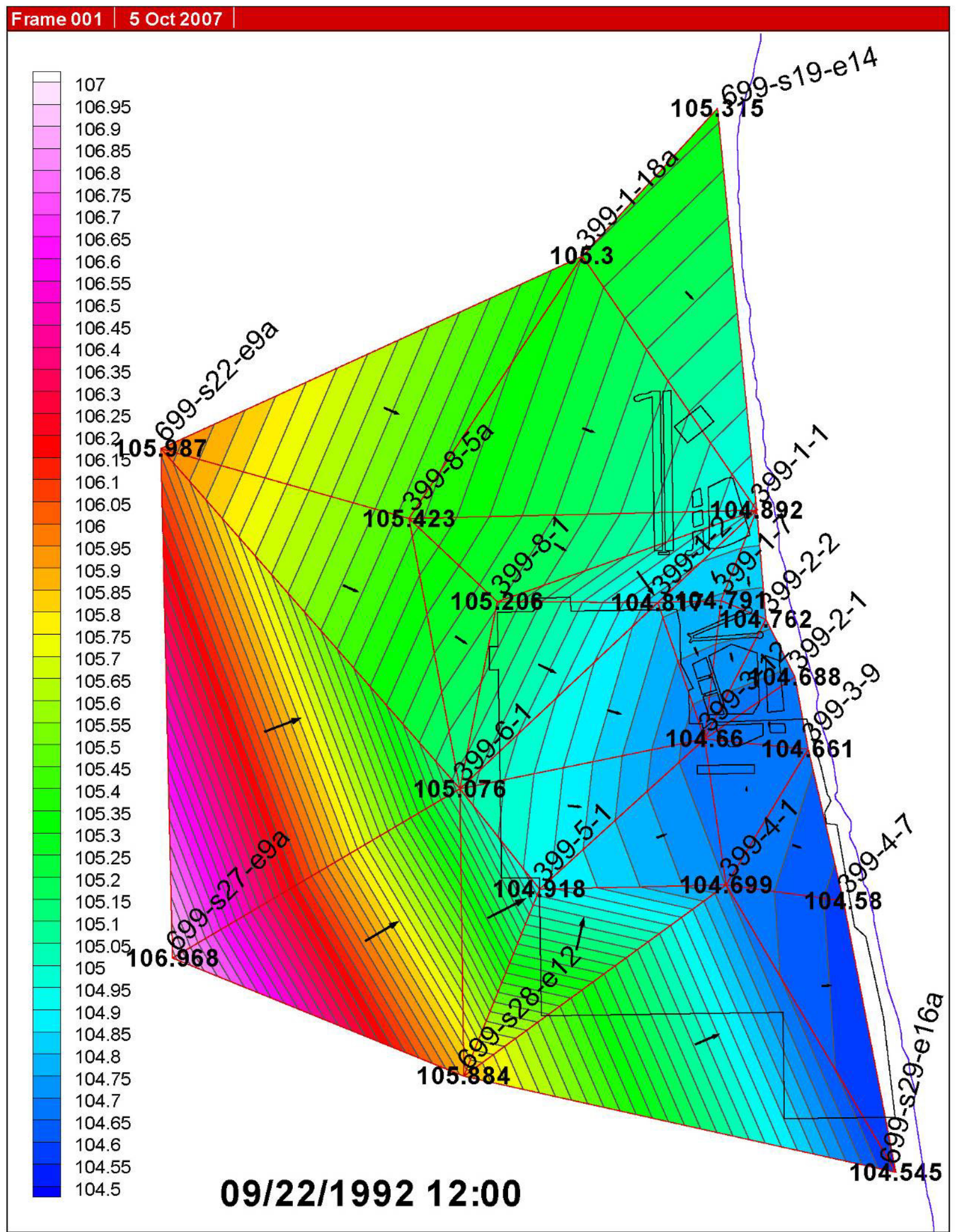

Figure 2.27. Wells in the Early 1990s Water-Level Monitoring Network. Low-river stage example. 


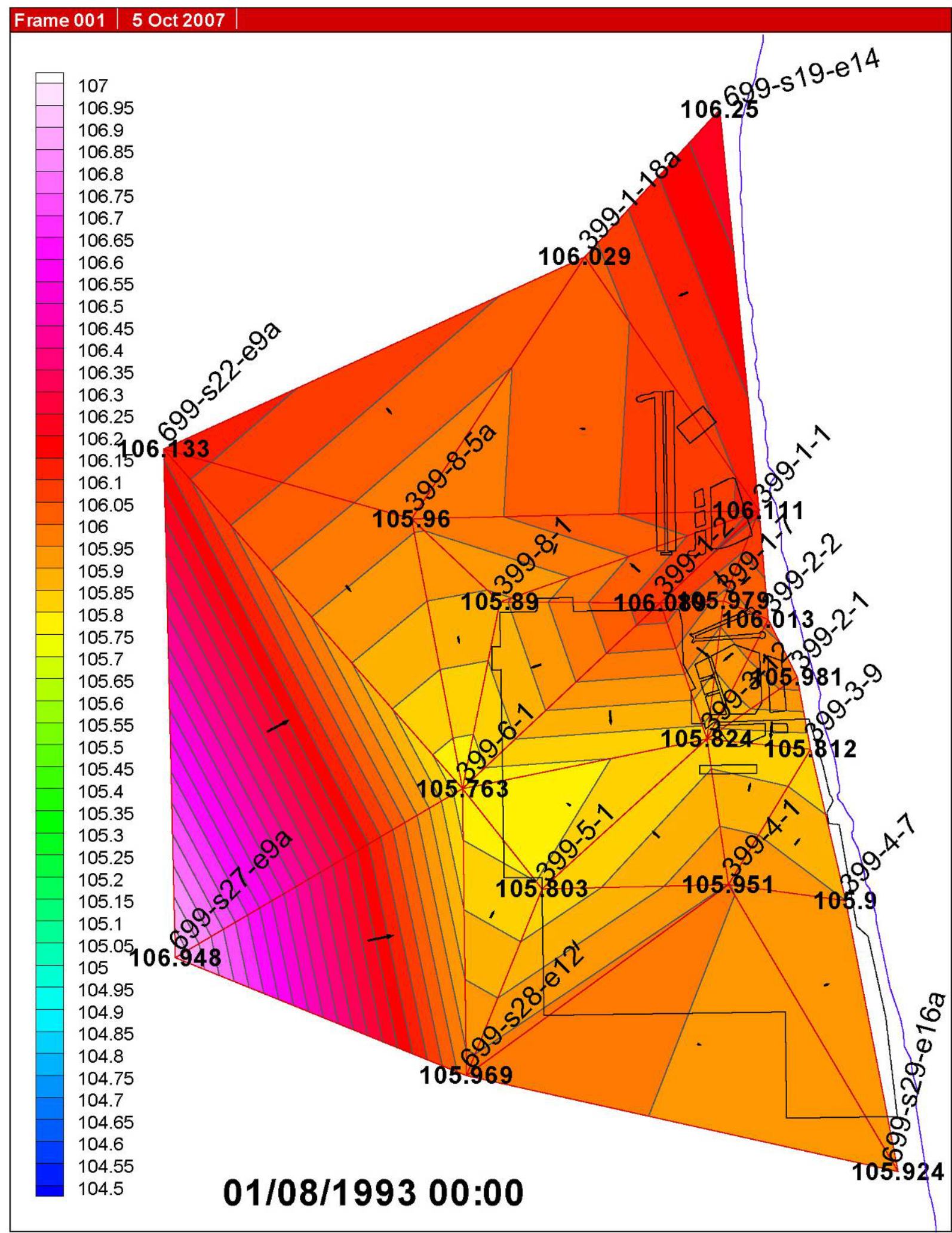

Figure 2.28. Wells in the Early 1990s Water-Level Monitoring Network. High-river stage example. 


\subsubsection{Polyphosphate Treatability Test Flow Rates and Directions}

Work on a treatability test in the 300-FF-5 Operable Unit for uranium stabilization in the aquifer using polyphosphate started in FY 2006, with field testing occurring during FY 2007 (Vermeul et al. 2007). Laboratory tests (Wellman et al. 2006, 2007) have shown that injection of polyphosphate solutions into uranium-bearing saturated porous media immobilized uranium through the formation of the low solubility mineral autinite. This technology also creates an apatite mineral (calcium phosphate) in the aquifer through the excess injected phosphate and calcium that can provide long-term treatment capacity for uranium migrating into the treatment areas.

The polyphosphate treatability test field site is located around well 399-1-23 (see Figure 1.2). The current monitoring network for the test is shown in Figure 2.29. The injection well for this test, 399-1-23, was installed as part of the 300 Area LFI (see Williams et al. 2007). Nine of the monitoring wells for this test were installed in November 2006 for a tracer test and six more wells were installed at the south portion of the site in May 2007 for the polyphosphate injection test. Three pairs of monitoring wells at the site are screened in the upper and lower portions of the Hanford Site's unconfined aquifer. The rest of the wells at the site fully screen the Hanford formation aquifer (approximately 4.5-m [15-ft] thick).

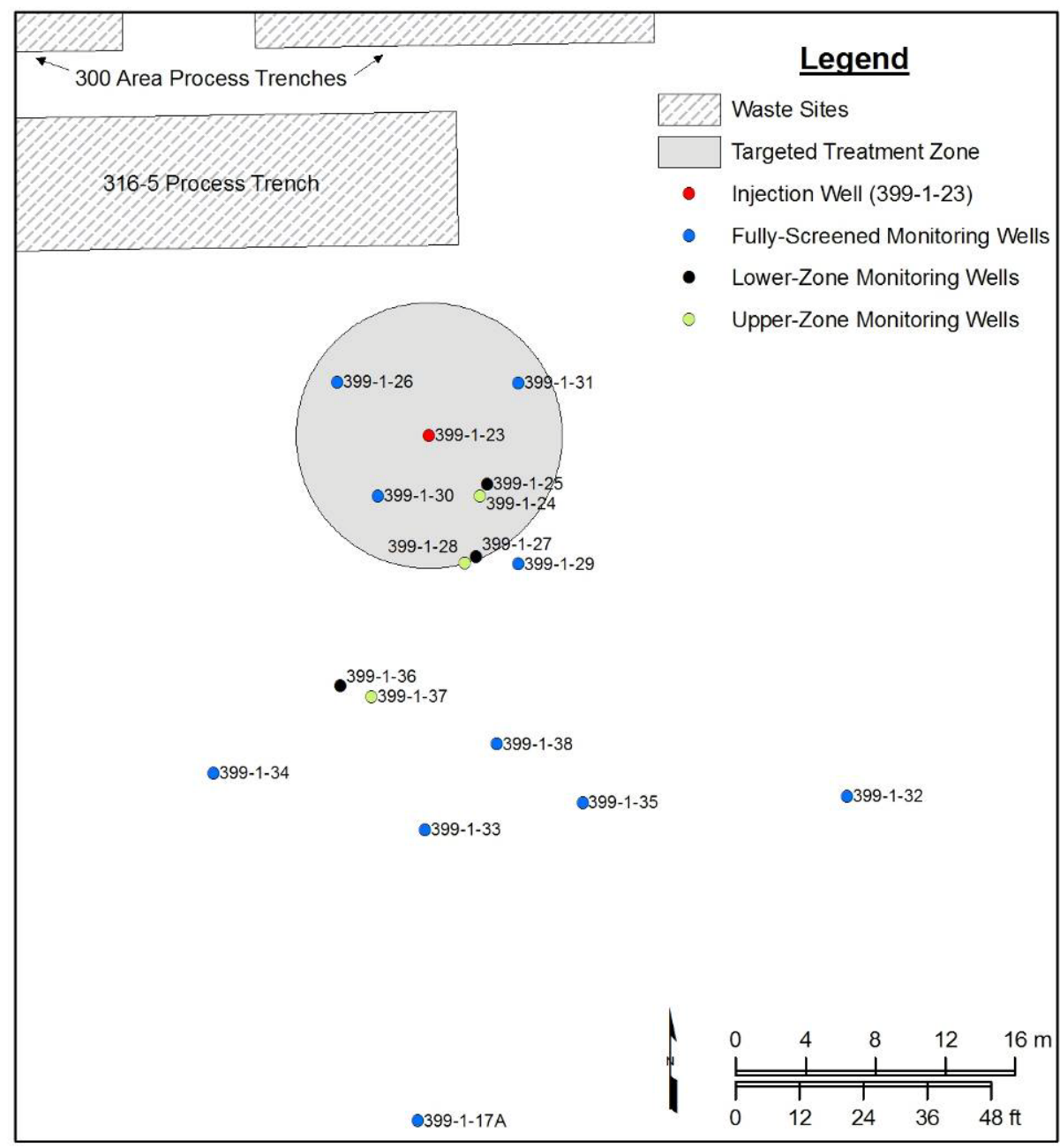

Figure 2.29. Monitoring Well Network for the Polyphosphate Treatability Test Site 
A tracer test was conducted at the polyphosphate treatability test site located around well 399-1-23 on December 13, 2006. The test injected 539,800 L (142,600 gal) of sodium bromide tracer (at a concentration of $87 \mathrm{mg} / \mathrm{L} \mathrm{Br}$-) into well 399-1-23 at a rate of $757 \mathrm{Lpm}(200 \mathrm{gpm})$ over an 11.9-hr duration. The water for the tracer test was supplied from well 399-1-7, which is located $188 \mathrm{~m} \mathrm{(620} \mathrm{ft)}$ southeast of the injection well (see Figure 1.2), by pumping during the test. Preliminary results of the tracer concentrations measured in the monitoring and downgradient wells after the injection estimated the tracer velocity to be $15 \mathrm{~m} / \mathrm{d}(50 \mathrm{ft} / \mathrm{d})$ toward the southeast during the remainder of December 2006 and into January 2007. Relatively high concentrations of tracer (up to $70 \%$ of the injection concentration) were measured in well 399-1-32 (located $31.7 \mathrm{~m}$ [104 ft] southeast of the injection well) about 2 days after the injection was over. Low concentrations of tracer were also detected by an in-situ ion-selective electrode in well 399-1-7 from 14 to 55 days after the injection. The effective porosity of the aquifer was estimated at $18 \%$ from analysis of tracer arrivals in wells around the injection well during the injection.

The polyphosphate injection test, which occurred from June 11 to June 15, 2007, injected approximately $3,785,000 \mathrm{~L}(1,000,000$ gal) of reagent into well 399-1-23. The injection used three steps with an initial 946,000 L (250,000 gal) of polyphosphate solution (a mixture of ortho-, pyro-, and tripolyphosphate), followed by 1,893,000 L (500,000 gal) of a calcium-chloride solution, with a final injection of another $946,000 \mathrm{~L}$ (250,000 gal) of polyphosphate solution. Preliminary overall plume monitoring of the polyphosphate test, during and a few weeks following the injection, showed the plume drift is predominantly toward the south during this time period (as compared to the southeast during the tracer test).

\subsection{Area Hyporheic Zone Studies}

Groundwater in the 300 Area unconfined aquifer, except water extracted by wells (e.g., water supply well 399-4-12), eventually discharges to the Columbia River. Some of this discharge is revealed as riverbank springs and seeps when the river stage is low. However, most of the discharge occurs in the riverbed. Groundwater in the unconfined aquifer is unlikely to flow across to the eastern side of the Columbia River because the hydraulic head is higher in the unconfined aquifer on the eastern side of the river (Cole et al. 2001).

The subsurface zone where river flow influences the underlying aquifer (i.e., the hyporheic zone) plays an important role in the movement of groundwater and changes to water quality because of mixing between river water and groundwater. The river channel is incised into Hanford and Ringold Formation sediments, including the fine-grained Ringold unit, as revealed by work conducted under the Groundwater Remediation Project's science and technology investigations (Fritz et al. 2007, Mackley and Fritz 2007). In addition, late-Holocene to recent deposition by the Columbia River has resulted in a layer of sediment along the river channel that forms a zone of lower permeability (relative to the Hanford formation in the 300 area) and restricts the upwelling of groundwater from the aquifer to the river (Fritz and Arntzen 2007). The heterogeneous nature of sediments at the aquifer-river interface results in preferential flow paths for groundwater that may vary temporally depending on the river-stage elevation.

The aquifer/river interface in the current EarthVision hydrogeologic model framework is based on the September 2006 update of the Hanford and Ringold Formation contact (see Figure 2.2), and a recently completed update to river bathymetry, based on data from the U.S. Fish and Wildlife Service (Anglin et al. 2006). The aquifer/river interface at the 300 Area was the focus of recent work to better understand 
the nature of the connection between the aquifer and river, and also to test methods to quantify the rate of groundwater discharge to the river (Fritz et al. 2007, Mackley and Fritz 2007, Mendoza et al. 2007).

Activities undertaken to characterize this interface are described in the following sections (see Fritz et al. 2007 for a comprehensive discussion on the methods and results of these recent investigations).

\subsubsection{Drive-Point Penetration}

One-inch diameter steel rods with rounded points were driven into the river bed at 14 locations until a "refusal" depth was reached. The refusal depth generally reflects the depth of the Hanford and Ringold contact because of the more consolidated nature of the Ringold sediments. This is especially likely if the fine-grained Ringold subunit exists at the top of the Ringold Formation. However, there is some uncertainty with this technique because a large boulder within the Hanford formation may also cause refusal. To help minimize this uncertainty or bias, multiple and repeat penetration tests were conducted.

The locations of the drive-point penetrations and the depth of refusal results are shown in Figure 2.30. Contact elevations from the drive-point penetration results generally agree with the interpretation by Williams et al. (2007) based on larger-scale inland borehole geologic data. The elevation of the refusal layer trends upward in the downstream direction; however, the deepest penetration occurred south of Spring 9 between drive points 4 and 9 . This indicates a structural low in the hydrogeologic confining layer (Ringold subunit), which suggests this is an area of preferential flow and increased discharge to the river.

\subsubsection{Piezometer Head Measurements and Slug Tests}

The vertical hydraulic gradient across sediments in the riverbed was measured in three piezometers installed adjacent to Spring 9, a historical environmental monitoring location (Figure 2.31) (Fritz and Arntzen 2007). The tops of the piezometer screens were located at depths below the top of the river bed of $19 \mathrm{~cm}$ (7.4 in.), $86 \mathrm{~cm}$ (33 in.), and $142 \mathrm{~cm}$ (55 in.), respectively, and they were spaced about $1 \mathrm{~m}$ (3.2 ft) apart laterally. The piezometer screens were 18-in long. Hydraulic head and gradients measured in the piezometers varied as the river stage changed. The largest gradient was across the shallowest interval, between the top of the riverbed and 19-cm (7.4-in.) deep. Slug tests were also conducted in these piezometers and in six additional piezometers installed at distances up to $3 \mathrm{~m}(9.8 \mathrm{ft}$ ) away (Arntzen et al. 2006, Fritz and Arntzen 2007). The depth of the top of the screen for these six additional piezometers ranged from 55 to $180 \mathrm{~cm}$ ( 21 to $70 \mathrm{in}$.) below the riverbed. Slug test results also showed that sediment near the top of the riverbed had the lowest permeability (Fritz and Arntzen 2007). Vertical water-flux through the riverbed was calculated from the slug test, which determined hydraulic conductivity, and measured gradients. The resulting estimated vertical water-flux varied between 0.24 and $-0.37 \mathrm{Lpm} / \mathrm{m}^{2}$ over the study period from August 2004 through October 2005. A positive water flux indicates net water movement into the river and negative flux indicates movement into the aquifer. The integrated flux over time showed a net discharge to the river, but at a lower magnitude than estimated previously from monitoring well measurements (Fritz and Arntzen 2007).

\subsubsection{Underwater Video}

The bottom of the river channel along the western shore was video recorded to map the textural characteristics of alluvial sediment and identify outcrops of the Ringold Formation on the river bed. 
Although the majority of the riverbed along the 300 Area is composed of coarse-grained alluvium, exposures of the Ringold fine-grained unit were identified in the deeper portions of the river channellikely exposed by erosion associated with strong river currents.

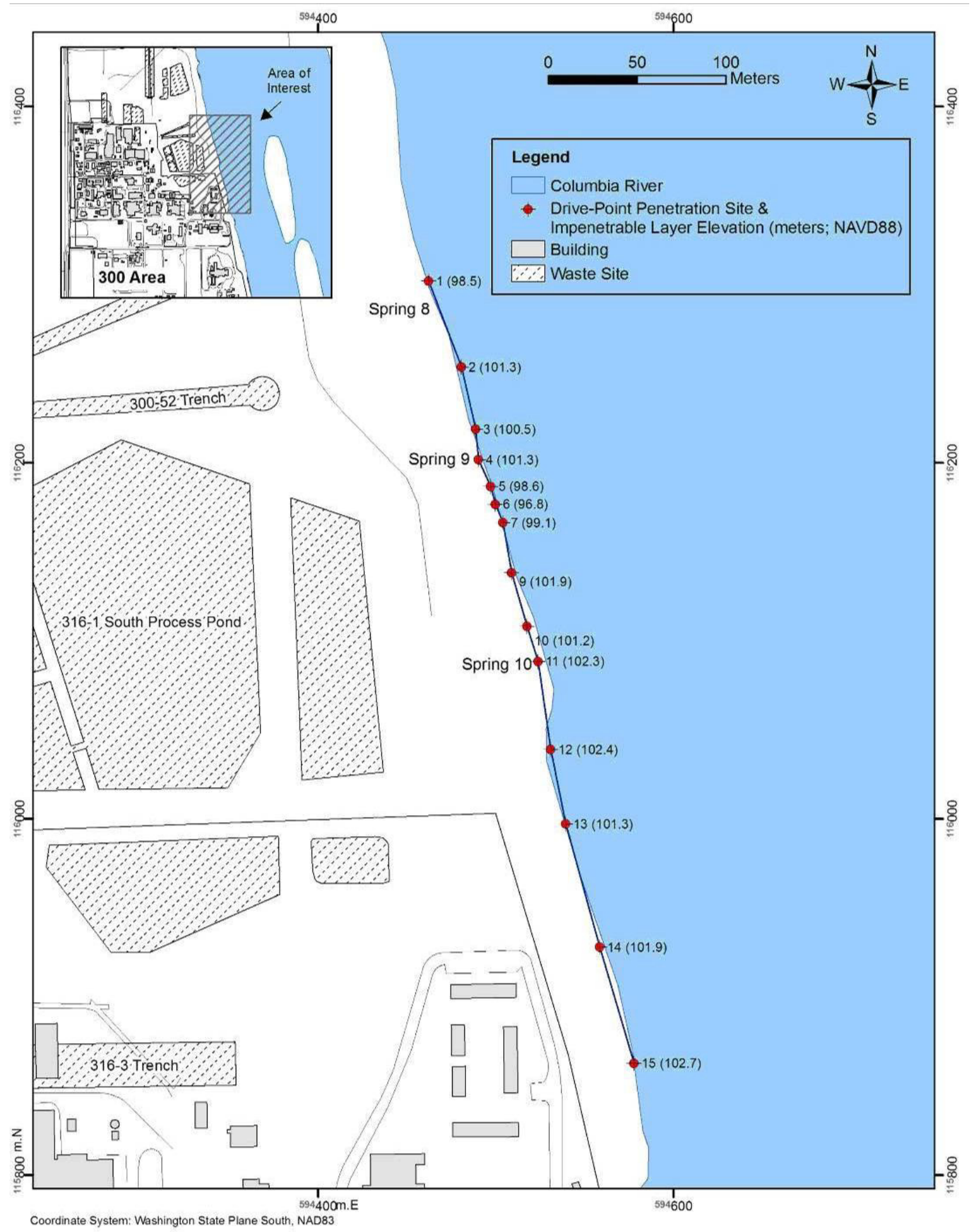

Figure 2.30. Locations of the Drive-Point Penetrations and the "Depth of Refusal" Results (Fritz et al. 2007) 


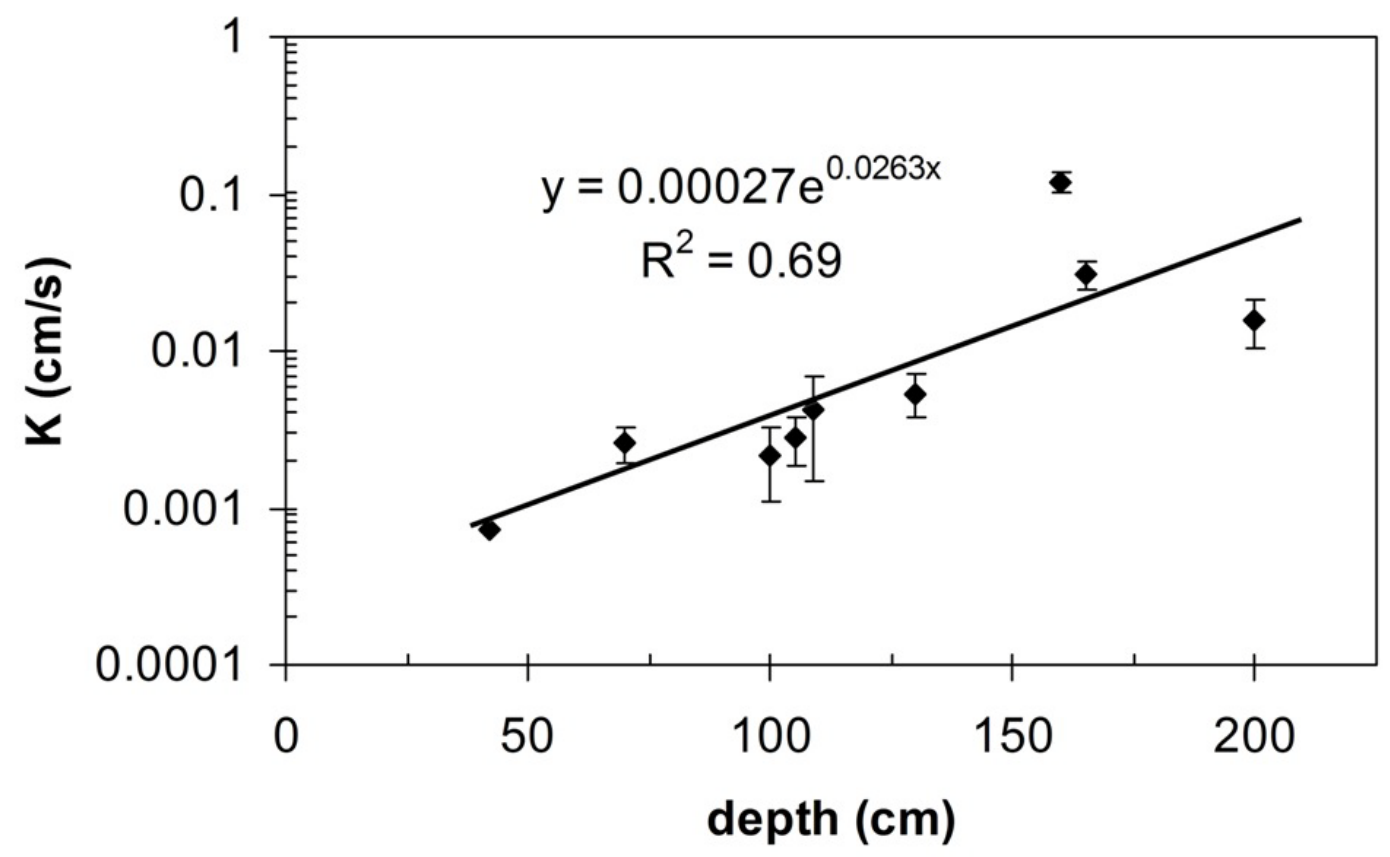

Figure 2.31. Hydraulic Conductivity Measured in Piezometers in the Hyporheic Zone Near Spring 9 Along the Columbia River Shoreline. Error bars represent standard error from multiple slug tests in each piezometer (Fritz and Arntzen 2007).

\subsubsection{Bathymetry}

A revised interpretation of Columbia River bathymetry adjacent to the 300 Area was created from data collected by the U.S. Fish and Wildlife Service as part of its program to study fall Chinook salmon in the Hanford Reach (Anglin et al. 2006). These data present a three-dimensional model of the river channel in high-resolution that make it possible to investigate the relation between the form of the river and the underlying geology. Fritz et al. (2007) identified features in the plan and profile views of the Columbia River related to outcrops seen in underwater video and from direct grab samples collected from the river bottom as discussed in the following two sections (2.4.5 and 2.4.6).

\subsubsection{Sub-Bottom Profiling}

Acoustic profiling of the riverbed was conducted along multiple transects along the 300 Area, some of which are shown in Figures 2.32 and 2.33 (see Mackley and Fritz [2007] for additional transects). The objectives were to identify the river bottom depth, assess comparative densities of sediment on the river bottom, and image stratigraphic features (e.g., Ringold subunit) below the riverbed surface. The coarsegrained nature of alluvial sediments in the river channel made it difficult to achieve significant penetration below surface sediments, except in locations where alluvium was relatively finer grained or thinly bedded. However, there are several locations where the acoustic profiling data reveal exposures of the fine-grained Ringold subunit outcropping in the deeper areas of the river channel (Mackley and Fritz 2007). Two of these locations are shown in Figure 2.33. 


\subsubsection{Sediment Sampling}

Sediment cores beneath the riverbed were obtained adjacent to Springs 9 and 10 using a Geoprobe Macro-Core ${ }^{\circledR}$ Sampler. ${ }^{1}$ In addition, surface sediment grab samples were obtained in locations where the fine-grained Ringold subunit could be seen outcropping in the riverbed in the underwater video surveys. The locations of these samples and photos of the sediments are shown in Figure 2.34. Core samples of the fine-grained unit from three of the LFI boreholes are also shown for comparison.

Because Hanford formation sediments have much higher hydraulic conductivity than the Ringold Formation, most of the water discharging to the Columbia River comes from the Hanford formation. Figure 2.35 shows the area of the riverbed adjacent to part of the 300 Area that is in contact with the Hanford formation based on the EarthVision hydrogeologic model, as revised in September 2006. This represents the major "contributing area" for groundwater flow that resulted from extrapolation into the riverbed of the Hanford and Ringold contact surface based on available borehole data. However, new information from the work in the river channel itself indicates that the contact may occur at a higher elevation, resulting in a smaller contributing area. Additional work is planned to better define the Hanford and Ringold contact in the riverbed.

\footnotetext{
${ }^{1}$ Geoprobe Macro-Core is a registered trademark of Geoprobe Systems, Salina, Kansas.
} 


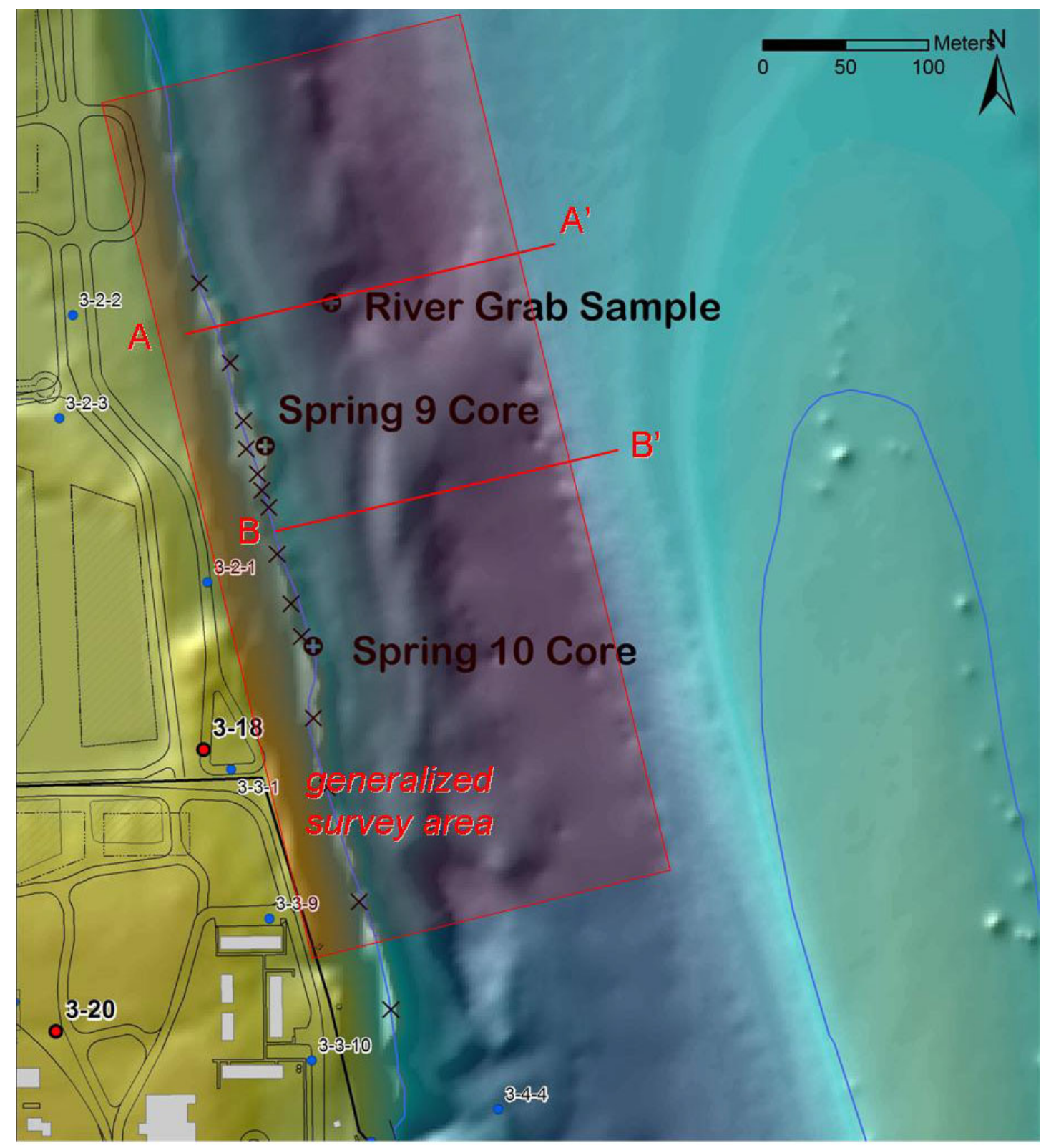

Figure 2.32. Transects for Acoustic Profiles of the River Bed Shown in Figure 2.33 (Source: Mackley and Fritz 2007). Blue dots show locations of existing monitoring wells (399 well name prefix was shortened to 3). Red dots show locations of LFI wells (399 well name prefix omitted). Aquifer tube locations are shown by Xs. 

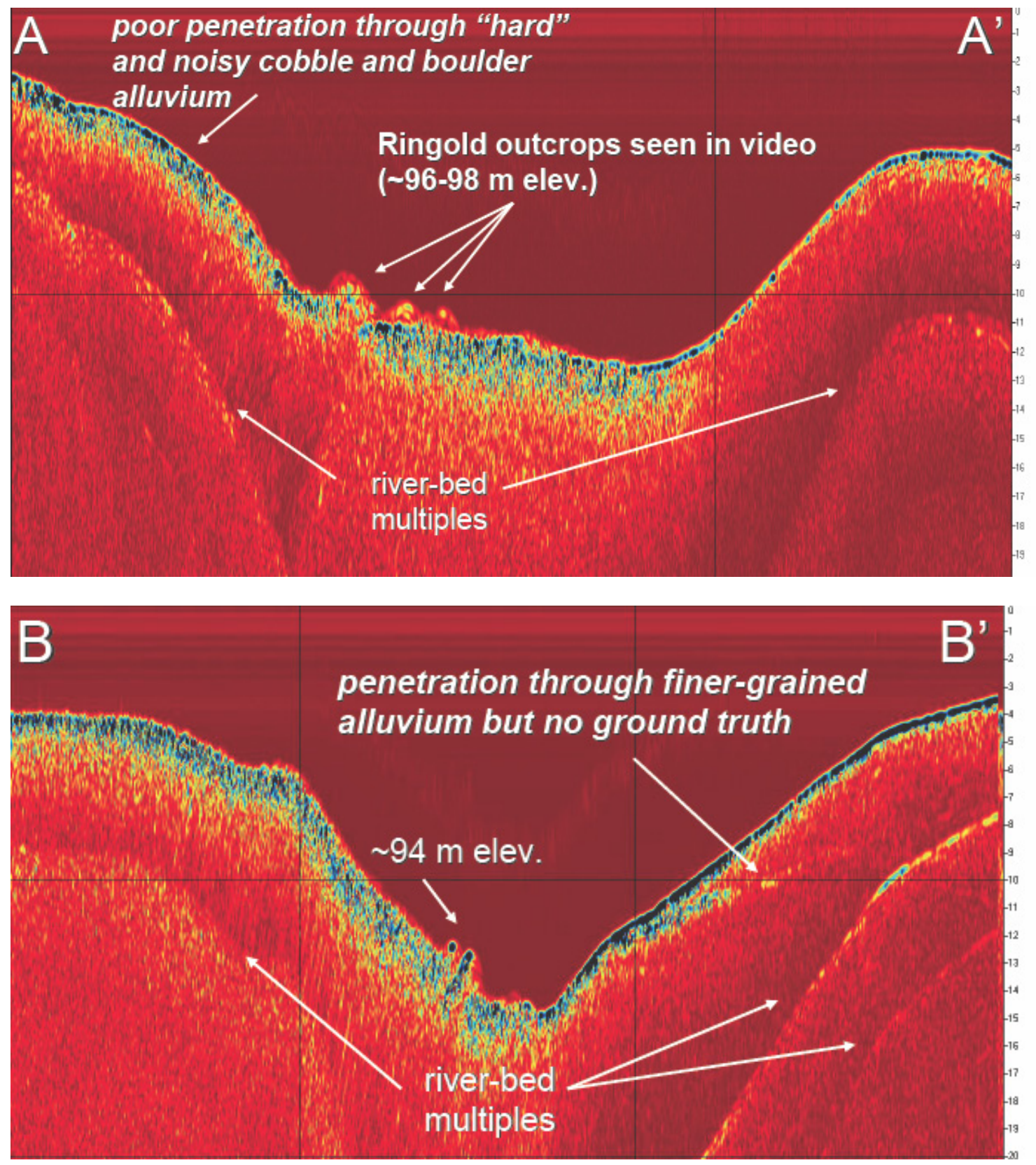

Figure 2.33. Example Acoustic Profiles of the River Bed Along the Transects Shown in Figure 2.32 (Source: Mackley and Fritz 2007). Profile lengths are shown in Figure 2.32. Elevation arrows at $\sim 96-98 \mathrm{~m}$ in the upper profile and $\sim 94 \mathrm{~m}$ in the lower profile show examples of finer-grained Ringold Formation material. River-bed multiples are echoes of the reflections of the river bed. 


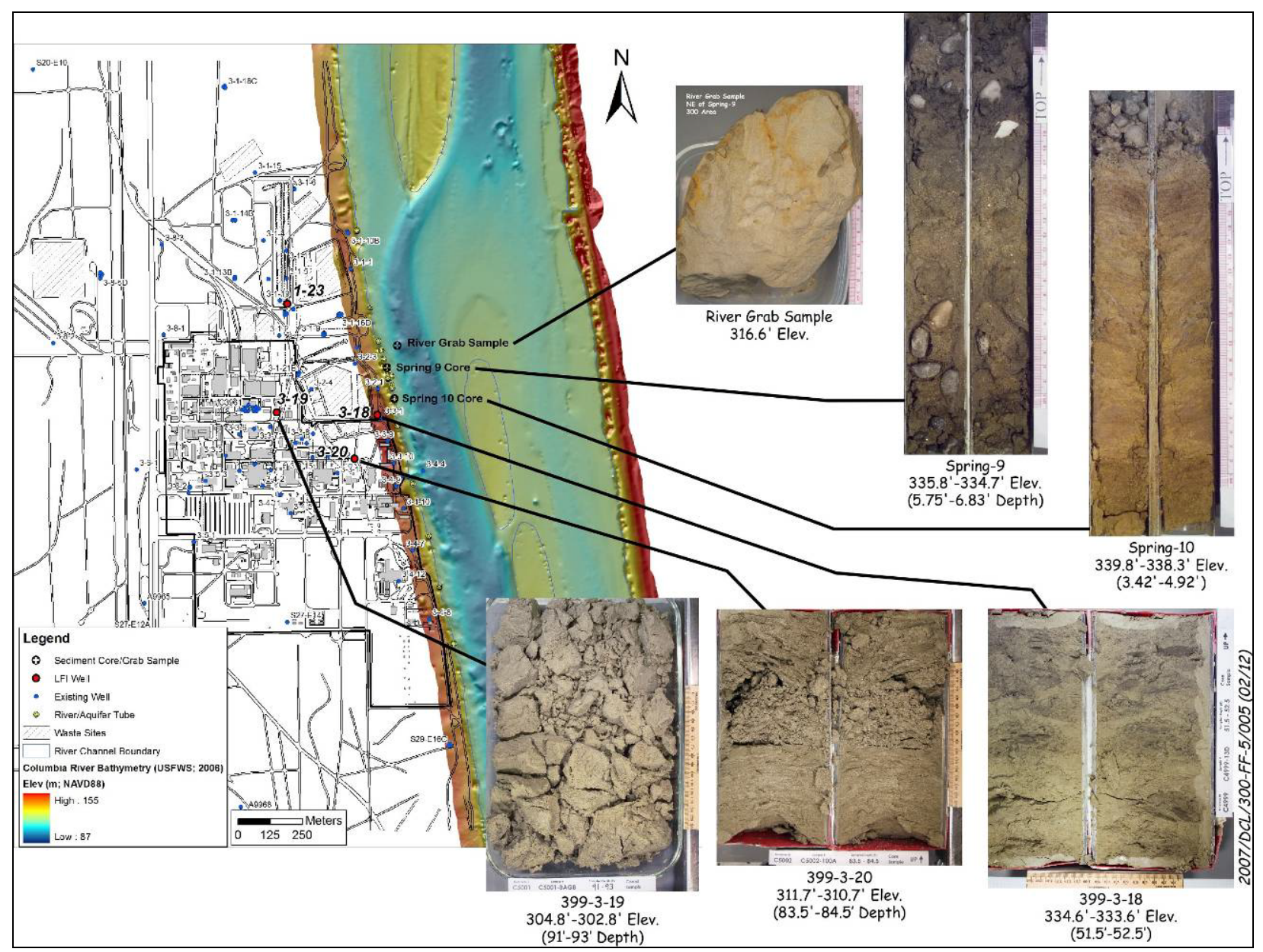

Figure 2.34. Locations of Sediment Samples Collected from the River Bed and Sediment Photos (Source: Mackley and Fritz 2007) 


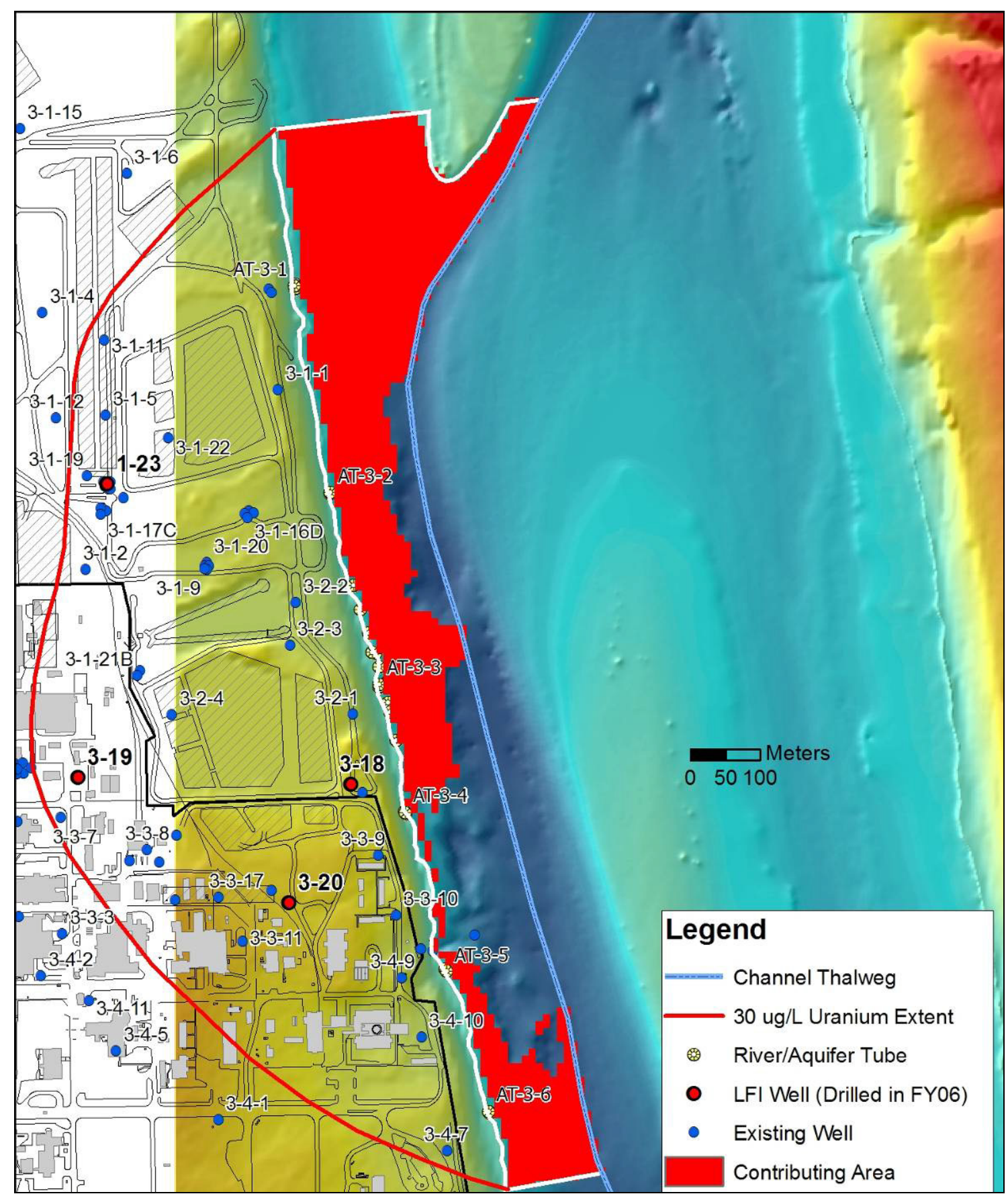

Figure 2.35. Area Where Saturated Hanford Formation Sediment is in Contact with the River Channel Based on the Current Hydrogeologic Model (Source: Mackley and Fritz 2007) 


\subsection{Large-Scale 300 Area Groundwater Flow and Transport Model}

The large-scale 300 Area groundwater flow and transport model described in this section (see Figure 1.2) was developed using the data from the early 1990s water-level monitoring well network. This model was used to 1) evaluate different hydraulic conductivity distributions, 2) provide water-flux estimates along the model boundaries (including the Columbia River) over a range of hydraulic conductivities during the simulated time period, and 3) provide tracer plume drift directions and velocities during multiple river stage/water-table conditions starting from waste sites of interest. This model uses the STOMP code, a general-purpose tool developed at PNNL for simulating subsurface flow and transport (White and Oostrom 2000, 2004). The hydrogeology and parameters (i.e., model structure and material properties) developed for this large-scale model is also used for the small-scale flow and transport model discussed in Section 4.0. The configuration of the large-scale groundwater flow and transport model is described in Section 3.1 and simulation results are discussed in Section 3.2.

\subsection{Model Description}

This groundwater model was developed for the purpose of refining the 300 Area hydrogeologic conceptual model and estimating hydraulic properties of the Hanford and Ringold gravel units. Hydraulic properties are estimated by comparing simulation results over a range of specified values with extensive hourly water-level measurements collected from a network of wells around the 300 Area from December 1991 through March 1993 (Campbell 1994, Campbell and Newcomer 1992). Wells with water levels in the uppermost portion of the aquifer during this time period are shown in Figure 2.27. A review of previous aquifer tests conducted in the 300 Area showed a large range in hydraulic conductivity for the hydrostratigraphic units of interest, as discussed in Section 2.2. This large range in aquifer test results reflected the heterogeneity of the sediment within the aquifer. However, the test results could also be affected by the use of analysis techniques that are unsuitable for very high transmissivity formations or could be influenced by fluctuations in the Columbia River stage during the aquifer tests. Simulations with this numerical model that used a range of hydraulic parameter values for the main Hanford Site gravel unit were assessed based on calculated residuals (simulated value-measured value) for individual wells. Three hydraulic property distribution models were tested:

1. Single values (each) for the main Hanford and Ringold gravel units

2. Main Hanford gravel unit subdivided into zones with different properties (based on hydraulic gradient analysis)

3. Stochastic distribution of hydraulic properties based on geostatistical analysis of physical property measurements from soils collected during well drilling in the area (e.g., Schalla et al. 1988, Swanson et al. 1992).

The STOMP model domain, hydraulic properties, boundary conditions, sources/sinks, and the process used for estimating hydraulic properties in this flow model are described in the following sections. 


\subsubsection{Model Grid}

Figure 3.1 is a plan view of the STOMP finite difference model grid developed for the large-scale 300 Area groundwater flow and transport simulations. The grid is oriented approximately 10 degrees counterclockwise from the north, so in the plan view it is approximately aligned with the Columbia River. The grid consists of $70 \times 122 \times 33$ nodes in the $\mathrm{x}, \mathrm{y}$, and $\mathrm{z}$ directions, respectively, for a total of 281,820 nodes. Some of these nodes along the southwest and northwest portions of the rectangular model grid are designated as inactive to keep the model boundaries within the polygon formed by wells used for specifying boundary conditions. Nodes above the bottom of the Columbia River in the model domain are also inactive. The final large-scale model grid has 242,290 active nodes and 39,530 inactive nodes.

In the $\mathrm{x}$ (east-west) direction, grid block sizes vary from a minimum of $10 \mathrm{~m}(32.8 \mathrm{ft})$ to a maximum of $100 \mathrm{~m}(328 \mathrm{ft})$. In the y direction (north-south), grid block sizes vary from a minimum of $10 \mathrm{~m}$ $(32.8 \mathrm{ft})$ to a maximum of $102 \mathrm{~m}(335 \mathrm{ft})$. The overall $\mathrm{x}-\mathrm{y}$ domain is defined to include groundwater flow below the waste sites of interest for the 300 -FF- 5 focused feasibility study, and is also based on the availability of hourly water-level data collected from wells in the early 1990s. The 10-m (32.8 ft) x-y grid refinement area is for transport simulations around the important waste sites and continuing to the Columbia River. Preliminary tracer pulse runs at different times of the year (i.e., different watertable/river stage regimes) were used to determine the northern, western, and southern extents of the $10 \mathrm{~m}$ $(32.8 \mathrm{ft})$ refinement.

The model domain extends vertically from an elevation of 90 to $109 \mathrm{~m} \mathrm{(295} \mathrm{to} 358 \mathrm{ft}$ ) relative to the North American Vertical Datum of 1988 (NAVD88; see Zilkoski et al. 1992). This vertical range encompasses three hydrostratigraphic units (from top to bottom): the undifferentiated Hanford formation gravels and sands, a fine-grained Ringold subunit, and Ringold unit E gravels. Although this model domain extends into the capillary fringe region, it does not include most of the vadose zone that extends up to the ground surface. In the vertical direction, variable grid block sizes are used, with 1-m (3.2-ft) spacing in the lower part of the domain from 90 - to $95-\mathrm{m}$ (295- to 312-ft) elevation followed by $0.5-\mathrm{m}$ (1.6-ft) vertical grid spacing from 95 to $109 \mathrm{~m}$ (312 to $357 \mathrm{ft}$ ) for the upper part of the unconfined aquifer and capillary fringe region. The model extends partially into the vadose zone to be able to encompass the range of water-table fluctuations expected as a result of changes in river stage.

For the river bottom, three $0.5-\mathrm{m}$ vertical nodes below the bathymetry ( $1.5 \mathrm{~m}$ total) are designated as river alluvium material. Node selection from the finite difference grid for the lateral extent of the river channel and bathymetry was determined using EarthVision (see Figure 2.2 for shoreline map and Section 2.1.4 for bathymetry).

\subsubsection{Hydrogeology}

The EarthVision hydrogeologic framework developed for the 300 Area (discussed in Section 2.1) was sampled at the three-dimensional finite difference STOMP model node locations to provide the hydrostratigraphic units for each node. The main hydrostratigraphic units in the model domain are the Hanford formation sands and gravels (unit 1), a fine-grained Ringold subunit (unit 4), and Ringold E gravels (unit 5). The river alluvium, as discussed previously, was assigned to unit 11 for the model. Figure 3.2 shows a three-dimensional view of the main hydrostratigraphic units as represented in the STOMP finite difference grid of the large-scale model. 


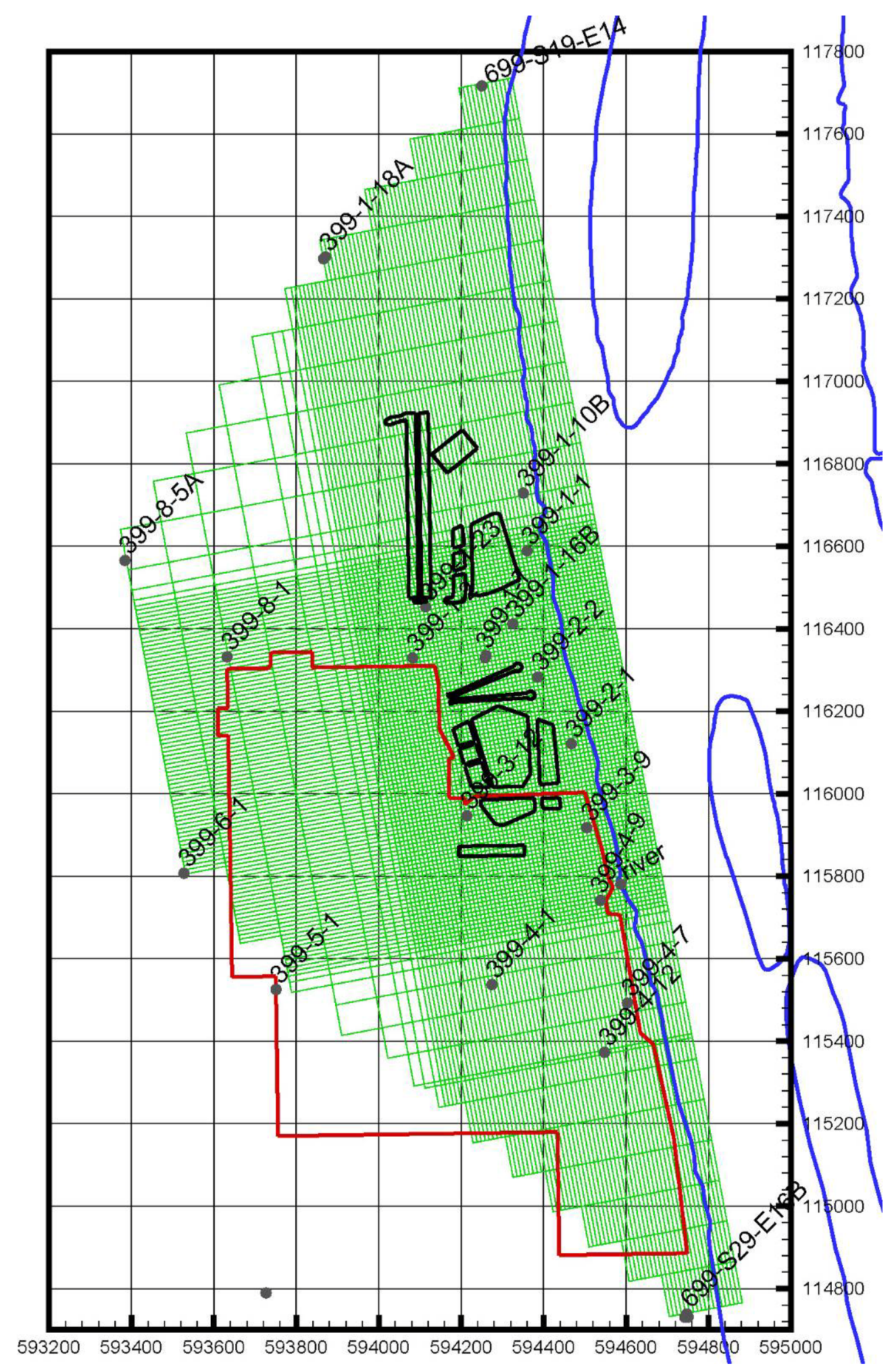

Figure 3.1. Plan View of Large-Scale 300 Area STOMP Model Grid (node-centered cells shown by green lines) with Selected Wells (solid gray circles). Also shown are outlines of the 300 Area (red lines), primary waste disposal areas (heavy black lines), and the Columbia River shoreline/islands (blue lines). 


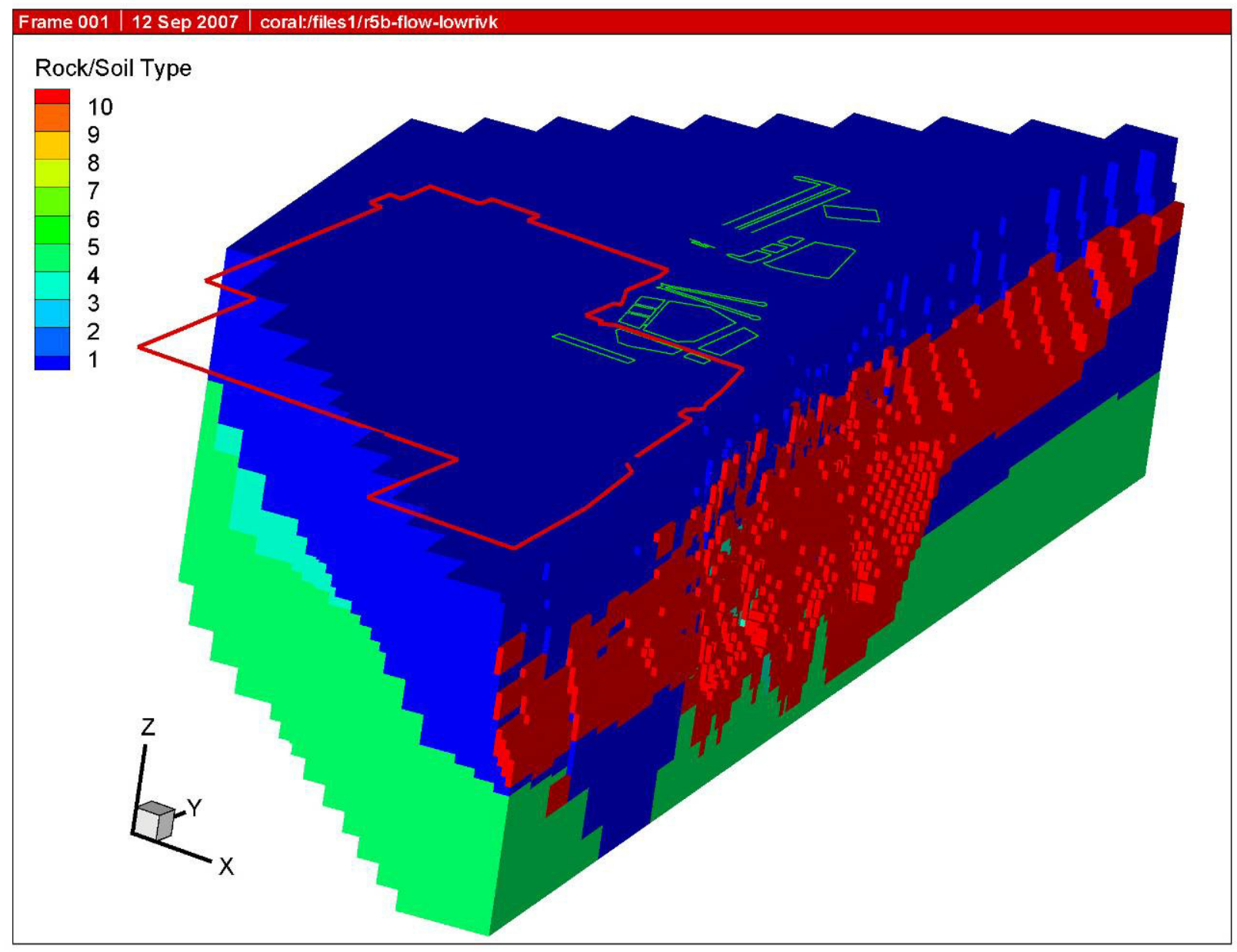

Figure 3.2. Three-Dimensional View of STOMP Model Grid R5B with the Top of the Model Domain in the Vadose Zone at an Elevation of $109 \mathrm{~m}$ (358 ft) NAVD88. The blue color is the Hanford formation (unit 1), the blue-green color is the fine-grained Ringold subunit (unit 4), the green color is the Ringold E gravels, and the red color is the river alluvium (unit 11). Also shown is the outline of the 300 Area (red line) and primary waste disposal sites (green lines).

Material properties were assigned to each of the hydrostratigraphic units for the uniform hydraulic property and zoned hydraulic property cases. An alternative stochastic, or spatially heterogeneous, representation of the material properties and model parameters was also developed based on sediment physical property measurements and geophysical logs from wells in the 300 Area. Material properties included porosity, bulk density, hydraulic conductivity, and soil properties (e.g., Brooks-Corey parameters, residual saturation, and relative permeability function). Material property values used in the uniform and zoned hydraulic property cases are provided in Section 3.2. Details on the development and implementation of the stochastic property cases are provided in Section 3.1.5.2. 


\subsubsection{Boundary Conditions}

\subsubsection{Hydraulic-Head Boundaries}

Boundary conditions for cell faces on the north, south, west, and east (river) sides of the model domain were specified as linked lists of seepage faces. For seepage-face boundary conditions, Dirichlet-type (specified head) boundary conditions were applied to the outer cell faces of grid blocks that had aqueous pressures greater than or equal to atmospheric pressure (101,325 Pa). No-flow boundary conditions were applied to the outer cell faces of grid blocks that had aqueous pressures less than atmospheric pressure (e.g., unsaturated conditions). This led to flow into or out of the model domain, or no-flow conditions, depending on the pressures at the boundaries and the adjacent nodes. Boundary pressures were computed based on the aqueous pressure and coordinates for the first surface defined in the linked list. Changes in gravitational potential associated with differences between the elevation of the reference cell face and all other cell faces in the linked list were automatically accounted for. In addition, hydraulic gradients in $\mathrm{x}-\mathrm{y}$ directions were specified to account for gradients in the river stage or between wells.

Model boundaries were calculated from hourly water-level measurements collected during the early 1990s (see Section 2.3.2) from wells on the north, south, and west sides of the domain (see Figure 3.1). The large-scale model domain was determined by the well locations that had data available from the early 1990s water-level monitoring network. Wells for the boundary conditions were selected based on having data from approximately January 1992 to March 1993, a period that overlapped with the majority of wells in the network. Hourly water-level measurements from wells 399-6-1 and 699-S29-E16B were applied to the southern boundary with hydraulic heads linearly interpolated to model boundary surfaces between these wells. Note that well 699-S29-E16B had a deeper screen than the uppermost screen in well 699-S29-E16A (in the same well cluster) but had similar values; however, a portion of the data for well 699-S29-E16A during the second half of 1992 was suspect (i.e., did not respond to river fluctuations). Hourly water-level measurements from wells 399-6-1 and 399-8-5a were applied on the western model boundary. The northern boundary was broken into two segments between three wells: 399-8-5a, 399-118a, and 699-S19-e14.

The east boundary of the model (river) was calculated from hourly Columbia River stage measurements from a river stage recorder in the 300 Area (SWS-1). Transient Columbia River gradients were applied to the river stage on the eastern boundary of the model using values calculated from the MASS1 model (Waichler et al. 2005) from two points at different locations (north and south) along the 300 Area shoreline.

The hourly water level and river stage data were subsampled to specify the boundaries every 2 hours to reduce computational requirements of the simulations. Preliminary tests comparing simulated hydraulic heads using hourly and 2-hourly data showed similar results.

\subsubsection{Surface Recharge}

A water flux of $55.4 \mathrm{~mm}$ (2.18 in.) per year was applied to the top boundary of the model on the west of the river shoreline to represent the long-term average natural groundwater recharge rate. This rate was based on the analysis by Fayer and Walters (1995), which used data from the Buried Waste Test Facility 
in the 300 North Area (Rockhold et al. 1995, Table 3.1). Researchers recognized that natural groundwater recharge rates are not constant over the model domain in either space or time due to variable surface conditions (e.g., concrete structures, parking lots, excavated versus backfilled and revegetated former disposal areas). However, in the area of primary concern adjacent to the Columbia River water fluxes into and out of the model domain due to fluctuating river stages are far greater than fluxes caused by percolating water from natural precipitation. Therefore, these simulations considered the natural groundwater recharge rate to be uniform.

\subsubsection{Water Sources and Sinks}

During the model execution period for the large-scale groundwater model (1991 to 1993), the one known large source of water in the model domain was the 316-5 Facility, also known as the north process trenches. This facility received discharges from the 300 Area process sewer. Estimated volumes of water discharged to the 316-5 Facility are tabulated in Table 3-2 of DOE-RL (1997). In 1991, 1992, 1993, and 1994, the estimated volumes of water discharged to the 316-5 Facility were 1290, 568, 416, and $\sim 378$ million $\mathrm{L}$ (3.4E+8, 1.5E+8, 1.1E+8, and $\sim 1.0 \mathrm{E}+8$ gal), respectively (DOE-RL 1997). The 316-5 Facility is comprised of two parallel trenches located north of the 300 Area boundary (see Figure 1.2 and 3.1) and oriented north-south, with the east trench 366-m (1200-ft) long and the west trench 344-m (1130-ft) long (DOE-RL 1997). DOE-RL (1997), page 2-1, states the following: "Both trenches were approximately $3.5 \mathrm{~m}(11 \mathrm{ft})$ deep, $3 \mathrm{~m}(10 \mathrm{ft})$ wide at the bottom and $10 \mathrm{~m}(32 \mathrm{ft})$ wide at the top. Trench bottoms slope gently to the north and are approximately $3.4 \mathrm{~m}(11 \mathrm{ft})$ above the water table."

Discharge to the trenches ended in 1994 when the effluent from the process sewer was routed to the 300 Area Treated Effluent Disposal Facility. During operation, the east and west trenches were used alternately. DOE-RL (1997), page 3-1, states the following: "Effluent was delivered to one trench for 4 to 6 months or until it rose to an operationally determined level; it was then diverted to the other trench."

In 1991, an expedited response action was conducted at the 316-5 Facility where contaminated soil was removed from the bottom and sides of both trenches. Discharge to the west trench ended in November 1992 (Lindberg and Chou 2001) with only the east trench used for the remaining period of discharge to this facility in 1994.

While the total surface area of the $316-5$ process trenches was large $\left(\sim 7100 \mathrm{~m}^{2}\left[76,000 \mathrm{ft}^{2}\right]\right.$ total $)$, DOE-RL (1997), page 2-2, states that “...during the last 2 years of operation, the liquid discharged to the east trench extended only about $6 \mathrm{~m}$ (20 ft) from the weir box before percolating into the soil." Based on this information, trench discharges were applied over four $10-\mathrm{m}$ by $10-\mathrm{m}$ (33-ft by $33-\mathrm{ft}$ ) grid blocks. This area is six times larger than the reported area for one trench discharge during the early 1990s to provide for additional spreading of the water source because the top of the model domain is below the bottom of the trenches, along with the grid spacing in this portion of the domain. Because detailed records for operations of the separate east and west trenches have not been found, the simulated timing of the alternating operation of the east and west trenches was estimated using a 6-month interval and the reported November 1992 ending of the west trench operations in Lindburg and Chou (2001).

One primary sink for water is known to have been operative during the simulation period. This sink is a result of pumping of well 399-4-12 to supply water for the aquariums in the 331 Building. Recent pumping records for well 399-4-12 were obtained by PNNL. The average pumping rate for well 399-4-12 from June 9, 2003, through July 6, 2004 was 1,431 Lpm (378 gpm). The screened interval for 
well 399-4-12 is from 98.67 to $104.76 \mathrm{~m}$ (324 to $344 \mathrm{ft}$ ) elevation (NAVD88). The well's average pumping rate of $1431 \mathrm{Lpm}$ (378 gpm) for 2003 to 2004 was partitioned over the model grid blocks that were situated within the screened interval for this well to determine sink terms for the model. The average pumping rate was assumed for the entire simulation period.

\subsubsection{Hydraulic Property Distributions}

A series of simulations were run over a range of hydraulic parameters using three hydraulic conductivity distribution models. The three hydraulic conductivity distribution models included single values of hydraulic properties for the Hanford and Ringold Formation gravel layers, hydraulic properties specified for two zones within the main Hanford gravel unit, and stochastic hydraulic property distributions. Each simulation was evaluated based on comparison of simulated hydraulic heads to the hourly water-level measurements collected from wells within the model domain from 1991 through 1993 (see Section 2.3.2 for locations). Hourly water-level measurements for 21 wells over this period in the model domain were used for a total of 196,000 measurements. Not all of the wells had complete water-level monitoring records over the simulated time period. Simulated hydraulic heads were extracted for comparison with the water-level data from the closest x,y node to the well coordinates, and for three vertical nodes across the well screen. Comparisons with water-level measurements were made with the simulation results from the uppermost of the three selected nodes that were below the water table during the simulation period. Residuals (simulated value-measured value) were calculated for each observation. Overall simulation residuals were reported for each well and were summed based on positive, negative, and the SSR.

\subsubsection{Plan-View Hanford Gravel Hydraulic Conductivity Zonation}

A plan-view zonation of the main Hanford formation gravel unit was developed based on the hydraulic gradient analysis of the water-level data collected in the early 1990s, as described in Section 2.3.2. Contour plots of the measured hydraulic heads show steeper gradients in the water-table aquifer in the northern portion of the model domain, within the Hanford formation, particularly at low-river stage conditions as shown in Figure 2.27. The regions of steeper hydraulic gradients are indicative of lower hydraulic conductivities. Note that steeper gradients on the western and southern portions of the monitoring data, as shown in Figure 2.27, are where the Ringold Formation is at the water table and are outside of the large-scale model domain.

Figure 3.3 shows the simple hydraulic property zonation within the Hanford formation created based on the higher hydraulic gradient in this northern portion of the model domain. Figure 3.3 shows a plan-view of the zonation of the large-scale model at two elevations within the aquifer, 106 and $102 \mathrm{~m}$ (NAVD88). The lower elevation shown in Figure $3.3(102 \mathrm{~m})$ shows Ringold Formation units in the aquifer, both Ringold E gravels and a finer grained Ringold unit within the model as described in Section 2.1. 

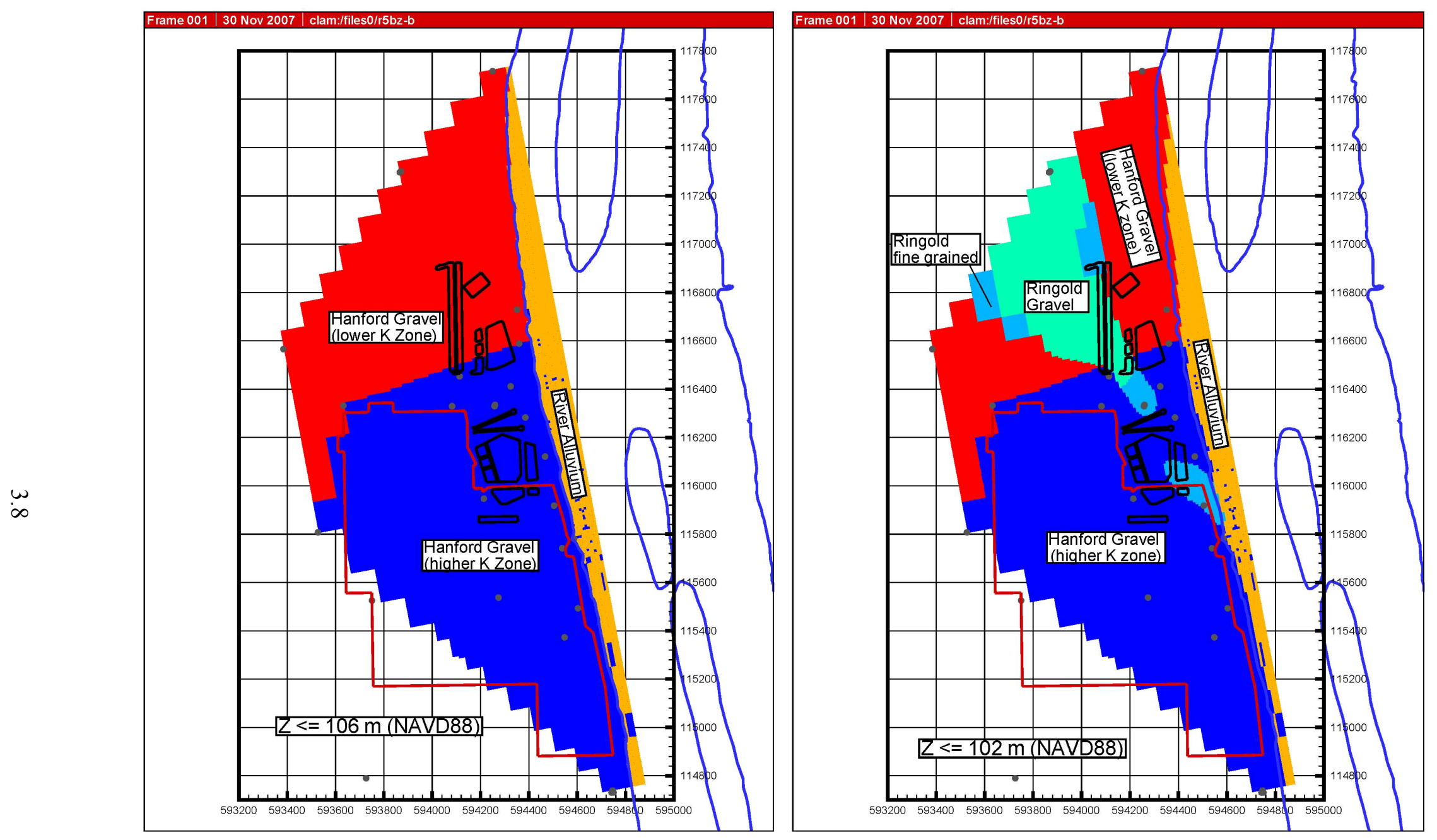

Figure 3.3. Plan-View Zonations of the Hanford Formation at 106-m Elevation (left figure) and 102-m Elevation (right figure). The river alluvium shown on both plots is below the 106-m elevation. 


\subsubsection{Stochastic Hydraulic Property Distributions}

This section describes geostatistical analyses, stochastic conditional simulations, gamma log-grain size correlation functions, and estimation of hydraulic parameters, including upscaling procedures, for generating heterogeneous models.

Stochastic distributions of physical and hydraulic parameters were developed from geostatistical analyses and conditional simulations of physical property data from core samples collected from 16 wells (Schalla et al. 1988, Swanson et al. 1992, Williams et al. 2006, Williams et al. 2007) and from borehole geophysical logging data representing 45 wells distributed over the 300 Area. Conditional simulation refers to the generation of stochastic realizations of parameter fields that preserve the hard data at their measurement locations (or nearest grid block), as well as reproduce the histogram of the data and its spatial auto- and cross-correlation structures. The physical property data include porosity (Appendix A) and grain-size distribution metrics inferred from gross-gamma logs and gamma log-grain size correlation functions. Analyses of borehole geophysical data were limited to gross gamma log data that were standardized and cross-calibrated with gamma log data from the LFI boreholes (Appendix B). Although grain-size distribution data are available for several hundred core samples from the 300 Area, the analyses presented here are limited to selected samples from the LFI boreholes (Appendix C). These samples were larger in diameter (13-cm [5-in.]) than typical core samples (10-cm [4-in.]), and drilling of the LFI wells was performed using the resonant sonic drilling method, which causes less sample disturbance than the standard cable-tool drilling method. Therefore, the LFI cores were assumed to be more representative of the gravel- and cobble-dominated sediments than the core samples that were collected during earlier characterization activities in the 300 Area. Figure 3.4 shows the well locations for which core porosity and/or geophysical logging data were available for use in these analyses. Relative to the model domain size, the well coverage is notably sparse. In particular, there are no wells with core or geophysical logging data within the footprints of either the former north or south process ponds. This is a case where surface geophysical methods (e.g., electrical resistance tomography, ground penetrating radar, and/or seismic) would be useful for characterization of the areas between wells. Unfortunately, no surface geophysical data were available for use on this project. Such work is currently ongoing as part of other DOE Environmental Remediation Sciences Division projects in the 300 Area. ${ }^{1}$

Directional auto-correlation structures were analyzed using the normal-score transforms (Deutsch and Journel 1998) of the pooled total porosity data (Appendix A), the normal-score transforms of the pooled and standardized gross gamma log data (Appendix B), and subsets of these data grouped by hydrostratigraphic units (e.g., units 1, 4, 5, 8, and 9 as described in Section 2.1.4), and formation (e.g., Hanford [unit 1], Ringold [units 4, 5, 8, and 9]). The normal score transforms of the data were generated using the nscore program from Deutsch and Journel (1998). The directional experimental variograms were computed using the gamv (Deutsch and Journel 1998) and gameas (Carle 1999) programs. In general, the pooled data sets yielded more well-defined spatial autocorrelation structures than did the subsets of data. Therefore, only the analyses for the pooled data sets are presented and discussed in this report.

\footnotetext{
${ }^{1}$ See http://ifchanford.pnl.gov/ for additional information. Site last accessed on June 17, 2008.
} 

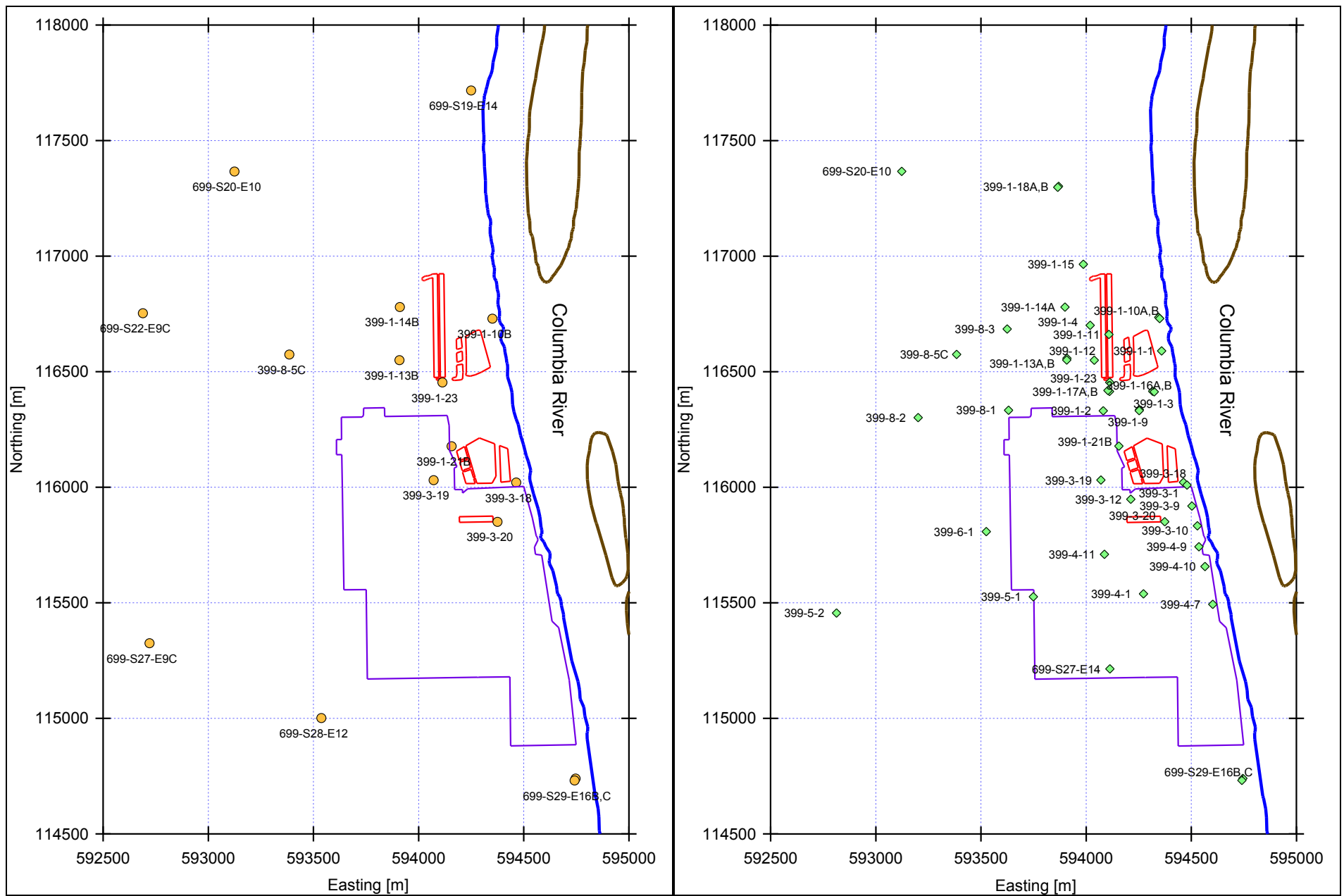

Figure 3.4. Locations of Boreholes from Which Core Porosity (left figure) and Gross Gamma Log Data (right figure) Were Collected 
Experimental correlograms were computed and then expressed in variogram form (Isaaks and Srivastava 1989). Figure 3.5 shows the experimental and model variograms for the horizontal and vertical directions for both porosity and the standardized gamma log data. For the porosity data, there are an insufficient number of wells to reliably quantify the short-range autocorrelation structure in the horizontal plane. The situation is better for the gamma log data, because of the increased number of borehole locations for those data. For the vertical direction, both the porosity and gamma log data show relatively well-defined structure. Separate directional variogram analyses were also performed for different directions in the horizontal plane, but no significant anisotropy in the horizontal plane was evident, as a result of the limited number of wells and their arrangement.

The experimental variogram data were fitted to a spherical model with three nested structures of the form as expressed in Equation (3.1):

$$
\gamma(h)=C_{0}+\sum_{i=1}^{3} C_{i}\left[1.5\left(\frac{h}{a_{i}}\right)-0.5\left(\frac{h}{a_{i}}\right)^{3}\right]
$$

where $\gamma$ is the (semi-) variogram value, $h$ is the lag separation distance), $C_{0}$ is the nugget, and $C_{i}$ and $a_{i}$ and the sills and actual ranges, respectively, for each spherical model. Model parameters are listed in Table 3.1.

Table 3.1. Parameters of Nested Spherical Variogram Models for 300 Area Porosity and Gamma Log Data

\begin{tabular}{|c|c|c|c|c|}
\hline \multirow[b]{2}{*}{ Variogram Model Parameter } & \multicolumn{4}{|c|}{ Variable } \\
\hline & \multicolumn{2}{|c|}{ Porosity } & \multicolumn{2}{|c|}{ Gamma } \\
\hline $\mathrm{C} 0$ & \multicolumn{2}{|c|}{0} & \multicolumn{2}{|c|}{0} \\
\hline $\mathrm{C} 1$ & \multicolumn{2}{|c|}{0.35} & \multicolumn{2}{|c|}{0.35} \\
\hline $\mathrm{C} 2$ & \multicolumn{2}{|c|}{0.65} & \multicolumn{2}{|c|}{0.3} \\
\hline \multirow[t]{2}{*}{$\mathrm{C} 3$} & \multicolumn{2}{|c|}{--} & \multicolumn{2}{|c|}{0.35} \\
\hline & Vertical & Horizontal & Vertical & Horizontal \\
\hline$a_{1}(\mathrm{~m})$ & 1.2 & 150 & 4 & 30 \\
\hline$a_{2}(\mathrm{~m})$ & 8.5 & 380 & 14 & 200 \\
\hline$a_{3}(\mathrm{~m})$ & -- & -- & 25 & 1400 \\
\hline
\end{tabular}

In Table 3.1 and Figure 3.5, note that a spherical model with two nested structures was used to fit the porosity variogram data, while a spherical model with three nested structures was used to fit the gamma log variogram data. In both cases, a zero nugget was assumed. Given the very sparse well coverage for the core porosity data, and the less sparse well coverage for the gamma log data (Figure 3.4), the cross-correlation of these two variables was examined to determine if the gamma log data could possibly be used as soft data for stochastic conditional simulation of porosity. The term soft data refers to surrogate data that are usually more plentiful and can be correlated with the sparser hard data of interest.

The standardized Group 1 (LFI) -equivalent gamma log data (Appendix B) were interpolated to the porosity core sample measurement locations to generate a subset of co-located gamma log data. The 
current 300 Area EarthVision model was used to assign a hydrostratigraphic unit designation to each sample location. Figure 3.6 shows a cross-plot of the co-located porosity and gamma log data, grouped by hydrostratigraphic unit.
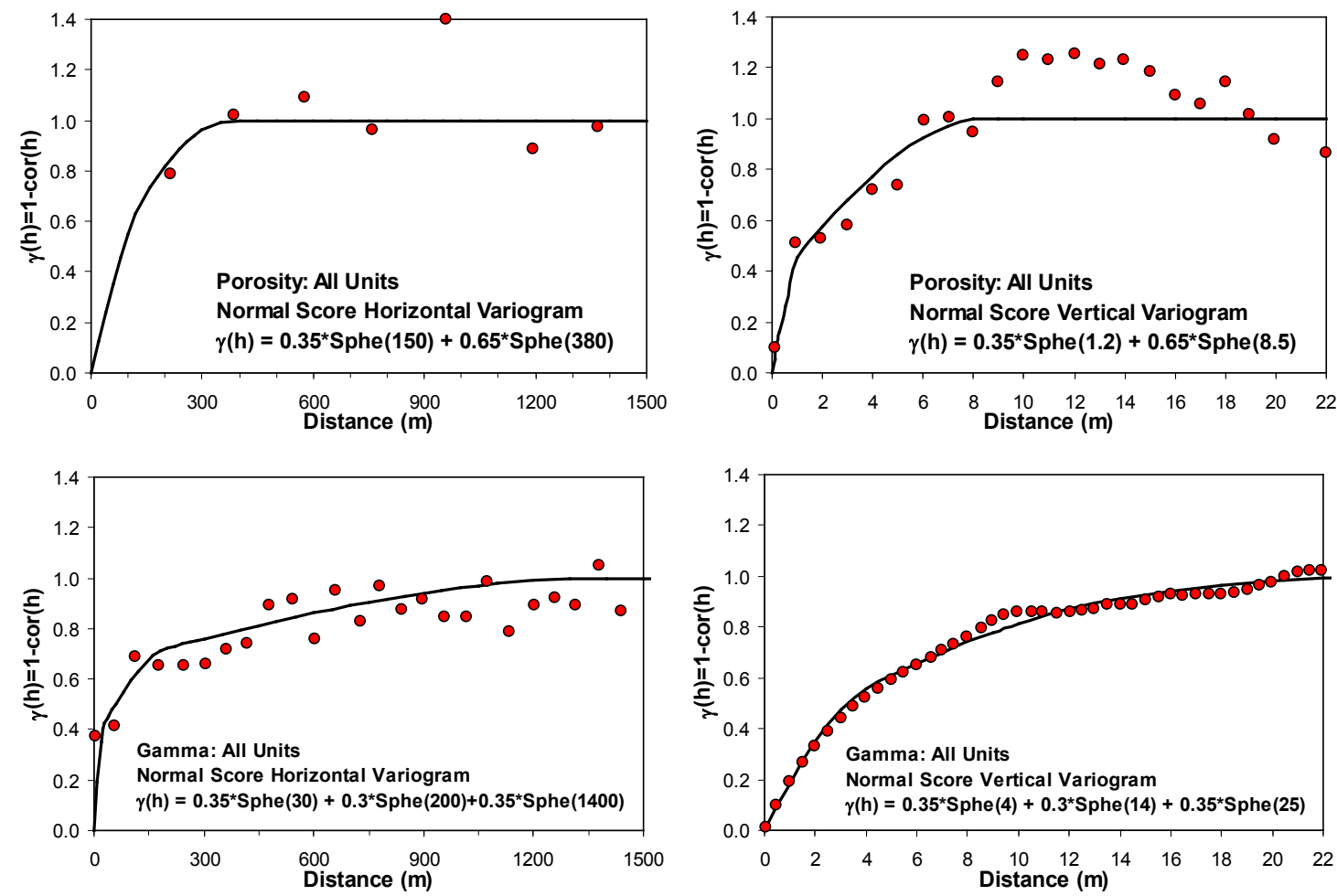

Figure 3.5. Directional Experimental and Model Variograms for Total Porosity and Gross Gamma Log Data in the 300 Area

As illustrated in Figure 3.6, the Hanford formation (u1) sediments have significantly lower-average gamma log counts than the Ringold Formation ( $u 4, \mathrm{u} 5, \mathrm{u} 8)$ sediments (Appendix B), while $\mathrm{u} 1$ and $\mathrm{u} 5$ have very similar average total porosities (Appendix A). While the differences in the average gamma log counts for the different Ringold units appear to be relatively small, the differences in their average porosities are significant. The ellipses in Figure 3.6 show the outlines of the subsets of data grouped by hydrostratigraphic units. There are several samples that appear to be misclassified, such as the four samples identified as u4 (pink squares) and the two samples identified as u8 (black x's) that are within the ellipse representing u5. There are also several samples identified as u5 (green triangles) within the ellipse representing $\mathrm{u} 1$. For the pooled data set (all units combined), there is a moderate to weak but positive correlation between the gamma log and porosity data, with a correlation coefficient of 0.43 . If only the data classified as $\mathrm{u} 1$ are considered, the correlation coefficients for the data and their normal-score transforms are 0.45 and 0.41 , respectively.

The sequential Gaussian simulation program (SGSIM) in the Geostatistical Software Library (GSLIB) (Deutsch and Journel 1998) was used to generate equally drawn, stochastic conditional simulations of the gamma log data. A spiral-search strategy is usually employed with the SGSIM algorithm, but a two-part super block search strategy was used for generating realizations of the gamma fields due to data configuration, and for reasons stated in Deutsch and Journel (1998, p. 36-37). 


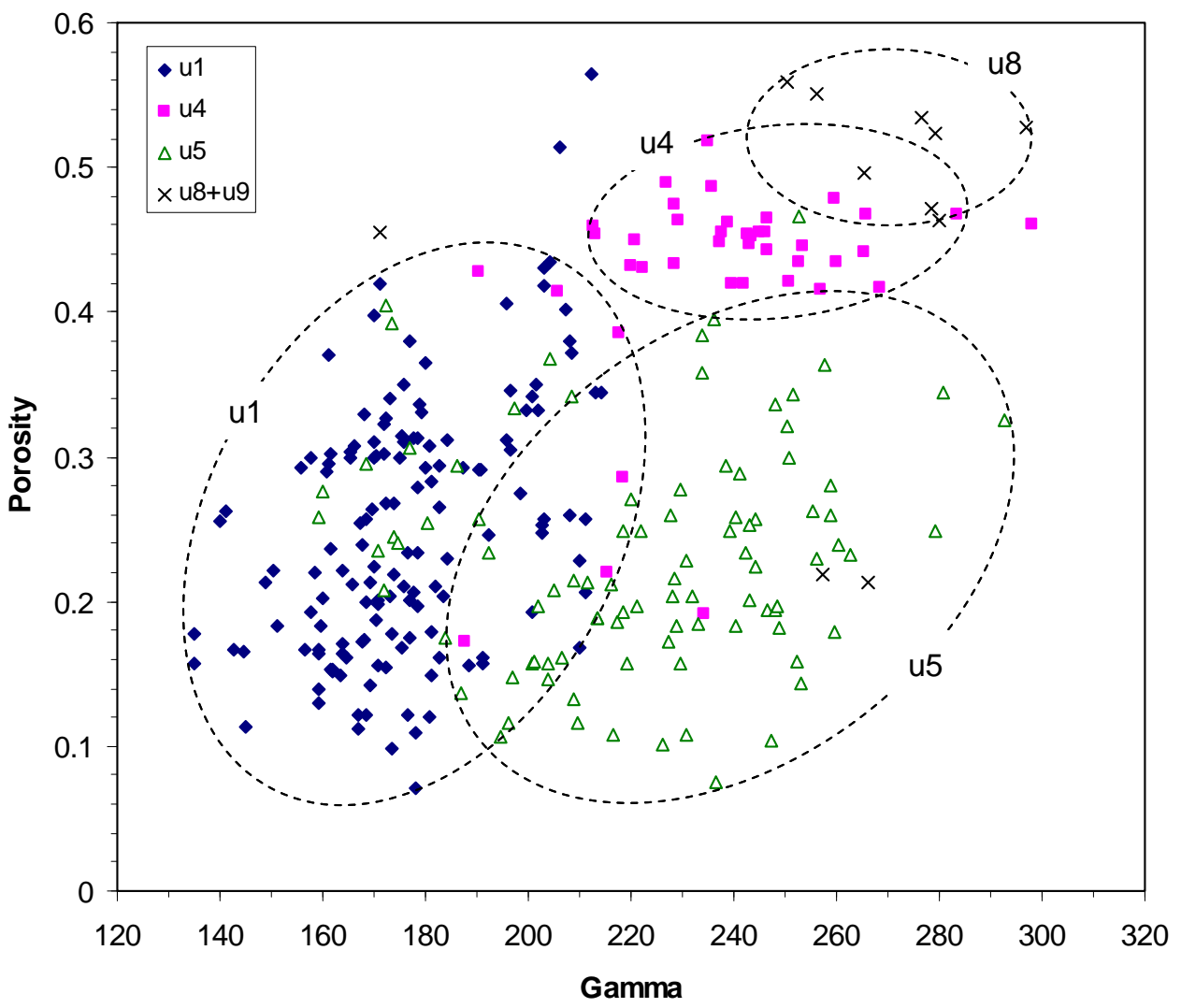

Figure 3.6. Cross-Plot of Co-Located Porosity and Gamma Log Data for 300 Area Wells

After the gamma fields were generated, the SGSIM program was used again, but with the co-kriging option, to generate conditional simulations of the porosity data using the simulated gamma log data as soft data. A cross-correlation coefficient of 0.41 was assumed for the normal-score transformed data. The geostatistical stochastic conditional simulations of the gamma log and porosity data were generated on a 227 x 605 x $38(5,218,730)$ node grid representing the physical domain of interest. Uniform 5-m node spacing was used in the $\mathrm{x}$ - and $\mathrm{y}$-directions, and uniform 0.5 -m node spacing was used in the vertical direction.

In addition to porosity, simulations of flow and transport in variably saturated porous media require estimates of hydraulic conductivity and parameters that describe the constitutive relative permeability-saturation-capillary pressure (k-S-P) relations. Gamma log-grain size correlation functions were developed using grain-size distribution data from selected LFI core samples (Appendix C). Hydraulic conductivities and parameters representing the k-S-P relations were then estimated from the gamma log-grain size correlation functions and pedotransfer functions (PTF).

Figure 3.7 shows gamma log-grain size correlation functions for two grain-size distribution metrics, the geometric mean diameter, $d_{g}(\mathrm{~mm})$, and the ratio of the geometric mean grain-diameter to the geometric standard deviation, $d_{g} / \sigma_{g}$. The grain-size metrics in Figure 3.7 were fit using the function expressed in Equation (3.2):

$$
\text { Metric }=p_{2}+\left(p_{1}-p_{2}\right) \times\left[1+\left(p_{3} \times g g\right)^{p_{4}}\right]^{-p_{5}}
$$


where $p_{1}, p_{2}, p_{3}, p_{4}$, and $p_{5}$ are parameters and $g g$ represents the Group 1 (LFI) -equivalent gross gamma $\log$ count data. When the metric is $d_{\mathrm{g}}$, parameters $p_{1}$ and $p_{2}$ have physical meaning as the largest and smallest geometric mean grain-diameter, respectively. Parameters $p_{3}, p_{4}$, and $p_{5}$ are fitting parameters that affect the shape of the correlation functions. An $S$-shaped function of the form given in Equation (3.2) was used rather than a linear function to avoid extrapolation to excessively large or small (including nonphysical negative) values of the grain-size distribution metrics. Note that Equation (3.2) is the same form as the well-known van Genuchten (1980) water-retention function. Table 3.2 lists the parameters used to generate the curves shown in Figure 3.7.
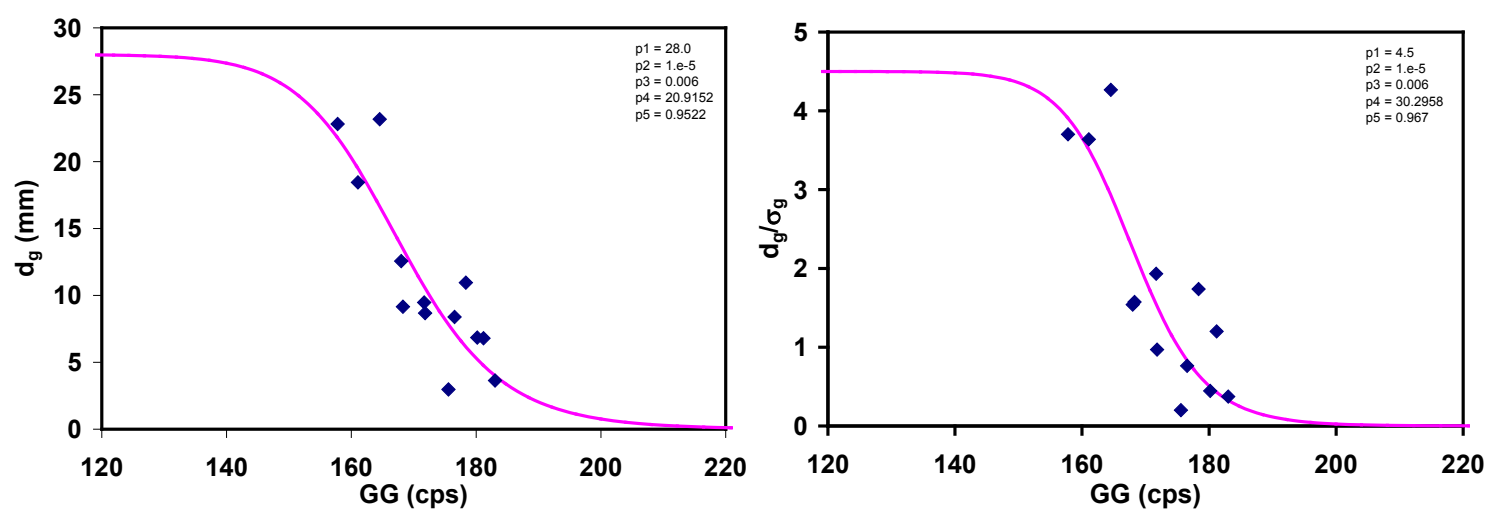

Figure 3.7. Gamma Log - Grain Size Correlation Functions Representing Selected Samples from LFI Boreholes

Table 3.2. Parameters of Gamma Log - Grain Size Correlation Functions Shown in Figure 3.7

\begin{tabular}{ccc}
\hline $\begin{array}{c}\text { Parameters in Gamma Log-Grain Size } \\
\text { Correlation Functions }\end{array}$ & $d_{\mathrm{g}}$ & $d_{\mathrm{g}} / \sigma_{\mathrm{g}}$ \\
\hline$p_{1}$ & 28 & 4.5 \\
$p_{2}$ & 0.00001 & 0.00001 \\
$p_{3}$ & 0.006 & 0.006 \\
$p_{4}$ & 20.9152 & 30.2958 \\
$P_{5}$ & 0.9522 & 0.967 \\
\hline
\end{tabular}

Figure 3.8 shows cutaway views of three stochastic realizations of $d_{\mathrm{g}}(\mathrm{mm})$ computed from the SGSIM-simulated gross gamma log fields and the gamma log-grain size correlation function shown in Figure 3.7. The vertical extent of each realization shown in Figure 3.8 is $19 \mathrm{~m}(62 \mathrm{ft})$, over the 90 - to 109-m (295- to 357-ft) elevation interval, and the vertical exaggeration is $2 \mathrm{X}$. As noted earlier, these fields were generated using uniform 5-m (16-ft) grid spacing in the $\mathrm{x}$ - and $\mathrm{y}$-directions, and uniform $0.5-\mathrm{m}(1.6-\mathrm{ft})$ grid spacing in the vertical direction. 


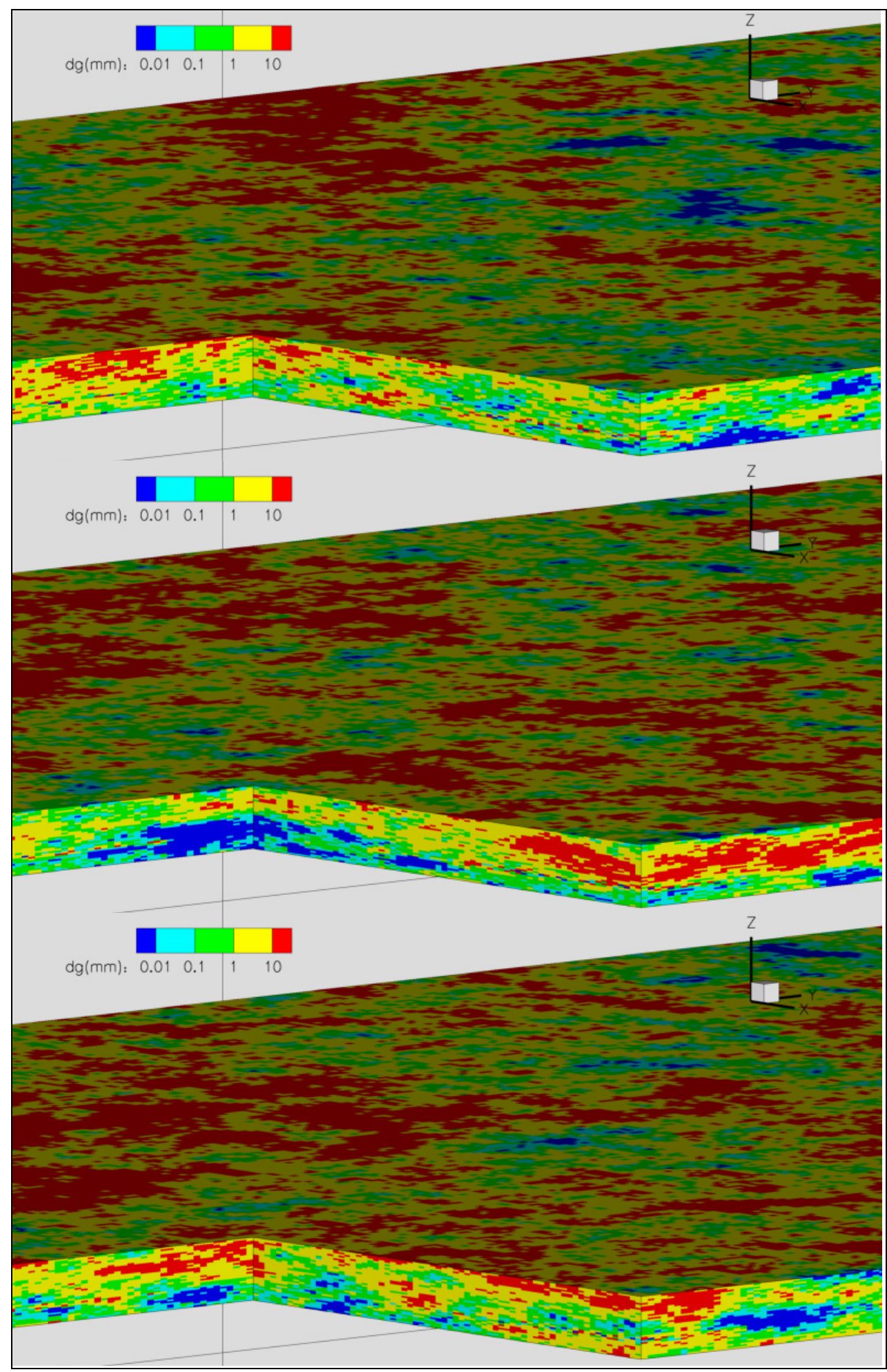

Figure 3.8. Oblique Views (from southeast) of Three Stochastic Realizations of $d_{\mathrm{g}}(\mathrm{mm})$ Generated Using SGSIM with Gamma Log Data and Gamma Log-Grain Size Correlation Functions. The vertical extent of each simulated field is $19 \mathrm{~m}(62 \mathrm{ft})$ and the vertical exaggeration is $2 \mathrm{X}$. 
Unlike the layered EarthVision model representation of the domain, which is based on idealized hydrostratigraphic zonations, the $d_{\mathrm{g}}$-fields depicted in Figure 3.8 exhibit much more variability. Although these $d_{\mathrm{g}}$ fields are conditioned on the gamma log data from 45 wells in the 300 Area (Figure 3.4), the extent to which these realizations correspond with actual properties in the field is unknown. At this point, the simulated $d_{\mathrm{g}}$ fields are purely geostatistical, with no explicit geological considerations or constraints.

Figure 3.9 shows cutaway views of three stochastic realizations of porosity, computed with SGSIM using the simulated gamma fields as soft data. On initial inspection of Figures 3.8 and 3.9, it appears that the simulated porosity fields bear little resemblance to the simulated $d_{\mathrm{g}}$ fields. As shown in Figure 3.7, however, larger values of $d_{\mathrm{g}}$ correspond to smaller values of simulated gross gamma log counts, so regions of large values of $d_{\mathrm{g}}$ should have smaller values of simulated porosities. Inspection of Figures 3.8 and 3.9 prove this is generally the case. The correlation lengths of the first horizontal structures, $a_{1}$, for the porosity and gamma log data are $150 \mathrm{~m}(492 \mathrm{ft})$ and $30 \mathrm{~m}(98 \mathrm{ft})$, respectively (Table 3.2). The longer correlation length for the porosity data results in much stronger spatial continuity in the horizontal direction relative to the gamma log data. Because there are essentially no porosity data pairs for horizontal lags of less than approximately $200 \mathrm{~m}(656 \mathrm{ft})$, it is possible the short-range horizontal correlation structure for the porosity data is actually more similar to the gamma log data than was modeled in this report. However, it is impossible to know without having additional porosity data at shorter horizontal lags; there is considerable uncertainty in the horizontal correlation length(s) for porosity. It is likely that $\sigma_{\mathrm{g}}$ would exhibit a stronger (albeit inverse) correlation with porosity than gamma does because more poorly sorted sediments tend to have lower porosities. However, $\sigma_{\mathrm{g}}$ was found to be poorly correlated with gamma so it was not used as soft data for porosity estimation.

An explicit correlation function could be developed for $\sigma_{\mathrm{g}}$ and porosity from core samples, which could then be used in conjunction with the gamma log grain-size correlation functions in Figure 3.7 and Table 3.2 to estimate porosities explicitly from the simulated gamma log data. However, this theory was not pursued in this research.

Hydraulic conductivity, $K_{\mathrm{s}}$, was estimated at the resolution of the fine geostatistical model grid from the simulated $d_{\mathrm{g}}$ and porosity fields depicted in Figures 3.8 and 3.9 using the Kozeny-Carmen equation (Bear 1972, p. 166) as shown in Equation (3.3):

$$
K_{s}=\left(\frac{\rho_{w} g}{\mu}\right)\left[\frac{n^{3}}{(1-n)^{2}}\right]\left(\frac{d_{m}^{2}}{180}\right)
$$

where

$\rho_{\mathrm{w}}$ and $\mu=$ density and viscosity of water, respectively

$g=$ gravitational constant

$n=$ porosity

$d_{m}=$ representative grain size, taken here to be $d_{g}(\mathrm{~mm})$. 


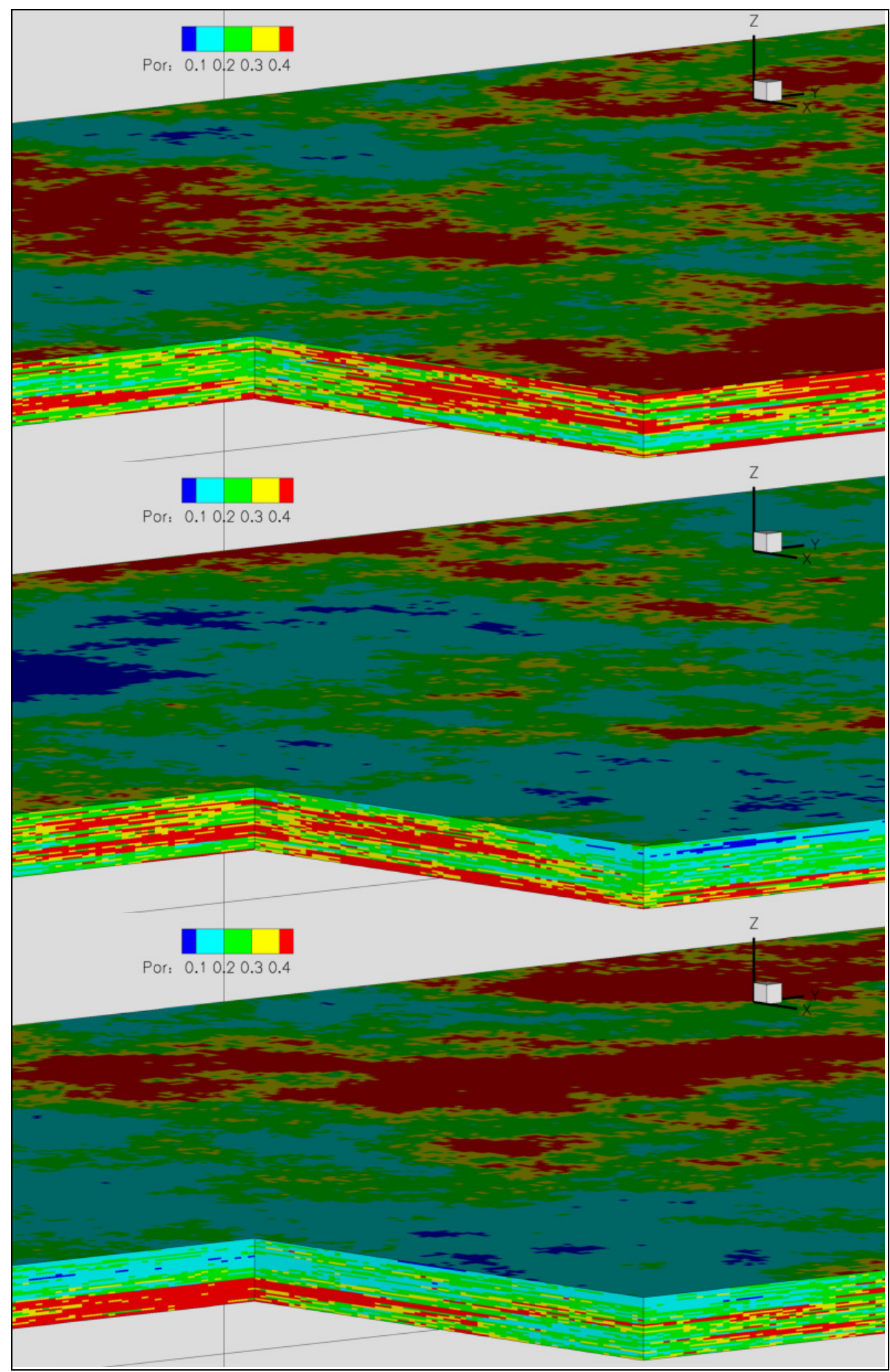

Figure 3.9. Oblique Views (from southeast) of Three Stochastic Realizations of Total Porosity Generated Using SGSIM with Simulated dg fields as Soft Data. The vertical extent of each simulated field is $19 \mathrm{~m}(62 \mathrm{ft})$ and the vertical exaggeration is $2 \mathrm{X}$. 
Parameters for the Brooks and Corey (1964) model water-retention function were also estimated at the resolution of the fine geostatistical model grid from the ratio $d_{\mathrm{g}} / \sigma_{\mathrm{g}}$ using the PTFs reported by Ward et al. (2006). Note that the PTFs reported by Ward et al. (2006) represent much finer-textured agricultural soils. When applied to the $d_{\mathrm{g}} / \sigma_{\mathrm{g}}$ values estimated from the 300 Area gamma log-grain size correlation functions (Figure 3.7 and Table 3.2), these PTFs still generated reasonable parameter values and were therefore used here. However, the authors of this report recommend that 300 Area site-specific PTFs be developed if the types of parameterization methods used in this report are pursued in future work. Several alternative PTFs for estimating hydraulic parameters from soil texture and other types of data are in Guber et al. (2006). These alternative PTFs have not been tested for Hanford Site soils, but it is assumed that PTFs generated using site-specific data will be more accurate than those based on generic or non-sitespecific sources.

\subsubsection{Parameter Upscaling}

Most stochastic simulation programs, including SGSIM, generate results on a grid with uniform spacing. The spacing can be different for each direction, but in any given direction it is usually uniform (constant). The grid resolutions typically chosen for stochastic simulation are generally much finer than the resolutions that can be used practically for numerical flow and transport modeling. Therefore, upscaling procedures are required to map the results of the high-resolution geostatistical model grids to the coarser-resolution and usually irregular grids that are used for flow and transport modeling. The following upscaling procedures were used.

The porosity or saturated water content, $\theta_{\mathrm{s}}$, was upscaled using volume averaging, as shown in Equation (3.4):

$$
\theta_{s C}=\frac{\sum_{j=1}^{n} \theta_{s F, j} V_{F, j}}{\sum_{j=1}^{n} V_{F, j}}
$$

where $V$ is the (partial or full) volume of a fine-grid block and the subscripts $C, F$, and $j$ refer to the coarse numerical model grid block, the fine-geostatistical model grid block, and the index of the fine-grid block, respectively. The summations were taken over all $n$ fine-grid blocks that were contained (either partially or completely) within each coarse-model grid block. Volume averaging is required for conservation of mass and volume for scalar variables such as porosity.

The principal components of the saturated hydraulic conductivity (or intrinsic permeability) tensor for the coarse (superscript $C$ )-model grid blocks were computed as follows. Lower bounds (superscript $L$ ) on hydraulic conductivity for each principal direction were first computed from the area-weighted arithmetic mean of the length-weighted harmonic mean of the fine-grid block $K$ values, as seen in Equations (3.5, 3.6, and 3.7): 


$$
\begin{aligned}
& K_{x}^{C, L}\left(S_{e}\right)=\sum_{k=1}^{n z}\left[\sum_{j=1}^{n y}\left\{\left(d y_{j} d z_{k}\right)\left[\sum_{i=1}^{n x} d x_{i} / \sum_{i=1}^{n x} \frac{d x_{i}}{K_{x}^{F}\left(S_{e}\right)}\right]\right\} / \sum_{j=1}^{n y}\left(d y_{j} d z_{k}\right)\right] \\
& K_{y}^{C, L}\left(S_{e}\right)=\sum_{k=1}^{n z}\left[\sum_{i=1}^{n x}\left\{\left(d x_{i} d z_{k}\right)\left[\sum_{j=1}^{n y} d y_{j} / \sum_{j=1}^{n y} \frac{d y_{j}}{K_{y}^{F}\left(S_{e}\right)}\right]\right\} / \sum_{i=1}^{n x}\left(d x_{i} d z_{k}\right)\right] \\
& K_{z}^{C, L}\left(S_{e}\right)=\sum_{i=1}^{n x}\left[\sum_{j=1}^{n y}\left\{\left(d x_{i} d y_{j}\right)\left[\sum_{k=1}^{n z} d z_{k} / \sum_{k=1}^{n z} \frac{d z_{k}}{K_{z}^{F}\left(S_{e}\right)}\right]\right\} / \sum_{j=1}^{n y}\left(d x_{i} d y_{j}\right)\right]
\end{aligned}
$$

where $d x, d y$, and $d z$ are the dimensions of the fine-grid blocks; $n x, n y$, and $n z$ are the number of fine-grid blocks in each principal direction; and $S_{e}$ is the effective saturation, which is equal to one for fully water-saturated conditions. Upper bounds (superscript $U$ ) on hydraulic conductivity for each principal direction were computed from the length-weighted harmonic mean of the area-weighted arithmetic mean of the fine-grid $K$ values, as seen in Equations (3.8, 3.9, and 3.10):

$$
\begin{aligned}
& K_{x}^{C, U}\left(S_{e}\right)=\sum_{i=1}^{n x} d x_{i} / \sum_{i=1}^{n x}\left[d x_{i} / \sum_{k=1}^{n z}\left\{\sum_{j=1}^{n y}\left[d y_{j} d z_{k} K_{x}^{F}\left(S_{e}\right)\right] / \sum_{j=1}^{n y}\left(d y_{j} d z_{k}\right)\right\}\right] \\
& K_{y}^{C, U}\left(S_{e}\right)=\sum_{j=1}^{n y} d y_{j} / \sum_{j=1}^{n y}\left[d y_{j} / \sum_{k=1}^{n z}\left\{\sum_{i=1}^{n x}\left[d x_{i} d z_{k} K_{y}^{F}\left(S_{e}\right)\right] / \sum_{i=1}^{n x}\left(d x_{i} d z_{k}\right)\right\}\right] \\
& K_{z}^{C, U}\left(S_{e}\right)=\sum_{k=1}^{n z} d z_{k} / \sum_{k=1}^{n z}\left[d z_{k} / \sum_{j=1}^{n y}\left\{\sum_{i=1}^{n x}\left[d x_{i} d y_{j} K_{z}^{F}\left(S_{e}\right)\right] / \sum_{i=1}^{n x}\left(d x_{i} d y_{j}\right)\right\}\right]
\end{aligned}
$$

The upper and lower bounds for $K$ are referred to as the Cardwell and Parsons bounds (Cardwell and Parsons 1945, Renard and de Marsily 1997). Effective $K$ values for each coarse-model grid block were computed using Equations (3.11, 3.12, and 3.13) (Malik and Lake 1997, Li et al. 2001):

$$
\begin{aligned}
& \bar{K}_{x}^{C}\left(S_{e}\right)=\sqrt{K_{x}^{C, L}\left(S_{e}\right) K_{x}^{C, U}\left(S_{e}\right)} \\
& \bar{K}_{y}^{C}\left(S_{e}\right)=\sqrt{K_{y}^{C, L}\left(S_{e}\right) K_{y}^{C, U}\left(S_{e}\right)} \\
& \bar{K}_{z}^{C}\left(S_{e}\right)=\sqrt{K_{z}^{C, L}\left(S_{e}\right) K_{z}^{C, U}\left(S_{e}\right)}
\end{aligned}
$$

For water-saturated conditions $\left(S_{e}=1\right)$, Equations (3.4) through (3.13) produce exact results in all cases for which exact solutions are known; namely, the harmonic mean for flow normal to layers that are 
perfect and uniform, the arithmetic mean for flow parallel to layers that are perfect and uniform, and the geometric mean for two-dimensional flow in statistically homogeneous, stationary isotropic random $K$ fields. For all other cases, these equations produce approximate results whose accuracy depends on the character of the heterogeneities and their connectivity. Although Equations (3.4) through (3.13) are written such that $K$ is a function of effective saturation, $S_{e}$, these equations were only applied here for upscaling the saturated hydraulic conductivity, $K_{s},\left(S_{e}=1\right)$. Volume averaging (Equation 3.4) was used to estimate upscaled values of water-retention parameters.

Figure 3.10 depicts the spatial distributions of upscaled hydraulic conductivity $(\mathrm{m} / \mathrm{d})$ in the horizontal direction, generated from the $d_{g}$ and porosity fields shown in Figures 3.8 and 3.9. Figure 3.11 shows the upscaled porosity distributions. Note that a vertical exaggeration of $5 \mathrm{X}$ was used for Figures 3.10 and 3.11, and a smaller region of the domain is shown relative to Figures 3.8 and 3.9, which also use a different vertical exaggeration of $2 \mathrm{X}$. The gamma log-grain size correlation functions were generated using only Hanford formation data, so all grid blocks in the Ringold Formation, as determined from the current EarthVision model interpretation of the hydrostratigraphy, and all grid blocks designated as river alluvium deposits, were overwritten with constant, deterministic parameter values.

By comparing Figures 3.11 and 3.9, the effects of upscaling are obvious, particularly for the western one-third to one-half of the model domain, for which much larger-model grid blocks were used (see Figure 3.1). The patchy character of the spatial distributions of upscaled parameters is shown, clearly plotting the values of the individual grid blocks as opposed to rendering the images with smooth, flooded contours. Figure 3.12 shows the same hydraulic conductivity distributions depicted previously in Figure 3.10, but uses flooded contours. Although Figure 3.12 is visually more appealing and gives a perception of increased connectivity, Figure 3.10 is a truer representation of the actual variability of the simulated hydraulic conductivity fields.

Numerical simulations of flow and transport were performed using the hydraulic property fields that were generated using the procedures described in Section 3.1.5.2. Results are presented in Section 3.2. 


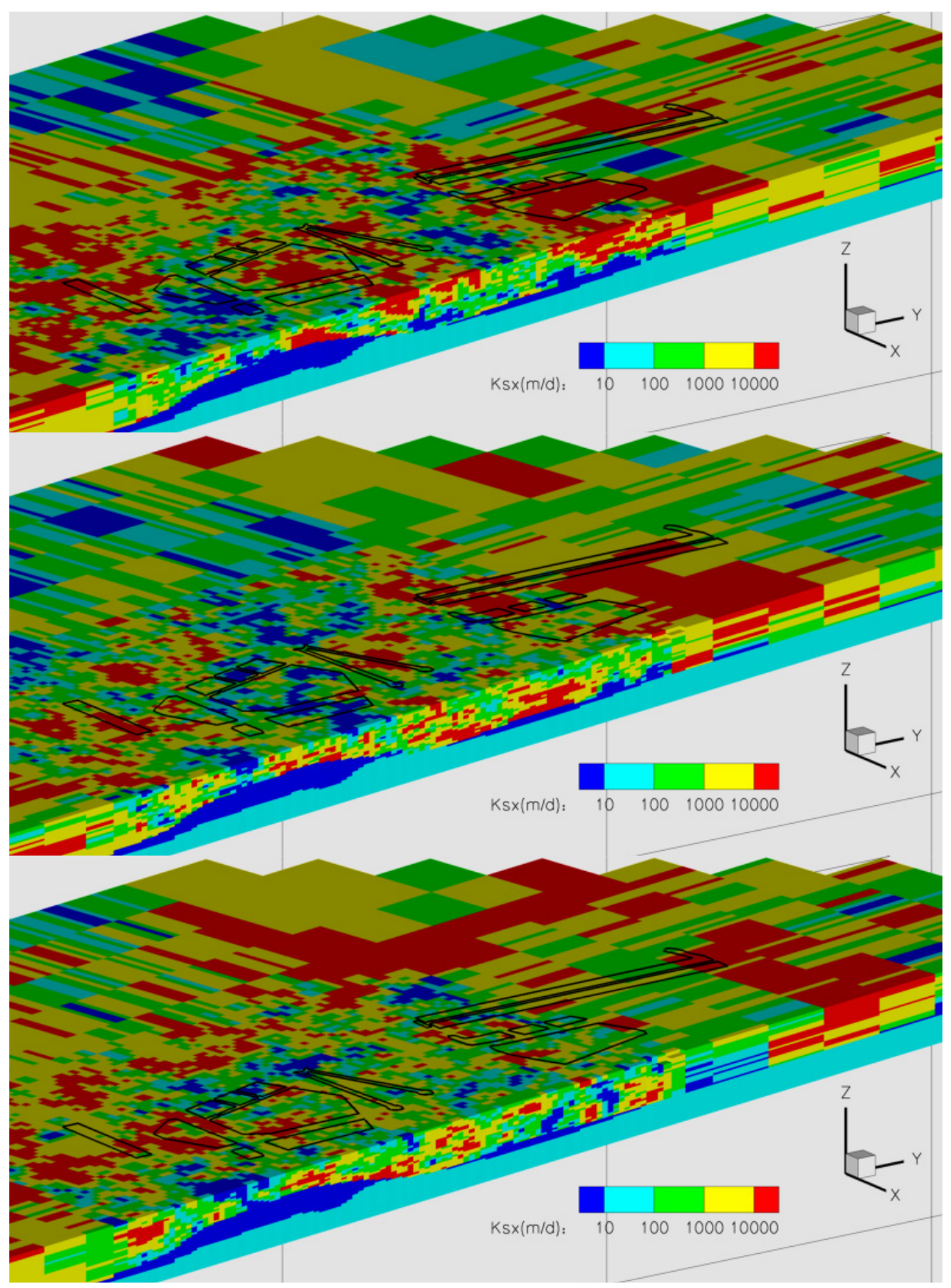

Figure 3.10. Oblique Views (from southeast) of Three Stochastic Realizations of x-Direction Hydraulic Conductivity $\left(\mathrm{K}_{\mathrm{sx}}\right)$ 


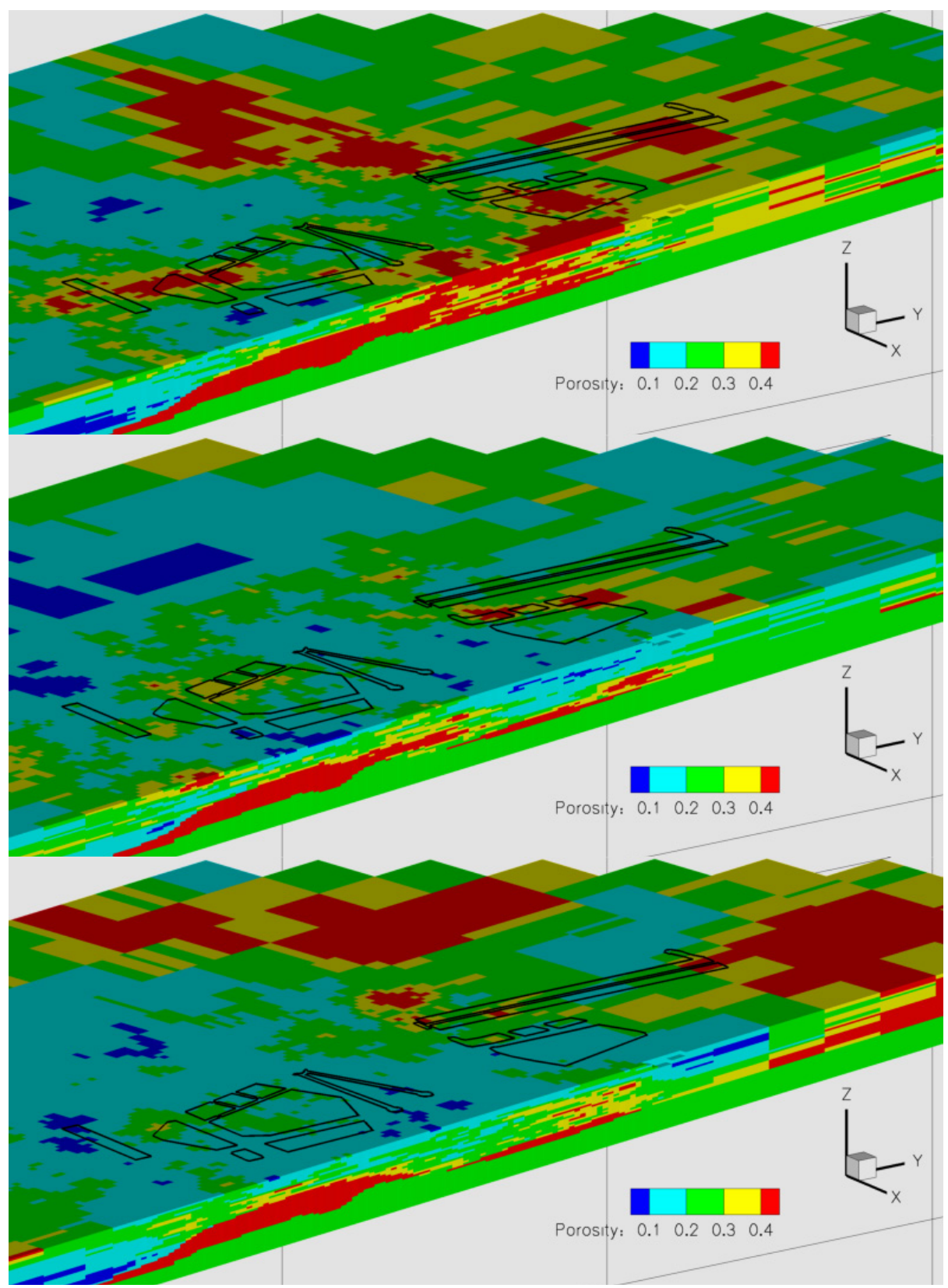

Figure 3.11. Oblique Views (from southeast) of Three Stochastic Realizations of Porosity 


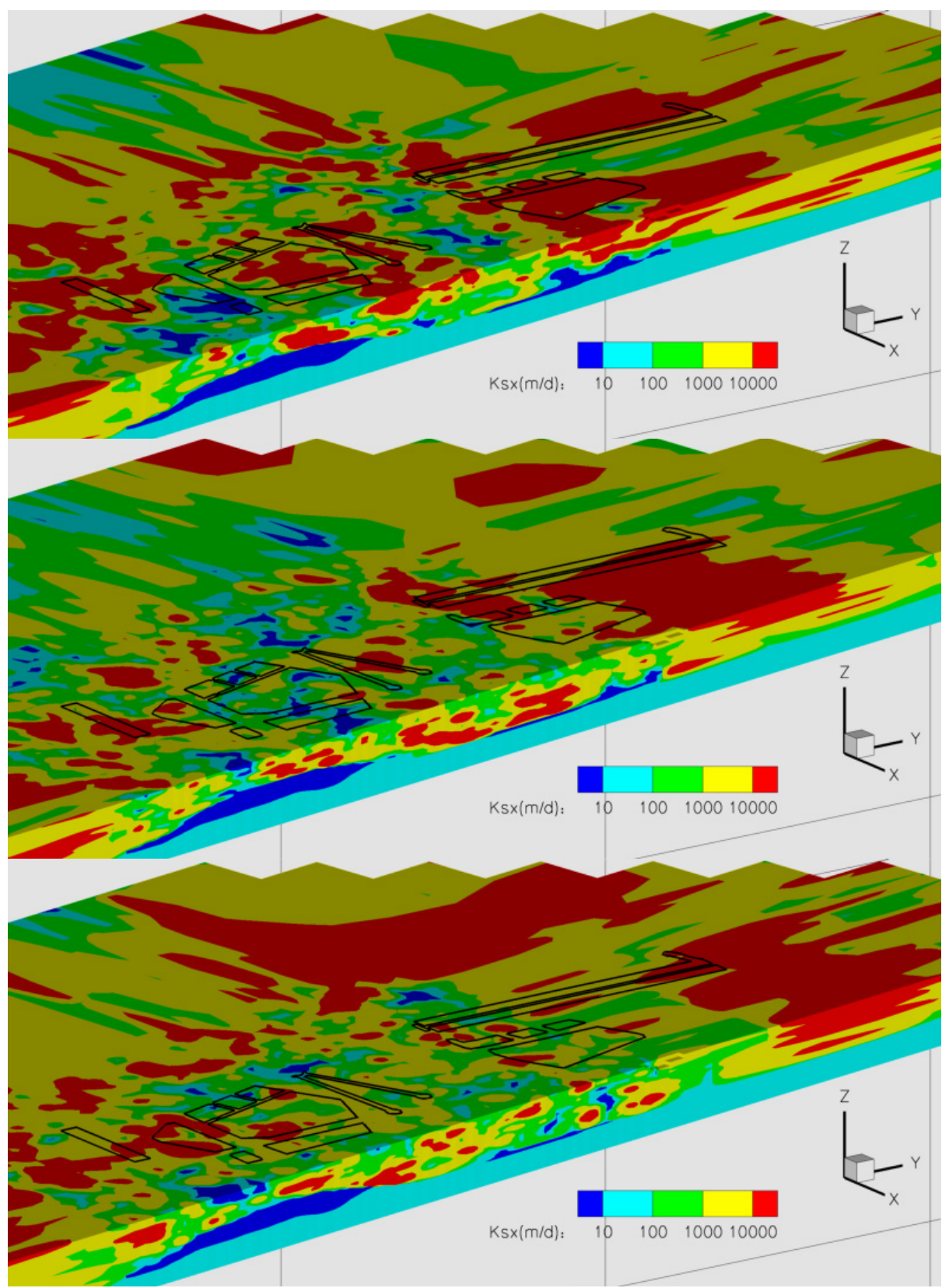

Figure 3.12. Oblique Views (from southeast) of Three Stochastic Realizations of x-Direction Hydraulic Conductivity $\left(\mathrm{K}_{\mathrm{sx}}\right)$ Generated Using Smoothed Contours 


\subsubsection{Spatial Moment Calculations}

Normalized spatial moments of the simulated tracer plumes were calculated to provide a quantitative basis for comparing the results of the different simulation cases, and to compute plume trajectories and velocities corresponding to different Columbia River stages and groundwater elevation conditions. The $i j k^{\text {th }}$ moment of the tracer concentration distribution in space is defined in Equation (3.14):

$$
M_{i j k}(t)=\int_{-\infty}^{\infty} \int_{-\infty}^{\infty} \int_{-\infty}^{\infty} \theta C(x, y, z, t) x^{i} y^{j} z^{k} d x d y d z
$$

where $\theta$ is the volumetric water content, $C$ is the tracer concentration, and $\mathrm{x}, \mathrm{y}$, and $\mathrm{z}$ are the spatial coordinates (Freyberg 1986). The integrals in Equation (3.14) were evaluated over the extent of the threedimensional model domain or over specified portions of the domain when tracer pulses were introduced at multiple locations.

The zeroth, first, and second $(\mathrm{i}+\mathrm{j}+\mathrm{k}=0,1$, or 2 , respectively) spatial moments of the tracer plumes were computed. These moments provide measures of the total mass, center of mass, and spread of the tracer plume about its center of mass. The zeroth moment, $\mathrm{M}_{000}$, is equal to the total mass in the domain. The first moment, normalized by the zeroth moment, defines the location of the center of mass $\left(\mathrm{x}_{\mathrm{c}}, \mathrm{y}_{\mathrm{c}}, \mathrm{z}_{\mathrm{c}}\right)$ as seen in Equation (3.15):

$$
x_{c}=\frac{M_{100}}{M_{000}} \quad y_{c}=\frac{M_{010}}{M_{000}} \quad z_{c}=\frac{M_{001}}{M_{000}}
$$

The second moment about the center of mass defines a spatial covariance tensor as seen in Equation (3.16):

$$
\begin{gathered}
\sigma^{2}=\left[\begin{array}{ccc}
\sigma_{x x}^{2} & \sigma_{x y}^{2} & \sigma_{x z}^{2} \\
\sigma_{y x}^{2} & \sigma_{y y}^{2} & \sigma_{y z}^{2} \\
\sigma_{z x}^{2} & \sigma_{z y}^{2} & \sigma_{z z}^{2}
\end{array}\right] \\
\sigma_{x x}^{2}=\frac{M_{200}}{M_{000}}-x_{c}^{2} \quad \sigma_{y y}^{2}=\frac{M_{020}}{M_{000}}-y_{c}^{2} \quad \sigma_{z z}^{2}=\frac{M_{002}}{M_{000}}-z_{c}^{2} \\
\sigma_{x y}^{2}=\sigma_{y x}^{2}=\frac{M_{110}}{M_{000}}-x_{c} y_{c} \quad \sigma_{x z}^{2}=\sigma_{z x}^{2}=\frac{M_{101}}{M_{000}}-x_{c} z_{c} \quad \sigma_{y z}^{2}=\sigma_{z y}^{2}=\frac{M_{011}}{M_{000}}-y_{c} z_{c}
\end{gathered}
$$

The components of the covariance tensor are directly related to the spread of the tracer plume about its center of mass, and can be related to the components of an effective dispersion tensor in the classic advection-dispersion equation (Freyberg 1986). 


\subsection{Simulation Results}

Based on the range and uncertainty of hydraulic properties in the 300 Area, several simulation cases were developed for this model over a range of hydraulic properties, specifically for the very high-permeability Hanford formation in the upper portion of the unconfined aquifer. Cases were also developed with different distributions of hydraulic properties within the Hanford formation using homogeneous properties for the main hydrostratigraphic units, a manually-defined plan-view zonation within the main Hanford formation gravel unit, and stochastic realizations. Details of an example case are provided in the following paragraphs, along with summary simulation results for the different cases that provide a range of estimates for transient groundwater water fluxes and flow directions.

Common material properties for the cases are shown in Table 3.3 and the hydraulic conductivity values for the different cases are listed in Table 3.4. Simulation results provided for each of the cases include comparison of simulated hydraulic head with water-level measurements, water fluxes, and analysis of tracer pulses introduced into the model domain. The differences between simulated and measured water levels (residual differences) are provided for wells from the automated water-level monitoring network during the simulated period. The water fluxes include the instantaneous and cumulative water fluxes for the Columbia River, model boundaries, and sources and sinks over the simulated time period. Tracer pulses were introduced into the model during periods of different river stage/water-table regimes at three different locations in the model: the south end of the north process trenches (316-5), within the south process pond (316-1), and the 307 trench (316-3). Tracer pulse durations were 1 day at 800 gpm $(1,152,000$ gal) over a fixed vertical interval, followed by a drift period to track plume migration (see Figure 3.13). Plots of the tracer plumes are provided at selected times after the injection of the tracer pulses, along with plume velocities calculated from the change in the plume center of mass.

Table 3.3. Common Parameters for Large-Scale 300 Area Model Runs ${ }^{(\text {a) }}$

\begin{tabular}{|c|c|c|c|c|c|c|}
\hline Unit & $\begin{array}{l}\text { Particle } \\
\text { Density } \\
\left(\mathrm{g} / \mathrm{cm}^{3}\right)\end{array}$ & Porosity & $\begin{array}{l}\text { Specific } \\
\text { Storage } \\
(1 / \mathrm{m})\end{array}$ & $\begin{array}{c}\text { Relative } \\
\text { Permeability }\end{array}$ & $\begin{array}{c}\text { Saturation Function } \\
\text { Brooks and Corey } \\
\text { psi, Lambda, and Residual } \\
\text { Saturation } \\
\end{array}$ & $\begin{array}{l}\text { Dispersivity } \\
\text { (m) }\end{array}$ \\
\hline $\begin{array}{l}\text { Hanford } \\
\text { High-K Zone } \\
\text { (u1a) }\end{array}$ & 2.76 & 0.20 & $1.0 \times 10^{-4}$ & $\begin{array}{l}\text { Burdine } \\
\text { (1953) }\end{array}$ & $14.04, \mathrm{~cm}, 1.97,0.16$ & $\begin{array}{l}\alpha_{1}=1 \\
\alpha_{t}=0.1\end{array}$ \\
\hline $\begin{array}{l}\text { Hanford } \\
\text { Low-K Zone } \\
\text { (u1b) }\end{array}$ & 2.76 & 0.20 & $1.0 \times 10^{-4}$ & $\begin{array}{l}\text { Burdine } \\
(1953)\end{array}$ & $14.04, \mathrm{~cm}, 1.97,0.16$ & $\begin{array}{l}\alpha_{1}=1 \\
\alpha_{t}=0.1\end{array}$ \\
\hline $\begin{array}{l}\text { Ringold fine- } \\
\text { grained (u4) }\end{array}$ & 2.65 & 0.43 & $1.0 \times 10^{-4}$ & $\begin{array}{l}\text { Burdine } \\
\text { (1953) }\end{array}$ & $71.31, \mathrm{~cm}, 0.5193,0.1299$ & $\begin{array}{l}\alpha_{1}=1 \\
\alpha_{t}=0.1\end{array}$ \\
\hline $\begin{array}{l}\text { Ringold E } \\
\text { Gravels (u5) }\end{array}$ & 2.65 & 0.25 & $1.0 \times 10^{-4}$ & $\begin{array}{l}\text { Burdine } \\
\text { (1953) }\end{array}$ & $71.31, \mathrm{~cm}, 0.5193,0.1299$ & $\begin{array}{l}\alpha_{1}=0.5 \\
\alpha_{t}=0.1\end{array}$ \\
\hline $\begin{array}{l}\text { River } \\
\text { Alluvium }\end{array}$ & 2.76 & 0.18 & $1.0 \times 10^{-4}$ & $\begin{array}{l}\text { Burdine } \\
\text { (1953) }\end{array}$ & $71.31, \mathrm{~cm}, 0.5193,0.1299$ & $\begin{array}{l}\alpha_{1}=0.5 \\
\alpha_{t}=0.1\end{array}$ \\
\hline $\begin{array}{l}\text { (a) Note: Som } \\
\text { Hanford pe } \\
\text { Hanford ar } \\
\text { Specific st }\end{array}$ & $\begin{array}{l}\text { difference } \\
\text { rticle dens } \\
\text { d Ringold } \\
\text { rage }=0.0\end{array}$ & $\begin{array}{l}\text { in paramet } \\
y=2.65, \mathrm{Ri} \\
\text { orosity }=0 \text {. }\end{array}$ & $\begin{array}{l}\text { s for r5b-flo } \\
\text { er Alluvium }\end{array}$ & $\begin{array}{l}\text { lowrivk case: } \\
\text { rticle density = }\end{array}$ & .65 & \\
\hline
\end{tabular}


Table 3.4. Large-Scale 300 Area Simulations - Hydraulic Conductivity Cases (values in m/d)

\begin{tabular}{|c|c|c|c|c|c|}
\hline Run & $\begin{array}{l}\text { Hanford - } \\
\text { High-K Zone } \\
\text { (u1a) }\end{array}$ & $\begin{array}{l}\text { Hanford - Low-K } \\
\text { Zone (u1b) }\end{array}$ & $\begin{array}{l}\text { Ringold Fine } \\
\text { Grained (u4) }\end{array}$ & $\begin{array}{l}\text { Ringold E } \\
\text { Gravels (u5) }\end{array}$ & $\begin{array}{l}\text { River } \\
\text { Alluvium }\end{array}$ \\
\hline $\begin{array}{l}\text { r5b-a } \\
\text { Location: clam: } \\
\text { /files0/ }\end{array}$ & $\begin{array}{l}\mathrm{Kxy}=8,000 \\
\mathrm{Kz}=800\end{array}$ & N/A & $\begin{array}{l}\mathrm{Kxy}=1 \\
\mathrm{Kz}=0.1\end{array}$ & $\begin{array}{l}\mathrm{Kxy}=40 \\
\mathrm{Kz}=4\end{array}$ & $\begin{array}{l}\mathrm{Kxy}=4 \\
\mathrm{Kz}=4\end{array}$ \\
\hline $\begin{array}{l}\text { r5b-b } \\
\text { Location: moray: } \\
\text { /files0/300ff5-runs/ }\end{array}$ & $\begin{array}{l}\mathrm{Kxy}=7,000 \\
\mathrm{Kz}=700\end{array}$ & N/A & $\begin{array}{l}\mathrm{Kxy}=1 \\
\mathrm{Kz}=0.1\end{array}$ & $\begin{array}{l}\mathrm{Kxy}=40 \\
\mathrm{Kz}=4\end{array}$ & $\begin{array}{l}\mathrm{Kxy}=3 \\
\mathrm{Kz}=3\end{array}$ \\
\hline $\begin{array}{l}\text { r5bz } \\
\text { Location: clam: } \\
\text { /files0/ }\end{array}$ & $\begin{array}{l}\mathrm{Kxy}=7,000 \\
\mathrm{Kz}=700\end{array}$ & $\begin{array}{l}\mathrm{Kxy}=2,000 \\
\mathrm{Kz}=200\end{array}$ & $\begin{array}{l}\mathrm{Kxy}=1 \\
\mathrm{Kz}=0.1\end{array}$ & $\begin{array}{l}\mathrm{Kxy}=40 \\
\mathrm{Kz}=4\end{array}$ & $\begin{array}{l}\mathrm{Kxy}=3 \\
\mathrm{Kz}=3\end{array}$ \\
\hline $\begin{array}{l}\text { r5bz-b } \\
\text { Location: clam: } \\
\text { /files0/ }\end{array}$ & $\begin{array}{l}\mathrm{Kxy}=7,000 \\
\mathrm{Kz}=700\end{array}$ & $\begin{array}{l}\mathrm{Kxy}=2,000 \\
\mathrm{Kz}=200\end{array}$ & $\begin{array}{l}\mathrm{Kxy}=1 \\
\mathrm{Kz}=0.1\end{array}$ & $\begin{array}{l}\mathrm{Kxy}=40 \\
\mathrm{Kz}=4\end{array}$ & $\begin{array}{l}\mathrm{Kxy}=1 \\
\mathrm{Kz}=1\end{array}$ \\
\hline $\begin{array}{l}\text { r5bz-c } \\
\text { Location: moray: } \\
\text { /files0/300ff5-runs/ }\end{array}$ & $\begin{array}{l}\mathrm{Kxy}=7,000 \\
\mathrm{Kz}=700\end{array}$ & $\begin{array}{l}\mathrm{Kxy}=2,500 \\
\mathrm{Kz}=250\end{array}$ & $\begin{array}{l}\mathrm{Kxy}=1 \\
\mathrm{Kz}=0.1\end{array}$ & $\begin{array}{l}\mathrm{Kxy}=40 \\
\mathrm{Kz}=4\end{array}$ & $\begin{array}{l}\mathrm{Kxy}=1 \\
\mathrm{Kz}=1\end{array}$ \\
\hline $\begin{array}{l}\text { r5bz-d } \\
\text { Location: moray: } \\
\text { /files0/300ff5-runs/ }\end{array}$ & $\begin{array}{l}\mathrm{Kxy}=8,000 \\
\mathrm{Kz}=800\end{array}$ & $\begin{array}{l}\mathrm{Kxy}=2,000 \\
\mathrm{Kz}=200\end{array}$ & $\begin{array}{l}\mathrm{Kxy}=1 \\
\mathrm{Kz}=0.1\end{array}$ & $\begin{array}{l}\mathrm{Kxy}=40 \\
\mathrm{Kz}=4\end{array}$ & $\begin{array}{l}\mathrm{Kxy}=1 \\
\mathrm{Kz}=1\end{array}$ \\
\hline $\begin{array}{l}\text { r5b-flow-lowrivk } \\
\text { Location: coral: } \\
\text { /files1/ }\end{array}$ & $\begin{array}{l}\mathrm{Kxy}=6,000 \\
\mathrm{Kz}=600\end{array}$ & N/A & $\begin{array}{l}\mathrm{Kxy}=1 \\
\mathrm{Kz}=0.1\end{array}$ & $\begin{array}{l}\mathrm{Kxy}=40 \\
\mathrm{Kz}=4\end{array}$ & $\begin{array}{l}\mathrm{Kxy}=1 \\
\mathrm{Kz}=1\end{array}$ \\
\hline $\begin{array}{l}\text { Stochastic run2a } \\
\text { Location: bessel: } \\
\text { /files0/300ff5/GG/ } \\
\text { SGSIM_2p_big/runs/ }\end{array}$ & Stochastic & N/A & $\begin{array}{l}\mathrm{Kxy}=1 \\
\mathrm{Kz}=0.1\end{array}$ & $\begin{array}{l}\mathrm{Kxy}=40 \\
\mathrm{Kz}=4\end{array}$ & $\begin{array}{l}\mathrm{Kxy}=4 \\
\mathrm{Kz}=4\end{array}$ \\
\hline $\begin{array}{l}\text { Stochastic run3 } \\
\text { Location: mobius: } \\
\text { /files0/300ff5/ } \\
\text { fy07_run3/ }\end{array}$ & Stochastic & N/A & $\begin{array}{l}\mathrm{Kxy}=1 \\
\mathrm{Kz}=0.1\end{array}$ & $\begin{array}{l}\mathrm{Kxy}=40 \\
\mathrm{Kz}=4\end{array}$ & $\begin{array}{l}\mathrm{Kxy}=4 \\
\mathrm{Kz}=4\end{array}$ \\
\hline $\begin{array}{l}\text { Stochastic run4 } \\
\text { Location: bessel: } \\
\text { /files0/300ff5/GG/ } \\
\text { SGSIM_2p_big/runs/ }\end{array}$ & Stochastic & N/A & $\begin{array}{l}\mathrm{Kxy}=1 \\
\mathrm{Kz}=0.1\end{array}$ & $\begin{array}{l}\mathrm{Kxy}=40 \\
\mathrm{Kz}=4\end{array}$ & $\begin{array}{l}\mathrm{Kxy}=4 \\
\mathrm{Kz}=4\end{array}$ \\
\hline
\end{tabular}




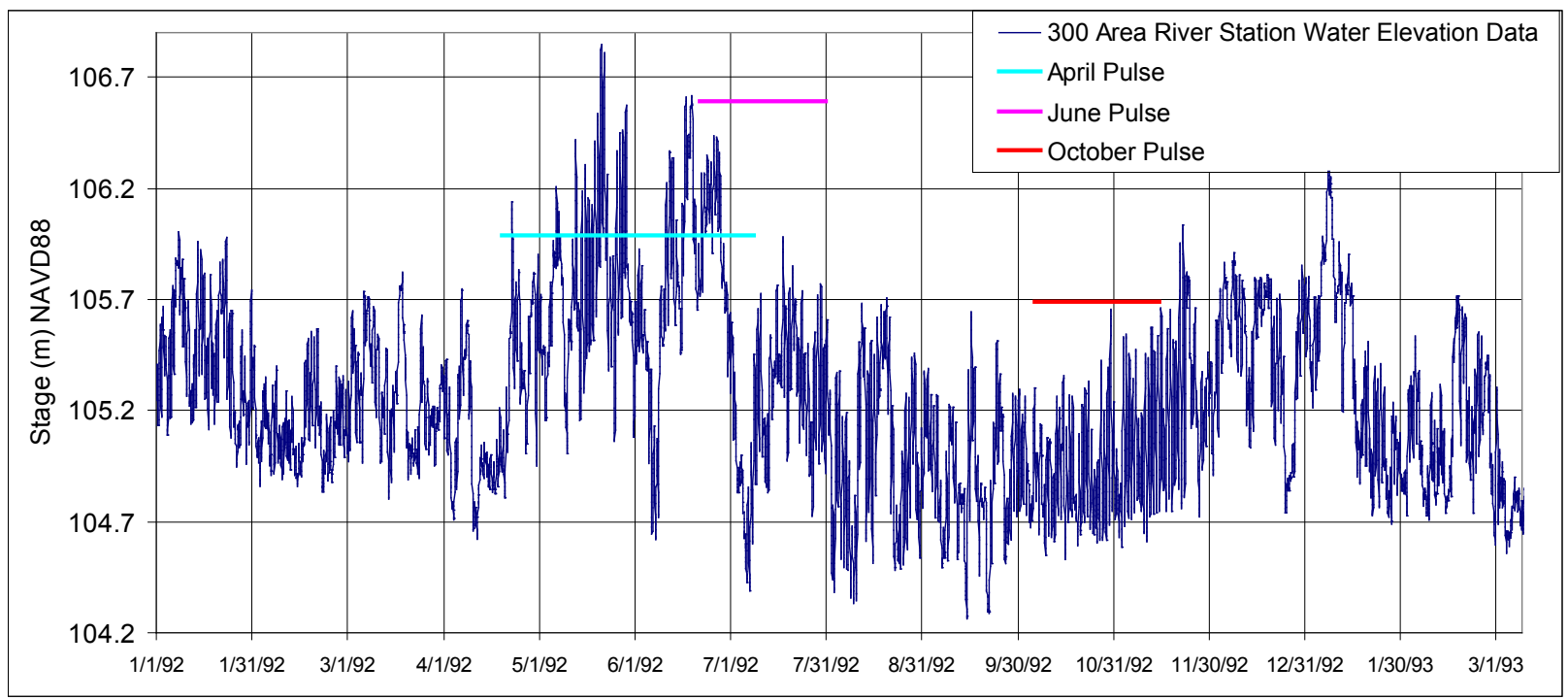

Figure 3.13. River Stage During Simulation Period Showing Times of Tracer Pulses and Drift. Tracers were injected in 24 hours followed by a longer drift period.

The number of cases that could be run was limited by the computational requirements for these large-scale 300 Area model simulations. Groundwater flow simulations for the 1.2-year simulation period with a 2-hour time step required approximately 2 weeks per run on a dual-processor 2.3-gigahertz Intel ${ }^{\circledR}$ Xeon ${ }^{\circledR}$ Linux workstation. ${ }^{1}$ Transport simulations for the tracer pulses had to be conducted separately following the flow simulation results and required up to 4 days for the April 2007 pulse (which had the longest simulated duration).

The following sections describe the detailed example case and discuss the results of all the simulation cases.

\subsubsection{Example Simulation Detailed Results}

Simulations for the larger-scale 300 Area model cases were run from January 1992 through March 1993. A 1-year period with constant boundary condition values equal to those of January 1, 1992, was simulated to supply initial conditions for the transient model. Material, hydraulic, and transport properties for the zones in the example case (r5bz-b) are shown in Tables 3.1 and 3.2. For this simulation, the Hanford formation was subdivided into two lateral zones (as shown in Figure 3.3) Detailed results for a deterministic case of this model with a single hydraulic conductivity for the Hanford formation gravels (r5b-flow-lowrivk, as listed in Table 3.4) are discussed in Peterson et al. (2008a). The following sections discuss the hydraulic head comparison, water fluxes, and simulated tracer pulses for the two-zone Hanford formation gravel case r5bz-b.

\footnotetext{
${ }^{1}$ Intel and Xeon are registered trademarks of Intel Corporation.
} 


\subsubsection{Hydraulic Head Comparison and Residuals}

Figures 3.14, 3.15, and 3.16 show comparisons of simulated hydraulic heads and measured water levels for wells in this example case (r5bz-b). Simulated hydraulic heads are extracted from the node locations closest to the $\mathrm{x}, \mathrm{y}$-well coordinates with three vertical locations across the well screen (s1, s2, and s3). The vertical well-screen locations were determined by the closest nodes to the elevations calculated at the midpoint of the well screen (s2), between the midpoint and the screen top (s1), and between the midpoint and the bottom of the well screen (s3). Due to the well construction, many of the uppermost screen nodes ( $\mathrm{s} 1$ or $\mathrm{s} 2$ ) for the wells were above the water table during portions of the simulation. Two wells (399-5-1 and 399-6-1) were not included in the residual calculations because even the S3 node position was unsaturated during portions of the simulation period.

The wells used for the boundary conditions for the simulation are shown in Figure 3.14. Measured and simulated hydraulic heads for wells within the model domain are shown for near-river wells in Figure 3.15 and for wells located further inland in Figure 3.16.

The difference between the simulated hydraulic heads and the measured water levels are calculated as a residual for each observation. Residuals are calculated for each observation by Equation (3.17):

$$
R=h-h^{*}
$$

where $\mathrm{R}=$ residual

$\mathrm{h}=$ simulated head

$\mathrm{h}^{*}=$ measured head.

Residual values are positive when the simulated values are greater than the measured values, and negative when the simulated values are less than the measured value. Total SSRs for all the observations for each simulation are calculated by Equation (3.18):

$$
S=\sum_{i=1}^{n h}\left(h_{i}-h_{i}^{*}\right)^{2}
$$

where $\mathrm{S}=$ sum of squared residuals

$\mathrm{nh}=$ number of head measurements.

The calculated residuals for this example case are provided in Table 3.5. Figure 3.17 has a plot of these data showing the total positive residual, total negative residual, the SSR, and the root mean squared error (RMSE) for each well. Note the number of observations is not the same for each well. Overall, the simulated water levels have a good fit to the measured values. As shown in Figure 3.17, the near-river wells had the largest residuals. Additional damping of the near-river well response to river stage fluctuations may be needed. The river alluvium layer is important in dampening the water-level responses in these wells from fluctuations in the Columbia River stage. Results from preliminary simulations without the river alluvium zone were dominated by the large head residuals in the near-river wells (a comparison is provided in the cases described in Section 4.0 for the small-scale model). 

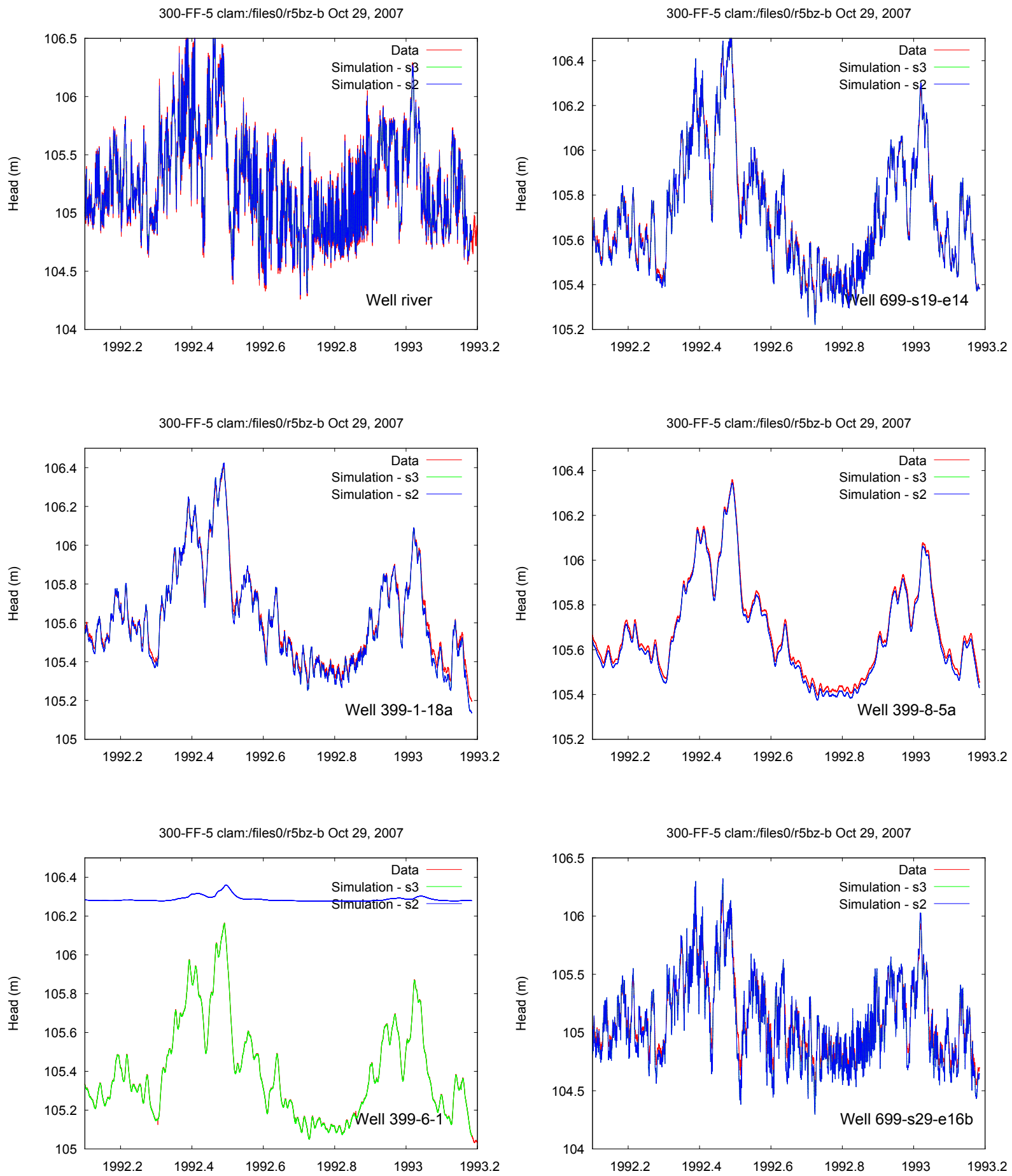

Figure 3.14. Comparison of Simulated Hydraulic Heads and Measured Water Levels for Boundary Wells. The s2 and $\mathrm{s} 3$ are simulation results from nodes at two depths across the well screen (see Section 3.2.1.1 for additional details). S2 is above the water table for well 399-6-1. 

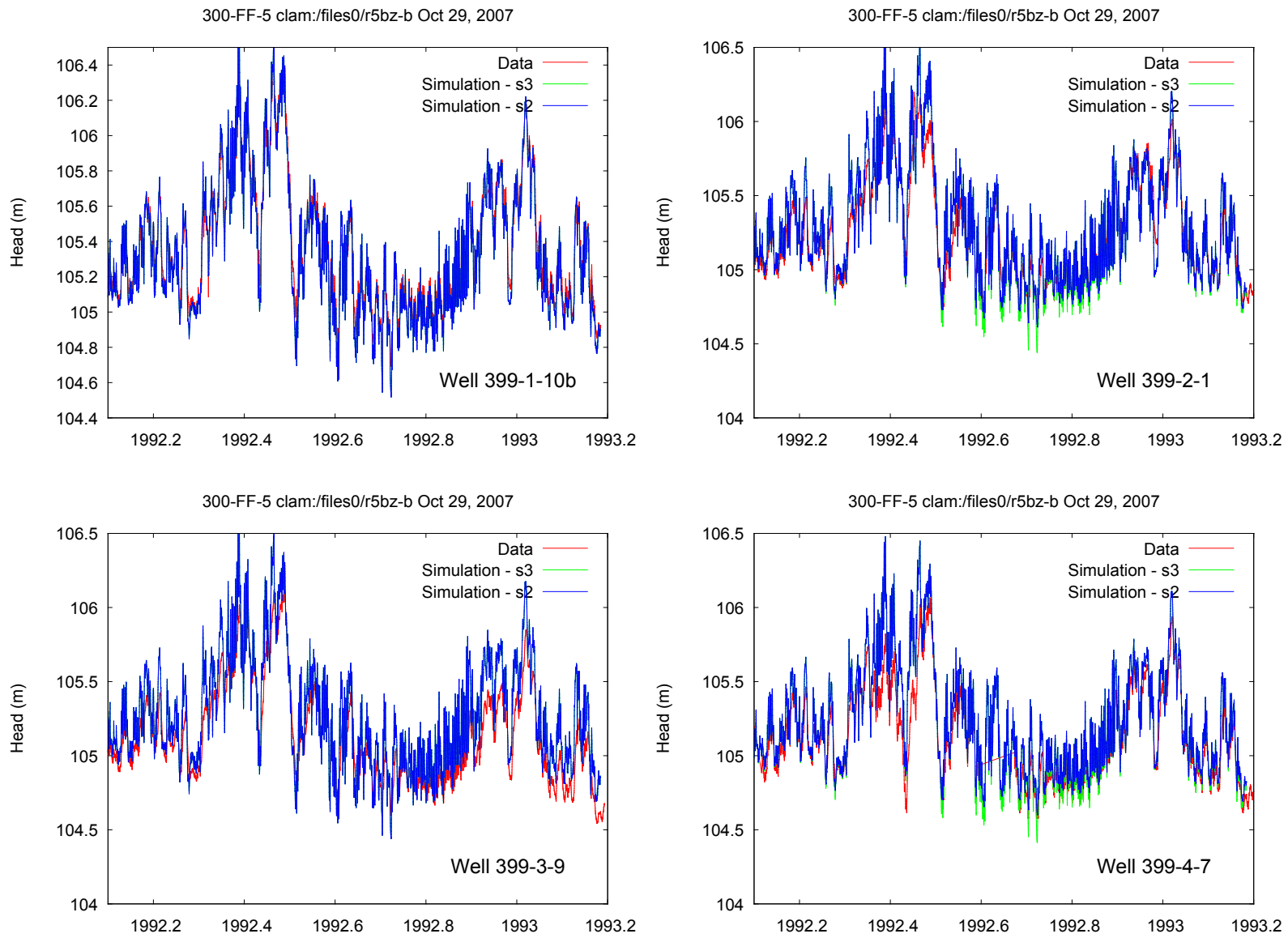

Figure 3.15. Comparison of Simulated Hydraulic Heads and Measured Water Levels for Selected Near-River Wells. The s2 and s3 are simulation results from nodes at two depths across the well screen (see Section 3.2.1.1 for additional details). Note: Data gap for well 399-4-7 during a portion of summer. 

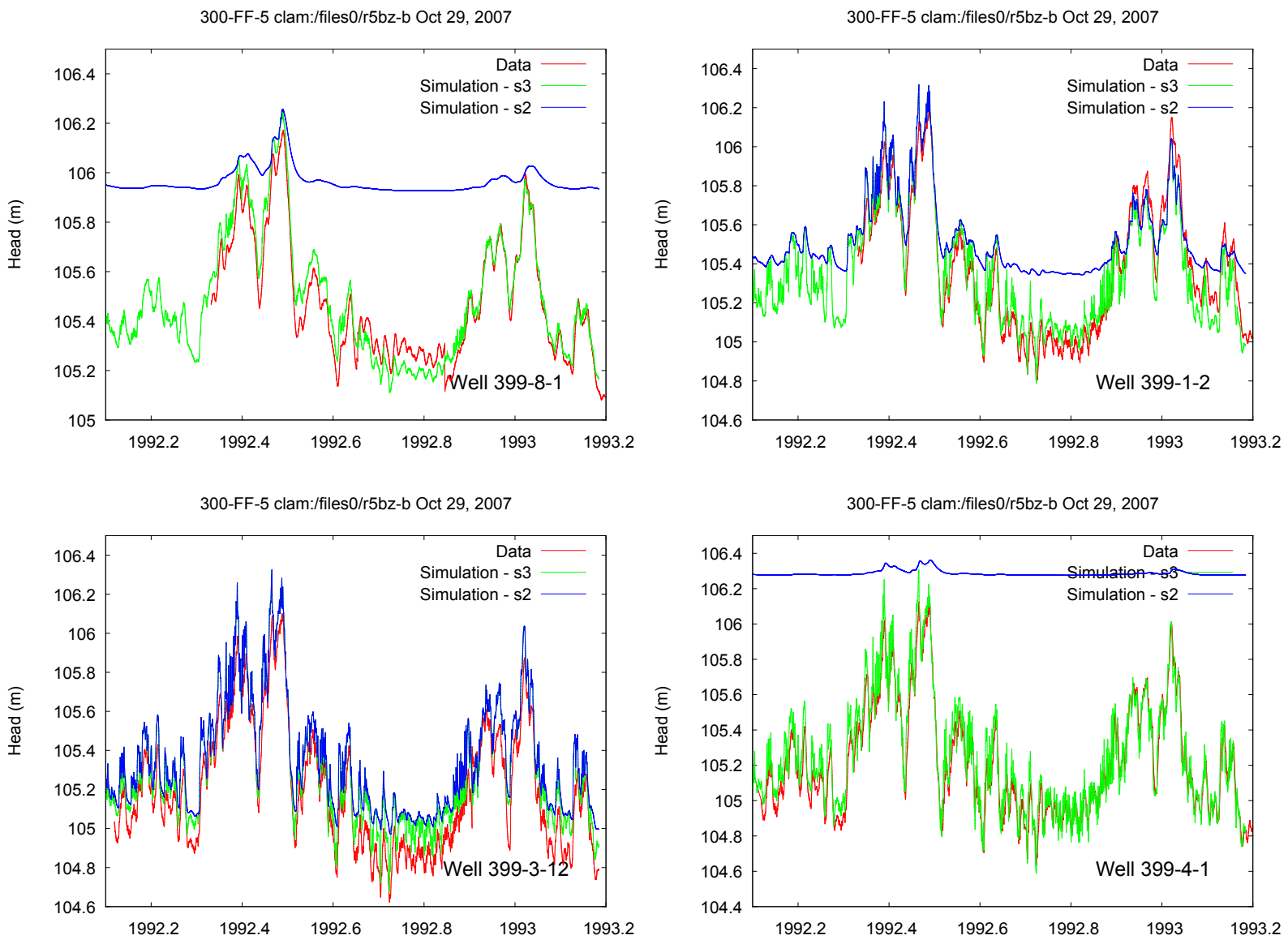

Figure 3.16. Comparison of Simulated Hydraulic Heads and Measured Water Levels for Selected Inland Wells. The s2 and $\mathrm{s} 3$ are simulation results from nodes at two depths across the well screen (see Section 3.2.1.1 for additional details). S2 is above the water table during portions of the simulation period wells 399-8-1, 3991-2, and 399-4-1. 
Table 3.5. Detailed Hydraulic Head Residuals Calculated for the Example Case (r5bz-b). Residuals are calculated from simulated value - measured value (e.g., positive residuals when the simulated values are greater than the measured value). See Section 3.2.1.1 for additional details on residual calculations. Boundary well 399-6-1 is omitted from these calculations.

\begin{tabular}{lcrrrrrr}
\hline Well Name & $\begin{array}{c}\text { Number of } \\
\text { Observations }\end{array}$ & $\begin{array}{c}\text { Number of } \\
\text { Positive } \\
\text { Residuals }\end{array}$ & $\begin{array}{c}\text { Number of } \\
\text { Negative } \\
\text { Residuals }\end{array}$ & $\begin{array}{c}\text { Sum of } \\
\text { Positive } \\
\text { Residuals }\end{array}$ & $\begin{array}{c}\text { Sum of } \\
\text { Negative } \\
\text { Residuals }\end{array}$ & $\begin{array}{c}\text { Sum of } \\
\text { Squared } \\
\text { Residuals }\end{array}$ & $\begin{array}{c}\text { Root Mean } \\
\text { Squared } \\
\text { Error (m) }\end{array}$ \\
\hline 399-1-2 & 7,478 & 4,547 & 2,931 & 384.15 & -304.26 & 85.91 & 0.107 \\
399-1-1 & 9,544 & 3,570 & 5,974 & 353.72 & -620.99 & 155.39 & 0.128 \\
399-1-10b & 9,675 & 2,574 & 7,101 & 104.40 & -398.59 & 41.45 & 0.065 \\
399-1-16b & 9,720 & 6,716 & 3,004 & 617.35 & -186.24 & 113.03 & 0.108 \\
399-1-18a & 9,729 & 1,876 & 7,853 & 19.77 & -177.95 & 6.14 & 0.025 \\
399-1-7 & 8,532 & 6,571 & 1,961 & 569.65 & -101.62 & 90.16 & 0.103 \\
399-1-8 & 9,655 & 8,092 & 1,563 & 864.75 & -82.13 & 143.72 & 0.122 \\
399-2-1 & 9,711 & 6,368 & 3,343 & 769.47 & -289.92 & 194.47 & 0.142 \\
399-2-2 & 4,167 & 2,347 & 1,820 & 209.38 & -129.82 & 45.23 & 0.104 \\
399-3-9 & 9,730 & 8,337 & 1,393 & $1,487.52$ & -121.56 & 394.35 & 0.201 \\
399-3-12 & 9,349 & 8,958 & 391 & $1,202.98$ & -17.74 & 199.19 & 0.146 \\
399-4-1 & 9,352 & 6,369 & 2,983 & 518.24 & -127.26 & 74.68 & 0.089 \\
399-4-7 & 8,699 & 7,612 & 1,087 & $1,019.57$ & -46.04 & 245.09 & 0.168 \\
399-8-1 & 7,473 & 4,998 & 2,475 & 322.85 & -141.14 & 39.21 & 0.072 \\
399-8-5a & 9,729 & 0 & 9,729 & 0.00 & -198.17 & 4.31 & 0.021 \\
699-s19-e14 & 9,730 & 2,098 & 7,632 & 24.50 & -134.42 & 3.76 & 0.020 \\
699-s29- & & & & & & & 0.082 \\
e16b & 9,704 & 2,581 & 7,123 & 114.40 & -527.00 & 65.43 & 0.112 \\
All & 151,977 & 83,614 & 68,363 & $8,582.70$ & $-3,604.82$ & $1,901.52$ & \\
\hline
\end{tabular}



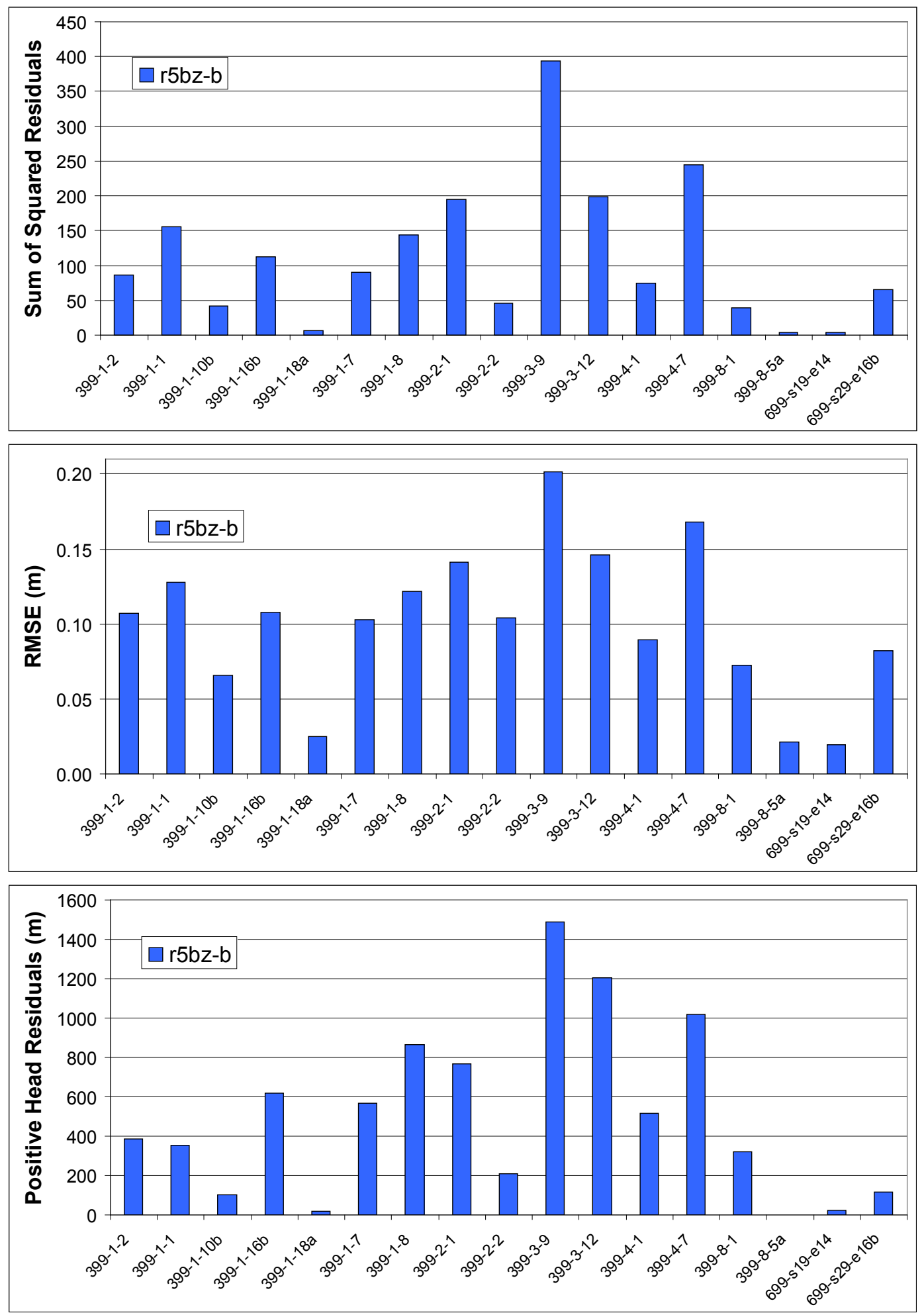

Figure 3.17. Calculated Head Residuals for Large-Scale 300 Area Model Example Case (r5bz-b). Note that the number of observations is not the same for each well (see Table 3.5). 


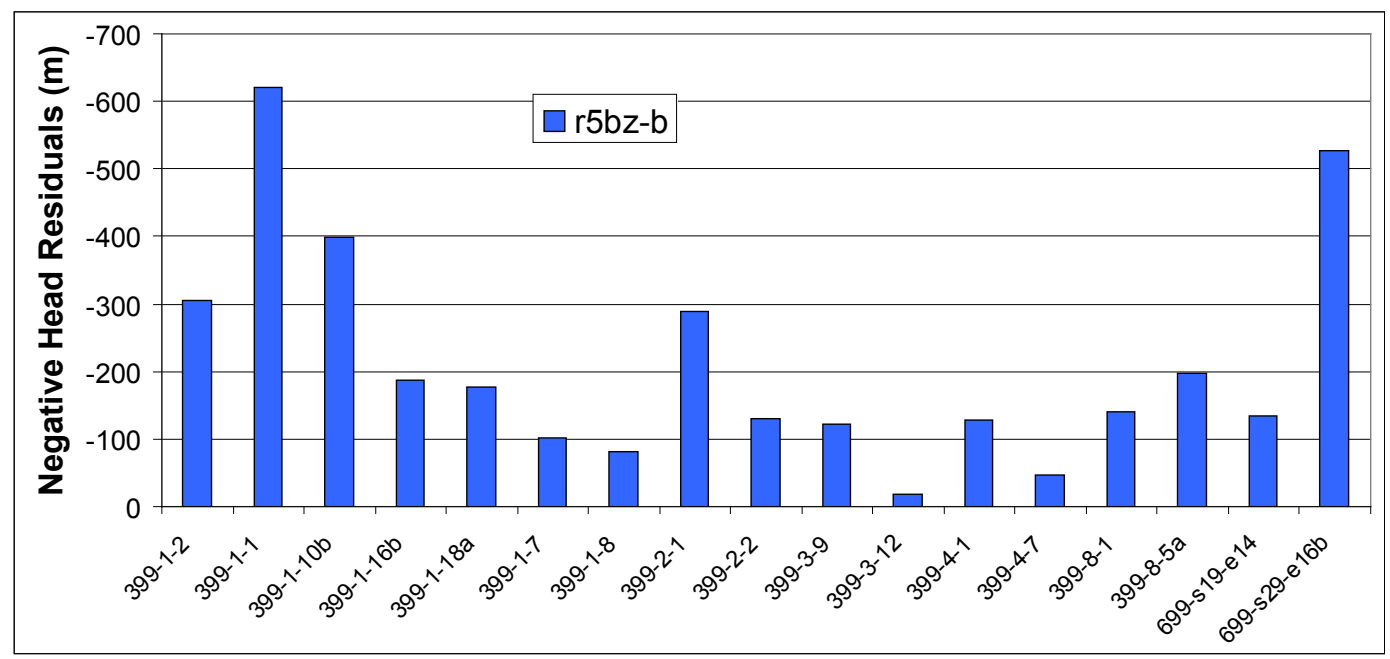

Figure 3.17. (Cont.)

\subsubsection{Water Fluxes}

Figure 3.18 shows the simulated water fluxes for the example case r5bz-b during the simulated period along the model boundaries, including the Columbia River boundary. The water fluxes along the river boundary have the largest range and show daily and seasonal changes in direction. The shoreline distance of the river for this model is $3019 \mathrm{~m}$ (9904 ft) (distance from 699-S19-E14 to 699-S29-E16B). Fluxes along the western and northern boundaries were predominantly into the model domain (negative values) and fluxes along the southern boundary were predominantly out of the model domain (positive values). Cumulative fluxes along the model boundaries during the simulation period are shown in Figure 3.19. Cumulative fluxes along the northern and western boundaries were relatively constant over the simulated time period; however, there were significant seasonal changes in the direction and rates at the river and southern boundaries. A summary of the cumulative fluxes along the model boundaries for a 1-year period, from February 1992 to February 1993, is shown in Figure 3.20. Natural recharge from the 316-5 trench and the discharge from well 399-4-12 are also shown in this figure for comparison to other boundary fluxes. For this period, the net water flux along the river boundary was into the river for the example case. However, the cumulative river fluxes were into the model domain during the spring when the river stage was high, as shown in Figure 3.19. Also shown in Figure 3.19, cumulative fluxes at the river boundary were higher, directed both into and out of the model domain, during portions of the year than the value at the end of this period (i.e., February 1993). The simulated river fluxes are strongly influenced by the hydraulic conductivities specified for the river alluvium and near-river Hanford formation.

Cumulative fluxes for the simulation period (Figure 3.19) show the impact of the seasonal changes of the Columbia River stage on the simulated direction and magnitude of the river boundary fluxes. During the first quarter of 1992 (an intermediate river stage period as shown in Figure 3.13), the cumulative groundwater discharge was relatively constant with slight inflow followed by outflow. The net input to the aquifer from the river increased significantly during the second quarter of 1992, which was the high-river stage period. Following the high-river stage period in July 1992, net discharge to the river occurred at a much greater rate than earlier in the year as a result of the steeper gradients between the elevated water table and low-river stage. The water discharge rates to the river decreased for the rest of 
1992, and the high-river stage that occurred again in January 1993 caused inflow into the model domain from the river, which reduced the annual net discharge for the simulated period.

The simulated groundwater flux into the model was relatively constant during the simulated period along the northern and western boundaries, as shown in Figure 3.19. Groundwater flux out of the model domain was relatively constant along the southern boundary for the first half of the 1992. The flux along the southern boundary slowed and reversed direction during the summer when the river stage dropped during the period with the greatest discharge out of the model on the river boundary. The simulated net discharge picked up again on the southern boundary in late summer of 1992 and was relatively constant for the remainder of the simulation period.

\subsubsection{Tracer Pulses}

Tracer pulses were introduced into the model during periods of different river stage/water-table regimes concurrently at three different locations in the model: the south end of the north process trenches (316-5), within the south process pond (316-1), and at the 307 trench (316-3). Tracer injection was simulated for 24 hours at 3,030 Lpm (800 gpm) for a total volume of 4,361,000 L (1,152,000 gal) over a fixed vertical interval, followed by a drift period, during which the tracer plume migration was tracked. The time periods of the three tracer pulse injections and drift tracking, shown in Figure 3.13 along with the river stage, are as follows: April 1992 during the initial large increase in the river stage for the year; June 1992 during high-river stage, which is followed by a steep drop; and October 1992 during relatively low-river stage conditions.

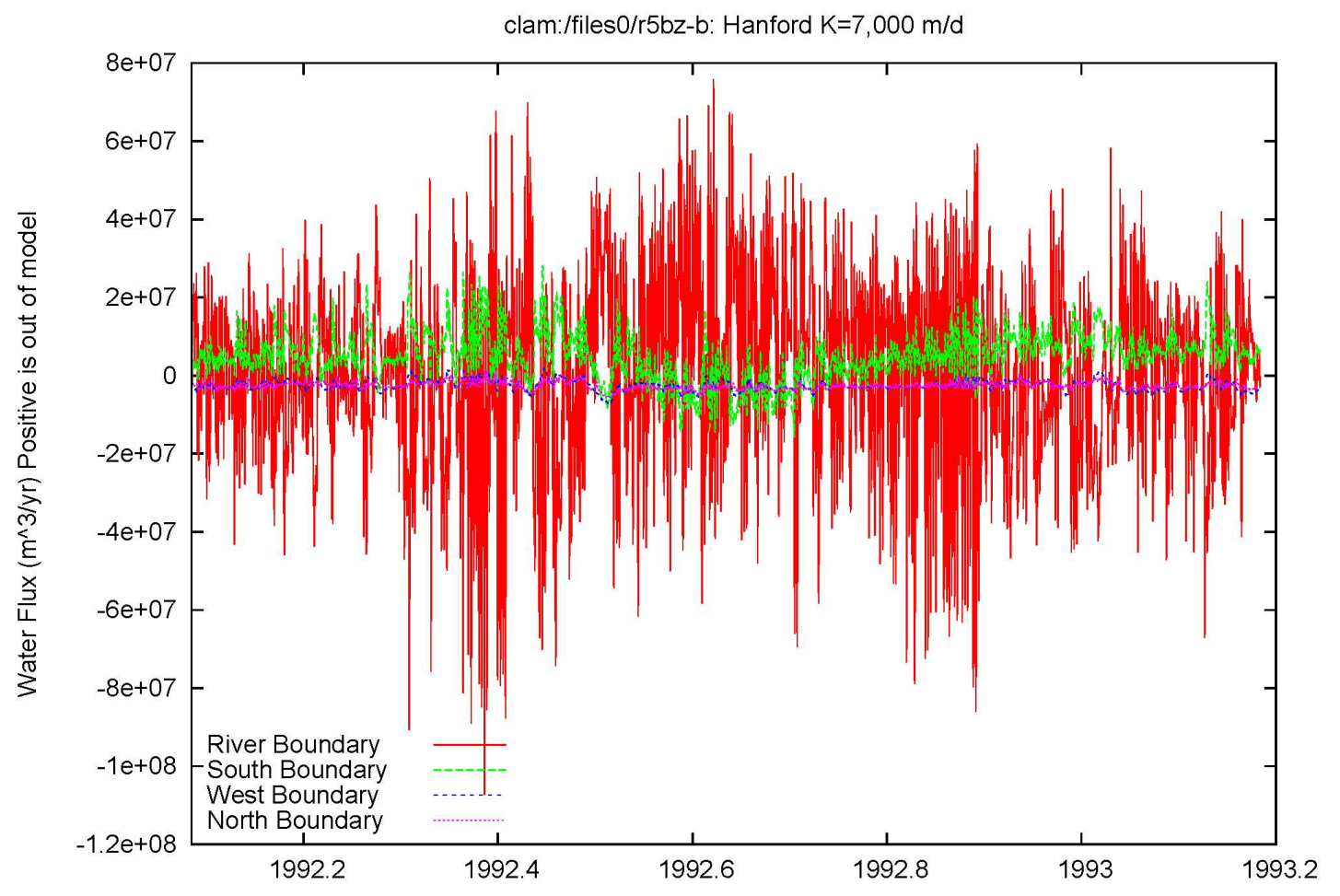

Figure 3.18. Simulated Instantaneous Water Fluxes Calculated for Model Boundaries (r5bz-b run) 


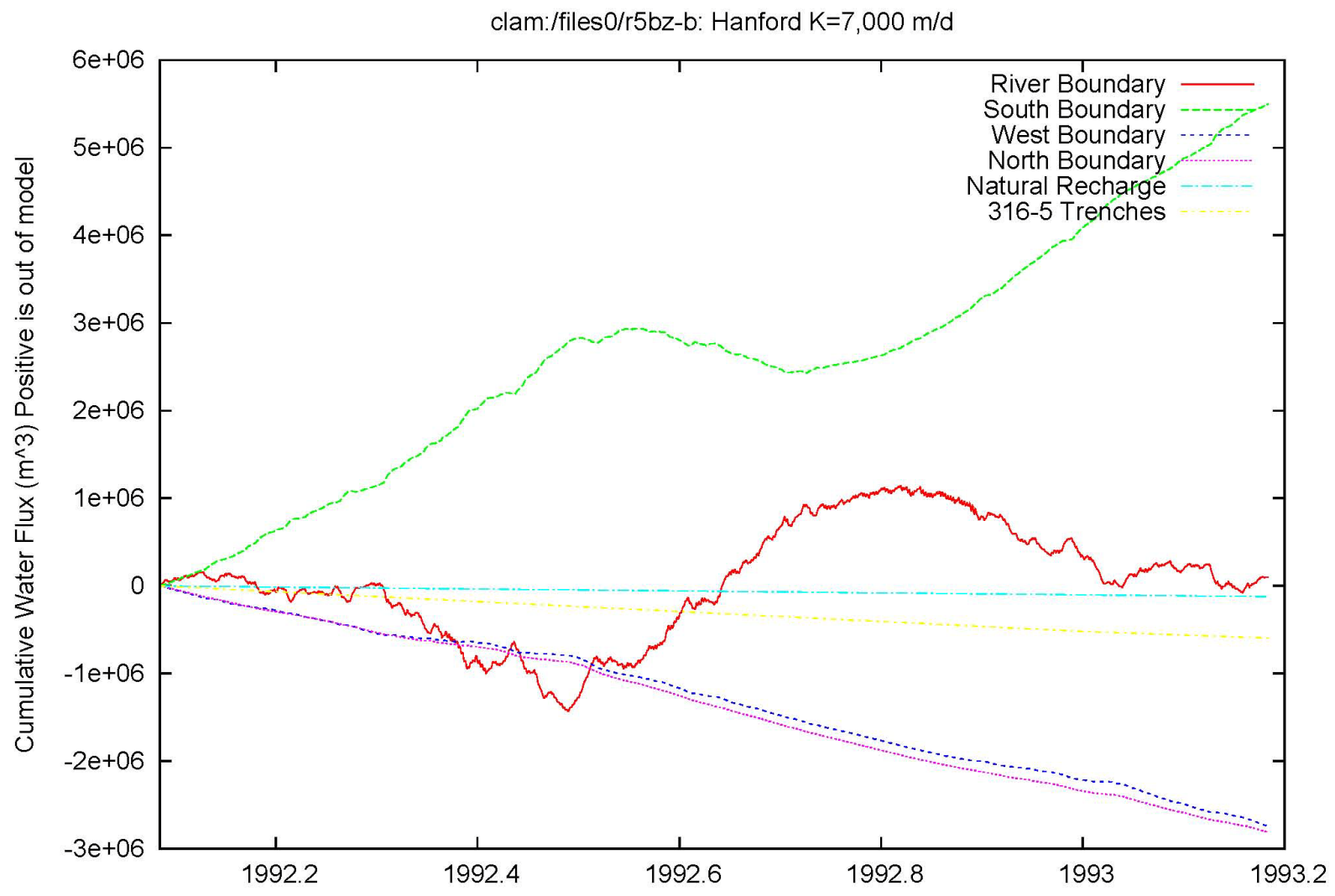

Figure 3.19. Simulated Cumulative Net Water Fluxes Calculated for Model Boundaries (r5bz-b run). Simulated discharge from production well 399-4-12 was $+754,000 \mathrm{~m}^{3}$ during the period. 


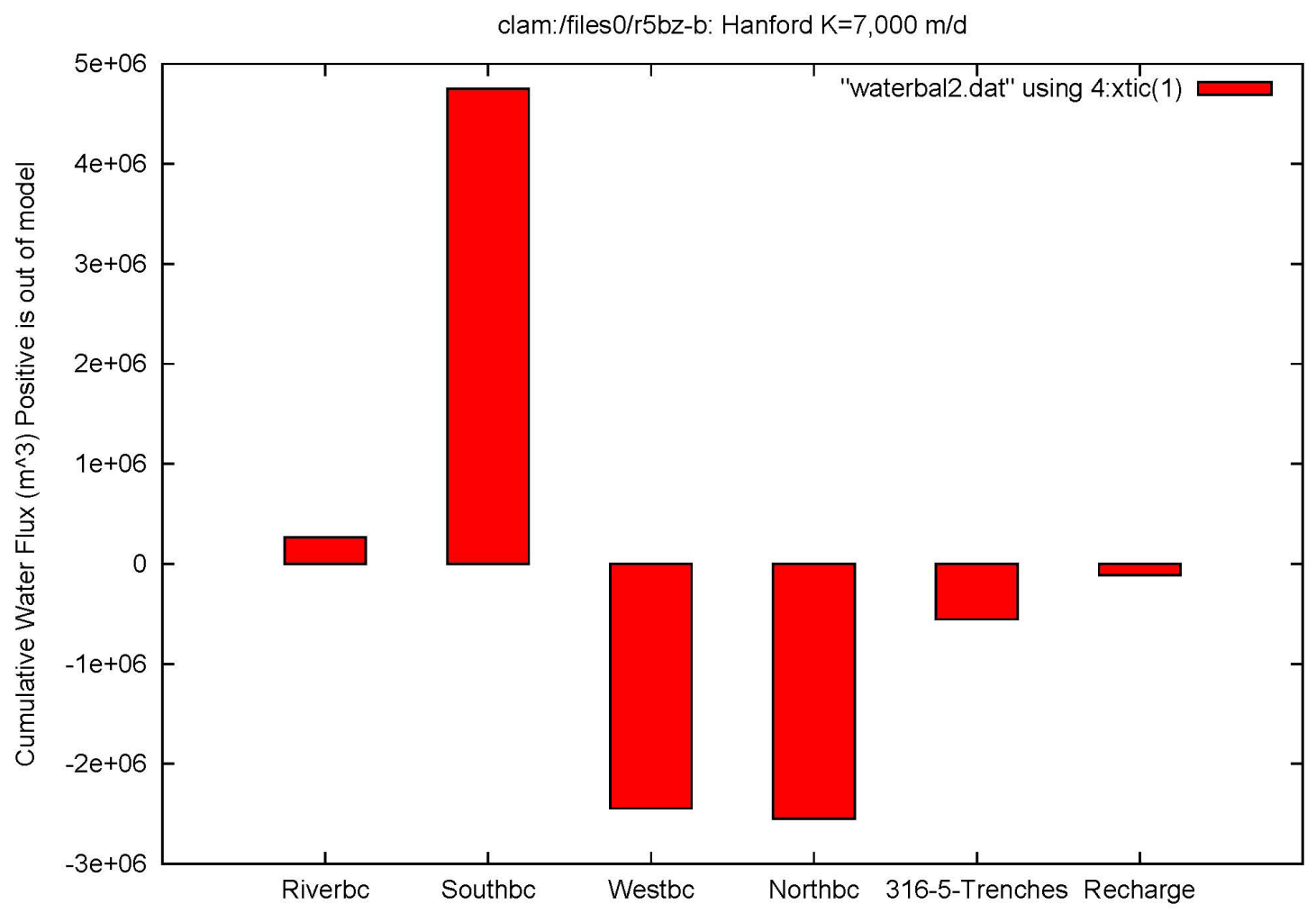

Figure 3.20. Simulated Annual Cumulative Water Flux for Period from February 1, 1992, to February 1, 1993. Shoreline distance $=3,019 \mathrm{~m}$. Simulated discharge from production well 399-4-12 was $+754,000 \mathrm{~m}^{3}$ during the period.

Plots of the tracer plumes immediately after the tracer injections and at selected times during the drift period are shown in Figure 3.21, 3.22, and 3.23 for the 1992 April, June, and October periods, respectively. In the April pulse, as shown in Figure 3.21, the tracer plumes migrate southwest during this period of rising river stage. The tracer pulse at the north process trenches differ from the more symmetrical plumes at the other locations due to the simulated water discharge in the north process trenches (see Section 3.1.4). For the June tracer pulse (Figure 3.22), the plumes initially migrate to the southwest while the river stage is still high, but then rapidly moves to the east when the river stage drops at the end of June (see Figure 3.13). For the low-river stage tracer pulse in October (Figure 3.23), the plumes migrate toward the east during the drift stage.

Tracer plume drift velocities were calculated by the change in the position of the center of mass (first moment) for each of the plumes, as described in Section 3.1.6. The tracer velocities for each of the three tracer pulses at the three different periods are shown in Figure 3.24. The simulated plume migration velocities were highly variable, with values up to $34 \mathrm{~m} / \mathrm{d}(112 \mathrm{ft} / \mathrm{d})$. The highest velocities occurred during the steep drop in river stage that followed the period of high-river stage when the gradients between the water-table elevation and river stage were the highest.

While there are some differences in conditions, a general comparison can be made between the simulated low-river stage tracer plume at the south end of the north process pond in this example case (Figures 3.23 and 3.24), and the polyphosphate tracer test conducted in December 2006 (discussed in Section 2.3.3). The differences in conditions include discharge to the north process trenches that was 
included in the simulation (which was not operating during the polyphosphate tracer test) and specific river stage during these times. The simulated tracer plume migrated toward the east (Figure 3.23) with velocities ranging from 0.39 to $19 \mathrm{~m} / \mathrm{d}$ (mean of $8.2 \mathrm{~m} / \mathrm{d}$ ). The preliminary results of the phosphate tracer test showed the tracer plume migrating toward the southeast at approximately $15 \mathrm{~m} / \mathrm{d}(50 \mathrm{ft} / \mathrm{d})$.

Additionally, hydraulic gradient directions calculated from the automated water-level monitoring network for 2006 show a southeast trend (see Section 2.3.1) during low-river stage periods.

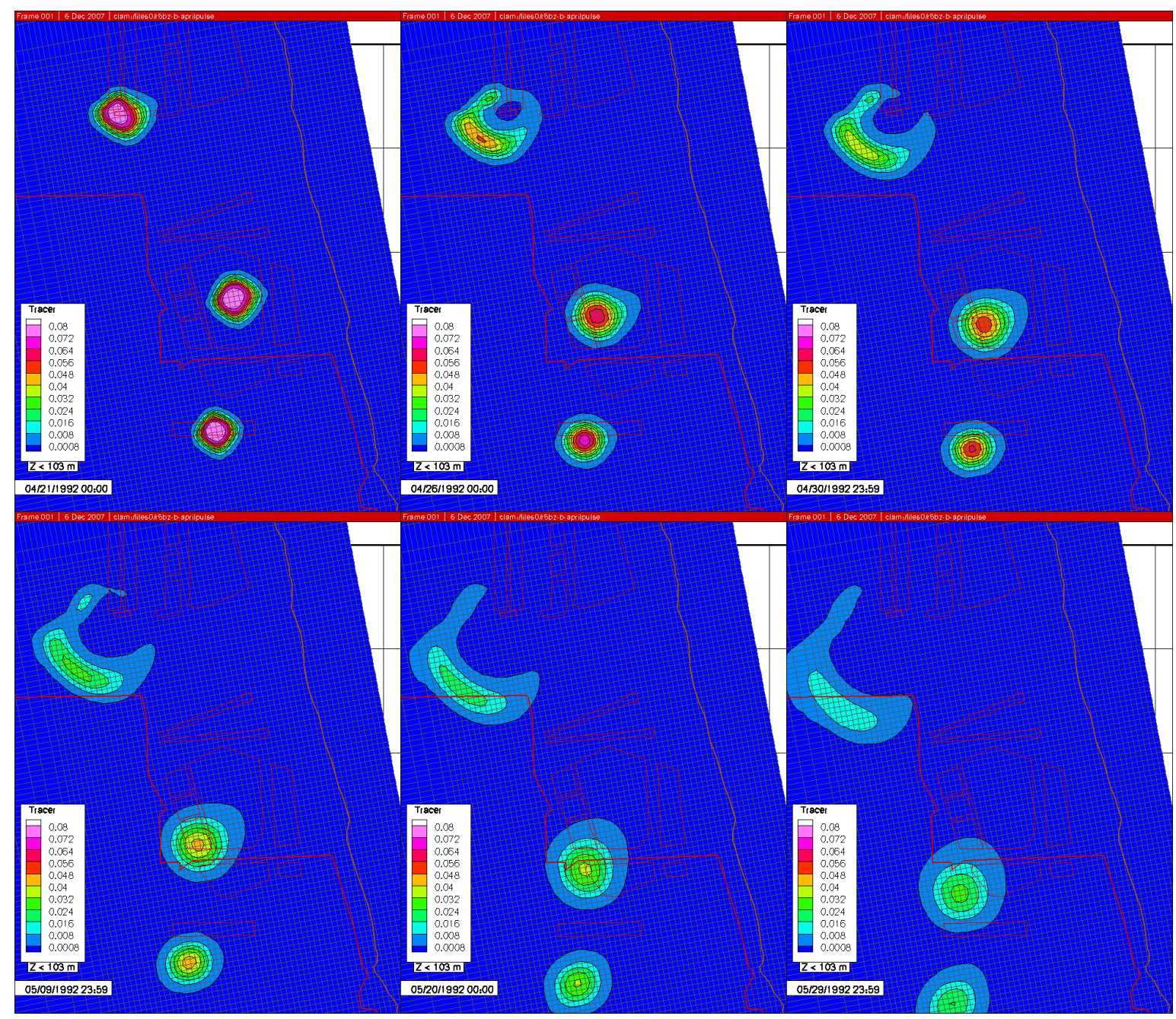

Figure 3.21. Simulated Conservative Tracer-April 20, 1992 Pulse; Initial High-River Stage Period. Plots show the plumes at the end of the 1-day pulse and at 5, 10, 20, 30, and 40 elapsed days. Upper-left plot shows the starting locations of tracer plumes. 


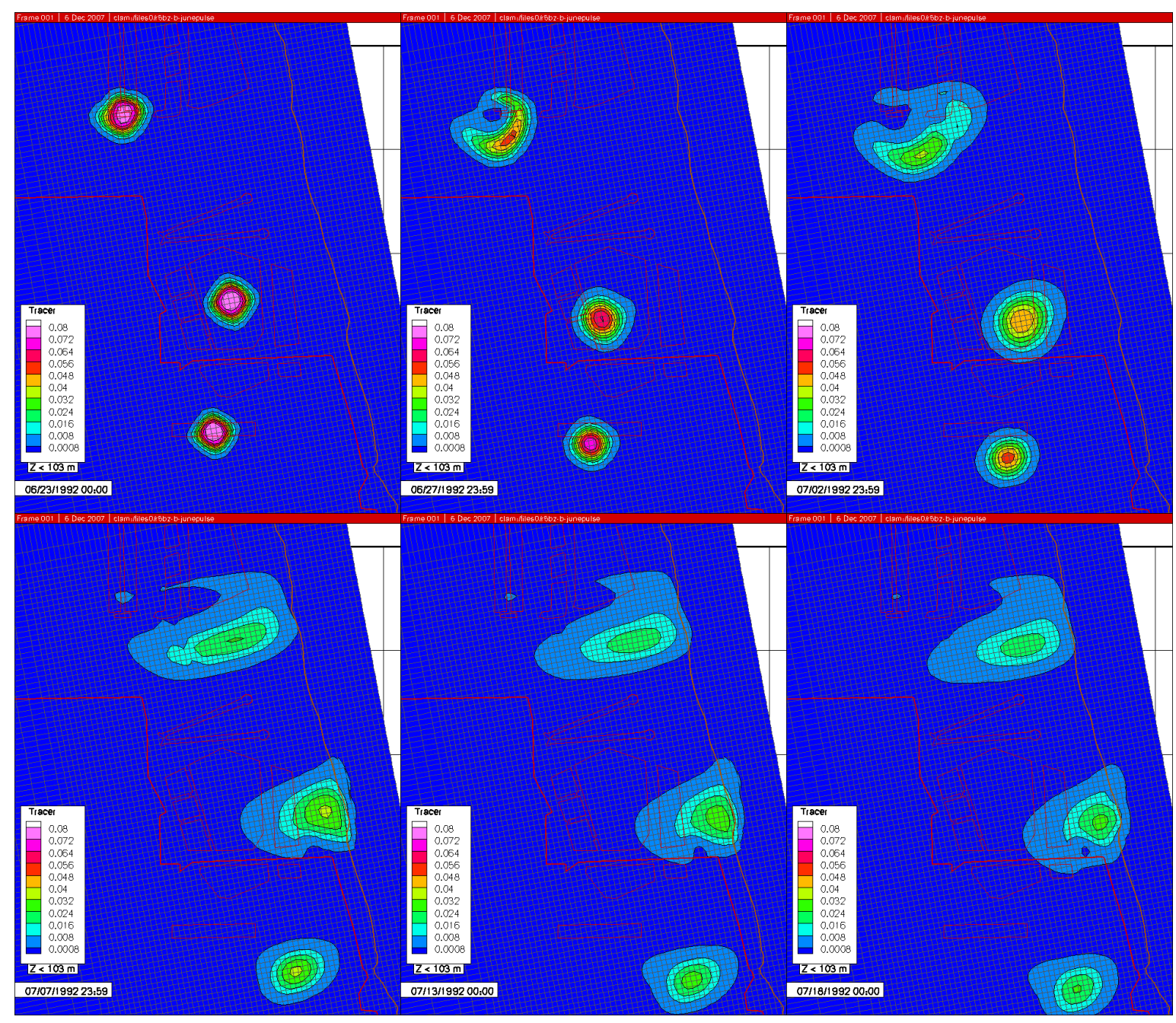

Figure 3.22. Simulated Conservative Tracer- June 22, 1992 Pulse; High- to Low-River Stage Period. Plots show the plumes at the end of the 1-day pulse and at 5, 10, 15, 20, and 25 elapsed days. 


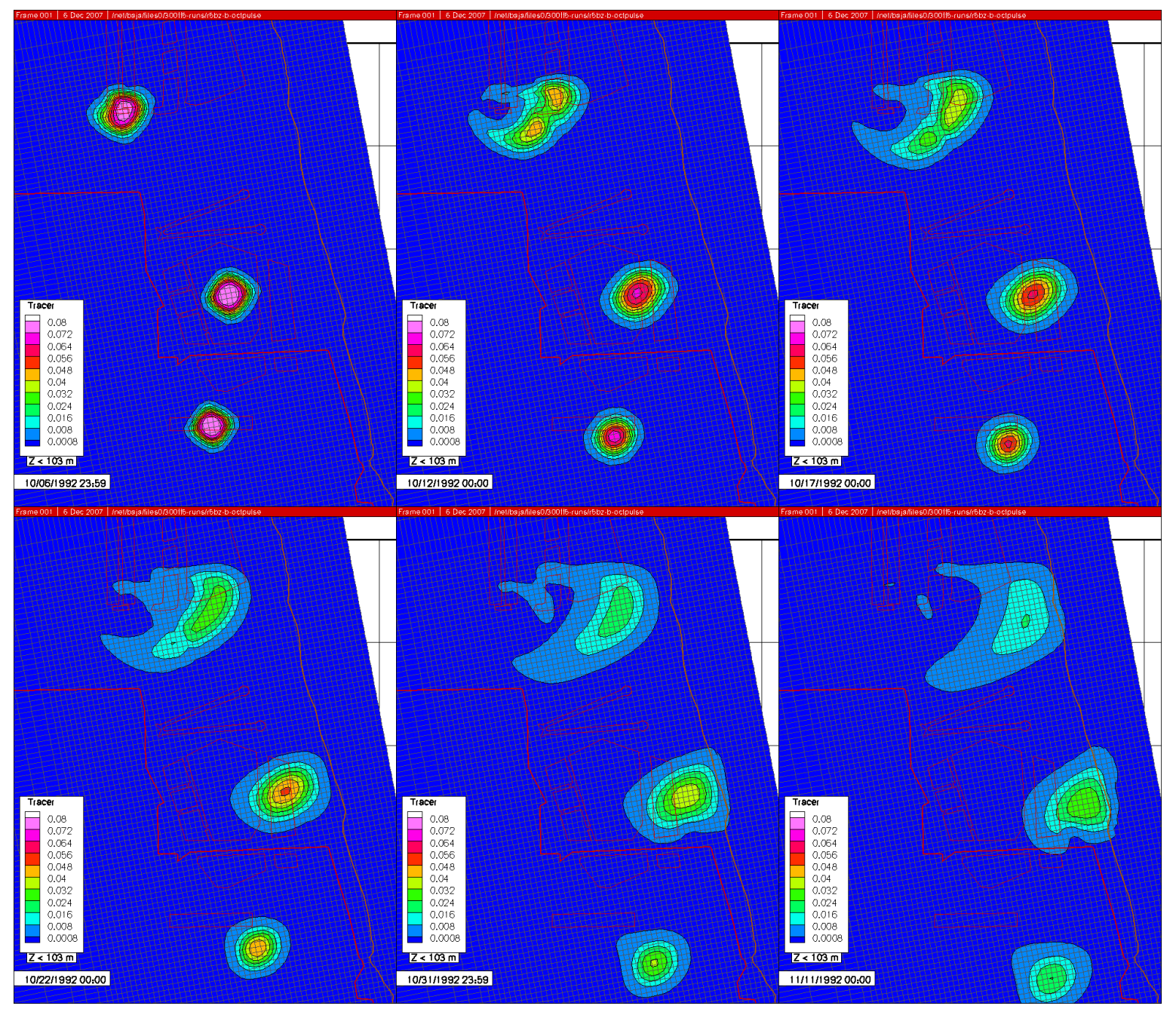

Figure 3.23. Simulated Conservative Tracer- October 6, 1992, Pulse; Low-River Stage Period. Plots show the plumes at the end of the 1-day pulse and at 5, 10, 15, 25, and 35 elapsed days. 

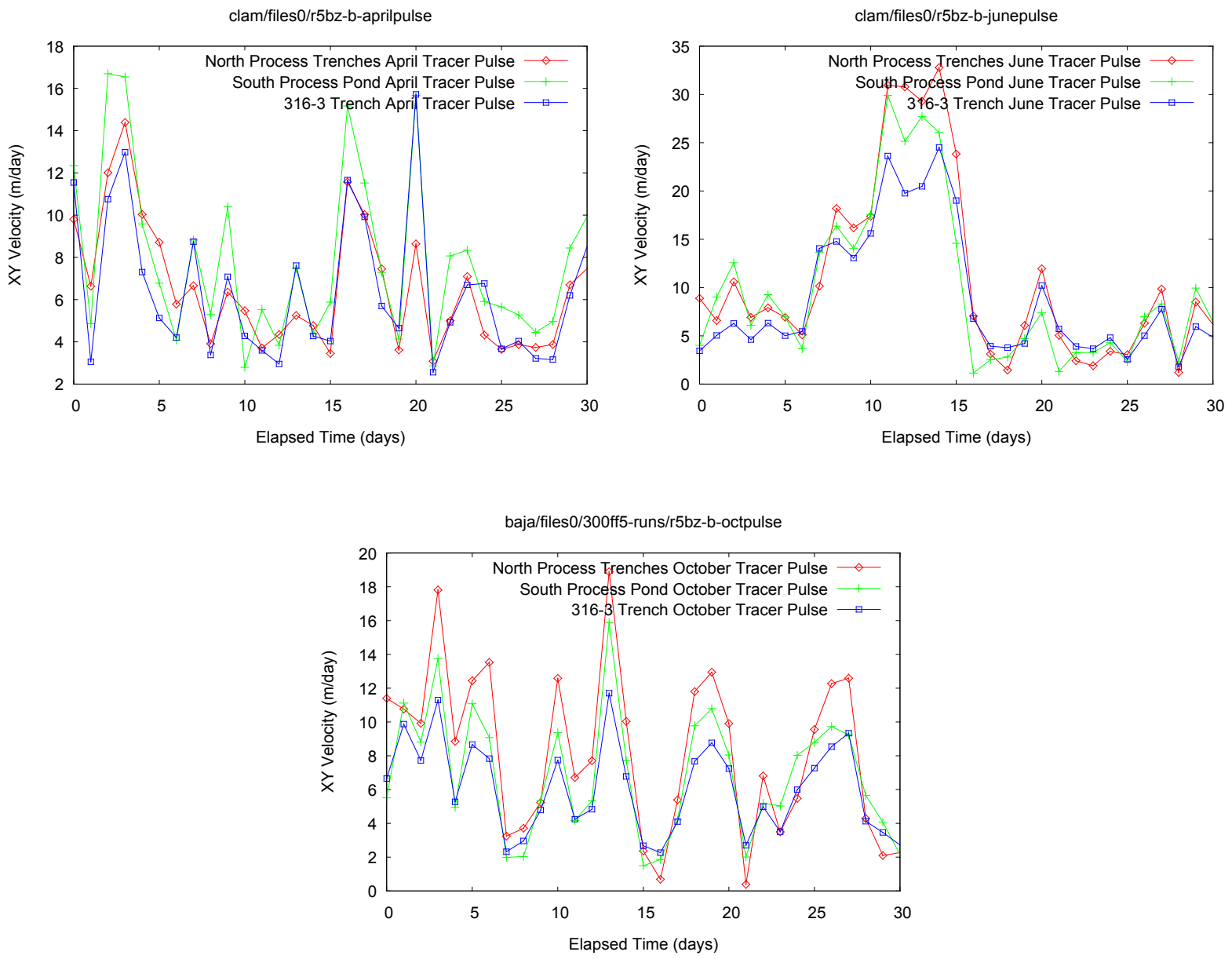

Figure 3.24. Plume Center-of-Mass Horizontal Velocity Magnitudes for April, June, and October 1992 Conservative Tracer Pulses

\subsubsection{Large-Scale 300 Area Model Cases}

Three types of cases were run for the large-scale 300 Area model: 1) homogeneous cases, which specified uniform properties for each of the major hydrostratigraphic units; 2) zoned cases with the main Hanford formation gravel unit subdivided into two zones; and 3) stochastic heterogeneous cases.

Table 3.4 lists the simulation matrix that contains the simulation names and the specified hydraulic conductivity values. Table 3.3 lists the common parameter values for these cases. For the stochastic heterogeneous cases, only three cases were run for comparison with the results of the deterministic cases. The SSR for hydraulic head, calculated using Equation (3.17), are plotted in Figures 3.25 and 3.26 by run and by well. Only one of the stochastic heterogeneous cases is shown in Figure 3.25 (the lowest SSR stochastic heterogeneous run); the remaining cases are shown in Figure 3.26.

Overall run r5bz-b (the two-zone case used as the example run in Section 3.2.1) had the lowest SSR. However, a number of other runs had a SSR that was very close to the lowest value case (see Figure 3.25). As in the example case, most of the highest hydraulic head SSRs for these runs were for near-river wells (e.g. 399-3-9, 399-2-1, 399-1-1, and 399-4-7) as shown in Figure 3.25. 

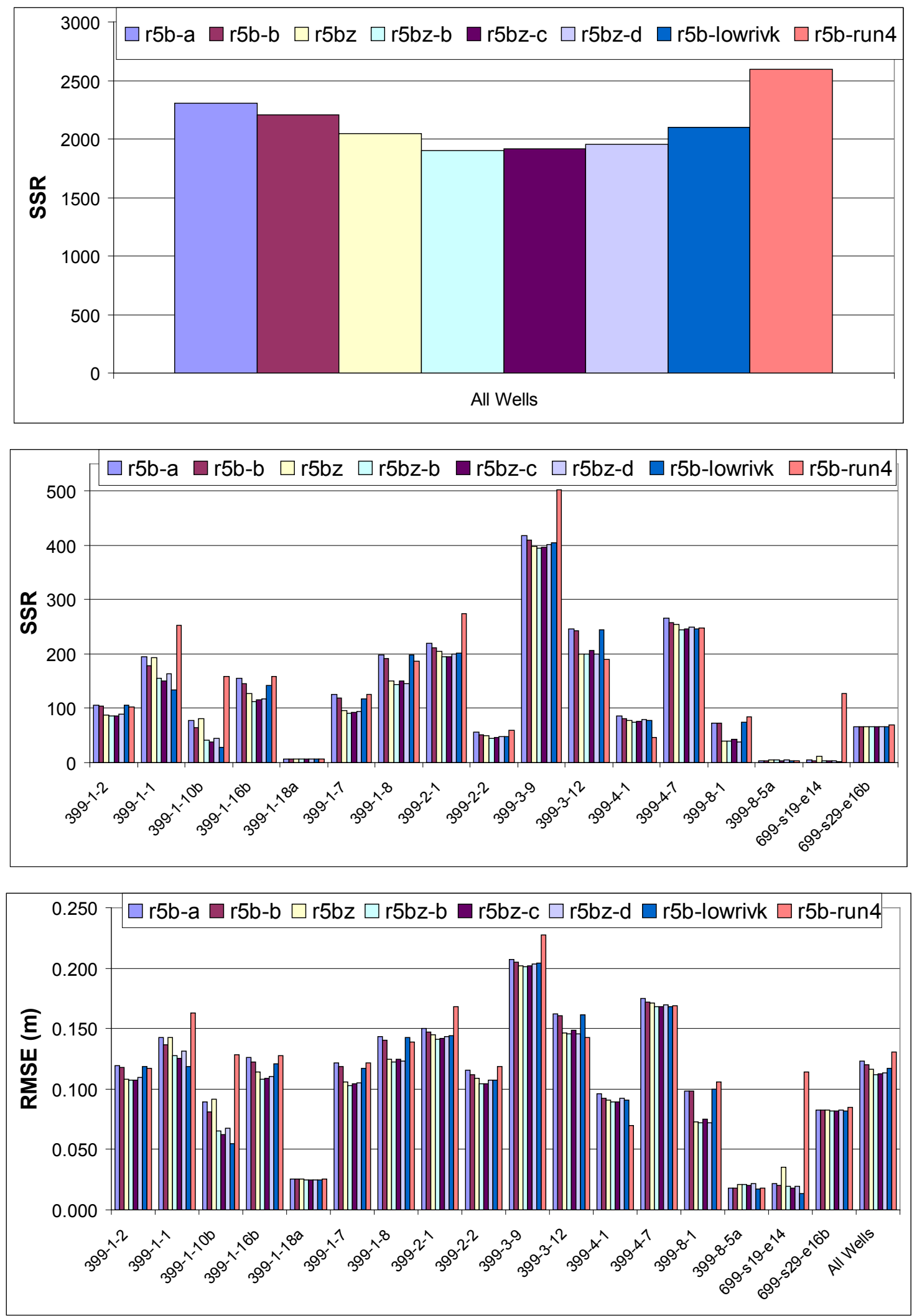

Figure 3.25. Comparison of Sum-of-Squared Hydraulic Head Residuals for Large-Scale 300 Area Model Simulations 

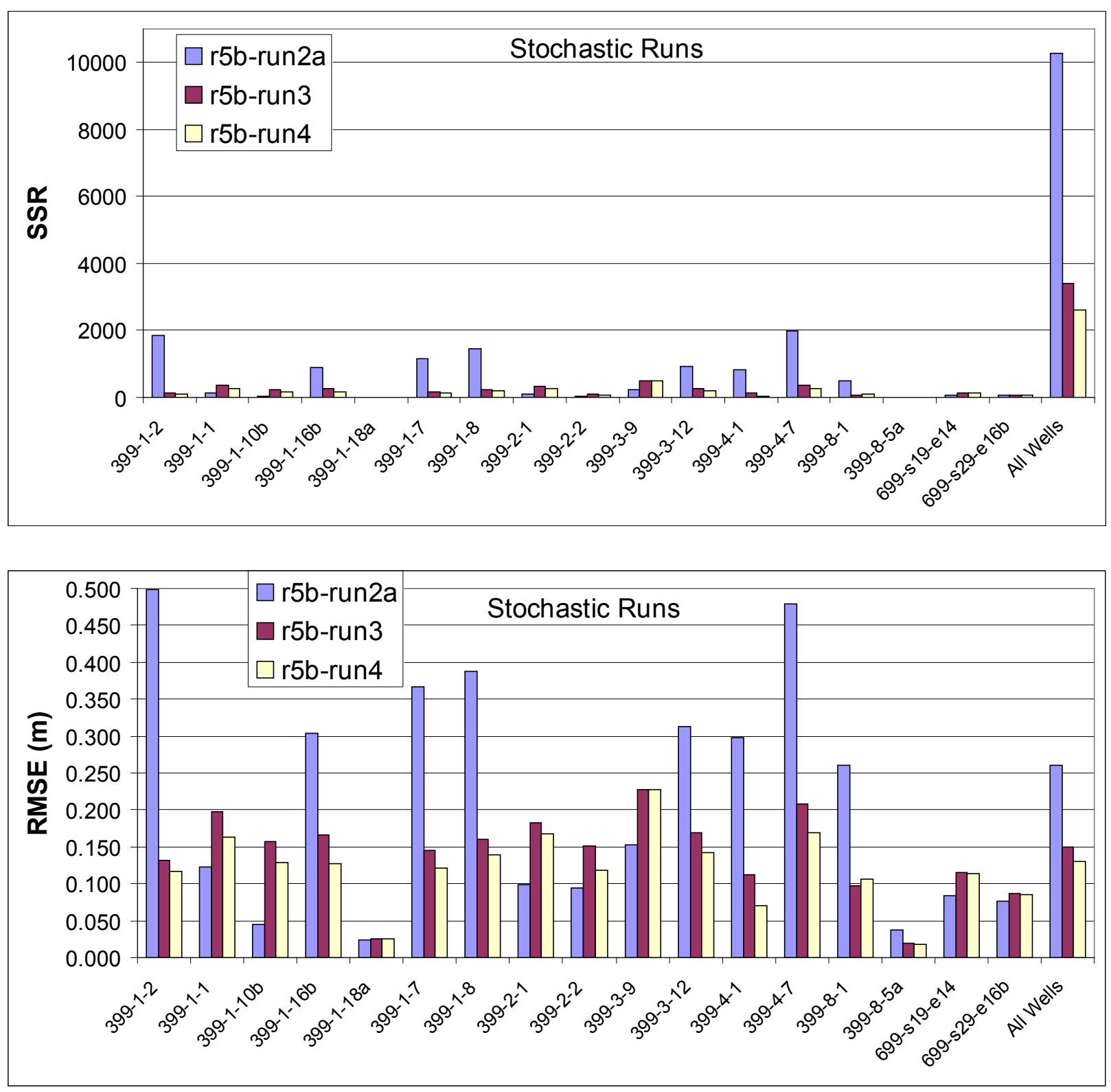

Figure 3.26. Comparison of Sum-of-Squared Hydraulic Head Residuals for All Stochastic Large-Scale 300 Area Model Simulations

The approach used for the deterministic cases (homogeneous and zoned), as shown in Table 3.4, was to initially vary hydraulic conductivity values for the Hanford Gravel unit and River alluvium zone for the homogeneous cases. Successively lowering the K values for these two units yielded lower head SSR values and therefore a better fit of the head measurements. Using the results of the homogeneous cases for guidance, an additional hydraulic conductivity zone was varied within the Hanford gravel unit that was subdivided into two zones (see Figure 3.3). The two-zoned Hanford gravel cases with lower hydraulic conductivity values specified for the zone in the northern portion of the domain, along with further reductions in the river alluvium zone K, yielded lower hydraulic head SSR values. 
Simulated cumulative annual water fluxes, from February 1992 to February 1993, for the model boundaries are shown for the deterministic cases and one stochastic case, rb5-run4, in Figure 3.27. Fixed water sources and sinks for the model (i.e., surface recharge, north process trench recharge, and production well 399-4-12) are not shown in this figure for simplicity (see Figure 3.20). All the cases had annual net inflow from the northern and western model boundaries and net outflow from the south; however, the amounts differed significantly for these cases, particularly for the north and river boundaries. All the cases, except for one that with a small inflow value (see Figure 3.27), had net outflow to the river. For the deterministic cases, the two-zone cases had lower inflow from the north due to the Hanford lower-K zone created in this portion of the model domain (see Figure 3.3). The two-zone cases also had lower river outflow for the annual period as shown in Figure 3.27.

The following sections provide additional discussion of the results of the deterministic cases (i.e., homogeneous and zoned case) and stochastic cases.

\subsubsection{Deterministic (Homogeneous and Zoned) Hydraulic Property Cases and Recommendations}

Earlier cases as part of this effort with homogeneous hydraulic properties and without a river alluvium zone resulted in relatively low estimates for the Hanford Site gravel unit $(\sim 1500 \mathrm{~m} / \mathrm{d})$ with the hydraulic head residuals dominated by the near-river wells (an example case with the smaller scale model is provided in Section 4). With the addition of the river alluvium zone, hydraulic conductivity estimates for the Hanford Site gravels in the 300 Area were much greater based on the hydraulic head residuals.

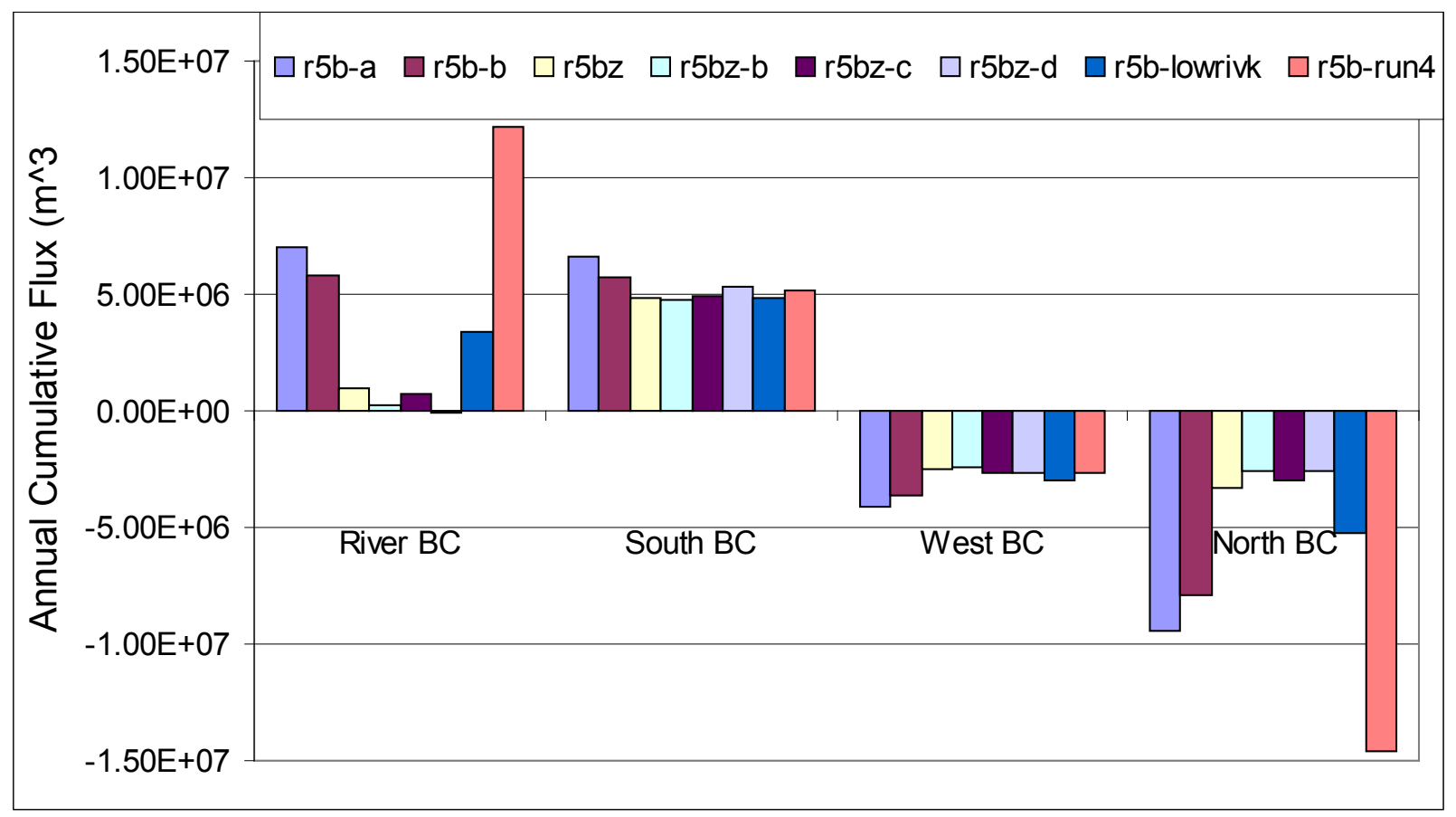

Figure 3.27. Summary of Simulated Cumulative Annual Water Fluxes for Large-Scale 300 Area Model Simulations. Fixed water sources and sinks for the model (i.e., surface recharge, north process trench recharge, and production well 399-4-12) are not shown in this figure for simplicity (see Figure 3.20). The length of the Columbia River shoreline for this model (from wells 699-s19-e14 in the north and well 699-s29-e16b in the south) is $3019 \mathrm{~m}$. 
While the number of cases for the large-scale 300 Area model were limited, some guidance in the hydraulic conductivity values for the zones in these deterministic simulations can be provided. For the single-zone Hanford gravel cases, the lower values of hydraulic conductivity tested for the Hanford gravel and river alluvium had better hydraulic head fit than the higher values. The two-zone Hanford gravel cases had a better hydraulic head fit than the single hydraulic conductivity Hanford gravel cases. The two-zone Hanford gravel configuration permits higher hydraulic conductivity values to be specified for the Hanford higher-K gravel zone with a better overall hydraulic head fit. In the two-zone Hanford gravel cases, the run with the $2000 \mathrm{~m} / \mathrm{d}$ hydraulic conductivity value for the Hanford lower-K gravel zone had a slightly better fit than the higher $2500 \mathrm{~m} / \mathrm{d}$ value tested (the hydraulic conductivity values for the river alluvium and higher K Hanford gravel zone were the same for both cases).

While the hydraulic conductivity values of these simulations were within an order of magnitude of aquifer test results for the Hanford formation in the 300 Area (see Section 2.2 and Figure 2.10), a detailed evaluation was not possible because many of the aquifer tests were unable to determine $\mathrm{K}$ values because of the extremely high permeability (only minimum $\mathrm{K}$ values were reported for many of the tests). Hydraulic conductivity values determined for the river alluvium at one study site along the 300 Area shoreline (see Section 2.4.2 and Figure 2.31) showed increasing values at increasing depth with the average for the upper $1.5 \mathrm{~m}(5 \mathrm{ft})$ of approximately $7 \mathrm{~m} / \mathrm{d}(23 \mathrm{ft} / \mathrm{d})$.

Additional runs are recommended to further bracket the hydraulic properties of the two-zone Hanford gravel unit model. The number of runs was limited for this study due to the long simulation execution times. The progression of simulations based on the hydraulic head fit (i.e., SSR) led to lower hydraulic conductivity values specified for the Hanford and river alluvium zones; however, this also lowered the simulated pore water velocities. Field estimates of pore water velocities at the 300 Area were determined during the polyphosphate tracer test (see Section 2.3.3) and estimates were based on historical plume events (see Peterson et al. 2008a).

\subsubsection{Stochastic Heterogeneous Hydraulic Property Cases}

Figure 3.26 shows the hydraulic head SSR values for each observation well and for all observation wells combined, for three different stochastic simulations. Figure 3.25 shows the SSR values for the deterministic simulation cases and the r5b-run4 stochastic simulation (which had the lowest total SSR among the stochastic cases). The head residuals for two of the three stochastic realizations (runs 3 and 4) were slightly larger, but similar in magnitude to those of the deterministic simulations, while one of the three stochastic realizations (run 2) had significantly higher-head residuals. Differences in the head residuals between the three stochastic simulation cases were a direct result of different combinations of model parameters. Note also that unlike most of the deterministic simulation cases, no attempt was made to adjust any parameters used for generating the stochastic realizations to get a better fit.

Each stochastic realization of parameter fields was generated using exactly the same process, previously described in Section 3.1.5.2, but different random seeds were used for each realization. In the SGSIM algorithm, the random seed dictates the starting position or the initial grid point from which a random path is generated that visits all other points on the simulation grid. The system of kriging equations used both the conditioning (or hard) data, as well as the previously simulated values within the search neighborhood. Therefore, different realizations can yield significantly different results, depending on the amount of conditioning data, their spatial distribution, and the order in which the grid blocks were visited for generating grid cell properties. Regardless of the random seed, however, the 
simulated results should approximately reproduce the histogram of the conditioning data and the experimental variograms, albeit with some statistical variations.

Considering the variability in SSR of the hydraulic head for the three stochastic simulation results reported in this document, it is possible that lower SSR could be obtained from different realizations produced using the same simulation process; i.e., if more realizations of the stochastic property fields were simulated, some of them would likely have lower SSR values than the ones reported here. Alternative approaches would be to calibrate the stochastic simulation results by 1) systematically adjusting parameters in the grain-size gamma-log correlation functions, PTFs, or auto-correlation functions for porosity, $d_{g}$, and $\sigma_{g}$; or 2) combining the results of multiple realizations using the gradual deformation method (Hu 2002, Hu and le Ravalec-Dupin 2004), or 3 ) using hybrid approaches. Other possibly more productive approaches would be to use alternative methods for generating spatially correlated random property fields such as multiple-point geostatistics (Strebelle 2002, Feyen and Caers 2006) or object-based simulation methods for simulating fluvial depositional systems (Deutsch and Tran 2002). However, it is possible that if solute transport data were also available, some of the stochastic parameter fields that were used might actually yield lower SSR for the combined and weighted data sets (head and concentration) than seen for some of the deterministic cases.

Deutsch (2002) suggests that multiple realizations generated using stochastic simulation algorithms, such as SGSIM, can also be used for uncertainty analyses. Peterson et al. (2005) used such an approach with historical aqueous concentration data to estimate the probability of exceeding the maximum detectable limit of uranium in groundwater for 300 Area wells.

Recommendations for improving the stochastic simulations are provided in Section 5.0. 


\subsection{Small-Scale North 300 Area Flow and Transport Model}

A small-scale flow and transport model was developed for the 300 Area between the south end of the north process trenches (316-5) and the area north of the south process pond (316-1), as shown in Figure 4.1. This model was developed based on the availability of hourly high spatial resolution water-level data. This well network was initiated in 2004 and was subsequently expanded to include additional wells (see Section 2.3.1 for details). The objective of the small-scale model was to investigate groundwater flow and transport more efficiently and in more detail than possible with the early 1990s water-level data. Extensive site characterization data collection is underway in a portion of this area for the polyphosphate treatability test (i.e., aquifer tests and large-scale tracer injection tests). Additionally, six wells in the 2004+ network are monitoring electrical conductivity and temperature, which provides the opportunity to assess transport within the groundwater/river water mixing zone during high-river stage periods.

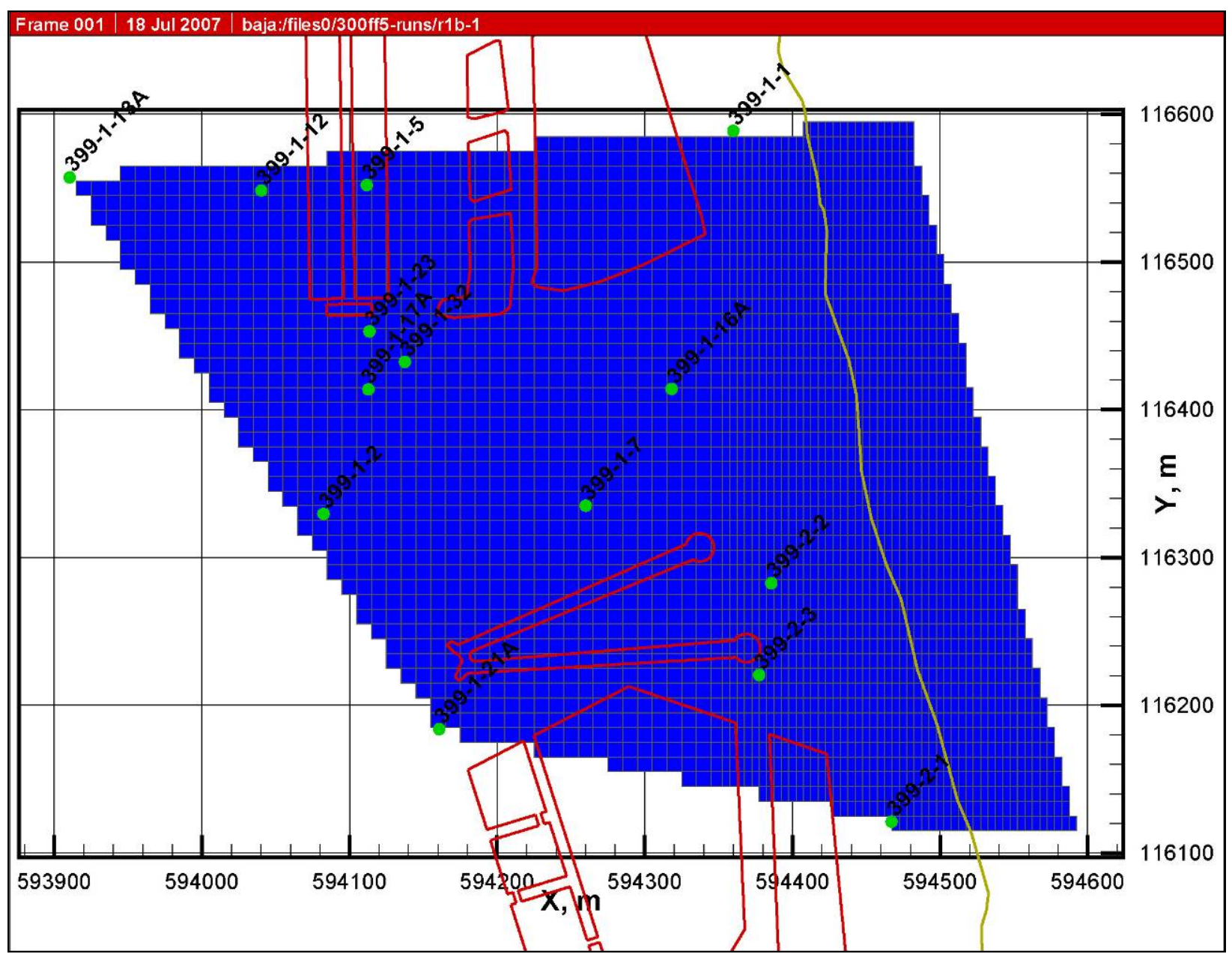

Figure 4.1. Plan View of Small-Scale Model Grid (node-centered cells shown by gray lines) with Selected Wells (solid green circles). Also shown are outlines of the primary waste disposal areas (red lines) and the Columbia River shoreline. 
This section describes the model grid, boundary conditions, sources/sinks, and simulation results for the small-scale model. Simulations with this grid were performed for the purposes of hydraulic property estimation, water flux estimation for a range of hydraulic properties, determination of tracer pulse migration from the south end of the north process trenches during different river stage regimes, and assessment of encroachment of river water during high-river stages.

\subsection{Small-Scale (R1B) Model Description}

\subsubsection{Model Grid Configuration}

The small-scale flow and transport model of a portion of the 300 Area is termed the R1B model. Figure 4.1 is a plan view of the grid that was used for the R1B model. The grid consists of 93 by 48 by 31 nodes in the $\mathrm{x}, \mathrm{y}$, and $\mathrm{z}$ directions, respectively, for a total of 138,384 nodes. The model grid was not rotated; however, some of these nodes along the sides of the model domain were inactive to align the grid with wells used for boundary conditions and the Columbia River shoreline. Nodes above the Columbia River bathymetry were also inactive. The total number of active nodes is 83,354 (55,030 inactive).

Grid spacing in the $\mathrm{x}$ direction varied, with $10-\mathrm{m}$ (32-ft) grid spacing in the western portion of the domain and 5-m (16-ft) grid spacing from the Columbia River and extending inland (see Figure 4.1). The higher resolution around the river and shoreline was needed to better resolve transport in the groundwater/river water mixing zone. In the y direction, grid spacing was uniform at $10 \mathrm{~m}(32 \mathrm{ft})$. The bottom of the model domain was at an elevation of $89.5 \mathrm{~m}(293 \mathrm{ft}$ ) NAVD88 (within the Ringold Formation), and the top of the model domain was at an elevation of $107.75 \mathrm{~m}(351 \mathrm{ft})$ in the lower vadose zone, which is above the highest river stage in the past few years. Vertical layering was $1 \mathrm{~m}(3.2 \mathrm{~m})$ from an elevation of $89.5 \mathrm{~m}(293 \mathrm{ft})$ to $92.5 \mathrm{~m}(303 \mathrm{ft})$ with $0.5-\mathrm{m}(1.6-\mathrm{ft})$ spacing above that elevation, except for 1-m spacing from 99.5 to $101.5 \mathrm{~m}$ elevation.

Vertical node spacing was important in this model, particularly near the fluctuating water table and along the river bottom. A finer vertical resolution variant of this model was tested, with 1-m spacing from elevations ranging from 89.5 to $92.5,0.5-\mathrm{m}$ spacing from 92.5 to $99.75 \mathrm{~m}$, and $0.25-\mathrm{m}$ spacing above this elevation to the top of the model domain at $107.75 \mathrm{~m}$. This refined grid had a total of 223,200 nodes with 130,101 active nodes. Results from a case run with this refined vertical grid model were similar to results for the case with the coarser vertical grid spacing as discussed in Section 4.2.3. The coarser resolution model was used for the simulation cases in the interest of computational efficiency.

\subsubsection{Model Boundary Conditions}

Boundary conditions for cell faces on the north, south, west, and east (river) sides of the model domain were specified as linked lists of seepage faces. For seepage-face boundary conditions, Dirichlettype (specified head) boundary conditions were applied to the outer cell faces of grid blocks that had aqueous pressures greater than or equal to atmospheric pressure (101,325 Pa). No-flow boundary conditions were applied to the outer cells faces of grid blocks that had aqueous pressures less than atmospheric pressure (e.g., unsaturated conditions). This led to flow into or out of the model domain, or no-flow conditions, depending on the pressures at the boundaries and the adjacent nodes. Boundary pressures were computed based on the aqueous pressure and coordinates for the first surface defined in the linked list. Changes in gravitational potential associated with differences between the elevation of the 
reference cell face and all other cell faces in the linked list were automatically accounted for. In addition, hydraulic gradients in $\mathrm{x}-\mathrm{y}$ directions can be specified to account for gradients in the river stage or between wells.

The outer-boundary conditions were specified based on hourly water-level measurements from the $2004+$ network of wells (see Section 2.3.1) on the north, south, and west sides of the domain. For the north boundary, water-level measurements for wells 399-1-13A and 399-1-1 (see Figure 4.1) were applied to the closest grid blocks with hydraulic heads linearly interpolated for the grid blocks between these wells on the boundary. Boundary conditions were specified in a similar manner for the south boundary using wells 399-1-21A and 399-2-1, and for the west boundary using wells 399-1-13A and 399-1-21A. Short sections of the model domain on the north and south are set to no-flow between the near-shore wells (399-1-1 and 399-2-1) and the Columbia River shoreline.

The eastern portion of the model domain, in the Columbia River channel, is specified using data from the 300 Area hourly river stage measurements from the Hanford Virtual Library Automated Water Level Network Data Module (AWLN), maintained by Fluor Hanford, Inc (Richland, Washington). The boundary condition values were applied to the tops and exposed sides of the grid blocks identified within the river using the bathymetry data in EarthVision (see Section 2.1). Values for the 300 Area Columbia River stage recorder (SWS-1) were translated north from the recorder to the southern boundary of the model using an estimated average Columbia River gradient for the 300 Area of $5.14 \times 10^{-5}$. This river gradient was also applied in a north/south orientation across the river boundary surfaces in the model. The average Columbia River gradient was estimated (no measurements in this area were found) based on the mean river gradient of $5.14 \times 10^{-5}$, which was calculated from the MASS1 (Waichler et al. 2005) model from locations north and south of the 300 Area during December 1, 1991, to January 1, 1994. This value is much lower than the average Columbia River gradient calculated from hourly river stage measurements provided by the AWLN between the 300 Area and 100-F Area stage recorders for December 2004 through May 2007 (for which the mean gradient was 0.00024). A lower river gradient for the 300 Area versus the values between the 300 Area and 100-F Area is expected because the 300 Area is still strongly influenced by the McNary pool. River gradient measurements along the 300 Area portion of the reach are planned for FY 2008 by the RACS project.

The bottom of the model domain within the Ringold Formation was defined as a no-flow boundary. This was justified for this model based on the very large contrast in hydraulic properties and the difference in water fluxes between the Hanford and Ringold Formations in the 300 Area. Vertical fluxes deeper in the Ringold Formation were very low compared to those in the Hanford formation.

Solute boundary conditions were specified as inflow-outflow for the model. This allowed solutes to exit the model domain when water fluxes were oriented outward. During inflow conditions, tracer concentrations were set to 0 for the north, west, and south boundaries. A river tracer concentration was set to 1 during inflow conditions for the eastern river boundary (inflow concentration of other solutes were set to 0 ).

\subsubsection{Model Sources and Sinks}

Fayer and Walters (1995) generated a Hanford Site-wide map of natural groundwater recharge rates by combining available information on land use, vegetation, soil types, lysimeter and tracer $(\mathrm{Cl})$ studies, and numerical simulations. For the 300 Area, the Fayer and Walters (1995) map indicates variable 
recharge rates ranging from near 0 to approximately $100 \mathrm{~mm} / \mathrm{yr}$ ( 0 to approximately $3.9 \mathrm{in}$./yr). The Fayer and Walters (1995) recharge map was based partially on data from the Buried Waste Test Facility (BWTF) lysimeter, located north of the 300 Area. Rockhold et al. (1995, Table 3.1) reported an 8-year (1985-1993) record of drainage rates (equivalent to natural groundwater recharge) from a bare (unvegetated) lysimeter at the BWTF that ranged from 111 to $24 \mathrm{~mm} / \mathrm{yr}$ (4.3 to $0.9 \mathrm{in}$./yr), with an average of $55 \mathrm{~mm} / \mathrm{yr}(2.1 \mathrm{in} / \mathrm{yr})$. Average annual precipitation rates at the Hanford Site have increased slightly since the 1985-1993 time frame, so a higher recharge rate of $60 \mathrm{~mm} / \mathrm{yr}$ (2.3 in./yr) was assumed and applied uniformly for the upper-surface boundary condition in the model.

Williams et al. (2006) used a chloride mass balance method to estimate a recharge rate of $1.8 \mathrm{~mm} / \mathrm{yr}$ ( $0.07 \mathrm{in./yr}$ ) for the undisturbed, vegetated area in the vicinity of well 699-S20-E10, located northwest of the 300 Area. Based on these data, and on the lysimeter data noted above, natural groundwater recharge rates in the 300 Area can be expected to range from an annual average of $<2 \mathrm{~mm} / \mathrm{yr}(<0.07 \mathrm{in}$./yr) (for undisturbed, vegetated areas) up to $60 \mathrm{~mm} / \mathrm{yr}$ ( $2.3 \mathrm{in}$./yr) or more (for disturbed, unvegetated areas). Note this range does not include locally elevated recharge rates that might occur; for example, adjacent to relatively impermeable surfaces such as buildings, roads, and parking lots. The area within the model domain has been undergoing extensive surface remediation over the past decade with the vegetation and top layer of the soil removed and backfilled. Water has also been applied to the surface via water trucks for dust-control during these activities (dust control timing, rates, and volumes are unknown). The implications of these surface remediation activities is that the recharge rates may be higher within the model domain in specific areas and times than the uniform recharge values applied based on the BWTF lysimeter data.

During the time period of the model simulations, polyphosphate treatability studies (Vermeul et al. 2007) have included well discharge and injection in the area represented by the small-scale model domain. The larger-volume activities included withdrawal from well 399-1-7 (used for a water supply well for the treatability testing) and injection into well 399-1-23 during hydraulic testing in November 2006, a 552,507-L (146,000-gal) tracer test conducted in December 2006, and an approximately $3,785,000 \mathrm{~L}$ (1,000,000-gal) polyphosphate/calcium chloride test in June 2007. These sources were not included in the small-scale model simulations because they were relatively small volumes, and the use of concurrent injection and pumping resulted in a small net water input/output. Similar volumes (i.e., $1,000,000$ gal) were used for simulations involving tracer pulses (discussed below), which were less than $0.4 \%$ of the annual net water flux estimated in the small-scale model domain for these cases.

\subsubsection{Model Hydrostratigraphy}

The hydrostratigraphy of the model was extracted from the common framework for the 300-FF-5 models developed in EarthVision as discussed in Section 2.1. Figures 4.2 and 4.3 show a plan-view of the material types in the model grid at two different vertical elevations. The largest structural feature in the model domain is the ridge of Ringold material trending northwest and southeast, resulting in a thinner saturated Hanford formation in the unconfined aquifer along this feature (see Figure 2.2).

The Hanford formation was laterally subdivided into two hydraulic conductivity zones as shown in Figures 4.2 and 4.3. This subdivision was based on the areas of steeper hydraulic gradients in the water-level monitoring network data (discussed in Section 2.3.1) during lower water-table conditions (see Figure 2.17). 
To account for the river alluvium identified during the 300 Area hyporheic zone studies (as discussed in Section 2.4), a river alluvium layer was specified in the model below the bathymetry within the Columbia River channel. Three vertical nodes below the bathymetry were configured to the river alluvium material type. The vertical layering in this zone was $0.5 \mathrm{~m}$ to $1.0 \mathrm{~m}$, which results in a $1.5-\mathrm{m}$ to 2.5-m thick river alluvium zone. Figure 4.4 shows a three-dimensional view of the model zonation with the top surface at the uppermost saturated node during the start of the model (January 1, 2006). Because the river alluvium zone was defined by only three vertical nodes over a relatively thin interval, the hydraulic conductivity values specified for this zone may not be directly comparable to field values. This was due to hydraulic property averaging between adjacent zones/nodes in the STOMP code.

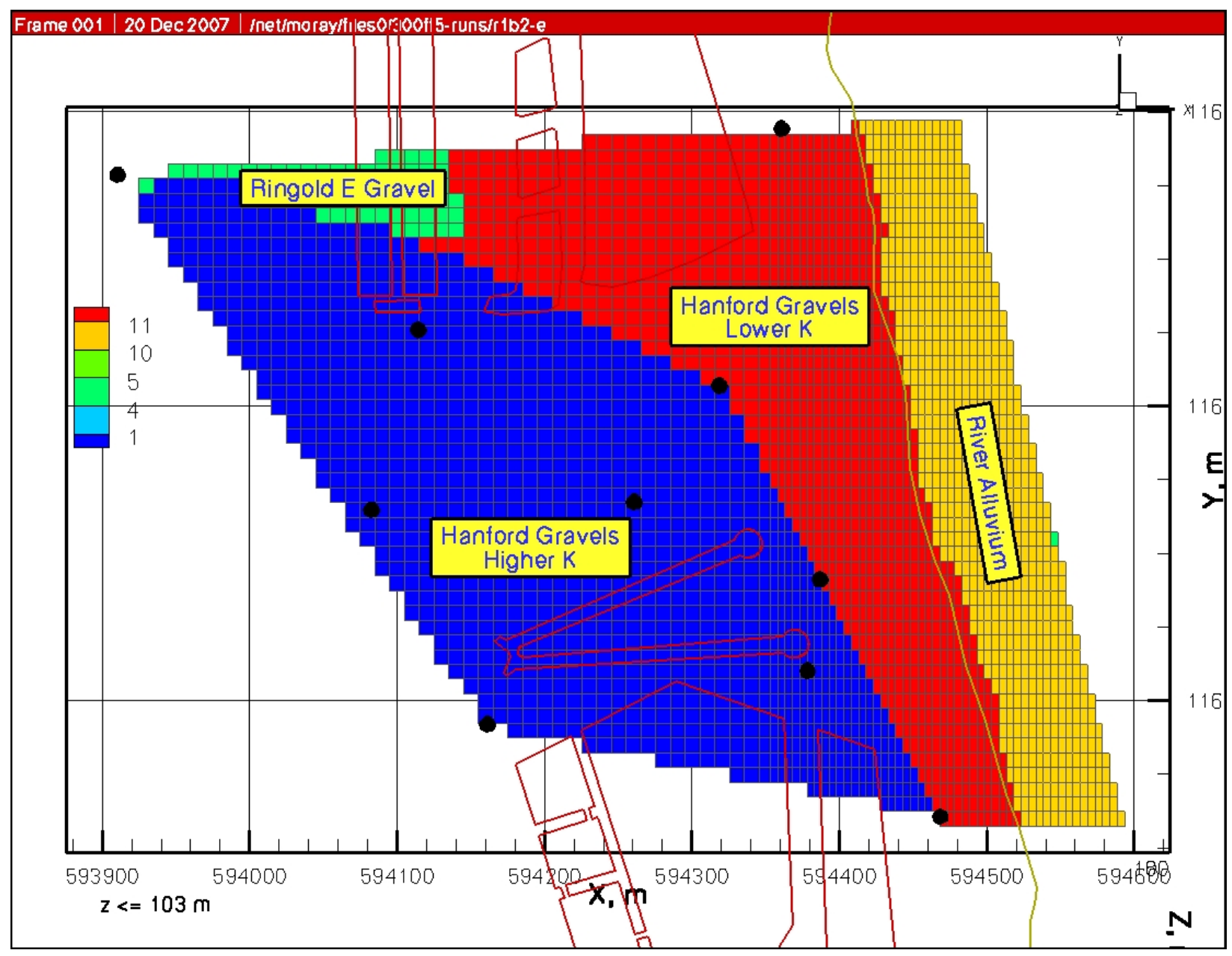

Figure 4.2. Hydraulic Property Zonation at 103-m Elevation (NAVD88) for the Small-Scale 300 Area Model. River alluvium could be at a lower elevation due to inactive nodes. 


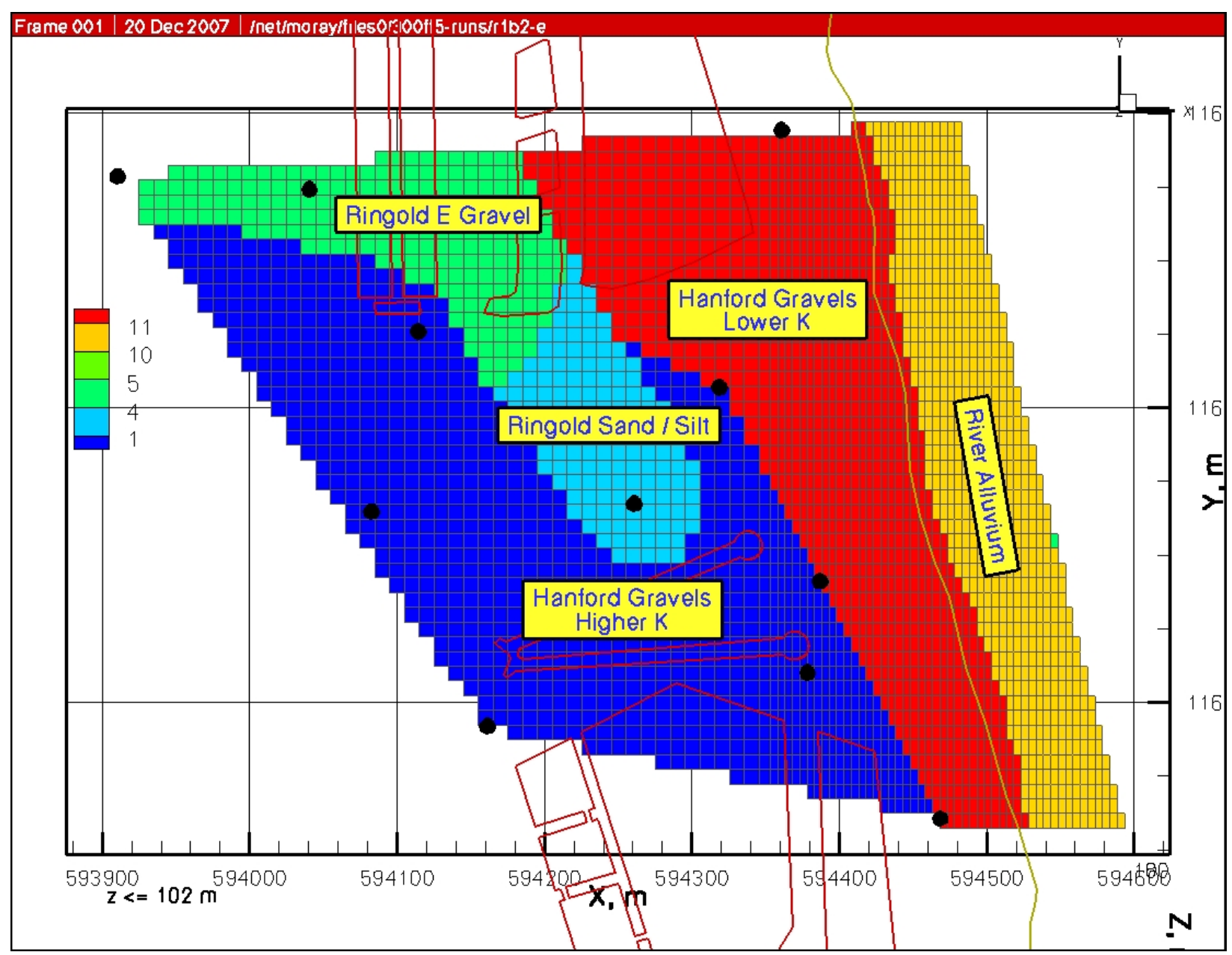

Figure 4.3. Hydraulic Property Zonation at 102-m Elevation (NAVD88) for the Small-Scale 300 Area Model. River alluvium could be at a lower elevation due to inactive nodes. 


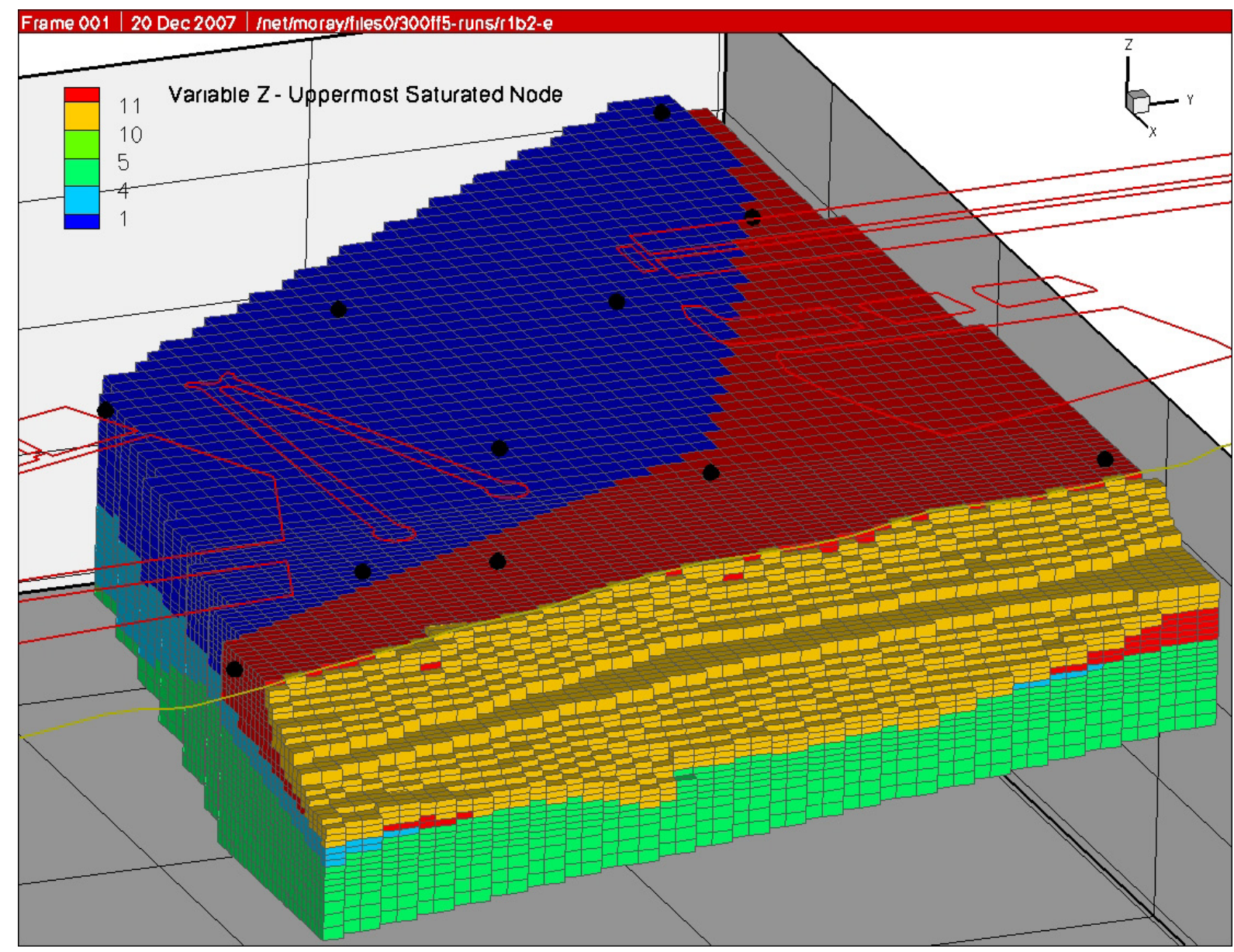

Figure 4.4. Three-Dimensional View of Hydraulic Property Zonation for the Small-Scale 300 Area Model. The top surface is the uppermost saturated node at model initial conditions (January 1, 2006).

\subsubsection{Model Material Properties}

Common material properties used in these models are summarized in Table 4.1. Cases with varying hydraulic conductivity specified for the Hanford Site and river alluvium zone are shown in Table 4.2.

Porosity and particle-density measurements from core samples in the 300 Area are described in Appendix A. The mean particle density, derived from bulk density measurements, was higher for the Hanford formation than the Ringold Formation in these analyses. Total and effective porosity values for the Ringold Formation (units 4 and 5), as shown in Table 4.1, were from Table A.7 in Appendix A. Total and effective porosity for the Hanford formation were set at $18 \%$, slightly lower than the $20 \%$ mean value determined for the Hanford formation below the 106-m (347-ft) elevation that was used for the large-scale model. This lower porosity was based on the preliminary results from the polyphosphate tracer test and on physical property measurements from cores collected as part of the LFI characterization for well 399-1-23. A constant value for specific storage was specified for all the units (see Table 4.1) based on the range of published values of rock compressibility for sands and gravels (Freeze and Cherry 1979). 
Table 4.1. Common Material and Transport Properties Used for the Smaller-Scale 300 Area Three-Dimensional Model ${ }^{(a)}$

\begin{tabular}{lcccccc}
\hline \multicolumn{1}{c}{ Unit } & $\begin{array}{c}\text { Particle } \\
\text { Density } \\
\left(\mathrm{g} / \mathrm{cm}^{3}\right)\end{array}$ & Porosity & $\begin{array}{c}\text { Specific } \\
\text { Storage } \\
(1 / \mathrm{m})\end{array}$ & $\begin{array}{c}\text { Relative } \\
\text { Permeability }\end{array}$ & $\begin{array}{c}\text { Brooks and Corey } \\
\text { psi, Lambda, and Residual } \\
\text { Saturation }\end{array}$ & $\begin{array}{c}\text { Dispersivity } \\
(\mathrm{m})\end{array}$ \\
\hline $\begin{array}{l}\text { Hanford K } \\
\text { Zones (u1) }\end{array}$ & 2.76 & 0.18 & $1.0 \times 10^{-4}$ & $\begin{array}{c}\text { Burdine } \\
(1953)\end{array}$ & $14.04, \mathrm{~cm}, 1.97,0.16$ & $\begin{array}{c}\alpha_{1}=0.5 \\
\alpha_{\mathrm{t}}=0.1\end{array}$ \\
$\begin{array}{l}\text { Ringold } \\
\begin{array}{l}\text { Fine-Grained } \\
\text { (u4) }\end{array}\end{array}$ & 2.65 & 0.43 & $1.0 \times 10^{-4}$ & $\begin{array}{c}\text { Burdine } \\
(1953)\end{array}$ & $71.31, \mathrm{~cm}, 0.5193,0.1299$ & $\alpha_{1}=0.5$ \\
$\begin{array}{l}\text { Ringold E } \\
\text { Gravels (u5) }\end{array}$ & 2.65 & 0.25 & $1.0 \times 10^{-4}$ & $\begin{array}{c}\text { Burdine } \\
(1953)\end{array}$ & $71.31, \mathrm{~cm}, 0.5193,0.1299$ & $\alpha_{\mathrm{t}}=0.1$ \\
$\begin{array}{l}\text { River } \\
\text { Alluvium }\end{array}$ & 2.76 & 0.18 & $1.0 \times 10^{-4}$ & $\begin{array}{c}\text { Burdine } \\
(1953)\end{array}$ & $71.31, \mathrm{~cm}, 0.5193,0.1299$ & $\alpha_{\mathrm{t}}=0.1$ \\
\hline
\end{tabular}

(a) Note: Some differences in parameters for r1b2- lowrivk case (see Table 4.2):

Ringold porosity $=0.18$

Specific storage $=0.0$

For unsaturated zone parameters in the STOMP code, a Brooks-Corey function was used along with a Burdine porosity distribution model for aqueous relative permeability (Burdine 1953). The air-entry pressure and lambda parameters for the Hanford formation were based on data from Rockhold et al. (1995 p. A.1), which represent the ("L-soil") sediment used in the BWTF lysimeters, located north of the 300 Area. The irreducible saturation parameter, $\mathrm{S}_{\mathrm{r}}$, was estimated at 0.16 based on data from well 699-S20-E10 (see Figure 8 in Williams et al. 2006).

Transport parameters for the model include effective porosity, dispersivity, and $\mathrm{K}_{\mathrm{d}}$ (linear equilibrium partitioning coefficient). As noted previously, the effective porosity was set to the same value as the total porosity. As shown in Table 4.1, the dispersivities were small compared to the horizontal grid spacing of

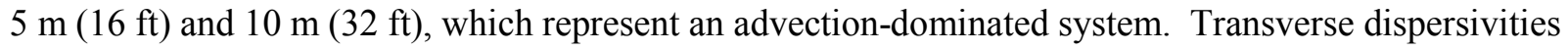
were set to $20 \%$ of the longitudinal dispersivities. Grid Peclet numbers $(\mathrm{Pe}=\mathrm{dx} / \mathrm{D})$ equaled 10 and 20 for the 5- and 10-m (16- and 32-ft) grid spacing, respectively. The Leonard-TVD transport option in STOMP was determined to be the appropriate method for handling this advection-dominated system with large-grid Peclet numbers. A $\mathrm{K}_{\mathrm{d}}$ of zero was specified for the conservative tracer and river tracer solutes in these simulations. The STOMP Courant limit option was used for transport simulation with the limit value set to 1.0. STOMP decreases the transport time step based on the simulated solute velocities for each time step to maintain the calculated Courant number below the specified limit in the transient, spatially variable, flow field.

Hydraulic conductivity values for the Ringold Formation (units 4 and 5) are from hydraulic testing results conducted during the 300 Area LFI (Williams et al. 2007) and were not varied in these cases. Hydraulic conductivities of the Hanford formation were not determined during the LFI hydraulic testing due to its high-hydraulic conductivity (minimum values were reported). A 0.1 value for hydraulic conductivity anisotropy (i.e., $\mathrm{Kz} / \mathrm{Kxy}=0.1$ ) is specified for all the units, except for the river alluvium zone. The hydraulic conductivity of the Hanford formation and the river alluvium were evaluated with this small-scale model as discussed in the following sections. 
Table 4.2. Hydraulic Property Values for the Small-Scale 300 Area Three-Dimensional Model Cases (values are in $\mathrm{m} / \mathrm{d}$ )

\begin{tabular}{|c|c|c|c|c|c|}
\hline Run & $\begin{array}{l}\text { Hanford - High- } \\
\text { K Zone (u1a) }\end{array}$ & $\begin{array}{l}\text { Hanford-- } \\
\text { Low-K Zone } \\
\quad(\mathrm{u} 1 \mathrm{~b})\end{array}$ & $\begin{array}{l}\text { Ringold Fine } \\
\text { Grained (u4) }\end{array}$ & $\begin{array}{c}\text { Ringold E } \\
\text { Gravels (u5) }\end{array}$ & $\begin{array}{c}\text { River } \\
\text { Alluvium }\end{array}$ \\
\hline $\begin{array}{l}\text { r1b2-a } \\
\text { Location: baja: } \\
\text { /files0/300ff5-runs }\end{array}$ & $\begin{aligned} \mathrm{Kxy} & =8,000 \\
\mathrm{Kz} & =800\end{aligned}$ & $\begin{aligned} \mathrm{Kxy} & =2,500 \\
\mathrm{Kz} & =250\end{aligned}$ & $\begin{array}{l}\mathrm{Kxy}=1 \\
\mathrm{Kz}=0.1\end{array}$ & $\begin{aligned} \mathrm{Kxy} & =40 \\
\mathrm{Kz} & =4\end{aligned}$ & $\begin{array}{c}\mathrm{Kxy}=4 \\
\mathrm{Kz}=4\end{array}$ \\
\hline $\begin{array}{l}\text { r1b2-b } \\
\text { Location: baja: } \\
\text { /files0/300ff5-runs } \\
\text { (Note: Tracer not } \\
\text { simulated) }\end{array}$ & $\begin{aligned} \mathrm{Kxy} & =7,000 \\
\mathrm{Kz} & =700\end{aligned}$ & $\begin{aligned} \mathrm{Kxy} & =7,000 \\
\mathrm{Kz} & =700\end{aligned}$ & $\begin{array}{l}\mathrm{Kxy}=1 \\
\mathrm{Kz}=0.1\end{array}$ & $\begin{aligned} \mathrm{Kxy} & =40 \\
\mathrm{Kz} & =4\end{aligned}$ & $\begin{array}{c}\mathrm{Kxy}=3 \\
\mathrm{Kz}=3\end{array}$ \\
\hline $\begin{array}{l}\text { r1b2-c } \\
\text { Location: moray: } \\
\text { /files0/300ff5-runs }\end{array}$ & $\begin{aligned} \mathrm{Kxy} & =7,000 \\
\mathrm{Kz} & =700\end{aligned}$ & $\begin{aligned} \mathrm{Kxy} & =2,500 \\
\mathrm{Kz} & =250\end{aligned}$ & $\begin{array}{l}\mathrm{Kxy}=1 \\
\mathrm{Kz}=0.1\end{array}$ & $\begin{aligned} \mathrm{Kxy} & =40 \\
\mathrm{Kz} & =4\end{aligned}$ & $\begin{array}{c}\mathrm{Kxy}=3 \\
\mathrm{Kz}=3\end{array}$ \\
\hline $\begin{array}{l}\text { r1b2-d } \\
\text { Location: coral: } \\
\text { /files1/ }\end{array}$ & $\begin{aligned} \mathrm{Kxy} & =7,000 \\
\mathrm{Kz} & =700\end{aligned}$ & $\begin{aligned} \mathrm{Kxy} & =2,500 \\
\mathrm{Kz} & =250\end{aligned}$ & $\begin{array}{l}\mathrm{Kxy}=1 \\
\mathrm{Kz}=0.1\end{array}$ & $\begin{aligned} \mathrm{Kxy} & =40 \\
\mathrm{Kz} & =4\end{aligned}$ & $\begin{array}{c}\mathrm{Kxy}=2 \\
\mathrm{Kz}=2\end{array}$ \\
\hline $\begin{array}{l}\text { r1b2-lowrk } \\
\text { Location: clam: } \\
\text { /files0 }\end{array}$ & $\begin{aligned} \mathrm{Kxy} & =6,000 \\
\mathrm{Kz} & =600\end{aligned}$ & $\begin{aligned} \mathrm{Kxy} & =2,000 \\
\mathrm{Kz} & =200\end{aligned}$ & $\begin{array}{l}\mathrm{Kxy}=1 \\
\mathrm{Kz}=0.1\end{array}$ & $\begin{aligned} \mathrm{Kxy} & =40 \\
\mathrm{Kz} & =4\end{aligned}$ & $\begin{array}{c}\mathrm{Kxy}=1 \\
\mathrm{Kz}=1\end{array}$ \\
\hline $\begin{array}{l}\text { r1b2-e } \\
\text { Location: moray: } \\
\text { /files0/300ff5-runs }\end{array}$ & $\begin{aligned} \mathrm{Kxy} & =7,000 \\
\mathrm{Kz} & =700\end{aligned}$ & $\begin{aligned} \mathrm{Kxy} & =2,500 \\
\mathrm{Kz} & =250\end{aligned}$ & $\begin{array}{l}\mathrm{Kxy}=1 \\
\mathrm{Kz}=0.1\end{array}$ & $\begin{aligned} \mathrm{Kxy} & =40 \\
\mathrm{Kz} & =4\end{aligned}$ & $\begin{array}{c}\mathrm{Kx} y=1 \\
\mathrm{Kz}=1\end{array}$ \\
\hline $\begin{array}{l}\text { r1b2-f } \\
\text { Location: baja: } \\
\text { /files0/300ff5-runs }\end{array}$ & $\begin{aligned} \mathrm{Kxy} & =4,000 \\
\mathrm{Kz} & =400\end{aligned}$ & $\begin{aligned} \mathrm{Kxy} & =2,500 \\
\mathrm{Kz} & =250\end{aligned}$ & $\begin{array}{l}\mathrm{Kxy}=1 \\
\mathrm{Kz}=0.1\end{array}$ & $\begin{aligned} \mathrm{Kxy} & =40 \\
\mathrm{Kz} & =4\end{aligned}$ & $\begin{array}{c}\mathrm{Kxy}=1 \\
\mathrm{Kz}=1\end{array}$ \\
\hline $\begin{array}{l}\text { r1b2-g } \\
\text { Location: coral: } \\
\text { /files1/ }\end{array}$ & $\begin{aligned} \mathrm{Kxy} & =7,000 \\
\mathrm{Kz} & =700\end{aligned}$ & $\begin{aligned} \mathrm{Kxy} & =2,500 \\
\mathrm{Kz} & =250\end{aligned}$ & $\begin{array}{l}\mathrm{Kxy}=1 \\
\mathrm{Kz}=0.1\end{array}$ & $\begin{aligned} \mathrm{Kxy} & =40 \\
\mathrm{Kz} & =4\end{aligned}$ & $\begin{aligned} \mathrm{Kxy} & =7,000 \\
\mathrm{Kz} & =700\end{aligned}$ \\
\hline $\begin{array}{l}\text { r1b2-h } \\
\text { Location: baja: } \\
\text { /files0/300ff5-runs }\end{array}$ & $\begin{aligned} \mathrm{Kxy} & =8,000 \\
\mathrm{Kz} & =800\end{aligned}$ & $\begin{aligned} \mathrm{Kxy} & =2,500 \\
\mathrm{Kz} & =250\end{aligned}$ & $\begin{array}{l}\mathrm{Kxy}=1 \\
\mathrm{Kz}=0.1\end{array}$ & $\begin{aligned} \mathrm{Kxy} & =40 \\
\mathrm{Kz} & =4\end{aligned}$ & $\begin{array}{c}\mathrm{Kxy}=1 \\
\mathrm{Kz}=1\end{array}$ \\
\hline $\begin{array}{l}\text { r1b2-k } \\
\text { Location: clam: } \\
\text { /files0/ }\end{array}$ & $\begin{aligned} \mathrm{Kxy} & =10,000 \\
\mathrm{Kz} & =1,000\end{aligned}$ & $\begin{aligned} \mathrm{Kxy} & =2,500 \\
\mathrm{Kz} & =250\end{aligned}$ & $\begin{array}{l}\mathrm{Kxy}=1 \\
\mathrm{Kz}=0.1\end{array}$ & $\begin{aligned} \mathrm{Kxy} & =40 \\
\mathrm{Kz} & =4\end{aligned}$ & $\begin{array}{c}\mathrm{Kxy}=1 \\
\mathrm{Kz}=1\end{array}$ \\
\hline $\begin{array}{l}\text { r1b2-mns } \\
\text { Location: moray: } \\
\text { /files0/300ff5-runs }\end{array}$ & $\begin{aligned} \mathrm{Kxy} & =7,000 \\
\mathrm{Kz} & =700\end{aligned}$ & $\begin{aligned} \mathrm{Kxy} & =4,000 \\
\mathrm{Kz} & =400\end{aligned}$ & $\begin{array}{l}\mathrm{Kxy}=1 \\
\mathrm{Kz}=0.1\end{array}$ & $\begin{aligned} \mathrm{Kxy} & =40 \\
\mathrm{Kz} & =4\end{aligned}$ & $\begin{array}{c}\mathrm{Kxy}=1 \\
\mathrm{Kz}=1\end{array}$ \\
\hline
\end{tabular}




\subsection{Simulation Results}

Several hydraulic conductivity cases were run with the small-scale 300 Area model to help estimate hydraulic conductivity values at the scale of the model (see Table 4.2). The simulated time period for the small-scale 300 Area model cases was from January 2006 through July 2007. Simulation results evaluated for each of the cases included the following: comparison of simulated hydraulic heads with water-level measurements, water fluxes, metrics of tracer pulses introduced into the model domain, and the inland extent of river water tracers. Hydraulic head residuals were calculated from the difference between the simulated and measured water levels in automated water-level monitoring wells. The water fluxes included the instantaneous and cumulative water fluxes for the Columbia River, model boundaries, and sources and sinks over the simulated time period. Tracer pulses were introduced into the model during periods of different river stage/water-table regimes at the south end of the north process trenches (316-5). Tracer-pulse durations were 1 day at 3,028 L/min (800 gpm [1,152,000 gal total volume]) over a fixed vertical interval, followed by a drift period to track the migration of the plume (see Figure 4.5). Plots of the tracer plumes are provided at selected times after these tracer pulses, along with plume velocities calculated from weekly changes in the plume center of mass. In addition to these tracer pulses, a separate river tracer was simulated during inflow conditions from the Columbia River boundary. Results of the river tracer were compared to measurements of electrical conductivity (available for some of the wells as part of the automated water-level monitoring network) as another measure for assessing these simulations and hydraulic property values.

Detailed simulation results are described below for an example case (r1b2-e described in Table 4.2). This is followed by summaries and a comparison of the results of all the cases to identify the best-fit case, and the range of possible system responses given the ranges evaluated and uncertainties in parameter values. Also discussed are the results of a test case using a grid with refined vertical node spacing for comparison to the standard grid used for these cases.

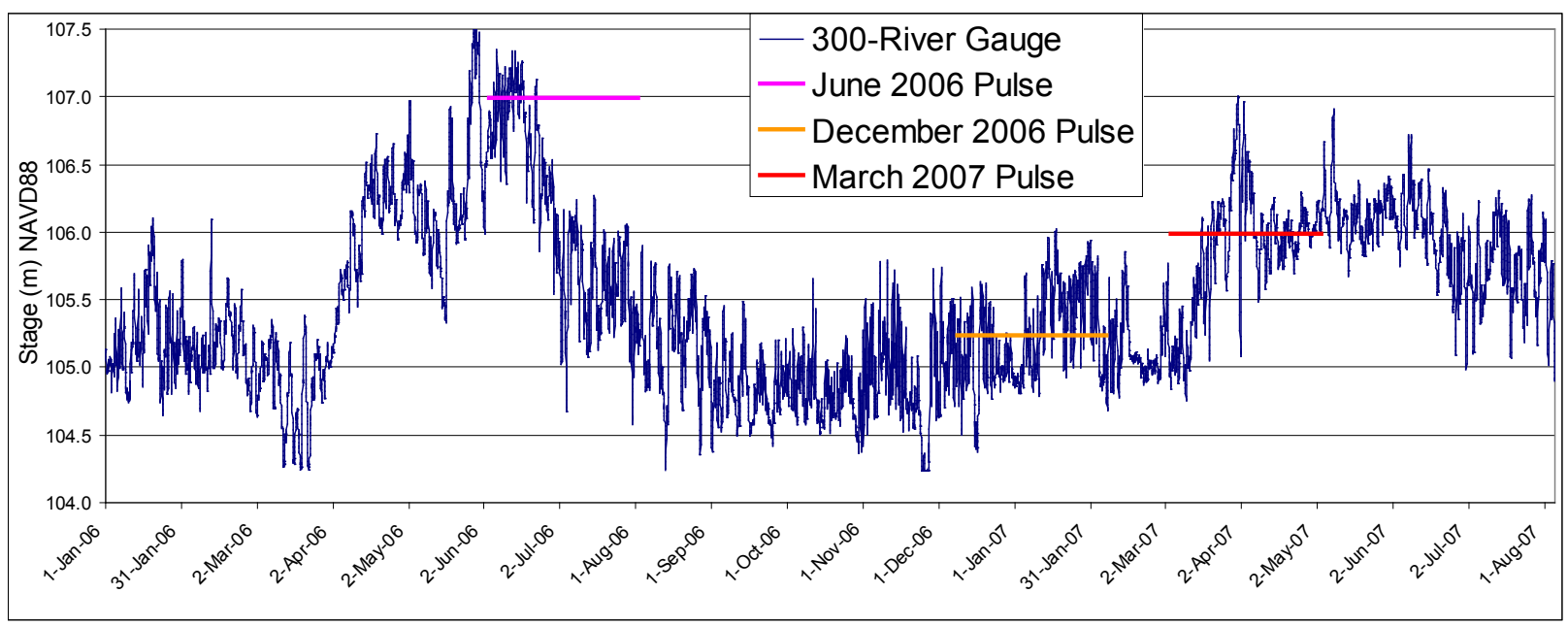

Figure 4.5. River Stage (2006 to Present) and Timing of Tracer Pulses. Tracer timing shows 1-day injection and 60 days of drift. 


\subsubsection{Detailed Example Simulation Case - r1b2-e}

The simulation period for the small-scale 300 Area model cases was from January 2006 through July 2007. A 1-year period with constant boundary condition values equal to those of January 1, 2006, was simulated to supply initial conditions for the transient model. Material, hydraulic, and transport properties for the zones in the example case (r1b2-e) are shown in Tables 4.1 and 4.2.

Figures 4.6, 4.7, and 4.8 show a comparison of simulated hydraulic heads and measured water levels for the wells in this example case (r1b2-e). Simulated hydraulic heads were extracted from the node locations closest to the $\mathrm{x}, \mathrm{y}$-well coordinates at three vertical locations across the well screen ( $\mathrm{s} 1, \mathrm{~s} 2$, and s3). The vertical well-screen locations were determined by the closest nodes to the elevations calculated at the midpoint of the well screen (s2), between the midpoint and the screen top (s1), and between the midpoint and the bottom of the well screen (s3). Because of well construction, many of the uppermost screen nodes (s1 or s2) for the wells were above the water table during portions of the simulation.

The wells that supplied the boundary conditions for the simulation are shown in Figure 4.6. Well 399-1-1 data gaps in the spring and summer of 2006 were due to pressure transducer over ranging during the high-river stage. The pressure transducer was subsequently raised; however, some data were lost again from this well when the water table dropped later in the summer because it was above the water table. Boundary condition values were interpolated from the starting and ending values over the data gaps at well 399-1-1. The smoothing along the boundary from interpolation of the data gaps for boundary well 399-1-1 resulted in a poor fit for peaks in boundary well 399-1-13a during these periods as shown in Figure 4.6. Measured and simulated hydraulic heads for wells within the model domain are shown for near-river wells in Figure 4.7 and for wells further inland in Figure 4.8 (these plots exclude the boundary wells).

The difference between the simulated hydraulic heads and the measured water levels were calculated as a residual for each observation in the simulations. The process and equations used to calculate the hydraulic head residuals are described in Section 3.2.1.1.

Table 4.3 shows detailed results of the hydraulic-head residuals for each well for the example case. Only one node per well (i.e., s1, s2 or s3) was used for the residual calculation, which was selected for each well depending on the node location below the water table (i.e., continuously saturated). These data are also shown in Figure 4.9. Simulated values are temporally interpolated when the simulated date and time do not exactly match the observation date and time. Based on these results, the well with the largest error was the inland well 399-1-2 (see Figure 4.1 for location). Because this well is close to the western boundary of the model, the simulated values were strongly influenced by the interpolation of hydraulic heads along this boundary from wells 399-1-13A and 399-1-21A. 

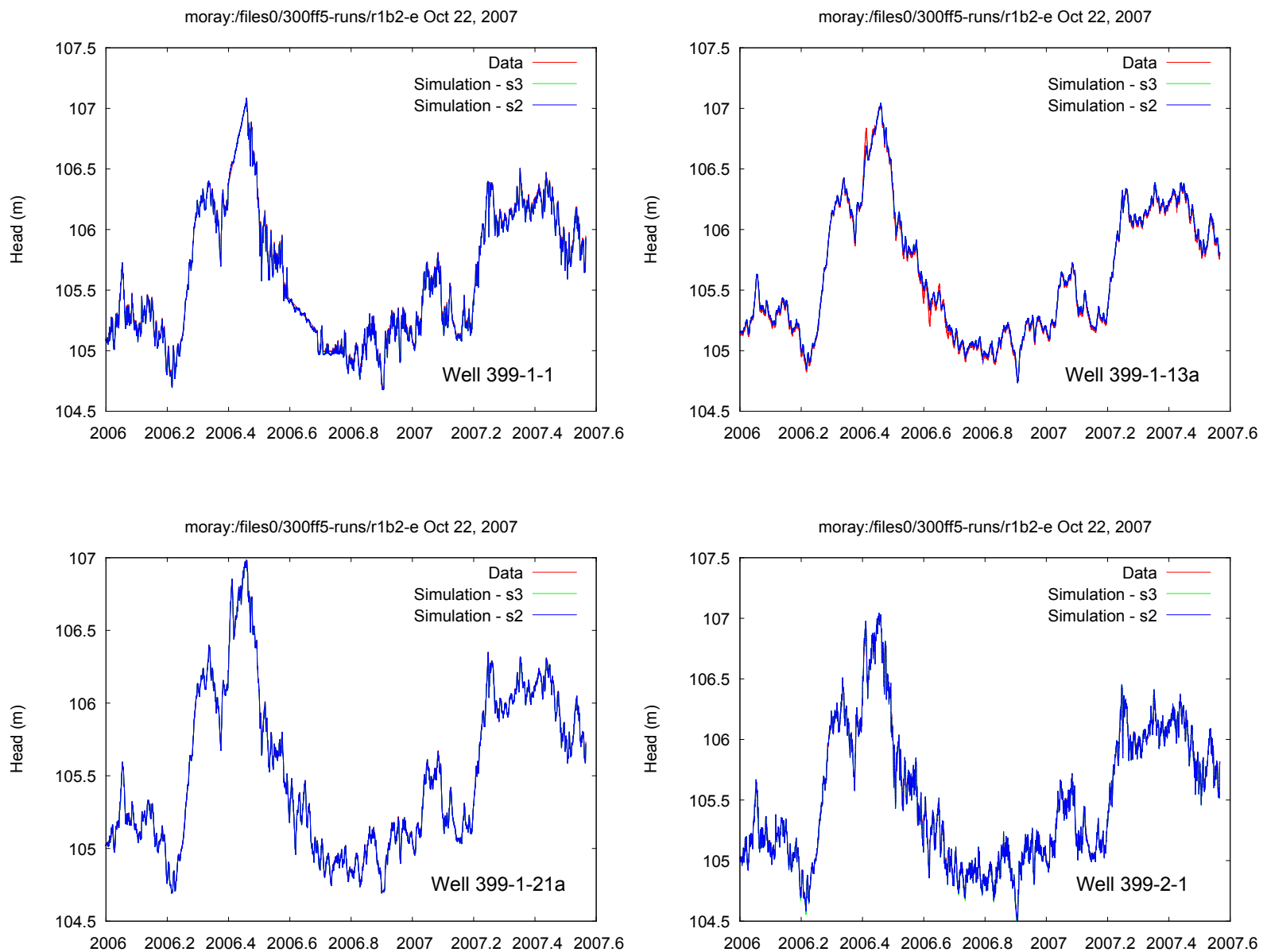

Figure 4.6. Comparison of Simulated Hydraulic Heads and Measured Water Levels for Boundary Wells. The s2 and s3 are simulation results from nodes at two depths across the well screen (see Section 4.2.1 for additional detail). Note that data gaps occur in water-level measurements for well 399-1-1 during the spring and summer of 2006; the boundary values are interpolated during these periods from the measurements before and after the data gaps. 

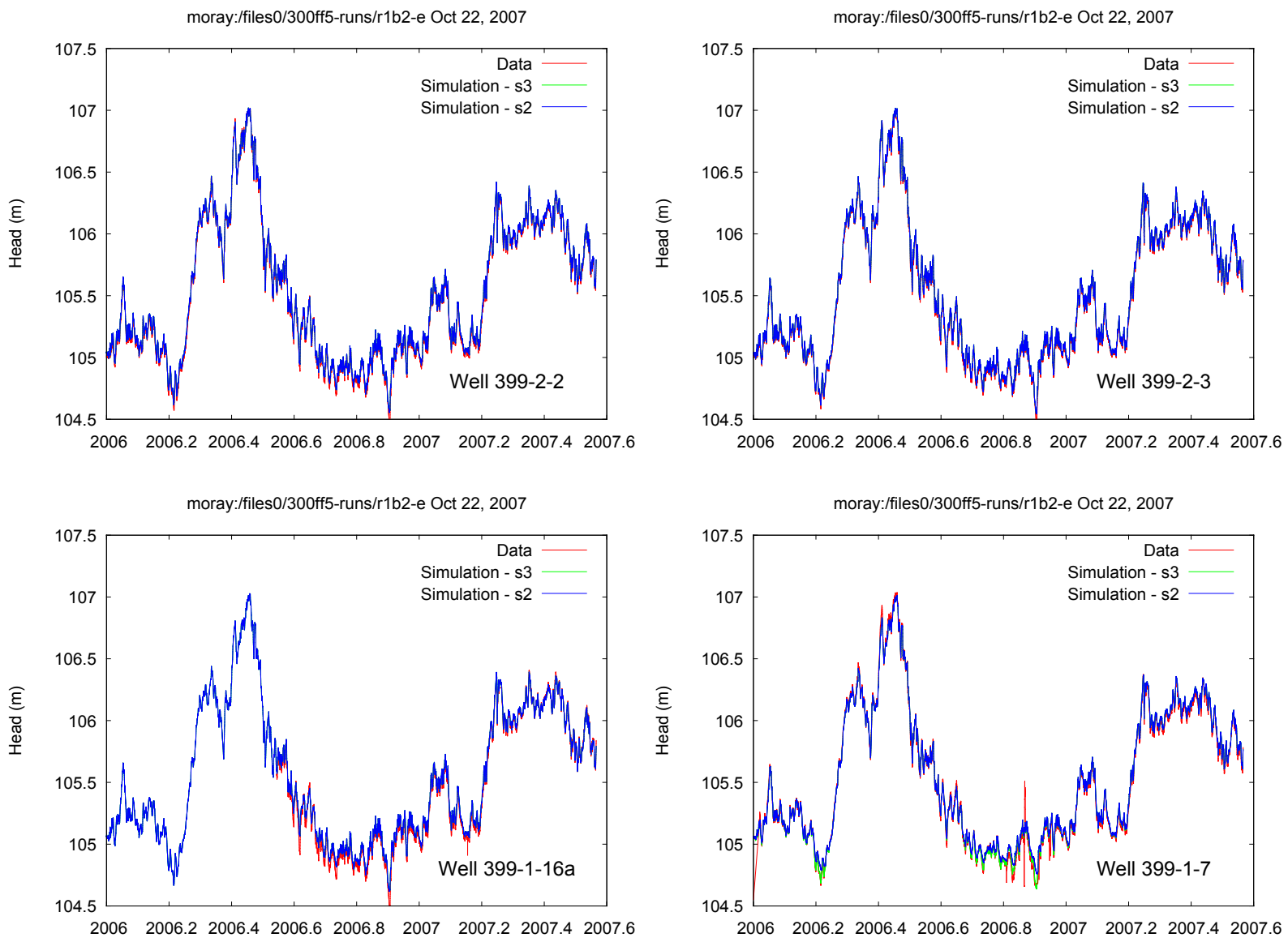

Figure 4.7. Comparison of Simulated Hydraulic Heads and Measured Water Levels for Near-River Wells Within the Model Domain. The s2 and s3 are simulation results from nodes at two depths across the well screen (see Section 4.2.1 for additional detail). 

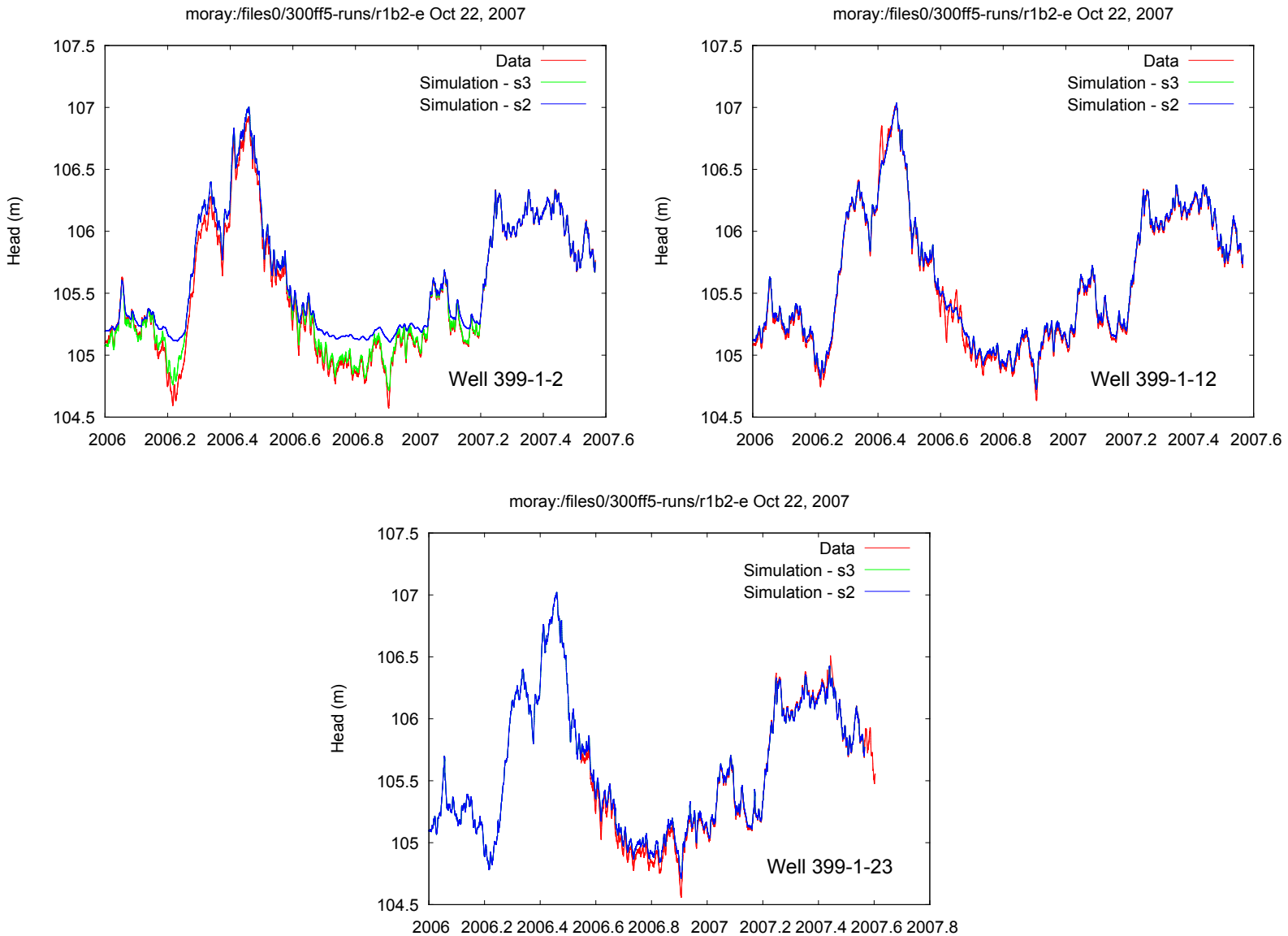

Figure 4.8. Comparison of Simulated Hydraulic Heads and Measured Water Levels for Inland Wells within the Model Domain. The s2 and s3 are simulation results from nodes at two depths across the well screen (see Section 4.2.1 for additional detail).

Hydraulic head values were linearly interpolated along this boundary between the wells specified for the boundary. Simulated values for well 399-1-2 were systematically higher than the measured values, as shown in Figure 4.8, and by the larger positive residuals shown in Table 4.3 and Figure 4.9. Overall, most of the simulated values were higher than the measured values for wells in this example case as seen by the higher magnitude positive residuals compared to the negative residuals. Neglecting the wells used for specifying the boundary conditions, the near-river wells (399-2-3, 399-2-2, and 399-1-16A) had lower SSRs than wells further inland. 
Table 4.3. Detailed Hydraulic Head Residuals Calculated for the Small-Scale Model Example Case (r1b2-e). Residuals are calculated from simulated value - measured value (e.g., positive residuals are when the simulated values are greater than the measured value). See Section 3.2.1.1 for additional details on residual calculations.

\begin{tabular}{lcrrrrrr}
\hline Well Name & $\begin{array}{c}\text { Number of } \\
\text { Observations }\end{array}$ & $\begin{array}{c}\text { Number of } \\
\text { Positive } \\
\text { Residuals }\end{array}$ & $\begin{array}{c}\text { Number of } \\
\text { Negative } \\
\text { Residuals }\end{array}$ & $\begin{array}{c}\text { Total } \\
\text { Positive } \\
\text { Residuals }\end{array}$ & $\begin{array}{c}\text { Total } \\
\text { Negative } \\
\text { Residuals }\end{array}$ & $\begin{array}{c}\text { Sum of } \\
\text { Squared } \\
\text { Residuals }\end{array}$ & $\begin{array}{c}\text { Root Mean } \\
\text { Squared } \\
\text { Error (m) }\end{array}$ \\
\hline 399-1-1 & 12,282 & 654 & 11,628 & 1.97 & -121.16 & 1.54 & 0.011 \\
$399-1-12$ & 13,507 & 12,638 & 869 & 365.87 & -47.75 & 22.91 & 0.041 \\
399-1-13a & 13,719 & 12,638 & 1,081 & 251.92 & -24.56 & 9.14 & 0.026 \\
$399-1-16 a$ & 8,839 & 7,338 & 1,501 & 269.16 & -15.85 & 13.68 & 0.039 \\
$399-1-2$ & 13,718 & 10,971 & 2,747 & 576.53 & -30.89 & 53.09 & 0.062 \\
$399-1-21$ a & 13,720 & 51 & 13,669 & 0.07 & -31.14 & 0.08 & 0.002 \\
$399-1-23$ & 8,765 & 6,380 & 2,385 & 284.05 & -32.65 & 20.24 & 0.048 \\
$399-1-7$ & 13,432 & 9,086 & 4,346 & 224.36 & -71.6 & 13.79 & 0.032 \\
$399-2-1$ & 13,671 & 5,178 & 8,493 & 36.26 & -84.89 & 1.81 & 0.012 \\
$399-2-2$ & 13,670 & 12,704 & 966 & 292.49 & -7.59 & 8.88 & 0.025 \\
$399-2-3$ & 13,567 & 13,369 & 198 & 258.37 & -0.67 & 5.93 & 0.021 \\
All & 138,890 & 91,007 & 47,883 & 2561.06 & -468.74 & 151.09 & 0.033 \\
\hline
\end{tabular}

Simulated water fluxes along the model boundaries, including the Columbia River boundary, are shown in Figure 4.10. The river water flux had the largest range and showed daily and seasonal changes in direction. The shoreline distance of the river for this model was $480 \mathrm{~m}$ (i.e., the distance from wells 399-1-1 to 399-2-1). Fluxes along the western boundary were predominantly into the model domain (negative values) and fluxes along the southern boundary were out of the model domain (positive values). The largest range of simulated instantaneous water flux was during the spring and summer of 2006. Cumulative fluxes along the model boundaries during the simulation period are shown in Figure 4.11. Cumulative fluxes along the western and southern boundaries were relatively constant over the simulated time period; however, there were significant seasonal changes in the direction and rates on the river boundary. Cumulative fluxes along the northern boundary were flat during extended periods except for times in the spring of 2006. A summary of the cumulative fluxes along the model boundaries for a 1-year period are shown in Figure 4.12. Natural recharge is also shown in this figure for comparison to the other boundary fluxes. For this example, the net water flux from the river boundary is into the aquifer for this time period. Given the variability along this river boundary, other time periods could show a net output to the river (e.g., summer and fall of 2006 or a 1-year period from July 2006 to July 2007). The river stage was also relatively high in 2006 compared to recent years. The simulated river fluxes are strongly influenced by the hydraulic conductivities specified for the river alluvium and near-river Hanford formation. 

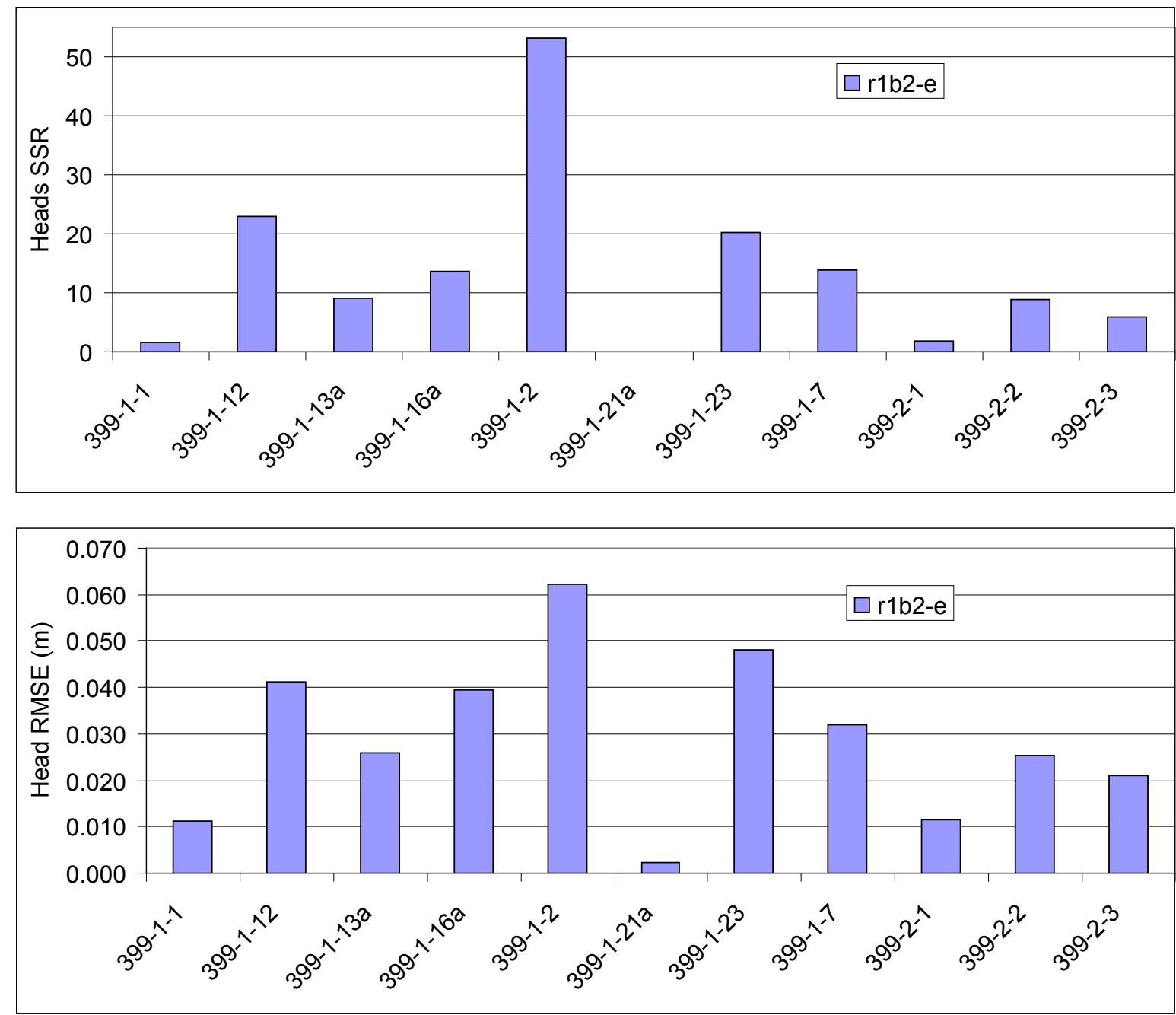

Figure 4.9. Calculated Head Residuals for Small-Scale 300 Area Model Example Case (r1b2-e). Note the number of observations is not the same for each well (see also Table 4.3). 

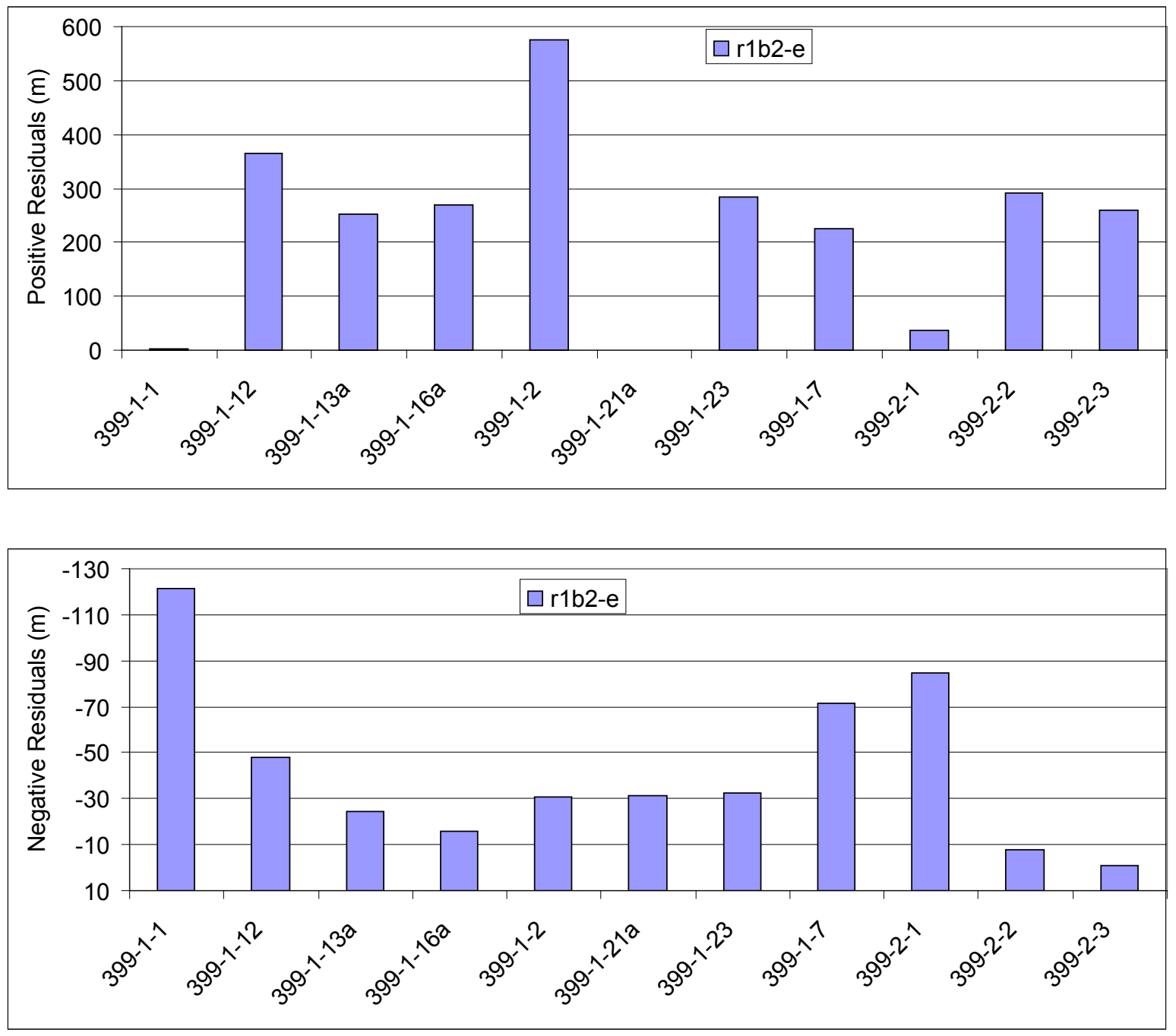

Figure 4.9. (Cont.) 


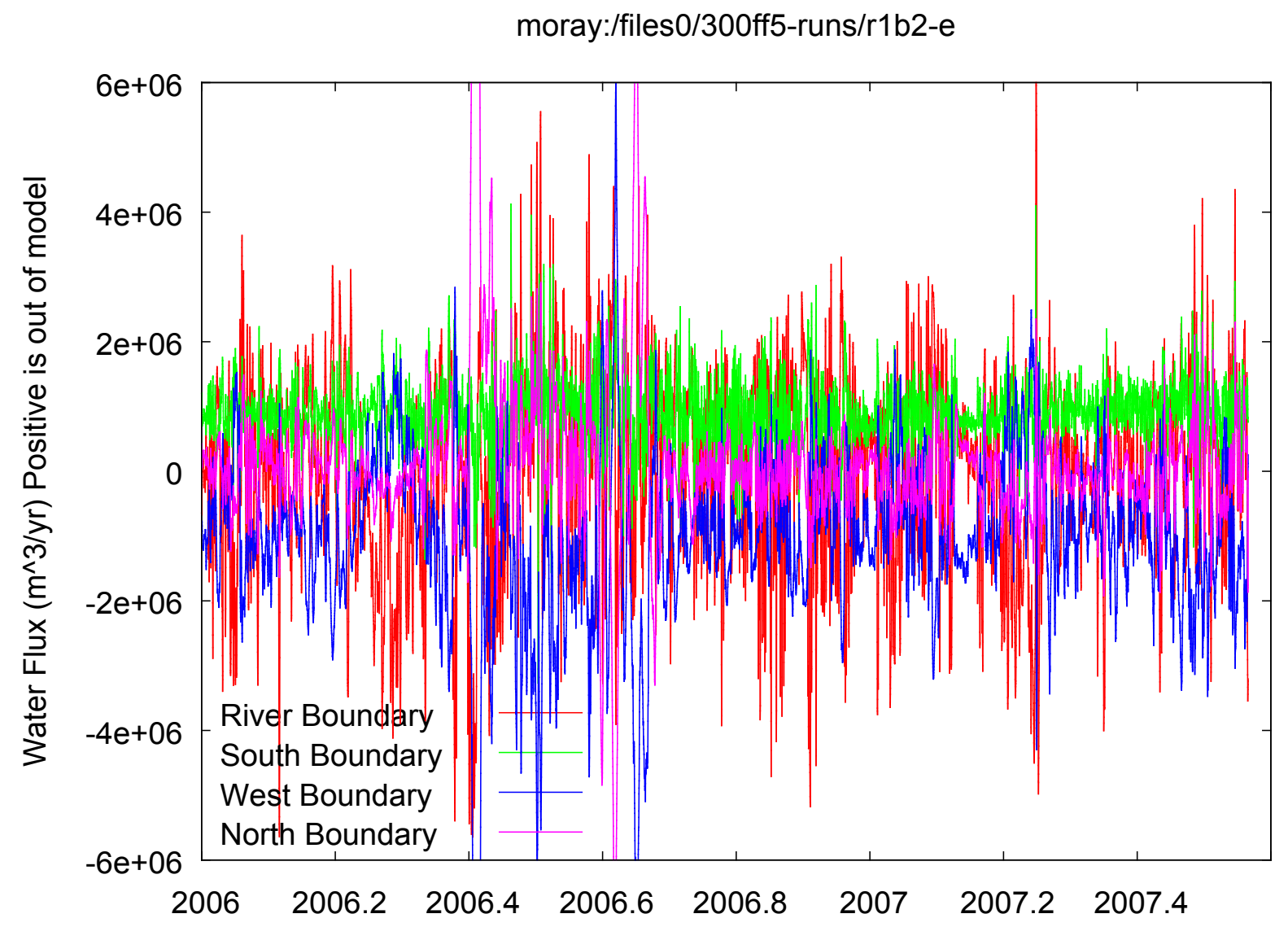

Figure 4.10. Simulated Instantaneous Water Fluxes Calculated for Model Boundaries (r1b2-e) 
moray:/files0/300ff5-runs/r1b2-e

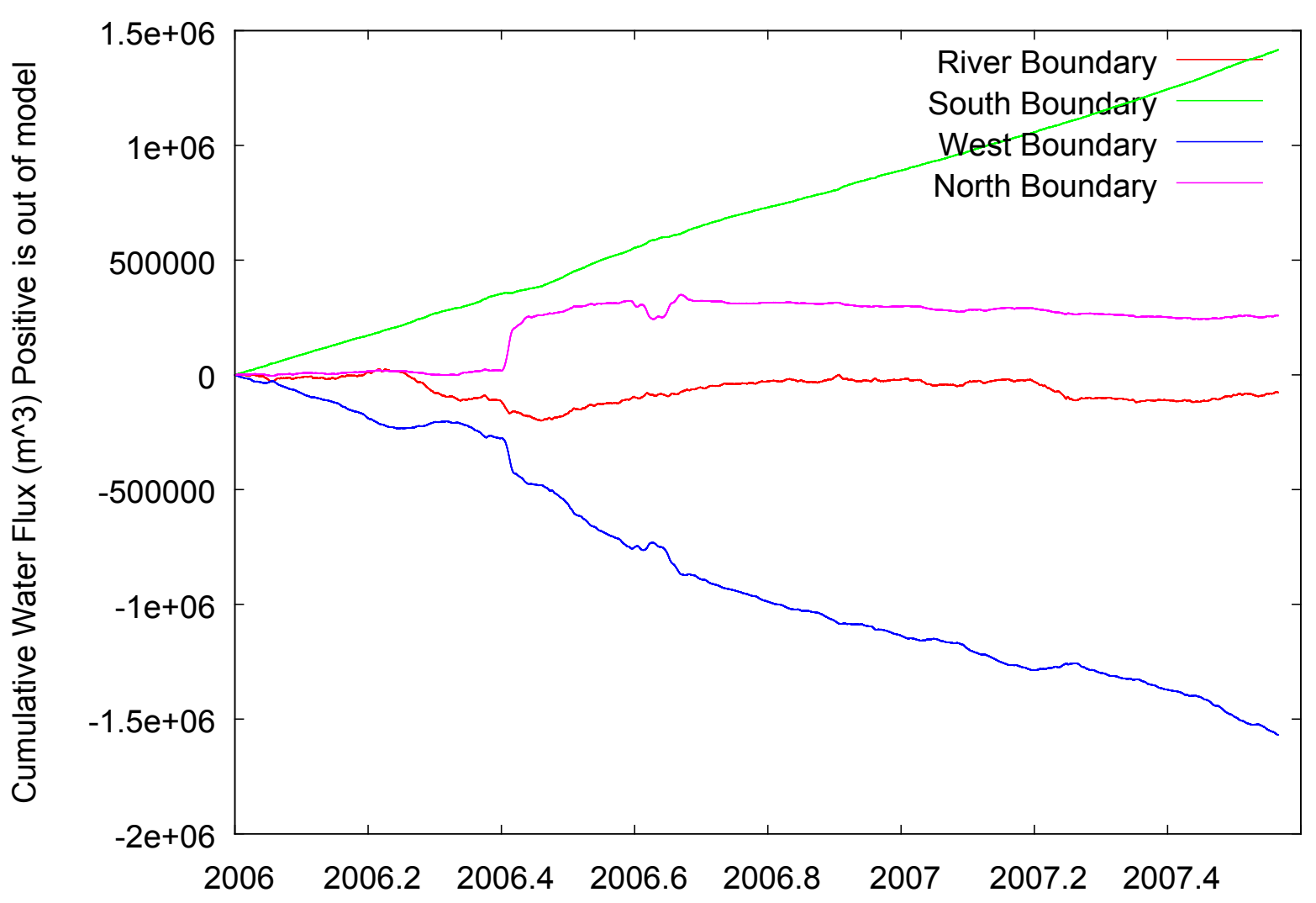

Figure 4.11. Simulated Net Cumulative Water Fluxes Calculated for the Small-Scale Model Boundaries (r1b2-e)

Transport simulations for conservative tracer pulses were conducted at seven different times to assess groundwater flow directions and rates during various river stage/water-table regimes (see Figure 4.5 for the timing of the three example pulses). The simulated tracer pulses were for 1 day of injection for a total volume of 4,360,000 L (1,152,000 gal [800 gpm for 24 hours]). Results of the initial plumes and subsequent drift for the three cases in Figure 4.5 are shown in Figures 4.13, 4.14, and 4.15. Plume-drift velocities calculated from the weekly changes in the position of the center of mass of the tracer plumes are shown in Figure 4.16 for the three example pulses and for the other simulated tracer pulses. For the March 2007 pulse (Figure 4.13), the initial plume-drift was toward the southeast until the river stage increased significantly at the middle and end of March, causing the plume to move toward the southwest. The plume drifted towards the south in April during the sustained high-river stage period. The second example tracer pulse/drift case occurred during the end of a high-river stage period in June 2006 that was followed by a steep stage drop in July (see Figure 4.14). The general direction of the plume drift during this period was toward the south-southeast with a large increase in the plume velocity occurring during the large drop in the river stage approximately at the beginning of July 2006 (see Figure 4.5). A third tracer drift case is shown in Figure 4.15 for sustained low-river stage conditions during December 2006 and January 2007. 


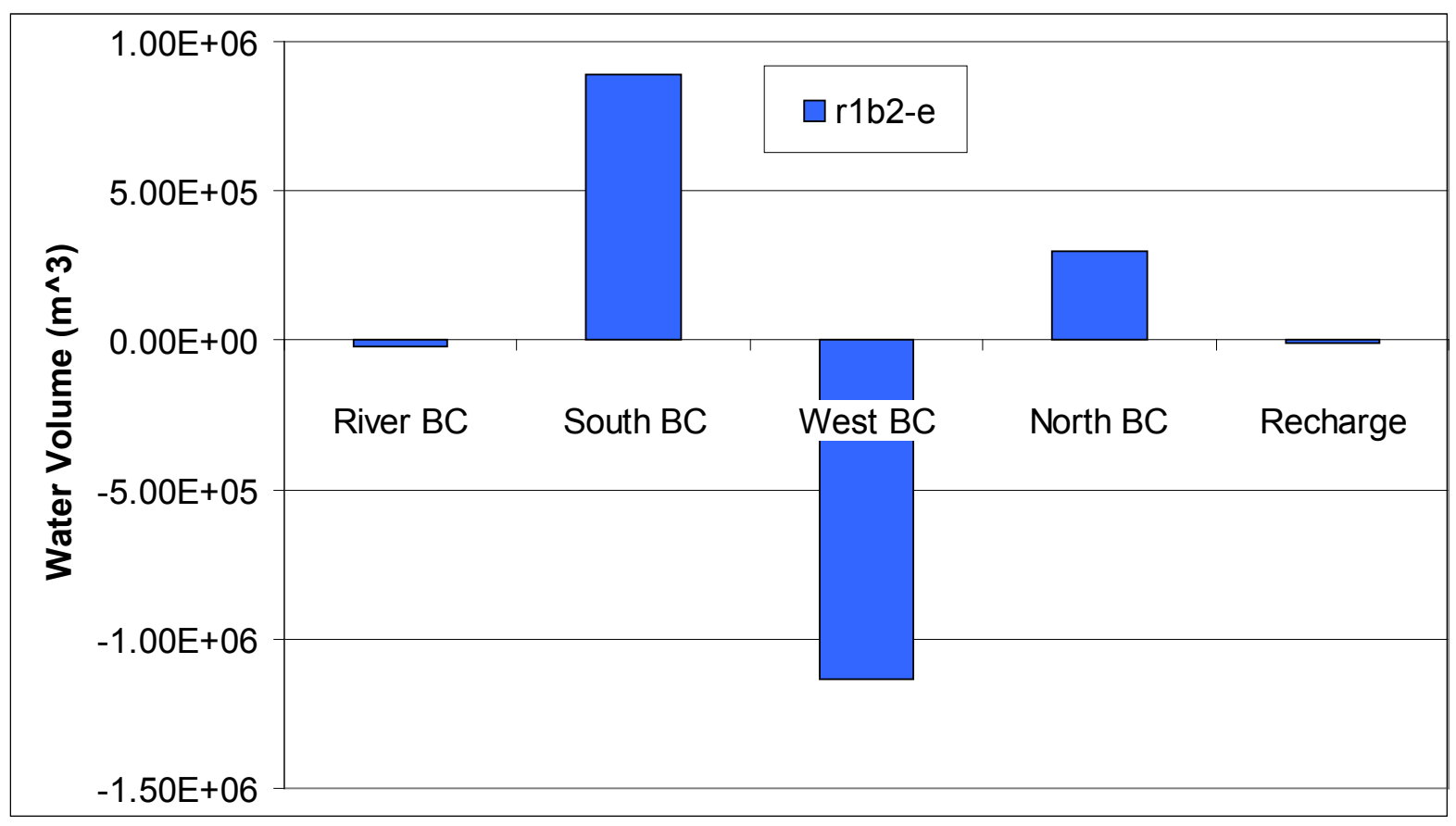

Figure 4.12. Simulated Annual Cumulative Water Flux for 2006 for the Small-Scale Model Example Case. Shoreline distance $=480 \mathrm{~m}$.

The highest velocities calculated from the simulated tracer pulses occurred about 30 days after the start of the June 2006 tracer pulse in the beginning of July when the Columbia River started dropping after the sustained high-river period (see Figures 4.16 and 4.5). Another period with high velocities shown by the tracer pulses occurred at the beginning of the September 2006 pulse during the initial low-river stage period when the water table was relatively high.

Velocities calculated for the tracer plume drift during these time periods (Figure 4.16) were less than the velocity for the polyphosphate tracer test conducted in December 2006 and January 2007 of $15 \mathrm{~m} / \mathrm{d}$ $(49 \mathrm{ft} / \mathrm{d})$. Simulations with higher hydraulic conductivity values for the Hanford formation are evaluated in the following section. Additionally, the direction of the polyphosphate tracer plume drift was from well 399-1-23 toward well 399-1-7, which had a more southeastern direction than the simulated plume that had a south-southeastern or southern direction (Figure 4.15).

Simulated river tracer results during the high-river stage period of 2006 are shown in Figures 4.17 and 4.18. The maximum inland extent of the river tracer in 2006 occurred during mid-June. A comparison of the measured electrical conductivity and simulated river tracer results during 2006 are shown in Figure 4.18. Results from the boundary wells, 399-2-1 and 399-1-1, are highly variable due to inflow/outflow conditions on the boundary (i.e., only fresh water enters the north and south domain during inflow conditions near these wells). The electrical conductivity and simulated river tracer have a good match for well 399-2-3 (away from the north and south model boundaries) for the example case; however, the simulated river tracer did not extend far enough inland to fit the measured electrical conductivity response for well 399-1-7. Results are not shown for well 399-1-12 because it showed very little measured response during 2006 (see Figures 2.24 and 2.25) and there was no simulated change in river tracer concentrations (i.e., constant zero value) at this location. 


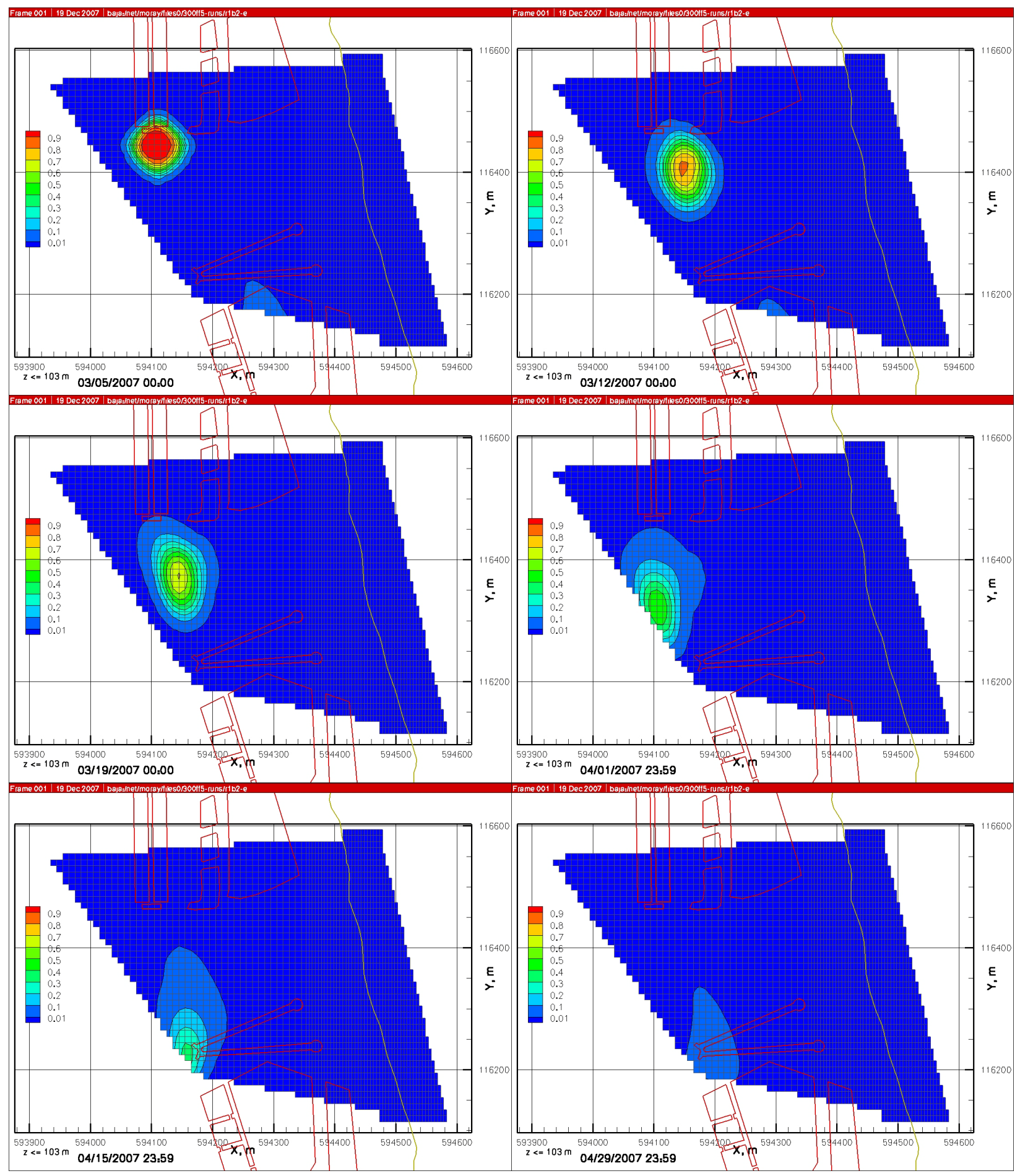

Figure 4.13. Simulated Conservative Tracer Pulse for Small-Scale Model Case r1b2-e During the Initial Seasonal River Stage Increase in March 2007 (see Figure 4.5 for stage and timing). One-million gallons of tracer injected in 1 day $(800 \mathrm{gpm})$ followed by a drift period. Note: The first two figures are 1 week apart with the remaining figures 2 weeks apart. 

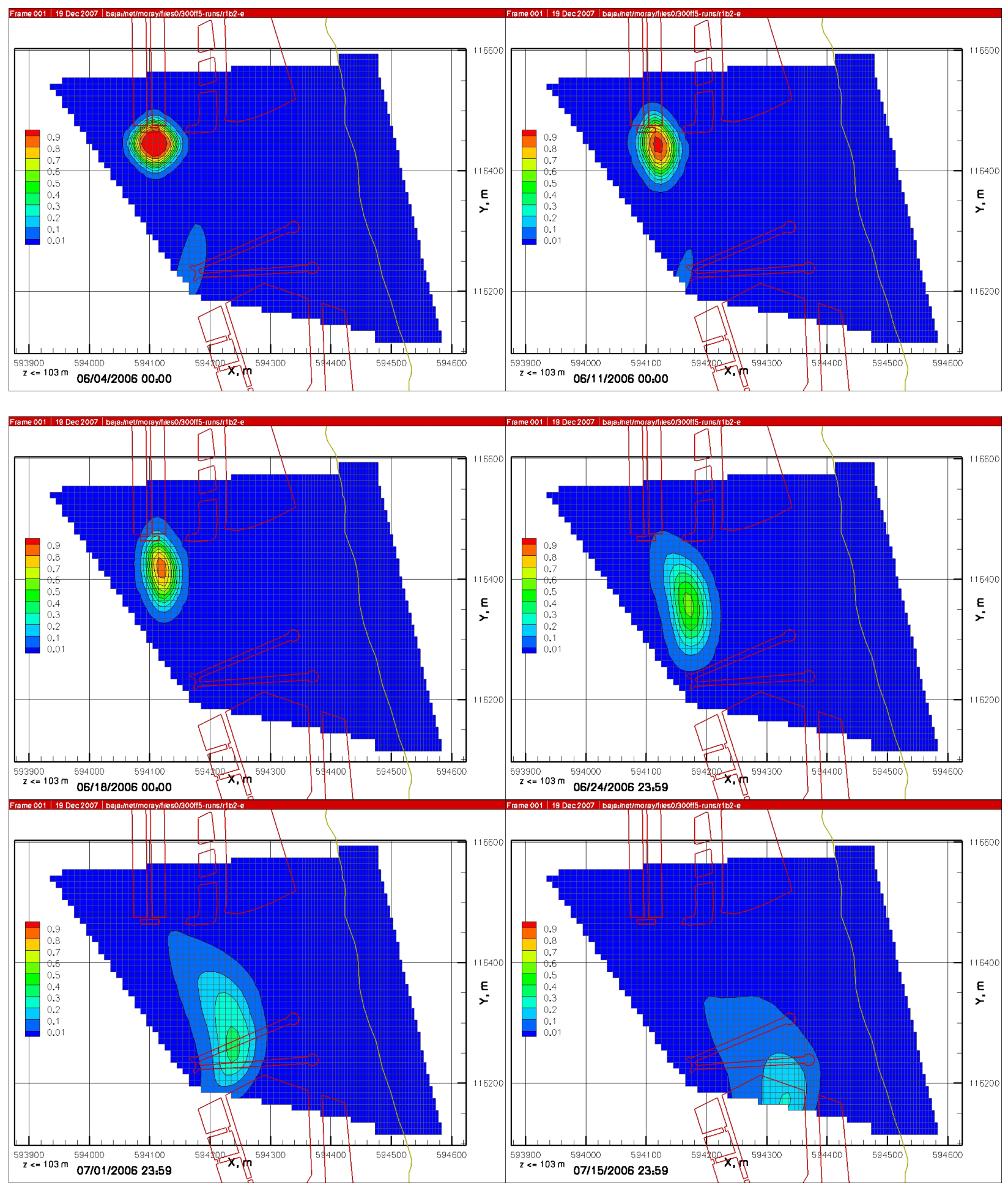

Figure 4.14. Simulated Conservative Tracer Pulse for Small-Scale Model Case r1b2-e During High-River Stage Period in June 2006 Followed by Lower Stage in July 2006 (see Figure 4.5 for stage and timing). One million gallons of tracer injected in 1 day (800 gpm) followed by a drift period. Note: The first through fourth figures are 1 week apart with the remaining figures 2 weeks apart. 

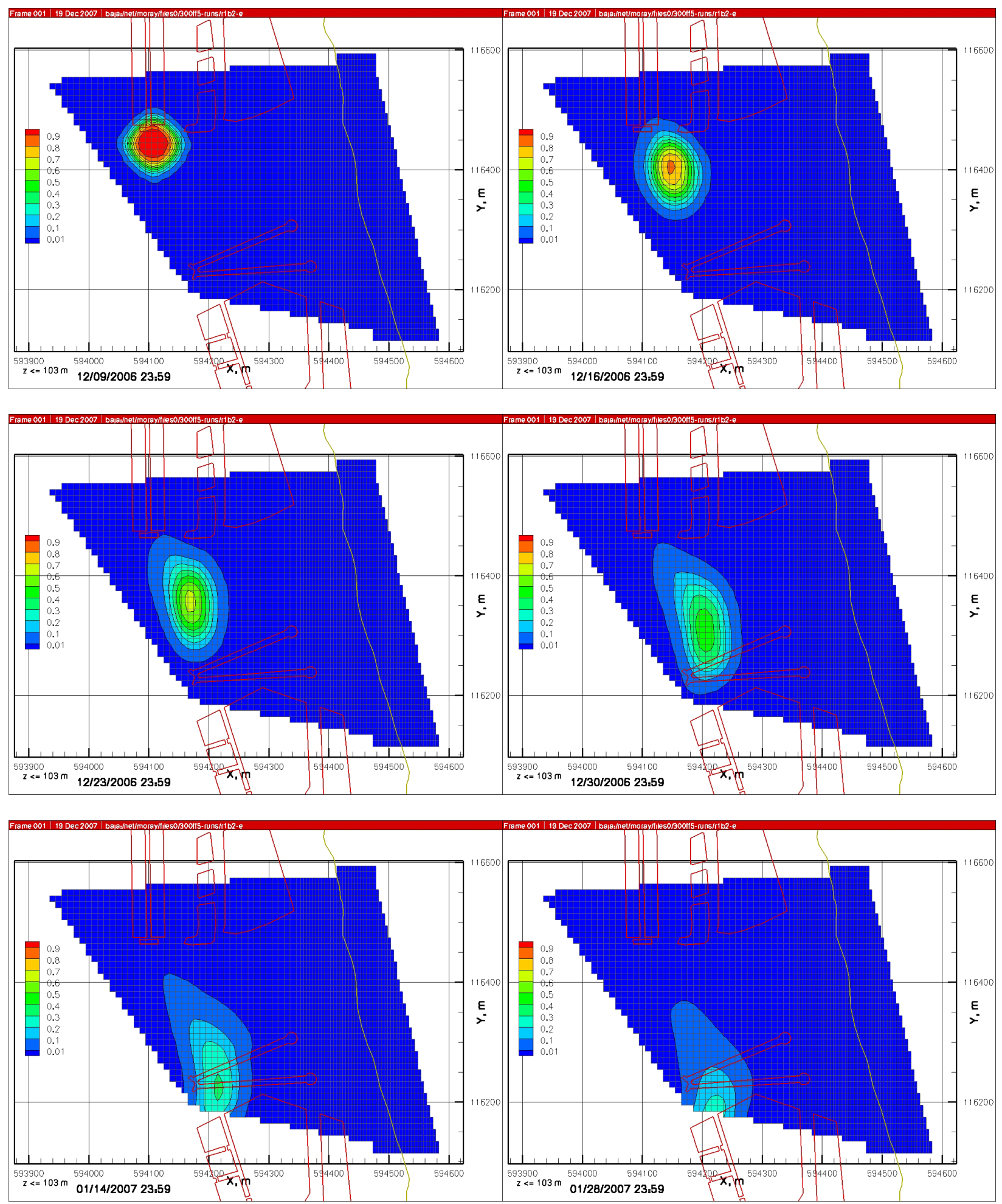

Figure 4.15. Simulated Conservative Tracer Pulse for Small-Scale Model Case r1b2-e During Low-River Stage Period in December 2006 and January 2007 (see Figure 4.5 for stage and timing). One million gallons of tracer injected in 1 day $(800 \mathrm{gpm})$ followed by a drift period. Note: The first through fourth figures are 1 week apart with the remaining figures 2 weeks apart. 
moray/files0/300ff5-runs/r1b2-e

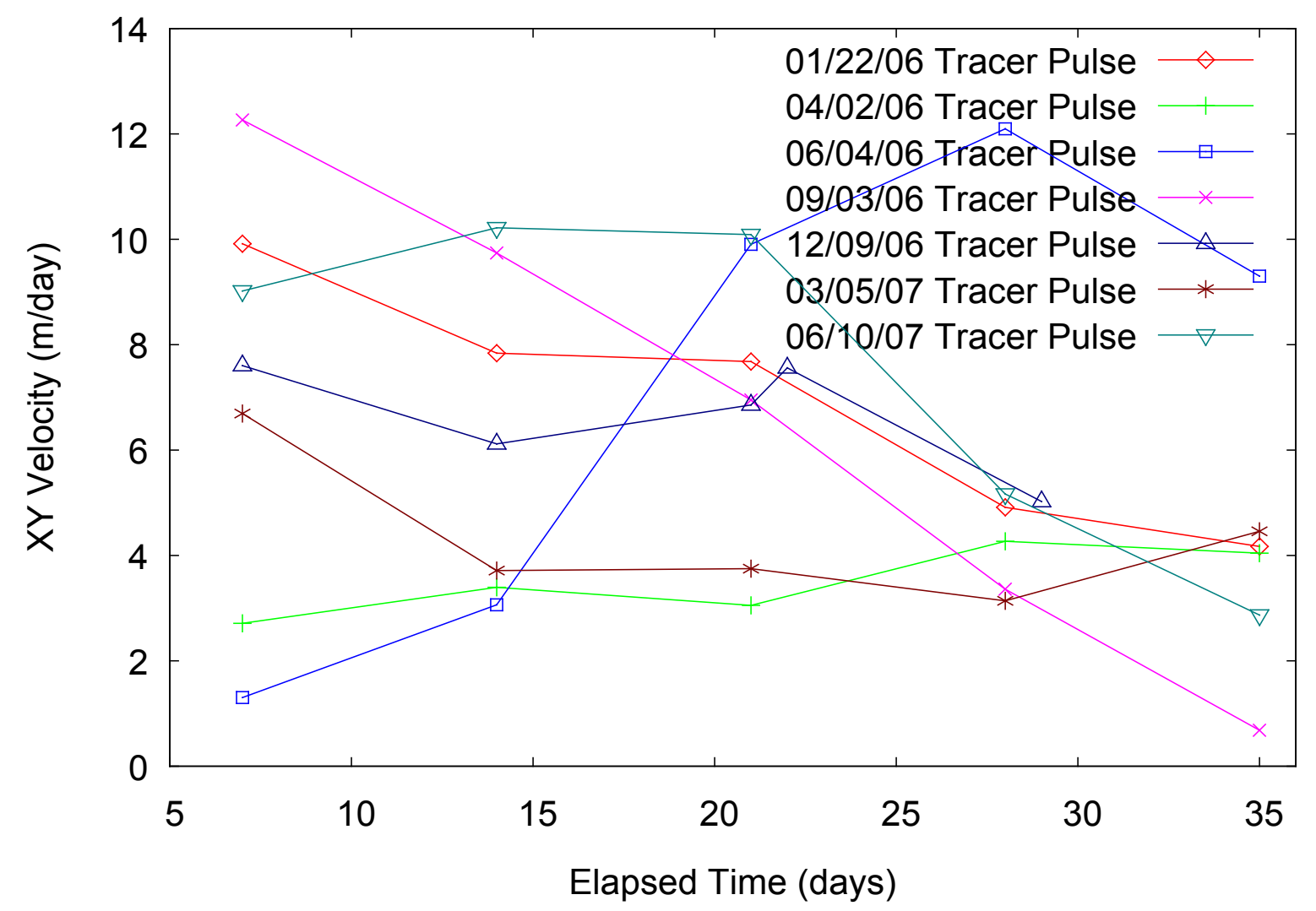

Figure 4.16. Weekly Average Simulated Tracer Horizontal Velocities from Calculated Center of Mass Positions of Tracer Pulses for Case r1b2-e (see Figures 4.12 and 4.13). Times are shown from the end of the 1-day tracer injection. 

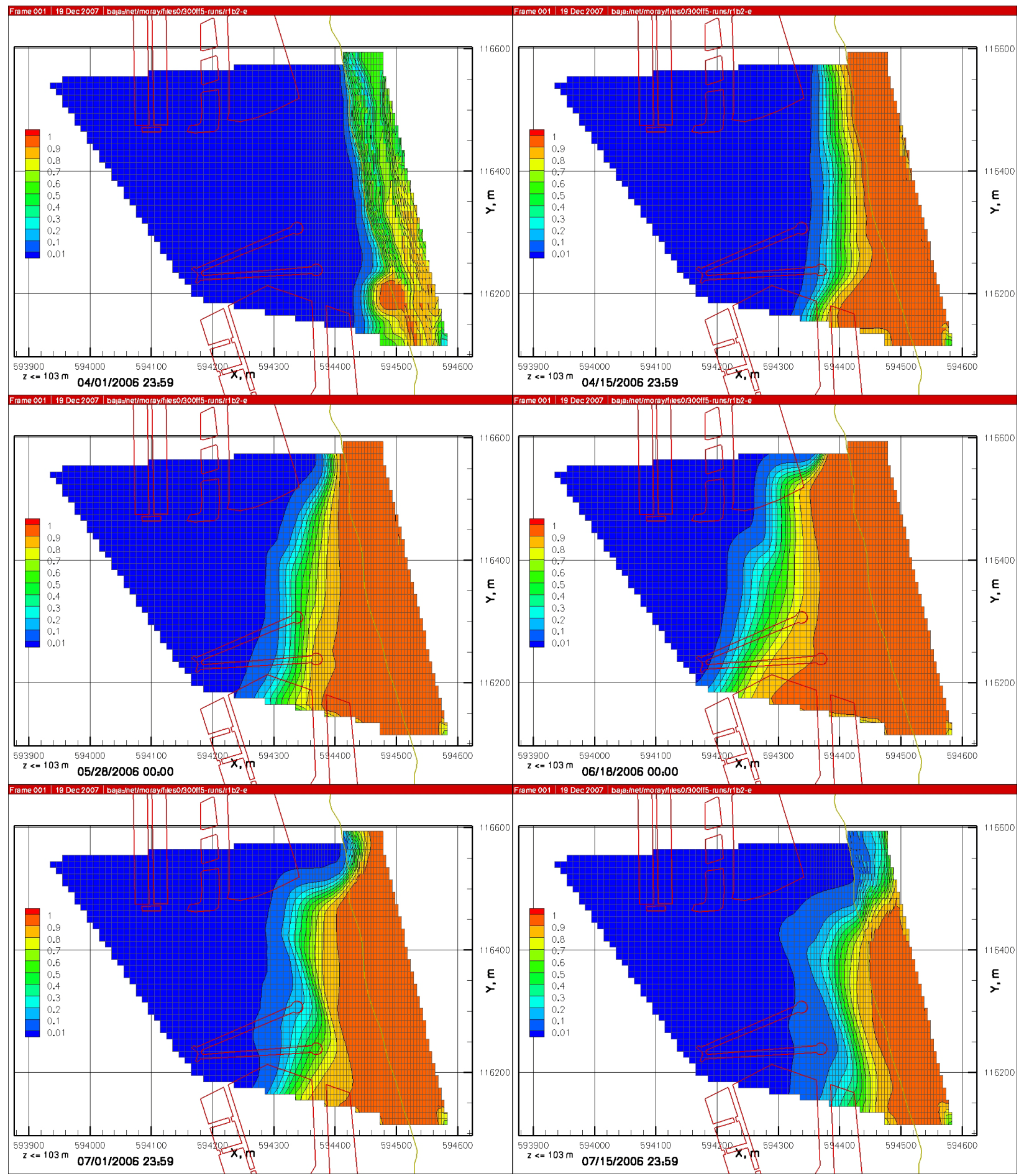

Figure 4.17. Simulated Conservative River Tracer for Small-Scale Model Case r1b2-e During HighRiver Stage Period in 2006 (see Figure 4.5 for river stage during this period) 

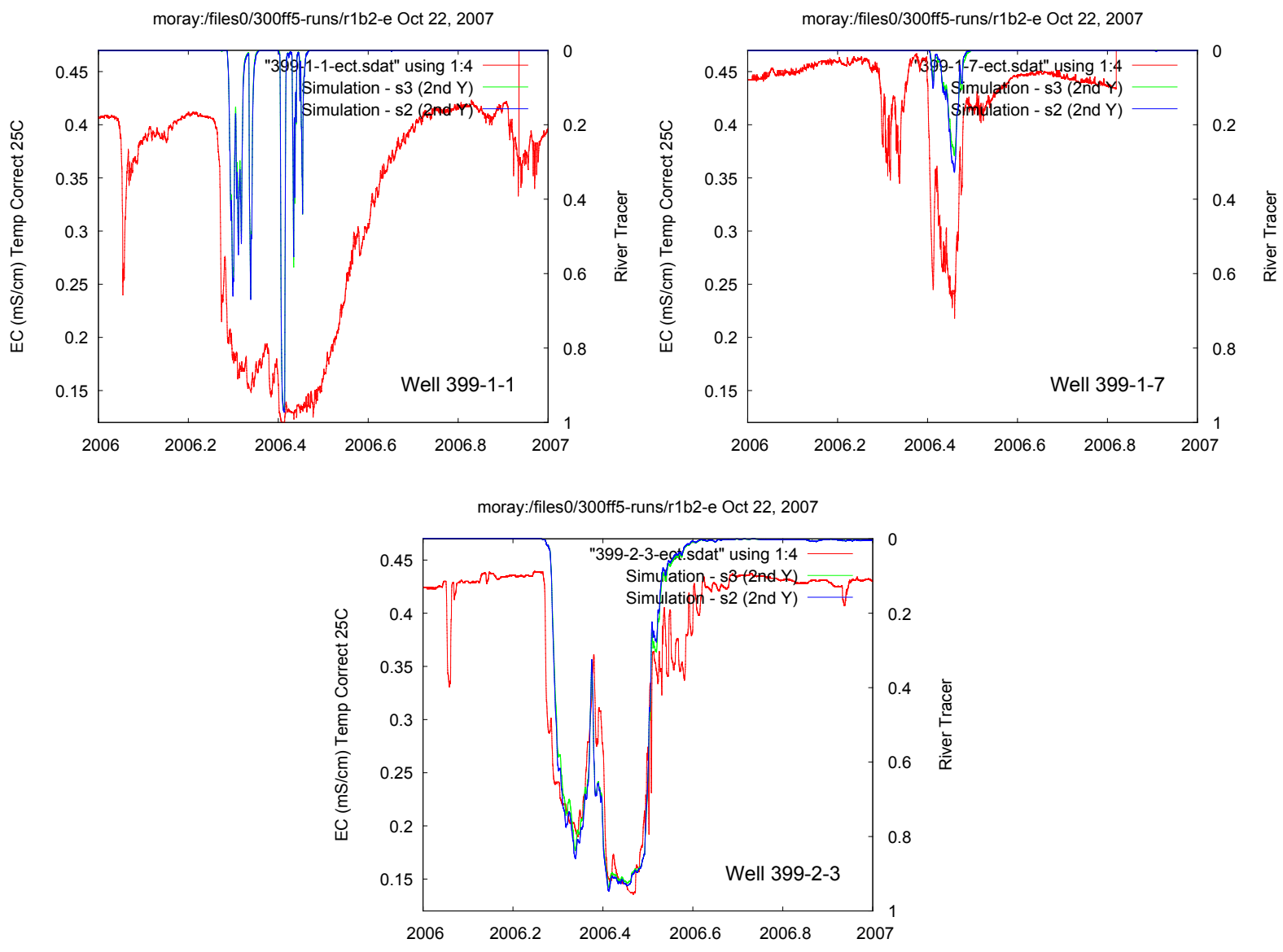

Figure 4.18. Comparison of Simulated River Tracer with Electrical Conductivity Measurements for 2006

\subsubsection{Comparison of Hydraulic Property Cases}

A number of cases were run over a range of hydraulic conductivity values for the Hanford formation and Columbia River alluvium for the small-scale 300 Area groundwater flow and transport model. These cases are shown in Table 4.2 and were selected to evaluate the model response to show the range over these ranges and bracket the hydraulic conductivity values used for the three zones in this model (highand low-K Hanford zones and river alluvium zone). The number of cases evaluated was limited by the simulation execution time of 7 to 8 days per case on Linux dual-processor Xeon ${ }^{\circledR 1}$ (Pentium 4, ranging from 3.2 to 3.6 gigahertz) workstations. The cases were evaluated with respect to the SSRs for the waterlevel measurements over the simulation period, the simulated plume-drift compared to groundwater velocity estimates from field tests, and the inland extent of simulated river tracer as compared to groundwater electrical conductivity measurements. A comparison of the cases is provided in the following sections. The overall water fluxes for these cases are also provided to show the range of groundwater fluxes over the range of hydraulic conductivity values tested.

\footnotetext{
${ }^{1}$ Xeon is a registered trademark of Intel Corporation in the U.S. and other countries.
} 


\subsubsection{Hydraulic Head Fit}

The calculated SSRs for the water-level measurements for all the cases are compared in Figure 4.19. Case r1b2-k, which had the highest hydraulic conductivity value for the Hanford formation of the cases tested, had the best fit based on the residual analysis; however, SSR results for several other cases were close to this value. The cases with the lowest SSR were all cases where the Hanford formation was subdivided into two hydraulic conductivity zones and had the lowest values for the river alluvium zone.

As shown in Figure 4.19, the cases with low hydraulic conductivity in the river alluvium zone had the largest impact on reducing the overall residuals. This zone significantly dampens the magnitude of the river stage fluctuations on the near-river wells (e.g., 399-2-2 and 399-2-3). The case without the lower hydraulic conductivity value for the river alluvium zone (r1b2-g) had the largest overall SSRs of the cases tested. The lowest hydraulic conductivity value of the river alluvium tested had a better fit compared to higher hydraulic conductivity values (compare cases r1b2-c, r1b2-d, and r1b2-e that used $3 \mathrm{~m}[9.8 \mathrm{ft}], 2 \mathrm{~m}$

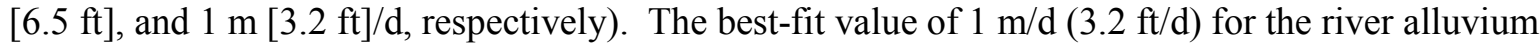
hydraulic conductivity is dependent on a relatively thin layer that is resolved with three vertical nodes. The values for the river alluvium used in these simulations may not be directly comparable to field measurements due to the effective thickness and hydraulic property averaging within the STOMP code with adjacent nodes for this thin layer (see Section 4.2.3 below for results with a finer vertical grid spacing).

Increasing the hydraulic conductivity in the Hanford high-K zone resulted in lower overall hydraulic head residuals (for the same hydraulic conductivity values in the other zones). The residuals for a $10,000 \mathrm{~m} / \mathrm{d}$ case were lower than 8000,7000 and $4000 \mathrm{~m} / \mathrm{d}$ cases (comparing case r1b2-k with r1b2-h, r1b2-e, and r1b2-f). Simulations with the lower values for the Hanford low-K zone had lower residuals. Case r1b2-b, which had the Hanford low-K zone set to the same hydraulic conductivity value as the Hanford high-K zone, had a much larger SSR than simulations with lower values for this zone (compare to case $\mathrm{r} 1 \mathrm{~b} 2 \mathrm{c}$, which had the same K values for the other zones). Case r1b2-b had the second highest overall SSR as shown in Figure 4.19. However, case r1b2-b also had a higher K-value for the river alluvium zone than the lowest SSR cases.

The impact of the Hanford Low-K zone can be seen by comparing SSR results for case r1b2-b, which had a single value specified for the entire Hanford formation, with case r1b2-c where the low-K zone had a value of $36 \%$ of the high-K zone (all other parameters were the same). The SSR results in Figure 4.19 shows a much better fit for the two-zone case. A pair of cases (r1b2-e and r1b2-mns) can be compared to determine the impact of an intermediate value for the Hanford low-K zone ( $36 \%$ and $57 \%$, respectively). The lower-K value case had a better SSR fit than the higher-K value case, as shown in Figure 4.19.

\subsubsection{Simulated Tracer Plume Drift}

Tracer plume drift velocities calculated from the weekly change in the plume center of mass are shown for selected cases in Figure 4.20. This figure shows the lower tracer velocities for the $4000 \mathrm{~m} / \mathrm{d}$ Hanford high-K zone (r1b2-f) and the greater tracer velocities for the 10,000 m/d Hanford high-K zone case (r1b2-k) compared to the example case $(7000 \mathrm{~m} / \mathrm{d}$ for $\mathrm{r} 1 \mathrm{~b} 2-\mathrm{e})$ in Figure 4.16 . While the simulated tracer velocities for the $10,000 \mathrm{~m} / \mathrm{d}$ case were higher than the example case, they were still slightly below the $15.2-\mathrm{m} / \mathrm{d}(50-\mathrm{ft} / \mathrm{d})$ value determined for the polyphosphate tracer test conducted in December 2006. 

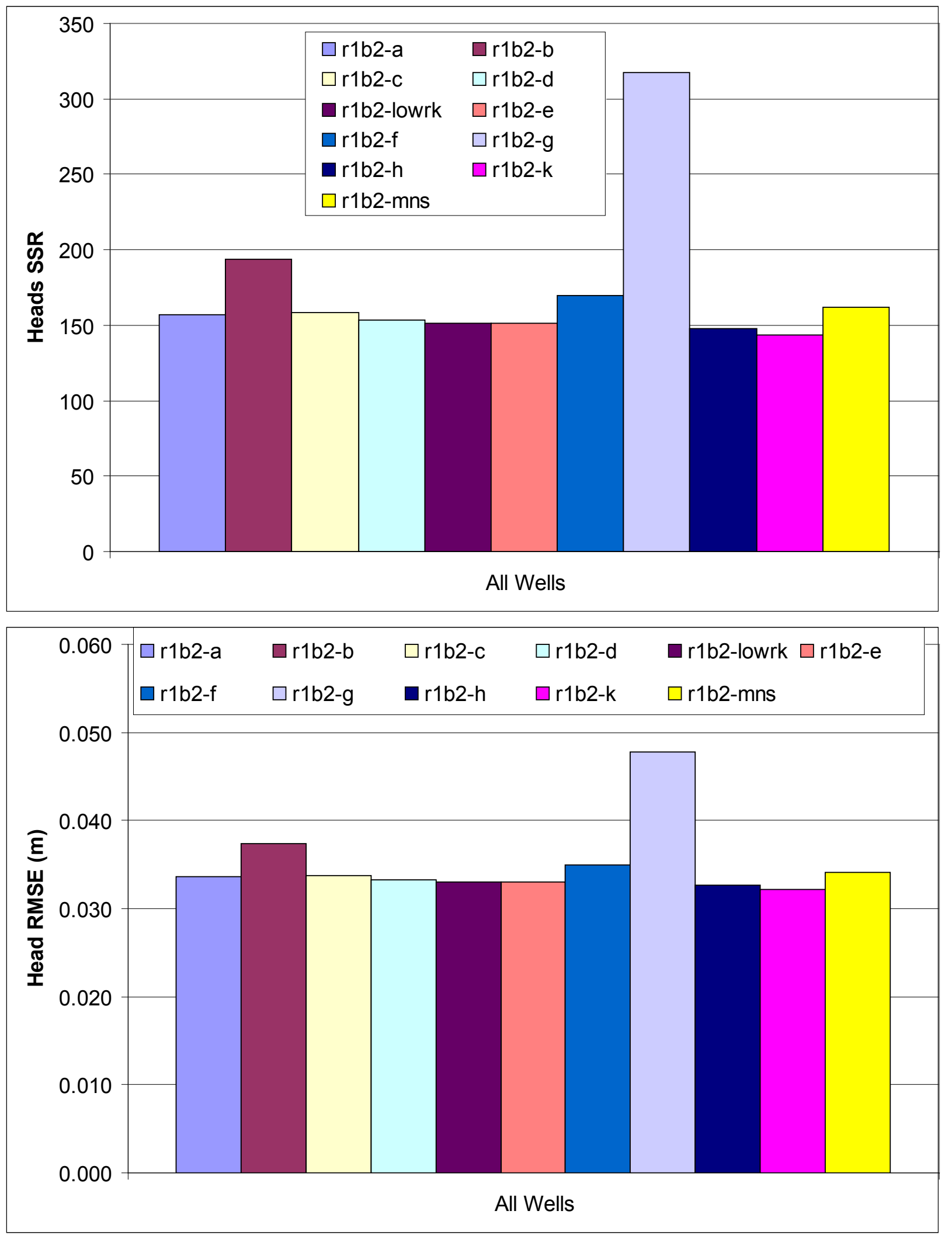

Figure 4.19. Comparison of Water-Level Measurement Fit of Small-Scale 300 Area Model Cases. Sum-of-squared residuals are calculated based on Equation (3.17). 

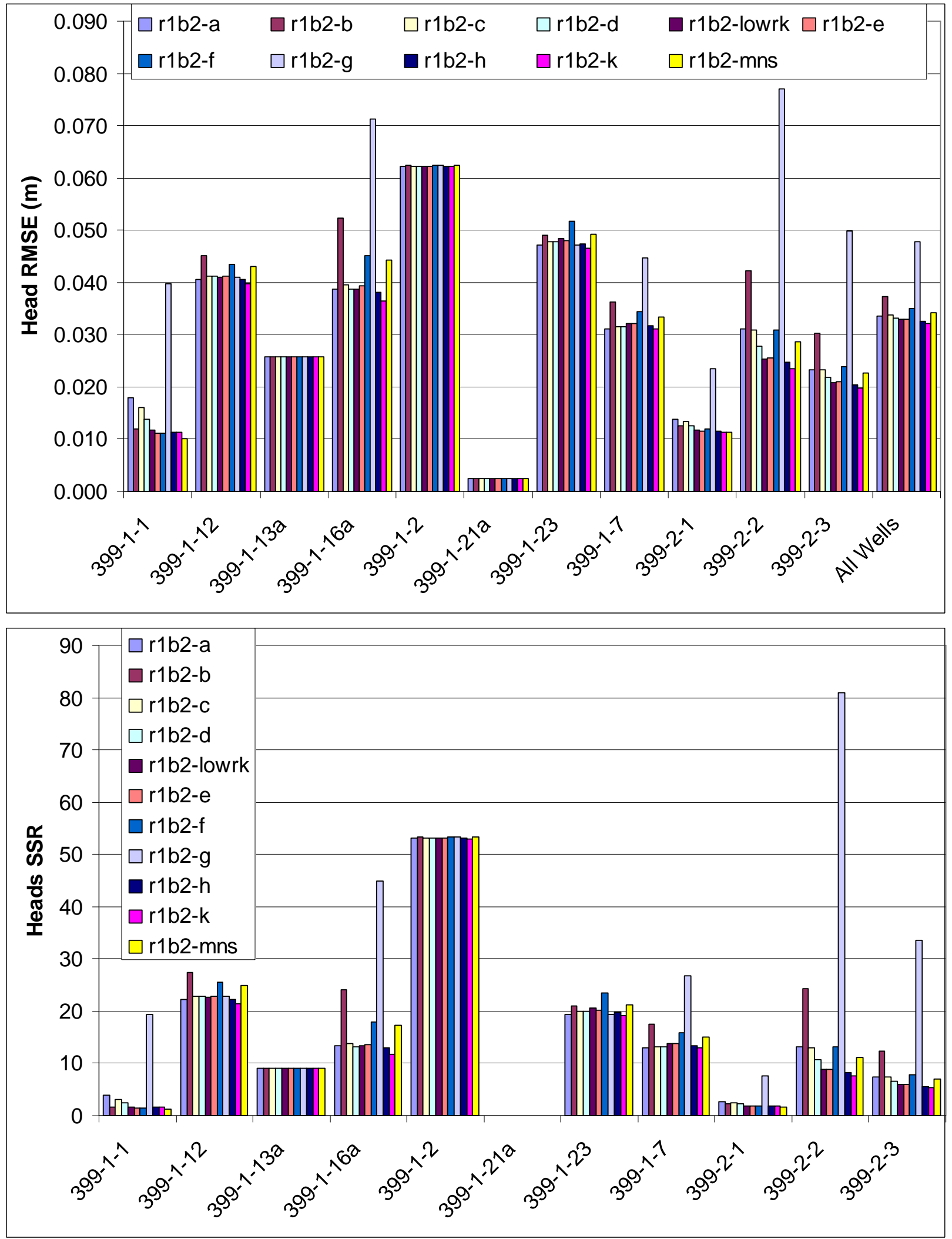

Figure 4.19. (Cont.) 
Figure 4.21 shows the December tracer pulse plume for case $\mathrm{r} 1 \mathrm{~b} 2-\mathrm{g}$, which is the simulation similar to the example case (r1b2-e) but without the river alluvium zone (compare to Figure 4.15). The direction of this plume has a more southeast trajectory during the first 4 weeks of drift than the example case.

Increasing the hydraulic conductivity values of the Hanford lower-K zone or river alluvium provide more groundwater flow toward the river instead of being directed predominantly to the south during low-river stage conditions.
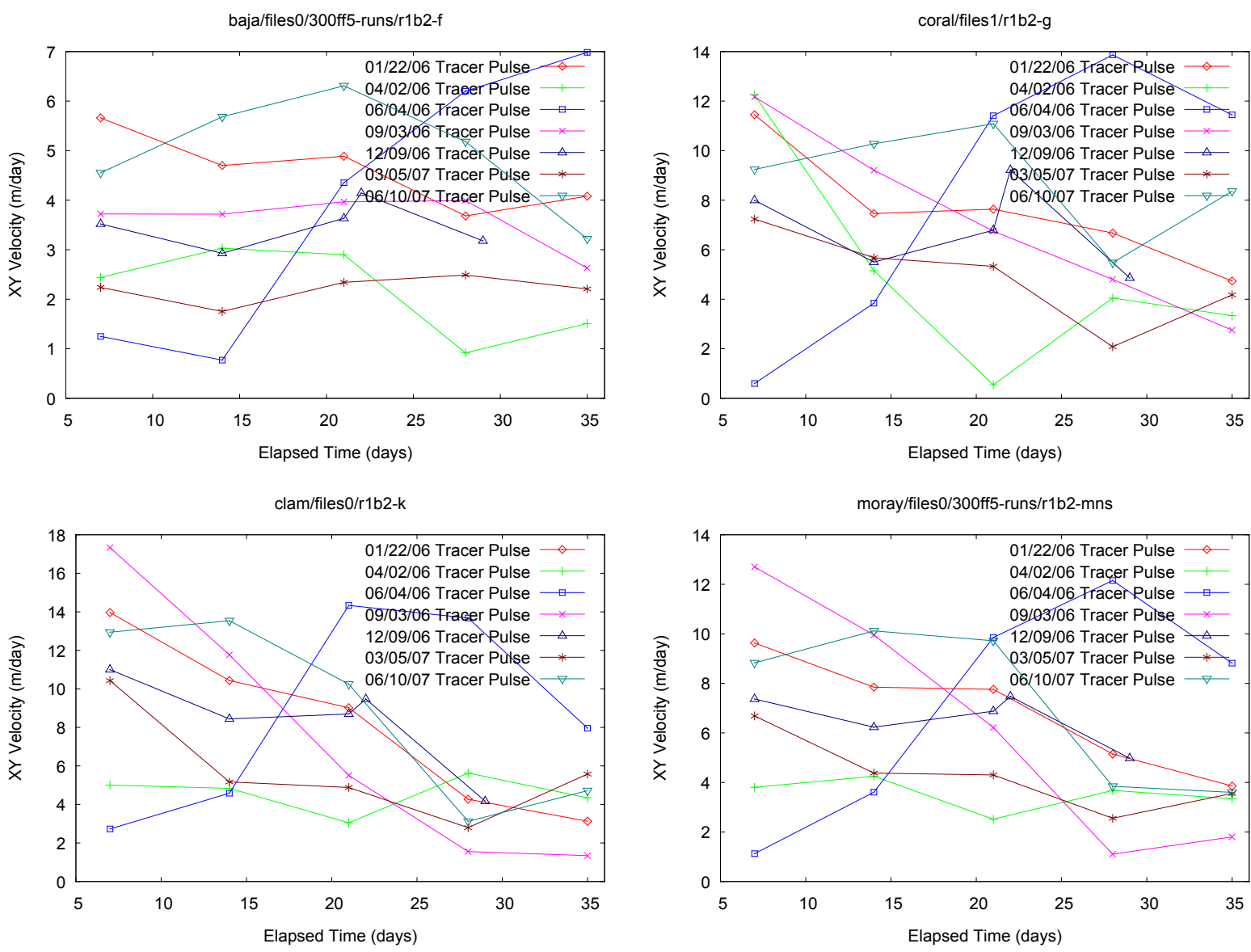

Figure 4.20. Comparison of Weekly Average Tracer Simulated Velocities ( $x-y$ magnitude) from Calculated Center of Mass Positions of Tracer Pulses for Selected Cases. Times are shown from the end of the 1-day tracer injection. Compare with the example case in Figure 4.16. Some pulses for r1b2-f may be biased due to remnant plumes from prior pulses.

\subsubsection{Inland Extent of River Water}

Figure 4.22 shows the maximum inland extent of the simulated Columbia River water tracer for selected cases. These can be compared to the river tracer plumes at different times for the example case (r1b2-e) in Figure 4.17. The difference in the maximum inland extent of river tracer from changes in the values of the Hanford high-K zone were small (cases r1b2-f and r1b2-e) because the Hanford low-K zone and river alluvium control the near-shore fluxes. Figure 4.22 shows a dramatic increase in the inland extent of the river water for the case with no river alluvium (compare case r1b2-g in Figure 4.22 with the detailed example case r1b2-e in Figure 4.17). Increasing only the hydraulic conductivity of the Hanford 
low-K zone had only a small impact on the inland extent of the river tracer (compare case r1b2-mns in Figure 4.22 with detailed example case r1b2-e in Figure 4.17).

The coverage of the electrical conductivity measurements from the automated monitoring network (described in Section 2.3.1.1) are not sufficient to determine the maximum extent of river water intrusion during the high-river stage period of 2006, except that it fell between wells 399-1-7 and 399-1-12 during this time (see Figure 2.25). However, there have been some low electrical conductivity measurements during high-river stage conditions measured in well 399-1-17a (which is further inland than 399-1-7; see Figure 1.2) from semiannual groundwater monitoring.

\subsubsection{Water Flux Comparison}

A comparison of the simulated annual cumulative water fluxes calculated for 2006 along the model boundaries for all the cases is shown in Figure 4.23. Natural recharge was omitted from this figure because it was constant for all the cases (see Figure 4.12 for values from the example case). The direction of the cumulative flux along the boundaries (i.e., in or out of the model domain) was the same for all the cases except for case r1b2-b. In general, water fluxes along the southern, western, and northern boundaries were larger for the cases with the larger hydraulic conductivity values for the Hanford high-K zone. Case $\mathrm{r} 1 \mathrm{~b} 2-\mathrm{k}$ with a $10,000 \mathrm{~m} / \mathrm{d}$ hydraulic conductivity for the Hanford high-K zone had the highest fluxes overall. Cases with larger-K values for the river alluvium and Hanford low-K zone also had higher fluxes (e.g., r1b2-g and r1b2-a).

Case r1b2-b did not have a Hanford low-K zone (its hydraulic conductivity value was set to the same value as the Hanford high-K zone as shown in Table 4.2) and it showed inflow from the northern boundary and outflow for the river boundary. This case also had the largest outflow on the southern boundary.

The cumulative annual water flux from the river boundary was relatively small compared to the other boundaries for all these cases (Figure 4.23). Note the cumulative annual river flux is a net value and does not indicate the amount of river water or groundwater exchange that occurred. As discussed in Section 4.2.1, the period chosen for calculating this value is also important.

\subsubsection{Refined Vertical Node Grid Spacing Model - R1C}

As discussed in Section 4.1.1, the vertical grid refinement of the model is important to the simulation results because of the fluctuating water table and the resolution of the river channel and thin river alluvium layer. A refined grid was built with the vertical node spacing decreased from $0.5-\mathrm{m}$ spacing for the vadose zone and upper portion of the aquifer to $0.25 \mathrm{~m}$. The lower elevation of the $0.25-\mathrm{m}$ vertical grid refinement also includes most of the upper portion of the riverbed, particularly near the shoreline (see Figure 4.24). For the refined grid, the river alluvium zone was assigned to the six uppermost nodes below the river bathymetry for the river alluvium layer (compared to three nodes for the standard grid). This refinement more than doubled the number of active nodes (2.4 times) from 55,030 nodes for the standard grid to 130,101 for the refined model. Simulation times increased from 7 days with the standard grid to 12 days with the refined grid (which was also on a slightly faster machine).

Hydraulic properties for the refined grid model (r1c) are the same as the highest-K standard grid case r1b2-k (see Table 4.2), which had the lowest overall hydraulic head residuals of the cases run. Hydraulic 
head SSRs were very close for the wells in the two cases, as shown in Figure 4.25. The difference in the overall SSR was $1.25 \%$ with the refined grid having the slightly lower value. Differences in the annual cumulative water fluxes are shown in Figure 4.26. The percentage difference between the cases for the cumulative annual flux for the river boundary was the largest at $38 \%$; however, the absolute difference in this value was relatively small $\left(7800 \mathrm{~m}^{3}\right)$ compared to the annual net system flux $\left(>1,500,000 \mathrm{~m}^{3}\right)$. The cumulative net fluxes were the same for both cases for the southern boundary and were $6 \%$ and $2 \%$ smaller with the refined grid for the northern and western boundaries, respectively. A visual comparison of the plots of the tracer and river tracer plumes for both cases were similar. The lower computational requirements for the coarser model, while providing similar results to the finer-resolution model, permitted more cases to be evaluated for this study. 

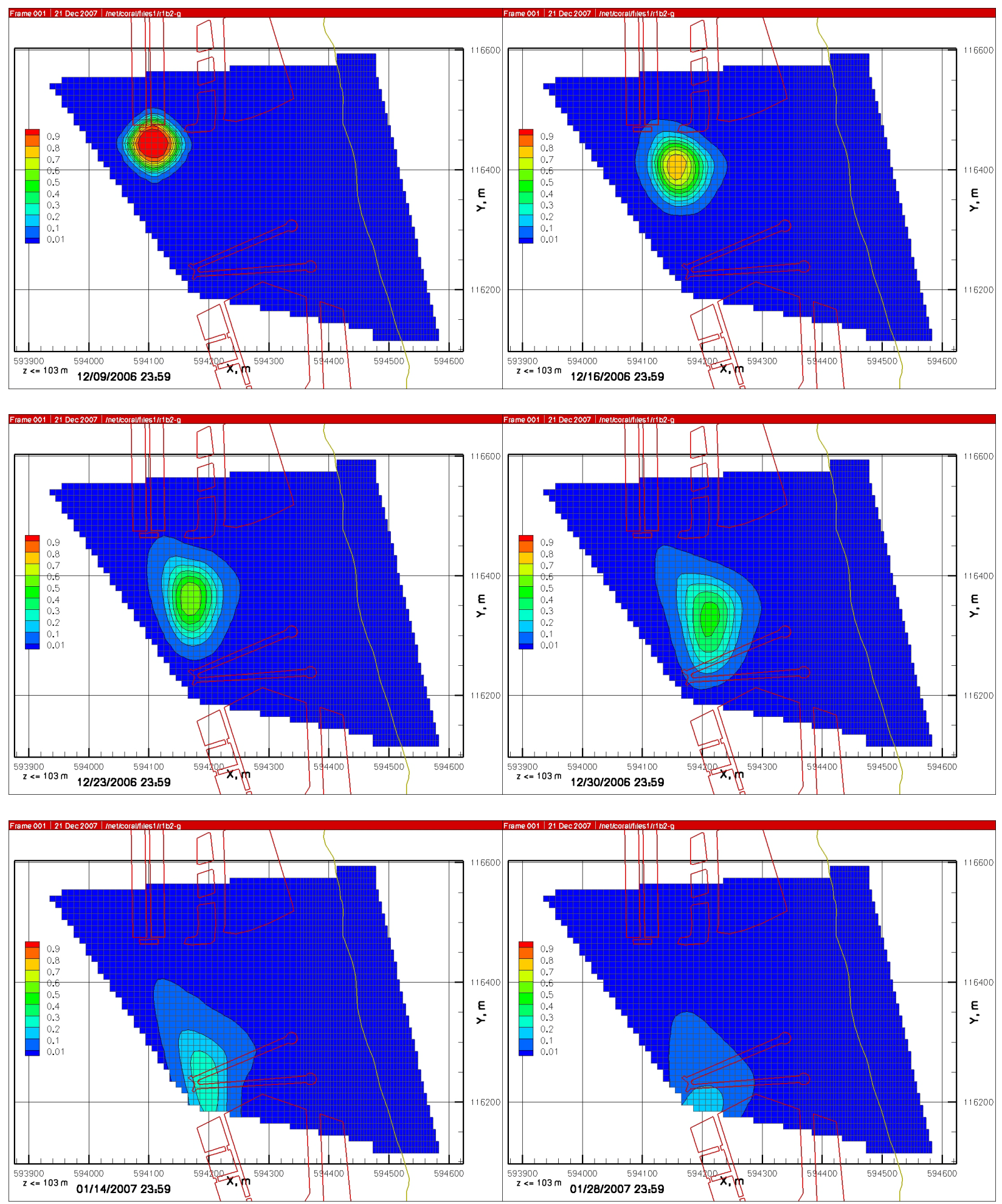

Figure 4.21. Simulated Conservative Tracer Pulse for Case r1b2-g During the Low-River Stage Period in December 2006 and January 2007 (see Figure 4.4 for river stage and timing). Note: The first through fourth figures are 1 week apart, with the remaining figures being 2 weeks apart. Compare to results for the example case (Figure 4.15). 

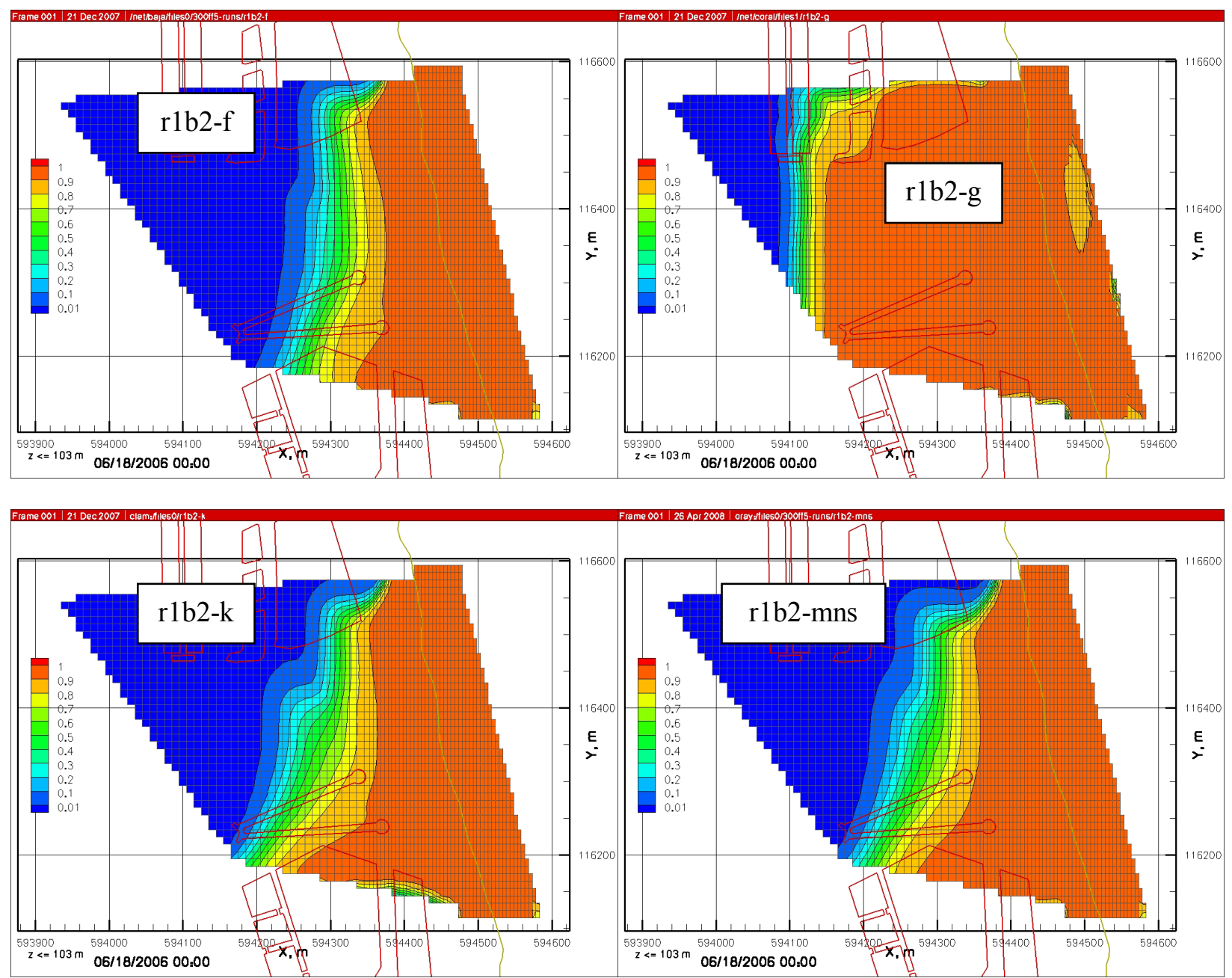

Figure 4.22. Comparison of Simulated Conservative River Tracer Maximum Inland Extent for Selected Cases During the High-River Stage Period in 2006 (see Figure 4.4 for the river stage during this period). Compare to the results for the example case (Figure 4.17). 


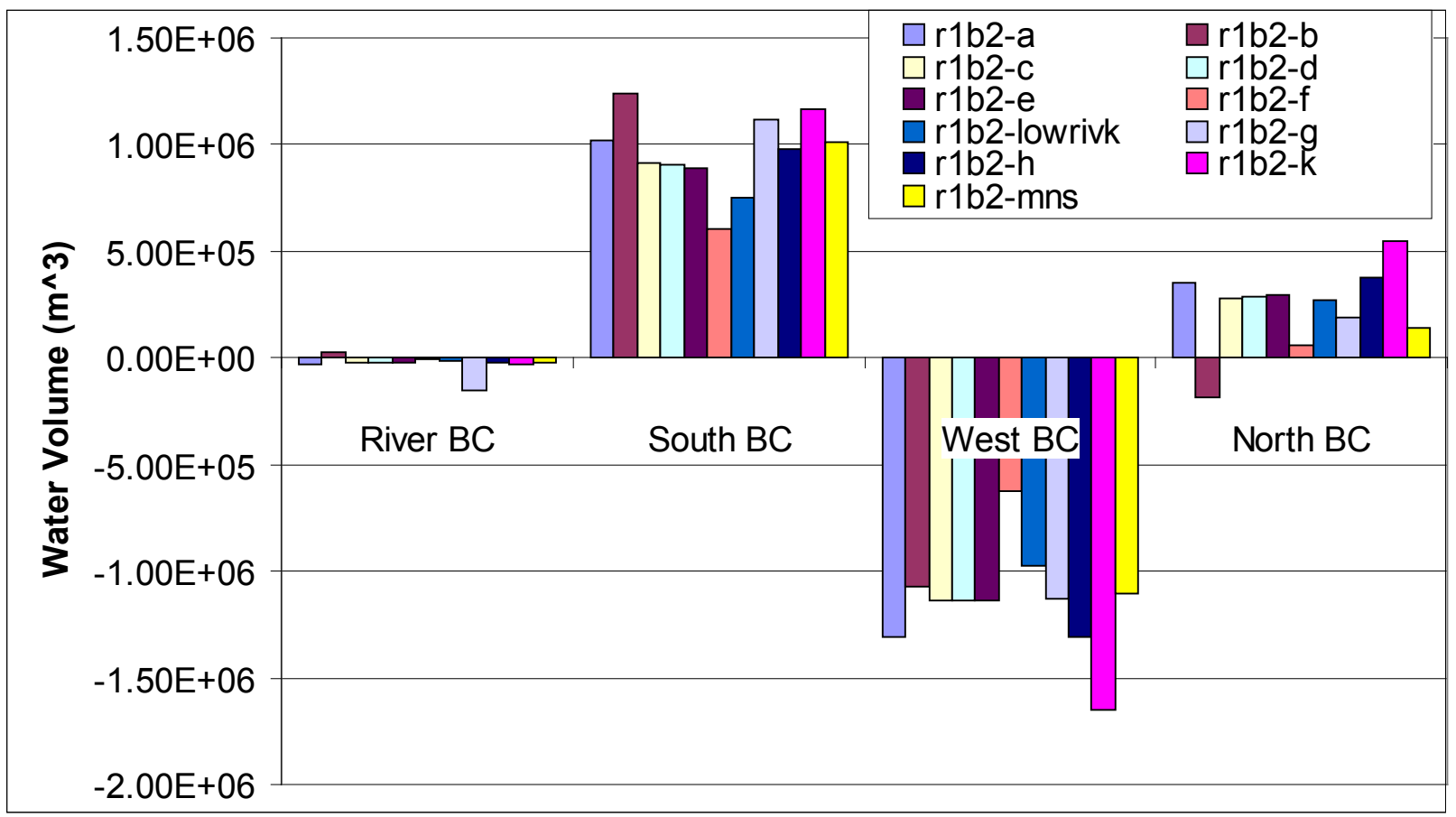

Figure 4.23. Comparison of Simulated Cumulative Net Annual Water Fluxes for the Small-Scale 300 Area Model Cases for 2006. Positive values indicate flow directed out of the model domain and negative values are for flow into the model domain. See Table 4.2 for case descriptions. Shoreline distance $=480 \mathrm{~m}$. 


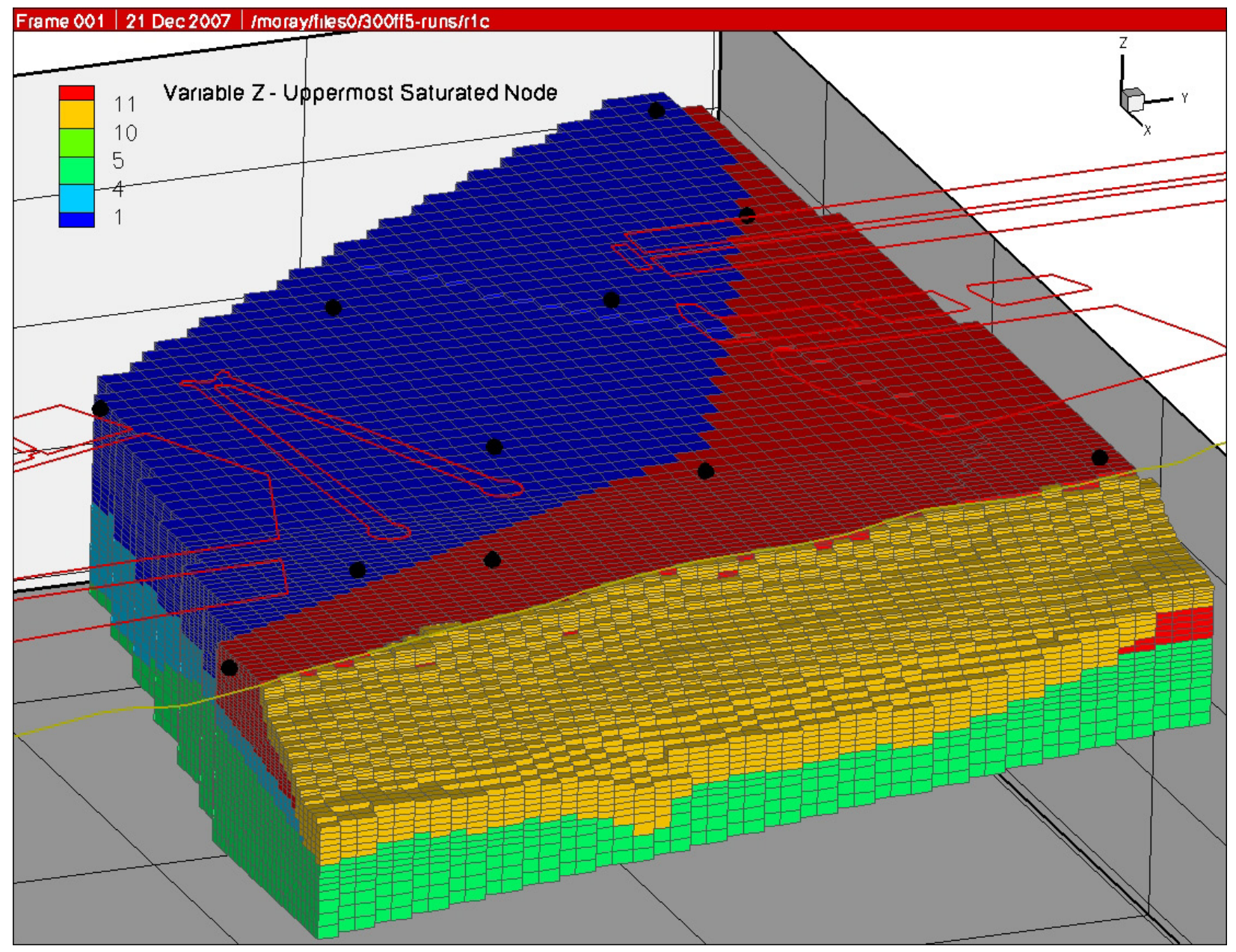

Figure 4.24. Three Dimensional View of the Hydraulic Property Zonation for the Refined Vertical Node Spacing $(0.25 \mathrm{~m})$ Small-Scale 300 Area Model. The top surface is the uppermost saturated node at model initial conditions (i.e., based on January 1, 2006). 


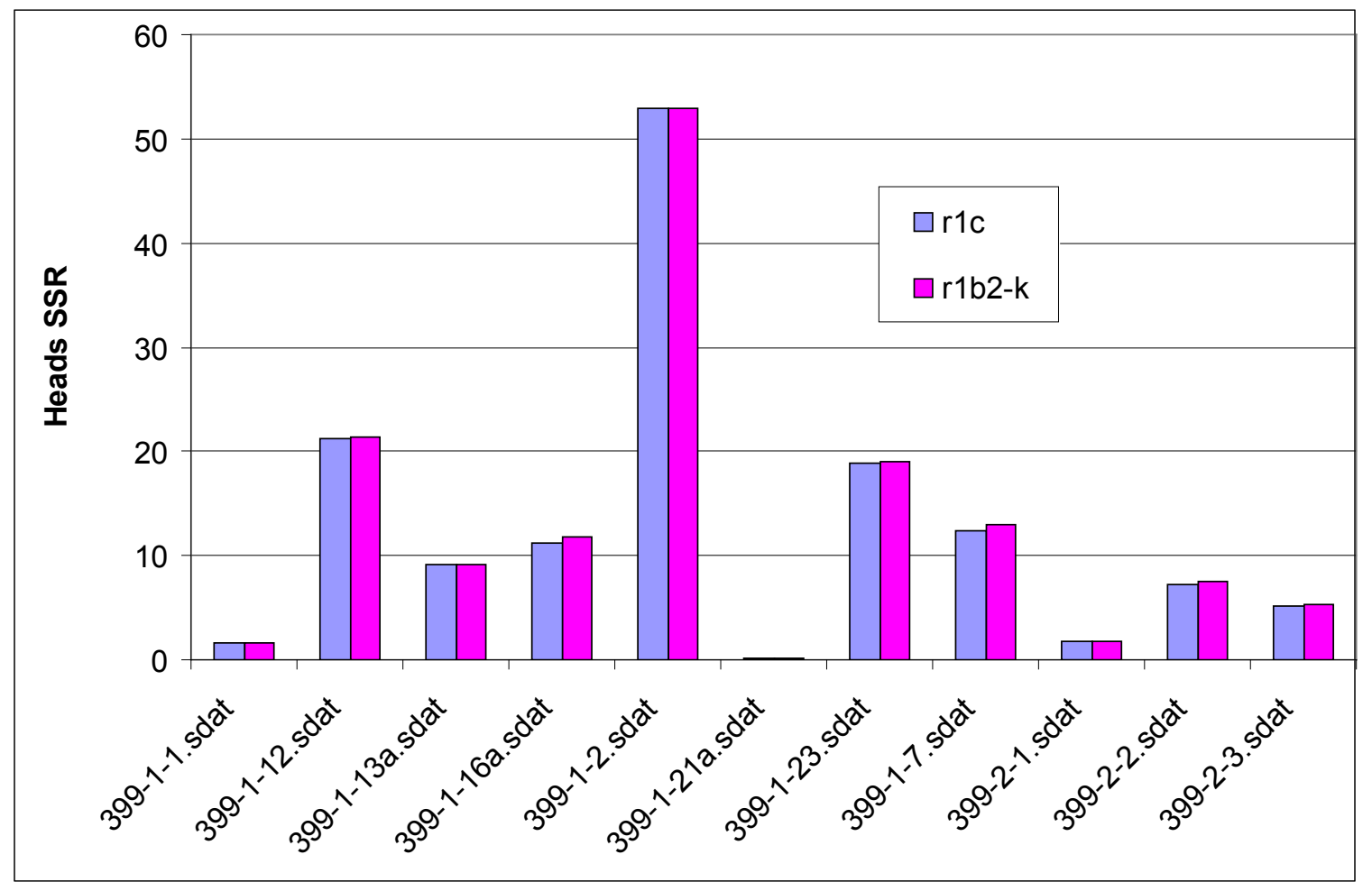

Figure 4.25. Comparison of Water-Level Measurement Fit for the Small-Scale 300 Area Model Cases With Refined Vertical Grid (r1bc) and Standard Grid (r1b2-k)

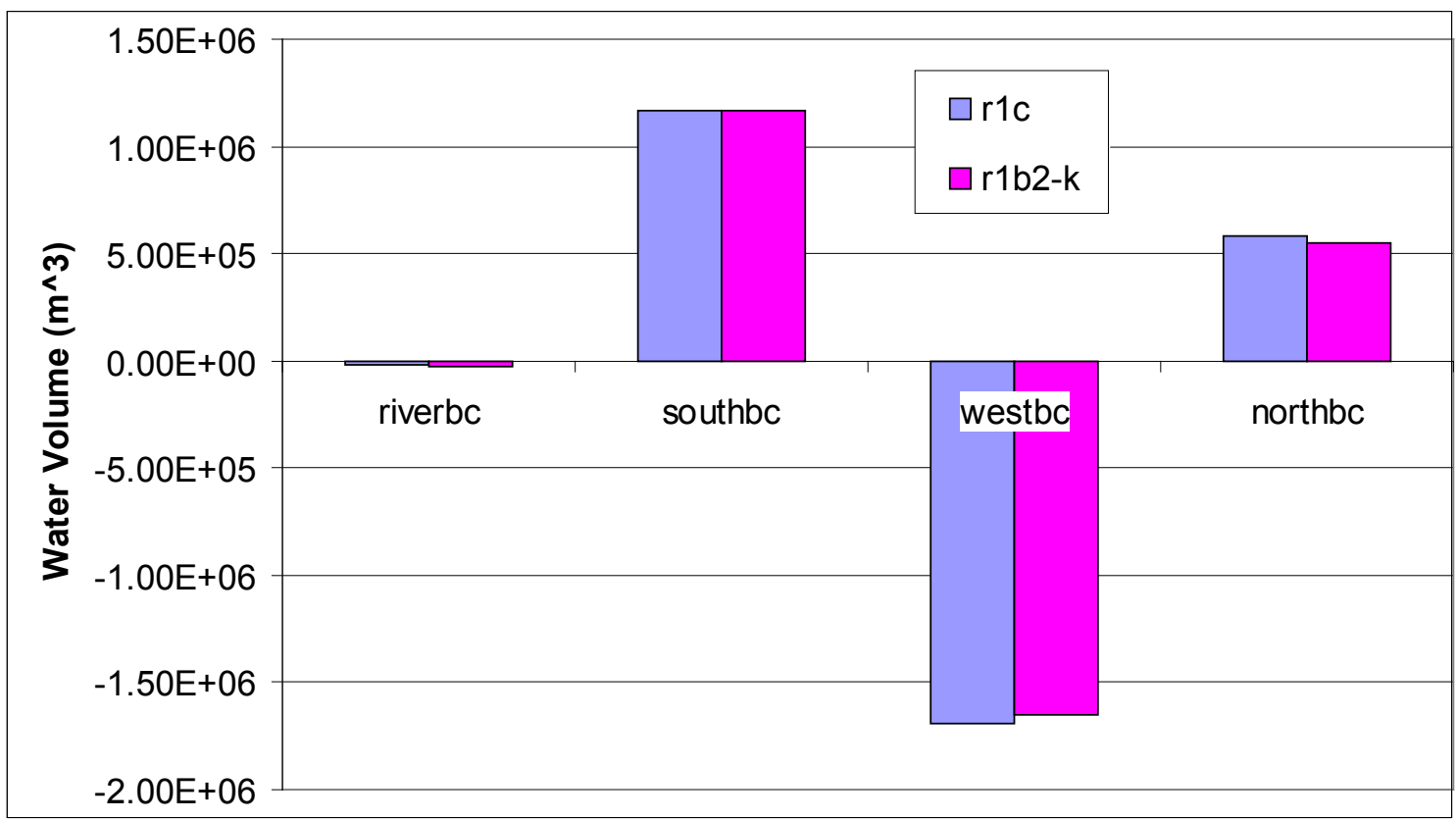

Figure 4.26. Comparison of Cumulative Net Annual Water Fluxes for the Small-Scale 300 Area Model Cases with Refined Vertical Grid (r1bc) and Standard Grid (r1b2-k). Positive values indicate flow directed out of the model domain and negative values are for flow into the model domain. 



\subsection{Summary and Recommendations}

\subsection{Summary}

Groundwater flow rates and directions in the 300 Area are very dynamic because of the high-hydraulic conductivities, along with the large daily, weekly, and seasonal fluctuations in the Columbia River stage. Quantifying the dynamics of groundwater flow and transport in the 300 Area aquifer will help understand the significant seasonal variability of the uranium plume concentrations seen in biannual groundwater monitoring, and will help evaluate remediation options. Groundwater flow rates are very high in the upper portion of the 300 Area unconfined aquifer (within the Hanford formation), with velocities up to 10 to $15 \mathrm{~m} / \mathrm{d}$ (35 to $50 \mathrm{ft} / \mathrm{d}$ ) based on a tracer test and limited plume-migration data (Peterson et al. 2008a). Variability in the groundwater-flow directions is apparent from analysis of hourly and subhourly automated water-level measurements from monitoring networks established in the 300 Area. Generalized flow directions in the area between the north and south process ponds are toward the east to south, with the directions changing toward the south and west during periods of increases in the river stage (daily and seasonal).

High-resolution water level and river stage data were required to simulate the dynamics of the 300 Area aquifer. Two scales of groundwater flow and transport models were developed based on the availability of high-resolution water-level monitoring data. A larger-domain model was developed that includes the 300 Area and extends north and south using data from the early 1990s water-level monitoring network. A smaller domain model was developed for the northern portion of the large-scale model domain that used water-level data from another well network established in 2004. These models focus on the highly permeable upper portion of the unconfined aquifer within the Hanford formation that has hydraulic conductivity values 2 to 3 orders of magnitude higher than the underlying Ringold Formation aquifers. These models simulate saturated and unsaturated groundwater flow and transport that use the STOMP code (White and Oostrom 2000, 2004). The model domains include the lower portion of the vadose zone to encompass the range of river stage and water-table elevation variations seen during the simulation periods.

The large-scale x-y-z finite difference grid was $70 \times 122 \times 33$ nodes (respectively, 281,820 total nodes that included 39,539 inactive nodes). Nodes are inactive outside the polygon defined by the locations of boundary condition wells and nodes above the Columbia River streambed. Grid spacing was variable in the large-scale model, with a range from $\sim 100 \mathrm{~m}$ to $10 \mathrm{~m}$ in the $\mathrm{x}-\mathrm{y}$ directions and from $1 \mathrm{~m}$ to $0.5 \mathrm{~m}$ in the vertical direction. Finer $\mathrm{x}-\mathrm{y}$ node spacing was specified in the portion of the domain near the river that had steeper hydraulic gradients. Finer z-node spacing was specified in the vadose zone and within the zone of water-table fluctuations. The small-scale model x-y-z grid was $93 \times 48 \times 31$ nodes (respectively, 138,384 total nodes that included 55,030 inactive nodes). Grid spacing for the small scale model was constant in the $y$-direction $(10 \mathrm{~m})$, and was variable in the x-direction $(10 \mathrm{~m}$ to $5 \mathrm{~m})$ and the $\mathrm{z}$-direction ( $1 \mathrm{~m}$ to $0.5 \mathrm{~m})$. A higher-resolution small-scale model (223,200 total nodes that included 93,099 inactive nodes) was also developed to test the impact of finer $\mathrm{z}$-direction grid spacing $(0.25 \mathrm{~m}$ in the fluctuating water-table zone).

The hydrostratigraphy, topography, and bathymetry for the three-dimensional models used a consistent framework developed using EarthVision. The hydrostratigraphic units were determined from 
previously published interpretations of the 300 Area (i.e., Shalla et al. 1988, Gaylord and Poeter 1991, Swanson et al. 1992), along with data from additional wells installed since those studies. A reanalysis of some of the older hydrostratigraphic unit picks from well logs in the area, along with using geophysical logs, was conducted based on the detailed knowledge gained from the 300 Area LFI boreholes (Williams et al. 2007). The primary hydrostratigraphic units within the model domain were the Hanford formation gravels, a fine-grained Ringold Formation unit that was encountered in many of the wells (although not completely continuous) in the 300 Area immediately below the Hanford and Ringold contact, and the underlying Ringold gravels. The three-dimensional hydrostratigraphy in the EarthVision database was sampled at the model finite difference node locations.

Recent studies of the hyporheic zone in the 300 Area have shown the importance of a layer of river alluvium with lower hydraulic conductivity (relative to the Hanford formation) that is dampening the response of wells near the river to river-stage fluctuations, and limiting the aquifer flux to and from the river (Fritz et al. 2007, Fritz and Arntzen 2007). Downhole probe measurements of electrical conductivity and temperature of the aquifer in wells near the Columbia River have shown the extent of the groundwater/river water mixing zone. For example, downhole probe measurements in 2006 revealed that river water entered the aquifer to a distance of more than $188 \mathrm{~m}(617 \mathrm{ft})$ inland when the river stage was high. Limited data on specific conductance (from biannual groundwater monitoring events) indicate that the inland extent of river water could be much greater in places.

The boundary conditions on the north, south, and west sides of the two models were Dirichlet hydraulic head boundaries, which were set from water-level monitoring network (subsampled at 2-hour intervals) well data along the boundaries. Values for the cells along the boundaries between well locations were linearly interpolated between well pairs. Boundary conditions on the eastern side of the models within the Columbia River channel were also Dirichlet hydraulic head boundaries (specifically seepage-face boundaries) set from data from a river stage recorder in the 300 Area (subsampled at 2-hour intervals). Estimated river gradients for this portion of the Hanford Reach were applied to the river stage recorder values for the river boundary conditions. The upper boundary (excluding the area of the river channel) is a recharge boundary set from estimates of natural recharge. The lower boundary was a noflow boundary within the Ringold Formation. The large-scale model also included water sources from discharges to the north process trenches occurring during the simulation time, and pumping from a water supply well in the southern portion of the model domain. These sources and sinks were not part of the small-scale model because discharge to the trench ended prior to the simulation time period and the water supply well was outside the small-scale model domain.

Simulations for the large- and small-scale models included groundwater flow and conservative tracer transport. Simulation time steps were 1 hour or less with boundary condition specifications of 2 hours for the Dirichlet boundaries from the well data and river stage. A 1-year steady state simulation was used to provide initial conditions for the transient simulations. Transient simulations were then conducted for a 1.2-year time period for the large-scale model and a 1.6-year period for the small-scale model. Groundwater flow simulations were conducted with the large-scale model for the entire simulation period. These simulation results were then used for restart values in separate flow and transport simulations for each of the tracer pulse periods. This process was used to reduce the overall run times for the large-scale model (i.e., transport simulations were not needed for the entire flow period and could be run on separate workstations for each tracer pulse). While the flow simulations also included transport solution, no tracer sources were introduced into the model during these simulations and the courant limiter was disabled to eliminate the reduction in time steps needed for transport. Combined flow and transport simulations 
could be conducted for the small-scale model because these runs took less time due to the smaller model grid. These simulations were run on Linux dual-processor Intel Xeon (3.2 to 3.6 gigahertz) workstations. Run times for the large-scale model flow simulations were approximately 14 days with an additional 4 days for each flow and transport tracer pulse period simulation. For the small-scale flow and transport simulations, the runtimes were 7 to 8 days per case (12 days for the refined vertical grid).

A number of large- and small-scale model simulations were run focusing on the hydraulic conductivity values and distribution within the Hanford formation and river alluvium zone. Simulations were run with uniform hydraulic conductivity values for the Hanford formation and with the Hanford formation subdivided laterally into two zones with different hydraulic conductivity values. Heterogeneous hydraulic properties in the Hanford formation were developed from stochastic hydraulic properties developed for the large-scale model. The hydraulic conductivity of the Hanford formation in the 300 Area was difficult to determine through common methods used for aquifer testing, such as slug tests and limited duration pumping tests, due to its very high permeability $(>1000 \mathrm{~m} / \mathrm{d})$ and the fluctuating water table induced by changes in the river stage. Hydraulic conductivities for the Ringold Formation were not varied and were set based on slug testing results. Other material properties for these units (e.g., porosity, soil characteristic curves, dispersivities) were not varied in these simulations. A simulation matrix was developed to bracket hydraulic conductivity values for the Hanford formation and to evaluate the different property distributions. The number of simulations that could be run was limited by the computational requirements of the runs and available resources. This precluded a rigorous inverse process for parameter estimation within the scope of this effort. However, this research did include some limited trial and error fitting of hydraulic conductivity based on analysis of previous runs.

Simulation results were assessed by a number of metrics including calculating the difference between simulated and measured water levels for wells from the automated water-level monitoring network within the model domain (SSR), simulated tracer plume drift directions and $x-y$ velocities calculated from changes in center of mass of the tracer plumes compared to the limited field tracer test results, and comparison of the arrivals and inland extent of a river water tracer (for the small-scale model only) with downhole measurements of specific conductance from the automated well network. Additionally, water fluxes are calculated for the model boundaries (north, south, east, and Columbia River) for evaluation in comparison with independent estimates and to show the range in simulated values for the different cases that were run.

Overall, the deterministic cases with the Hanford formation subdivided into two zones, along with a river alluvium zone, had the best fit based on the evaluation of the hydraulic head residuals for both the large- and small-scale models. However, only a few heterogeneous stochastic simulations could be evaluated in this effort. For the large-scale model cases tested, the best-fit case had hydraulic conductivity values of $7000 \mathrm{~m} / \mathrm{d}$ for the high-K Hanford formation zone, $2000 \mathrm{~m} / \mathrm{d}$ for the low-K Hanford formation zone in the northern portion of the domain, and $1 \mathrm{~m} / \mathrm{d}$ for the river alluvium zone. Other large-scale model cases had similar total residual values. For the small-scale model cases tested, the best fit had hydraulic conductivity values of $10,000 \mathrm{~m} / \mathrm{d}$ for the high-K Hanford formation zone, 2,500 $\mathrm{m} / \mathrm{d}$ for the low-K Hanford formation zone in the north and eastern portion of the domain, and $1 \mathrm{~m} / \mathrm{d}$ for the river alluvium zone. A number of simulations with the small-scale model had similar SSR values. Calculated hydraulic head RMSE values for the small-scale model were smaller than the large-scale model, possibly as a result of the lower hydraulic gradients across the small-scale model (i.e., flatter water table). The flatter gradients in the southern portion of the small-scale model may also be indicative of higher hydraulic conductivities within the Hanford formation in this location compared to the lower hydraulic 
conductivity in the best-fit case for larger-scale model that encompasses a larger area. The hydraulic conductivity values for the river alluvium in these best-fit cases may not be directly comparable to measurements (which averaged about $7 \mathrm{~m} / \mathrm{d}$ over a $1.5-\mathrm{m}$ thick zone) because of the discretization of this thin zone and hydraulic property averaging within the finite difference numerical code.

Tracer pulses were simulated for both the large-scale and small-scale models during different times of the year to assess the impact of the water table and river stage on plume drift direction and velocities. Plumes were simulated in three starting locations in the large-scale model: south of the north process trenches, within the south process pond, and within the 307 trench. Only one starting location was used for the small-scale model at the south of the north process trenches. General results showed that the tracer plumes moved inland (west or southwest) during rising or high-river stage periods (e.g., spring and early summer). Plumes moved toward the river (east or southeast) during low-river stage conditions. The highest simulated plume drift velocities were seen during the initial drop in the river stage in the summer that follows a period of sustained high-river stage. For the plumes at the south end of the north process trench, plume drift velocities were generally higher in the large-scale model compared to the small-scale model using similar hydraulic conductivity values for the Hanford formation. Simulated plume velocities showed a large range in values throughout the time periods, with a range up to $\sim 30 \mathrm{~m} / \mathrm{d}$ for the best-fit SSR case in the large-scale model and up to $\sim 17 \mathrm{~m} / \mathrm{d}$ for the best-fit case in the small-scale model. There was also a larger range and more variability in velocities for the larger-scale model because the velocities were calculated daily from changes in the plume center of mass, and the small-scale model velocities were from weekly changes.

Simulated tracer plumes during low-river stage conditions near the south end of the north process trenches can be compared to the polyphosphate tracer test results conducted in December 2006. The preliminary results of this test showed the plume moving toward the southeast at a velocity of $15.2 \mathrm{~m} / \mathrm{d}$ $(50 \mathrm{ft} / \mathrm{d})$. Simulated tracer plumes for the large-scale model moved eastward during the low-river stage conditions pulse (October 1992), with daily average velocities ranging from $\sim 1$ to $\sim 18 \mathrm{~m} / \mathrm{d}$ for the best-fit SSR case. Simulated tracer plumes for the small-scale model moved south-southeast during low-river stage conditions (December 2006), with weekly average velocities ranging from $\sim 2$ to $\sim 11 \mathrm{~m} / \mathrm{d}$ for the best-fit SSR case.

Other estimates of plume drift from limited historical plume events (Peterson et al. 2008a) had estimates of $10.7 \mathrm{~m} / \mathrm{d}(35 \mathrm{ft} / \mathrm{d})$ based on monitoring of an inadvertent release of tetrachloroethene, and several meters a day for uranium from monitoring of concentration peaks during a burial ground remediation. These contaminants can sorb to the aquifer sediments so their velocities would be retarded compared to a conservative tracer.

The small-scale model can also be evaluated based on a simulated river tracer compared to specific conductance measurements in downhole probes installed in some of the wells in the automated monitoring network during the simulation time-period. There was generally a good fit between the simulation results for the cases with the lowest hydraulic head SSRs and the specific conductance measurements. Changes in the hydraulic conductivity values for the low- and high-K Hanford zones did not have a large impact on the maximum inland extent of the simulated river tracer. However, the hydraulic conductivity value of the river alluvium has a large impact on the inland extent and is the probably the limiting factor in the range of cases tests. The distance between the two farthest inland wells with automated specific conductance monitoring is large (between wells 399-1-7 and 399-1-12), so the exact inland extent of the mixing zone from these data is not easily resolved (well 399-1-7 showed 
significant impact from river water and well 399-1-12 had little or no impact). Additionally, high-K zones within the Hanford formation may also have a spatial impact on the inland extent (i.e., semiannual monitoring of well 199-1-17a showed some impact during high-river stage conditions in June).

Water fluxes into and out of the 300 Area aquifer were calculated using the large-scale model for the period of February 1, 1992, to February 1, 1993, and for the small-scale model for 2006. These include boundary fluxes on the north, west, and south of the model domain and at the river boundary. River stage conditions during this period for the large-scale model were generally average and typical for the past 15 years, with stage-elevation ranging between 104.3 to $106.8 \mathrm{~m}$ (NAVD88). River stage conditions during 2006 used for the small-scale model were higher than usual, ranging between 104.2 to $107.5 \mathrm{~m}$ (NAVD88). All the cases for both the large and small-scale showed net annual water fluxes into the model domain along the western boundary, and net annual water fluxes out of the model domain along the southern boundary. The large-scale model had net annual water fluxes into the model domain for all the cases on the northern boundary. Most of the small-scale model cases had net annual water fluxes out of the model domain on the northern boundary. Most of the large-scale model cases had net annual water fluxes into the river from the aquifer whereas most of the small-scale model cases had net annual water fluxes into the aquifer from the river. The net annual water flux estimates can be compared between these two models by normalizing these values to the shoreline length (3019 $\mathrm{m}$ for the large-scale model and 480 $\mathrm{m}$ for the small-scale model). In addition to the higher-river stage conditions during the small-scale model, compared to the large-scale model, the domain of the smaller-scale model was on the northern portion of the 300 Area that did not include the thick sequence of Hanford formation gravels in the southern and western portion of the larger-scale model domain.

The simulated values of annual net flux to the river can be compared to the historical assumptions for the annual aquifer discharge along the 64-km length of the Hanford Reach and estimates from site-wide modeling efforts. Historical assumptions range from 560 to $1400 \mathrm{~m}^{3}$ per meter of shoreline, based on values of 36 million to 90 million $\mathrm{m}^{3}$ /year for the entire Hanford Site aquifer (summarized in Peterson et al. 2007). Recent site-wide groundwater modeling studies produced estimates of 480 and $700 \mathrm{~m}^{3}$ per meter of shoreline, based on estimates of 31 million and 45 million $\mathrm{m}^{3} /$ year for the entire Hanford Site (Vermeul et al. 2003 and Thorne et al. 2006, respectively). Fritz et al. (2007) also estimated the aquifer flux to the river around spring 9 in the 300 Area from results of multilevel piezometer measurements. Water flux results for the large-scale model simulations (a more typical river stage year than used for the small-scale model) using varying hydraulic properties ranged from -22 to $315 \mathrm{~m}^{3} /$ year per $1-\mathrm{m}$ of shoreline (see Figure 3.27 and Table 5.1 for comparison of the best-fit cases). These simulations also had higher fluxes out the southern model boundary (as shown in Figure 3.27 and Table 5.1) that would eventually discharge to the river south of the model domain. Results from these simulations show the importance of the hydraulic properties on the flux estimates, particularly for the Hanford formation and the river alluvium zones. The aquifer fluxes to the river in the 300 Area are expected to be higher than the site-wide average given the relatively high-hydraulic conductivities values in the 300 Area compared to other sites studied along the Hanford Reach (i.e., 100 Areas). 
Table 5.1. Net Aquifer Water Flux Estimates to the Columbia River Along the Hanford Site

\begin{tabular}{|c|c|c|c|c|}
\hline Study & $\begin{array}{l}\text { Shoreline } \\
\text { Length } \\
(\mathrm{km})\end{array}$ & $\begin{array}{l}\text { Net Aquifer Flux } \\
\qquad\left(\mathrm{m}^{3} / \text { year }\right)\end{array}$ & $\begin{array}{c}\text { Net Aquifer Flux per } \\
\text { 1-m of Shoreline } \\
\left(\mathrm{m}^{3} / \text { year }\right)\end{array}$ & $\begin{array}{l}\text { Net Aquifer flux }-300 \\
\text { Area Shoreline (assumes } \\
\text { 3-km length) } \\
\left(\mathrm{m}^{3} / \text { year }\right)\end{array}$ \\
\hline $\begin{array}{l}\text { Historical assumptions } \\
\text { (Peterson et al. 2007) }\end{array}$ & 64 & $3.6 \times 10^{7}$ to $9.0 \times 10^{7}$ & 560 to 1,400 & $1.7 \times 10^{6}$ to $4.2 \times 10^{6}$ \\
\hline $\begin{array}{l}\text { Site-wide groundwater } \\
\text { model (Vermuel et al. } \\
\text { 2003) }\end{array}$ & 64 & $3.1 \times 10^{7}$ & 480 & $1.4 \times 10^{6}$ \\
\hline $\begin{array}{l}\text { Site-wide groundwater } \\
\text { model (Thorne et al. } \\
\text { 2006) }\end{array}$ & 64 & $4.5 \times 10^{7}$ & 700 & $2.1 \times 10^{6}$ \\
\hline $\begin{array}{l}300 \text { Area large-scale } \\
\text { model simulations } \\
\text { (best-fit cases - this } \\
\text { study) }\end{array}$ & 3.02 & $\begin{array}{l}-6.7 \times 10^{4} \text { to } 9.5 \times 10^{5} \\
\text { River } \\
\left(4.7 \times 10^{6} \text { to } 5.3 \times 10^{6}\right. \\
\text { South boundary) }\end{array}$ & $\begin{array}{c}-22 \text { to } 315 \\
\text { (Does not include } \\
\text { southern boundary } \\
\text { fluxes) }\end{array}$ & $\begin{array}{l}-6.6 \times 10^{4} \text { to } 9.4 \times 10^{5} \\
\text { (Does not include } \\
\text { southern boundary } \\
\text { fluxes) }\end{array}$ \\
\hline
\end{tabular}

\subsection{Recommendations}

Recommendations for additional conceptual and numerical model development based on this study are listed below. These recommendations are organized by additional data needs, improvements that could be made to both large- and small-scale models, and specific areas for each.

The hydrostratigraphic interpretation used in this study could be updated based on new borehole data in the 300 Area along with refinements of the hydrostratigraphic interpretation based on ongoing surface geophysical surveying in the area. A significant amount of drilling and sediment characterization occurred in the 300 Area in 2007 and 2008. Four wells were installed as part of the volatile organic compound investigation (Peterson et al. 2008b) and 35 wells were installed for the 300 Area Integrated Field-Scale Subsurface Research Challenge project (see http://ifchanford.pnl.gov). Installation of these wells included extensive collection of core samples for physical property measurements and other laboratory analyses. Updated information from the 300 Area polyphosphate treatability test (Vermeul et al. 2007) could also be used as it becomes available. Direct measurements of the Columbia River gradient along the 300 Area is needed because these values were estimated in this modeling effort to apply upstream and downstream boundary conditions values from the river stage recorder location. Continued monitoring of the current 300 Area water-level monitoring network is needed to provide a longer-term record of water levels in the 300 Area under varying river stage conditions over many years. Expansion of the existing water-level monitoring network is needed to extend the size of the small-scale model domain to include the south process pond and 307 trench. Measuring the Columbia River gradient in the 300 Area and continuing monitoring, along with expansion of the water-level monitoring network, are planned for 2008. There is also need for higher frequency uranium monitoring in the 300 Area wells. Currently, most of the monitoring wells are sampled for uranium in semiannually (typically June and December) and show distinct differences. Additional sampling at other times of the year (i.e., monthly or bimonthly) would help to track the plume transition between high- and low-river stage conditions. Lastly, additional field tracer tests would be helpful to supplement the limited data currently available for use in documenting the range of groundwater velocities and in evaluating the simulations/bulk hydraulic properties. 
Refinements in hydraulic property estimates for both the large and small-scale models could be made through additional deterministic and stochastic simulations. Detailed residual analysis from the existing deterministic runs could also be used to develop further hydraulic conductivity zonations within the Hanford formation. The development of uranium transport, even with using a simplistic $\mathrm{K}_{\mathrm{d}}$ approach, could also be useful in providing additional transport data that could help condition the hydraulic properties, along with some bulk $\mathrm{K}_{\mathrm{d}}$ estimates. If additional computational resources are available, such as high performance computing, then inverse modeling methods could be used for a more formal parameter estimating process, a large number of stochastic hydraulic property distributions could be run and evaluated for the large-scale model, and the impact of higher-resolution grid refinement could be assessed (SciDAC Project is currently pursuing some of these objectives). ${ }^{1}$

Recommendations for further development of the stochastic simulations for the large-scale model are as follows:

- Stochastic cases that use lower-K values for the river alluvium zone.

- The available physical property and borehole geophysical data for the 300 Area are sparse, such that there is significant uncertainty in horizontal correlation lengths for physical and hydraulic properties. The databases established for this project should be updated whenever additional core samples and/or borehole geophysical data from new wells become available. The extensive physical property data being generated by the drilling and characterization efforts underway in the 300 Area (as discussed above) could provide significantly better spatial coverage, particularly with respect to informing short lag spacings for variogram analysis based on the close well spacing used at the Integrated Field Challenge project site. These new data, along with existing data across the 300 Area, should be analyzed to make recommendations for strategically placing a few new wells to improve the geostatistical analysis. Incorporating the results of these characterization efforts into the geostatistical analyses used for the generation of heterogeneous models, such as developed in this study, should result in improved models with significant reduction in uncertainty.

- Ongoing surface geophysical characterization activities in the 300 Area may provide additional information that can be used to supplement core and borehole geophysical data for estimating horizontal correlation lengths, subsurface structure, and physicochemical property variations. When these data become available, the EarthVision model used for this project should also be updated to reinterpret the elevation of the surface of the Hanford and Ringold Formation contact.

- Additional work should be performed to develop heterogeneous models with more realistic structure. The work reported herein used traditional two-point geostatistics (variogram modeling) to estimate correlation lengths and to generate stochastic simulations of parameter fields. Cutting-edge research in geostatistics has focused on multiple-point geostatistics, which are better able to quantify curvilinear features (such as buried stream channels). Alternative geostatistical methods, such as transition-probability geostatistics, should also be applied to the 300 Area.

\footnotetext{
${ }^{1}$ SciDAC began as a 5-year program by DOE to develop scientific computing software and hardware infrastructure needed to use terascale computers to advance DOE research programs in basic energy sciences, biological and environmental research, fusion energy sciences, and high-energy and nuclear physics.
} 
- Site-specific PTFs should be developed for the 300 Area. The work reported here used PTFs that were developed for finer-textured agricultural soils. Although it is believed that these PTFs provide reasonable parameter estimates for the 300 Area, their accuracy for the coarse gravel- and cobbledominated sediments in the 300 Area is unknown.

Recommendations specifically for the small-scale model include running cases with higher values of hydraulic conductivity for the Hanford high-K zone than bounded by this study. The simulated time period for the small-scale model can also be extended with the additional data now available because the water-level network is continuing to be monitored. The domain of the small-scale model could also be expanded toward the south based on additional wells being added to the network in 2008 . 


\subsection{References}

Anglin DR, SL Haeseker, JJ Skalicky, and H Schaller. 2006. Effects of Hydropower Operations on Spawning Habitat, Rearing Habitat, and Stranding/Entrapment Mortality of Fall Chinook Salmon in the Hanford Reach of the Columbia River. Final Report, August 2006, U.S. Fish and Wildlife Service, Columbia River Fisheries Program Office, Vancouver, Washington.

Argonne National Laboratory (ANL). 1993. Manual for Implementing Residual Radioactive Materials Guidelines Using RESRAD, Version 5.0. ANL/EAD/LD-2, Environmental Assessment Division, Argonne National Laboratory, Argonne, Illinois.

Arntzen EV, DR Geist, and PE Dresel. 2006. "Effects of Fluctuating River Flow on Groundwater/Surface Water Mixing in the Hyporheic Zone of a Regulated, Large Cobble Bed River." River Research and Applications 22(8):937-946.

Bear J. 1972. Dynamics of Fluids in Porous Media. Dover Publications Inc., New York.

Bechtel Hanford, Inc. (BHI). 2002. Protection of 300 Area Groundwater from Uranium-Contaminated Soils at Remediated Sites. BHI-01667, Rev. 0, Bechtel Hanford, Inc. Richland, Washington.

Bjornstad BN. 2004. Sampling and Hydrogeology of the Vadose Zone Beneath the 300 Area Process Ponds. PNNL-14834, Pacific Northwest National Laboratory, Richland, Washington.

Bjornstad BN. 2007. On the Trail of the Ice Age Floods: A Geological Field Guide to the MidColumbian Basin. KeoKee, Sandpoint, Idaho.

Bretz, JH. 1969. "The Lake Missoula Floods and the Channeled Scabland." Journal of Geology, 77:505-543.

Brooks RH and AT Corey. 1964. "Hydraulic Properties of Porous Media." Hydrol. Pap. 3, Civil Engineering Department, Colorado State University, Fort Collins, Colorado.

Burdine NT. 1953. "Relative Permeability Calculations from Pore-Size Distribution Data." Petr. Trans., Am. Inst. Mining Metall. Eng. 198:71-77.

Campbell GS. 1985. Soil Physics with Basic. Elsevier, New York.

Campbell MD and DR Newcomer. 1992. Automatic Measurement of Water Levels Within the 300-FF-5 Boundary. PNL-7874, Pacific Northwest Laboratory, Richland, Washington.

Campbell MD. 1994. Monitoring Groundwater and River Interaction Along the Hanford Reach of the Columbia River. PNL-9437, Pacific Northwest Laboratory, Richland, Washington.

Cardwell WT and RL Parsons. 1945. "Average Permeabilities of Heterogeneous Oil Sands." Trans. Am. Inst. Mining Met. Pet. Eng. 160:34-42.

Carle SF. 1999. TPROGS: Transition Probability Geostatistical Software, Version 2.1. University of California, Davis, California. 
Cole CR, MP Bergeron, CJ Murray, PD Thorne, SK Wurstner, and P Rogers. 2001. Uncertainty Analysis Framework Hanford Site-Wide Groundwater Flow and Transport Model. PNNL-13641, Pacific Northwest National Laboratory, Richland, Washington.

Cooper HH, Jr. and CE Jacob. 1946. "A Generalized Graphical Method for Evaluating Formation Constants and Summarizing Well-Field History.” American Geophysical Union, Transactions 27(4):526-534.

Deutsch CV and AG Journel. 1998. GSLIB: Geostatistical Software Library and User's Guide. Oxford University Press, New York.

Deutsch CV. 2002. Geostatistical Reservoir Modeling. Oxford Univ. Press, New York.

Deutsch CV, and TT Tran. 2002. "FLUVSIM: A program for object-based simulation of fluvial depositional systems." Comput. Geosci. 28:525-535.

DOE-RL 1994a. Phase I Remedial Investigation Report for the 300-FF-5 Operable Unit. DOE/RL-9321, Rev. 0, Vols. 1 (information) and 2 (data listings), U.S. Department of Energy, Richland Operations Office, Richland, Washington.

DOE-RL 1994b. Remedial Investigation/Feasibility Study Report for the 300-FF-5 Operable Unit. DOE/RL-94-85, U.S. Department of Energy, Richland Operations Office, Richland, Washington.

DOE-RL. 1997. 300 Area Process Trenches Modified Closure/Postclosure Plan. DOE/RL-93-73, Rev. 2, U.S. Department of Energy, Richland Operations Office, Richland, Washington.

DOE-RL. 2002. Standardized Stratigraphic Nomenclature for Post-Ringold-Formation Sediments Within the Central Pasco Basin. DOE/RL-2002-39, U.S. Department of Energy, Richland Operations Office, Richland, Washington.

DOE-RL 2005. Work Plan for Phase III Feasibility Study 300-FF-5 Operable Unit. DOE/RL-2005-41, Rev. 0, U.S. Department of Energy, Richland Operations Office, Richland, Washington.

Fayer MJ and TB Walters. 1995. Estimated Recharge Rates at the Hanford Site. PNL-10285, Pacific Northwest Laboratory, Richland, Washington.

Feyen L, and J Caers. 2006. "Quantifying Geological Uncertainty for Flow and Transport Modeling in Multi-Modal Heterogeneous Formations." Adv. Water. Resour. 29:912-929.

Flint AL and LE Flint. 2002. "Particle Density." In Methods of Soil Analysis, Part 4, Physical Methods, JH Dane and GC Topp (eds.), Soil Sci Soc Am, Inc., Madison, Wisconsin, pp. 229-240.

Folk RL. 1980. Petrology of Sedimentary Rocks. Hemphill Publishing Co., Austin, Texas.

Freeze RA and JA Cherry. 1979. Groundwater. Prentice-Hall, Inc., Englewood Cliffs, New Jersey.

Freyberg DL. 1986. "A Natural Gradient Experiment on Solute Transport in a Sand Aquifer, 2. Spatial Moments and the Advection and Dispersion of Nonreactive Tracers." Water Resour. Res. 22:2031-2046.

Fritz BG and EV Arntzen. 2007. "Effect of Rapidly Changing River Stage on Uranium Flux Through the Hyporheic Zone." Groundwater 45:753-760. 
Fritz BG, RD Mackley, NP Kohn, GW Patton, TJ Gilmore, DP Mendoza, D McFarland, AL Bunn, and EV Arntzen. 2007. Investigation of the Hyporheic Zone at the 300 Area, Hanford Site. PNNL-16805, Pacific Northwest National Laboratory, Richland, Washington.

Gaylord DR and EP Poeter. 1991. Geology and Hydrology of the 300 Area and Vicinity, Hanford Site, South-Central Washington. WHC-EP-0500, Westinghouse Hanford Company, Richland, Washington.

Gee GW, ML Rockhold, and JL Downs. 1989. Status of FY 1988 Soil-Water Balance Studies on the Hanford Site. PNL-6750. Pacific Northwest Laboratory, Richland, Washington.

Gee GW and D Orr. 2002. "Particle-Size Analysis." In Methods of Soils Analysis, Part 4. Physical Methods, JH Dane and GC Topp (eds.), Soil Sci Soc Am, Madison, Wisconsin, pp. 255-289.

Guber, AK, YA Pachepsky, MTh Van Genuchten, WJ Rawls, J Simunek, D Jacques, TJ Nicholson, and RE Cady. 2006. "Field-Scale Water Flow Simulations Using Ensembles of Pedotransfer Functions for Soil Water Retention." Vadose Zone J 5:234-247.

Hartman MJ, LF Morasch, and WD Webber. 2007. Hanford Site Groundwater Monitoring for Fiscal Year 2006. PNNL-16346, Pacific Northwest National Laboratory, Richland, Washington.

Hallenburg JK. 1984. Geophysical Logging for Mineral and Engineering Applications. PennWell Publishing, Tulsa, Oklahoma.

Hu LY. 2002. "Combination of Dependent Realizations Within the Gradual Deformation Method." Math. Geol. 34:953-963.

Hu LY, and M le Ravalec-Dupin. 2004. “An Improved Gradual Deformation Method for Reconciling Random and Gradient Searches in Stochastic Optimizations.” Math. Geol. 36:703-719.

Isaaks EH and RM Srivastava. 1989. An Introduction to Applied Geostatistics. Oxford University Press, New York.

Kipp KL, AE Reisenauer, CR Cole, and CA Bryan. 1972 (updated in 1976). Variable Thickness Transient Groundwater Flow Model-Theory and Numerical Implementation. BNWL-1703, Pacific Northwest Laboratory, Richland. Washington.

Li D, B Beckner, and A Kumar. 2001. "A New Efficient Averaging Technique for Scale-Up of Multimillion-Cell Geologic Models.” SPE Reservoir Evaluation and Engineering 8:297-307.

Lindberg JW and CJ Chou. 2001. 300 Area Process Trenches Groundwater Monitoring Plan. PNNL-13645, Pacific Northwest National Laboratory, Richland, Washington.

Lindberg JW and FW Bond. 1979. Geohydrology and Groundwater Quality Beneath the 300 Area, Hanford Site, Washington. PNL-2949, Pacific Northwest Laboratory, Richland, Washington.

Lindsey KA. 1995. Miocene- to Pliocene-Aged Suprabasalt Sediments of the Hanford Site, South-Central Washington. BHI-00184, Rev. 0, Bechtel Hanford, Inc., Richland, Washington.

Mackley RD, and BG Fritz. 2007. Characterizing the Hydrogeology of the Hyporheic Zone Along the 300 Area of the Hanford Site, Washington. PNNL-SA-56035. Oral presentation at the $6^{\text {th }}$ Washington Hydrogeology Symposium, May 1-3, 2007, Tacoma, Washington. 
Malik MA and LW Lake. 1997. "A Practical Approach to Scaling-Up Permeability and Relative Permeabilities in Heterogeneous Permeable Media." Paper SPE 38310, presented at the 1997 SPE Western Regional Meeting, Long Beach, California, June 25-27, 1997.

Mendoza F, BG Fritz, and GW Patton. 2007. Measurement of Contaminant Discharge into the Columbia River along the Hanford Reach Using a Passive Flux Chamber. PNNL-SA-53838. Poster presentation at the $6^{\text {th }}$ Washington Hydrogeology Symposium, May 1-3, 2007, Tacoma, Washington.

Meyer PD, M Ye, ML Rockhold, SP Neuman, and KJ Cantrell. 2007. Combined Estimation of Hydrogeologic Conceptual Model, Parameter, and Scenario Uncertainty with Application to Uranium Transport at the Hanford Site 300 Area. NUREG/CR-6940 (PNNL-16396), U.S. Nuclear Regulatory Commission, Washington, D.C.

Neuman SP and PJ Wierenga. 2003. A Comprehensive Strategy of Hydrogeologic Modeling and Uncertainty Analysis for Nuclear Facilities and Sites. NUREG/CR-6805, U.S. Nuclear Regulatory Commission, Washington, D.C.

Peterson RE, EJ Freeman, PD Thorne, MD Williams, JW Lindberg, CJ Murray, MJ Truex, SB Yabusaki, JP McDonald, VR Vermeul, and JM Zachara. 2005. Contaminants of Potential Concern in the 300-FF-5 Operable Unit: Expanded Annual Groundwater Report for Fiscal Year 2004. PNNL-15127, Pacific Northwest National Laboratory, Richland, Washington.

Peterson RE, MD Williams, and GW Patton. 2007. "Hanford Site Groundwater and the Columbia River, South-Central Washington.” PNNL-SA-56038, presented by RE Peterson at 6th Washington Hydrogeology Symposium, Tacoma, Washington, on May 3, 2007.

Peterson RE, ML Rockhold, RJ Serne, PD Thorne, and MD Williams. 2008a. Uranium Contamination in the Subsurface Beneath the 300 Area, Hanford Site, Washington. PNNL-17034, Pacific Northwest National Laboratory, Richland, Washington.

Peterson RE, BA Williams, and RM Smith. 2008b. Volatile Organic Compound Investigation Results, 300 Area, Hanford Site, Washington.. PNNL-17666, Pacific Northwest National Laboratory, Richland, Washington.

Reidel SP, KA Lindsey, and KR Fecht. 1992. Field Trip Guide to the Hanford Site. WHC-MR-0391, Westinghouse Hanford Company, Richland, Washington.

Renard PH and G de Marsily. 1997. "Calculating Equivalent Permeability: A Review." Adv. Water Resour. 20:253-278.

Rider M H. 1990. “Gamma-Ray Log Shape Used as a Facies Indicator: Critical Analysis of an Oversimplified Methodology. In Geological Applications of Wireline Logs, A Hurst, MA Lovell, and AC Morton (eds.), Geological Society Special Publication No. 48, pp. 27-37.

Rider MH. 1996. The Geological Interpretation of Well Logs. Whittles Publishing, Scotland.

Rockhold ML, MJ Fayer, CT Kincaid, and GW Gee. 1995. Estimation of Natural Groundwater Recharge for the Performance Assessment of a Low-Level Waste Disposal Facility at the Hanford Site. PNL-10508, Pacific Northwest National Laboratory, Richland, Washington. 
Runchal AL, R Sagar, and NW Kline. 1992. PORFLOW-3: A Mathematical Model for Fluid Flow, Head, and Mass Transport in Variably Saturated Geologic Media, Users Manual, Version 1.2.

WHC-EP-0385, Westinghouse Hanford Company, Richland, Washington.

Schalla R, RW Wallace, RL Aaberg, SP Airhart, DJ Bates, JVM Carlile, CS Cline, DI Dennison, MD Freshley, PR Heller, EJ Jensen, KB Olsen, RG Parkhurst, JT Rieger, and EJ Westergard. 1988. Interim Characterization Report for the 300 Area Process Trenches. PNL-6716, Pacific Northwest Laboratory, Richland, Washington.

Serne RJ, CF Brown, HT Schaef, EM Pierce, MJ Lindberg, Z Wang, P Gassman, and J Catalano. 2002. 300 Area Uranium Leach and Adsorption Project. PNNL-14022, Pacific Northwest National Laboratory, Richland, Washington.

Serra O and L Sulpice. 1975. "Sedimentological Analysis of Shale-Sand Series from Well Logs." Transactions of the SPWLA 16th Annual Logging Symposium, Paper W.

Strebelle S. 2002. "Conditional Simulation of Complex Geological Structures Using Multiple-Point Geostatistics." Math. Geol. 34:1-22.

Swanson LC, GG Kelty, KA Lindsey, KR Simpson, RK Price, and SD Consort. 1992. Phase 1 Hydrogeologic Summary of the 300-FF-5 Operable Unit, 300 Area. WHC-SD-EN-TI-052, Rev. 0, Westinghouse Hanford Company, Richland, Washington.

Theis, CV. 1935. "The Relation Between the Lowering of the Piezometric Surface and the Rate and Duration of Discharge of a Well Using Groundwater Storage." Transactions of the Amer. Geophys. Union 16:519-524.

Thorne PD, MP Bergeron, MD Williams, and VL Freedman. 2006. Groundwater Data Package for Hanford Assessments. PNNL-14753, Rev. 1, Pacific Northwest National Laboratory, Richland, Washington.

Vermeul VR, MP Bergeron, CR Cole, CJ Murray, WE Nichols, TD Scheibe, PD Thorne, SR Waichler, and Y Xie. 2003. Transient Inverse Calibration of the Site-Wide Groundwater Flow Model (ACM-2): FY03 Progress Report. PNNL-14398, Pacific Northwest National Laboratory, Richland, Washington.

Vermeul VR, MP Bergeron, P Dresel, EJ Freeman, RE Peterson, and PD Thorne. 2005. Evaluation of the Fate and Transport of Tritium Contaminated Groundwater from the 618-11 Burial Ground. PNNL-15293, Pacific Northwest National Laboratory, Richland, Washington.

Vermeul VR, MD Williams, BG Fritz, RD Mackley, DP Mendoza, DR Newcomer, ML Rockhold, BA Williams, and DM Wellman. 2007. Treatability Test Plan for 300 Area Uranium Stabilization Through Polyphosphate Injection. PNNL-16571, Pacific Northwest National Laboratory, Richland, Washington.

Waichler SR and SB Yabusaki. 2005. Flow and Transport in the Hanford 300 Area Vadose Zone-Aquifer-River System. PNNL-15125, Pacific Northwest National Laboratory, Richland, Washington.

Waichler SR, WA Perkins, and MC Richmond. 2005. Hydrodynamic Simulation of the Columbia River, Hanford Reach, 1940-2004. PNNL-15226, Pacific Northwest National Laboratory, Richland, Washington. 
Ward AL, ME Conrad, WD Daily, JB Fink, VL Freedman, GW Gee, GM Hoverston, MJ Keller, EL Majer, CJ Murray, MD White, SB Yabusaki, and ZF Zhang. 2006. Vadose Zone Transport Field Study Summary Report. PNNL-15443, Pacific Northwest National Laboratory, Richland, Washington.

Wellman DM, JS Fruchter, and VR Vermeul. 2006. Experimental Plan: Uranium Stabilization through Polyphosphate Injection - 300 Area Uranium Plume Treatability Demonstration Project. PNNL-16101, Pacific Northwest National Laboratory, Richland, Washington.

Wellman DM, EM Pierce, and MM Valenta. 2007. "Efficacy of Soluble Sodium Tripolyphosphate Amendments for the In-Situ Immobilization of Uranium." Environmental Chemistry 4:293-300.

White MD and M Oostrom. 2000. STOMP, Subsurface Transport Over Multiple Phases. Version 2.0. Theory Guide. PNNL-12030, Pacific Northwest National Laboratory, Richland, Washington.

White MD and M Oostrom. 2004. STOMP Subsurface Transport Over Multiple Phases, Version 3.1, User's Guide. PNNL-14478, Pacific Northwest National Laboratory, Richland, Washington.

Williams BA, BN Bjornstad, R Schalla, and WD Webber. 2000. Revised Hydrogeology for the Suprabasalt Aquifer System, 200-East Area and Vicinity, Hanford Site, Washington. PNNL-12261, Pacific Northwest National Laboratory, Richland, Washington.

Williams BA, BN Bjornstad, DC Lanigan, JM Keller, and ML Rockhold. 2006. Borehole Data Package for One CY2005 CERCLA Well 699-S20-E10, 300-FF-5 Operable Unit, Hanford Site, Washington. PNNL-15417, Pacific Northwest National Laboratory, Richland, Washington.

Williams BA, CF Brown, W Um, MJ Nimmons, RE Peterson, BN Bjornstad, RJ Serne, FA Spane, and ML Rockhold. 2007. Limited Field Investigation Report for Uranium Contamination in the 300 Area, 300-FF-5 Operable Unit, Hanford Site, Washington. PNNL-16435, Pacific Northwest National Laboratory, Richland, Washington.

Young JS, and JS Fruchter. 1991. Addendum to Data Compilation Task Report for the Source Investigation of the 300-FF-1 Operable Unit Phase I Remedial Investigation. EMO-1026. Prepared by Environmental Management Operations for the U.S. Department of Energy, Richland, Washington.

Zilkoski DB, JH Richards, and GM Young. 1992. "Results of the General Adjustment of the North American Vertical Datum of 1988." Surveying and Land Information Systems, 52:133-149. 
Appendix A

Hanford Site 300 Area Porosity Data 



\section{Appendix A}

\section{Hanford Site 300 Area Porosity Data - Descriptive Statistics}

\section{A.1 Descriptive Statistics}

This appendix contains calculated porosity data for 404 core samples obtained during drilling of 16 wells in and around the 300 Area. These data are from three sources:

1. Data for 244 core samples are from 4 boreholes/wells installed during a recent limited field investigation (LFI) described by Williams et al. (2007)

2. Data for 130 core samples are from 11 boreholes/wells installed as part of the Phase 1 remedial investigation/feasibility study (RI/FS), which is described by Swanson (1992)

3. Data for 30 core samples are from 1 borehole/well installed upgradient of the 300 Area for Comprehensive Environmental Resource, Compensation, and Liability Act of 1980 (CERCLA) monitoring, as described by Williams et al. (2006).

The porosity data from Swanson (1992) and Williams et al. (2006) were previously published, but any porosity data originally reported by Swanson (1992) with values less than 0.05 were not used. Given the gravel- and cobble-dominated nature of Hanford formation sediments in the 300 Area, it was assumed that porosities less that 0.05 were likely caused by large cobbles in the core barrel, and were probably not representative of the actual sediment. Furthermore, samples identified as basalt were not included. Most of the porosity data from LFI core samples were not reported by Williams et al. (2007) due to an oversight during the compilation of that document. However, this document only tabulates porosity data from the LFI for cores with complete (100\%) sample recovery that were not identified as drilling slough. Table A.1 provides the well names, coordinates, number of porosity samples, and the sampled elevation intervals.

Well locations for the sample data are depicted in Figure A.1. Also shown in Figure A.1 are the outlines of the 300 Area (purple outline) and the four primary uranium liquid waste disposal sites (red outlines). Considering the size of the area and the limited number of samples for some of the well locations (Table A.1), the available total porosity data for the 300 Area and its immediate surroundings are quite sparse.

Porosity, $n$, was not directly measured, but was calculated from measured bulk densities, $\rho_{b}$, and measured or assumed particle densities, $\rho_{s}$, as follows:

$$
n=1-\frac{\rho_{b}}{\rho_{s}}
$$


Table A.1. Well Names, Coordinates, Number of Samples, and Sampled Elevation Interval for Total Porosity Data of Hanford Site 300 Area Core Samples. Blue shading indicates LFI wells.

\begin{tabular}{clccccc}
\hline $\begin{array}{c}\text { Well } \\
\text { Count }\end{array}$ & \multicolumn{1}{c}{ Well Name } & $\begin{array}{c}\text { Easting } \\
(\mathrm{m})\end{array}$ & $\begin{array}{c}\text { Northing } \\
(\mathrm{m})\end{array}$ & $\begin{array}{c}\text { Number of } \\
\text { Core } \\
\text { Samples }\end{array}$ & $\begin{array}{c}\text { Min. Elev. } \\
(\mathrm{m})\end{array}$ & $\begin{array}{c}\text { Max. Elev. } \\
(\mathrm{m})\end{array}$ \\
\hline 1 & $399-1-10 \mathrm{~B}$ & 594350.85 & 116728.79 & 12 & 79.00 & 99.51 \\
2 & $399-1-13 \mathrm{~B}$ & 593909.59 & 116549.20 & 9 & 81.93 & 115.76 \\
3 & $399-1-14 \mathrm{~B}$ & 593910.92 & 116779.11 & 15 & 81.32 & 114.07 \\
4 & $399-1-21 \mathrm{~B}$ & 594157.21 & 116176.80 & 10 & 70.39 & 102.01 \\
5 & $399-1-23$ & 594113.51 & 116453.04 & 81 & 81.33 & 115.31 \\
6 & $399-3-18$ & 594464.71 & 116019.98 & 105 & 78.06 & 116.86 \\
7 & $399-3-19$ & 594071.94 & 116030.22 & 32 & 93.98 & 119.73 \\
8 & $399-3-20$ & 594375.42 & 115849.70 & 26 & 94.84 & 119.23 \\
9 & $399-8-5 C$ & 593386.06 & 116573.58 & 10 & 64.50 & 101.08 \\
10 & $699-$ S19-E14 & 594249.86 & 117716.19 & 1 & 106.73 & 106.73 \\
11 & $699-$ S20-E10 & 593124.37 & 117366.18 & 30 & 100.68 & 117.14 \\
12 & $699-$ S22-E9C & 592688.96 & 116752.62 & 15 & 63.08 & 105.17 \\
13 & $699-$ S27-E9C & 592720.92 & 115324.77 & 28 & 63.33 & 111.94 \\
14 & $699-$ S28-E12 & 593538.05 & 115000.75 & 6 & 99.73 & 115.94 \\
15 & $699-$ S29-E16B & 594746.91 & 114738.76 & 1 & 79.31 & 79.31 \\
16 & $699-$ S29-E16C & 594742.36 & 114730.53 & 23 & 63.41 & 111.63 \\
\hline
\end{tabular}

For the Swanson (1992) and Williams et al. (2006) data sets, both bulk and particle densities were measured. However, for the LFI core samples, only bulk densities were measured. Therefore, porosities for the LFI cores were estimated using their measured bulk densities and average particle densities.

The current EarthVision model of the 300 Area (Section 2.1 of this report) was used to determine a unit designation for each core sample based on five major hydrostratigraphic units ( $u 1, u 4, u 5$, $u 8$, and $u$ 9) that have been identified within the area depicted in Figure A.1. The discontinuous, uniform, fine-grained sand unit overlying the Ringold Formation unit E (u5) was identified in two of the four LFI boreholes and has tentatively been designated Ringold Formation unit $u 4$. Prior to the LFI, Ringold Formation unit $u 4$ had not been previously identified in the 300 Area (Williams et al. 2007). The EarthVision model was updated in part to accommodate the addition of this unit. However, it should be noted that in parts of the Hanford 200 Areas, a Hanford unit H4 has been designated. Although the Ringold u4 unit in the 300 Area and the Hanford H4 unit in the 200 Areas are not necessarily the same, they do occupy the same relative stratigraphic positions, at the top of the Ringold Formation or at the base of the Hanford formation.

The core sample data from Swanson (1992) and Williams et al. (2006) reports, and from the LFI core samples, were grouped by hydrostratigraphic unit. Descriptive statistics were calculated from the particle and bulk density data for each unit and for all Ringold Formation units combined. The particle and bulk density statistics are shown in Tables A.2 and A.3, respectively.

The average particle densities of the Hanford formation ( $\mathrm{u} 1)$ and combined Ringold Formation units ( $\mathrm{u} 4, \mathrm{u} 5, \mathrm{u} 8$, and $\mathrm{u} 9$ ) are 2.76 and $2.65 \mathrm{~g} / \mathrm{cm}^{3}$, respectively. Figure A.2 shows the distribution of particle densities with elevation. 


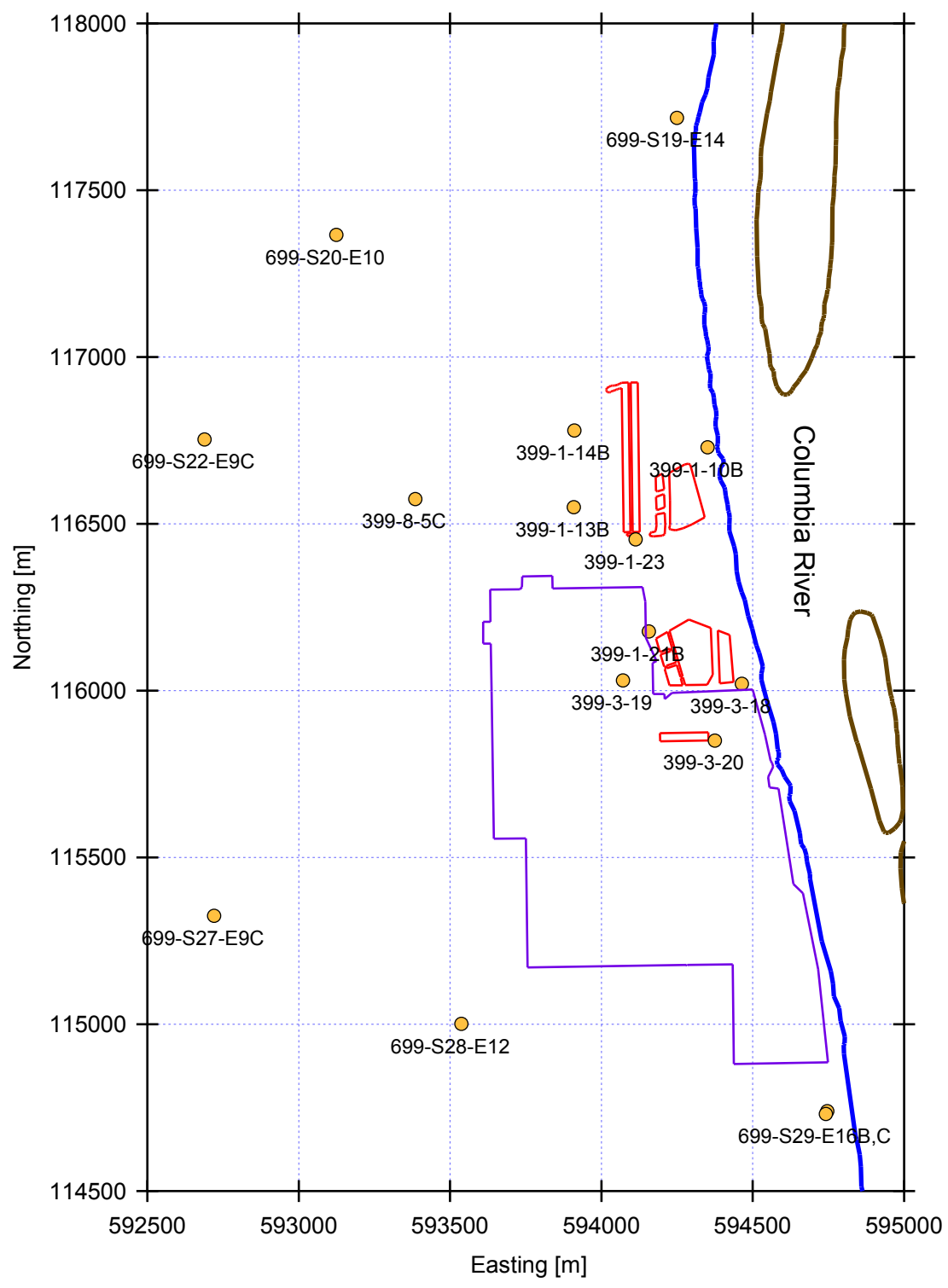

Figure A.1. Hanford Site 300 Area Wells for Which Total Porosity Data are Available

Table A.2. Descriptive Statistics for Particle Density $\left(\mathrm{g} / \mathrm{cm}^{3}\right)$ of Individual and Grouped Hydrostratigraphic Units in the 300 Area

\begin{tabular}{lccccc}
\hline \multicolumn{7}{c}{ Particle Density Statistics for 300 Area Core Samples } \\
\hline \multicolumn{1}{c}{ Statistic } & $\begin{array}{c}\text { Hanford } \\
(\mathrm{u} 1)\end{array}$ & $\begin{array}{c}\text { Ringold } \\
(\mathrm{u} 4)\end{array}$ & $\begin{array}{c}\text { Ringold } \\
(\mathrm{u} 5)\end{array}$ & $\begin{array}{c}\text { Ringold } \\
(\mathrm{u} 8+\mathrm{u} 9)\end{array}$ & $\begin{array}{c}\text { Ringold } \\
\text { (All units) }\end{array}$ \\
\hline Mean & 2.76 & 2.63 & 2.66 & 2.62 & 2.65 \\
Standard Error & 0.01 & 0.03 & 0.01 & 0.01 & 0.01 \\
Median & 2.77 & 2.65 & 2.67 & 2.62 & 2.66 \\
Mode & 2.73 & 2.65 & 2.68 & 2.56 & 2.65 \\
Standard Deviation & 0.05 & 0.08 & 0.07 & 0.08 & 0.07 \\
Variance & 0.002 & 0.01 & 0.01 & 0.01 & 0.01 \\
Kurtosis & 0.76 & -0.12 & 3.41 & 1.29 & 2.05
\end{tabular}


Table A.2. (Cont.)

\begin{tabular}{lccccc}
\hline \multicolumn{1}{c}{ Statistic } & $\begin{array}{c}\text { Hanford } \\
(\mathrm{u} 1)\end{array}$ & $\begin{array}{c}\text { Ringold } \\
(\mathrm{u} 4)\end{array}$ & $\begin{array}{c}\text { Ringold } \\
(\mathrm{u} 5)\end{array}$ & $\begin{array}{c}\text { Ringold } \\
(\mathrm{u} 8+\mathrm{u} 9)\end{array}$ & $\begin{array}{c}\text { Ringold } \\
\text { (All units) }\end{array}$ \\
\hline Skewness & -0.51 & -0.55 & 0.26 & 0.62 & 0.21 \\
Range & 0.25 & 0.26 & 0.52 & 0.38 & 0.52 \\
Minimum & 2.62 & 2.48 & 2.44 & 2.46 & 2.44 \\
Maximum & 2.87 & 2.74 & 2.96 & 2.84 & 2.96 \\
Sum & 146.24 & 23.64 & 228.93 & 76.11 & 328.68 \\
Number of Samples & 53 & 9 & 86 & 29 & 124 \\
Confidence Interval for & \pm 0.01 & \pm 0.06 & \pm 0.02 & \pm 0.03 & \pm 0.01 \\
the Mean at a 95\% & & & & & \\
Confidence Level & & & & & \\
\hline
\end{tabular}

Table A.3. Descriptive Statistics for Bulk Density $\left(\mathrm{g} / \mathrm{cm}^{3}\right)$ of Individual and Grouped Hydrostratigraphic Units in the 300 Area

\begin{tabular}{lccccc}
\hline \multicolumn{5}{c}{ Bulk Density Statistics for 300 Area Core Samples } \\
\hline \multicolumn{1}{c}{ Statistic } & $\begin{array}{c}\text { Hanford } \\
\mathrm{(u} 1)\end{array}$ & $\begin{array}{c}\text { Ringold } \\
(\mathrm{u} 4)\end{array}$ & $\begin{array}{c}\text { Ringold } \\
(\mathrm{u} 5)\end{array}$ & $\begin{array}{c}\text { Ringold } \\
(\mathrm{u} 8+\mathrm{u} 9)\end{array}$ & $\begin{array}{c}\text { Ringold } \\
\text { (all units) }\end{array}$ \\
\hline Mean & 2.08 & 1.56 & 2.04 & 1.42 & 1.86 \\
Standard error & 0.02 & 0.04 & 0.02 & 0.06 & 0.02 \\
Median & 2.10 & 1.47 & 2.08 & 1.26 & 1.97 \\
Mode & 2.23 & N/A & 2.00 & 1.26 & 2.00 \\
Standard deviation & 0.24 & 0.24 & 0.24 & 0.34 & 0.37 \\
Variance & 0.06 & 0.06 & 0.06 & 0.12 & 0.13 \\
Kurtosis & 0.48 & 2.91 & 0.20 & 0.58 & -1.01 \\
Skewness & -0.51 & 1.97 & -0.61 & 1.28 & -0.38 \\
Range & 1.46 & 1.02 & 1.31 & 1.27 & 1.59 \\
Minimum & 1.20 & 1.29 & 1.36 & 1.08 & 1.08 \\
Maximum & 2.66 & 2.31 & 2.67 & 2.35 & 2.67 \\
Sum & 330.07 & 71.60 & 337.19 & 51.07 & 459.86 \\
Number of samples & 159 & 46 & 165 & 36 & 247 \\
Confidence interval for & \pm 0.04 & \pm 0.07 & \pm 0.04 & \pm 0.12 & \pm 0.05 \\
the mean at a 95\% & & & & & \\
confidence level & & & & & \\
\hline
\end{tabular}

Although Table A.2 indicates differences in the mean values of particle density for the individual Ringold Formation units, there is significant variability and relatively few samples for the $u 4$ and $u 8+u 9$ units. Particle densities are typically measured using the pycnometer method (Flint and Flint 2002), which uses the less-than-2-mm-size fraction only. Relatively little is known about the particle densities of the coarser-size fractions.

Bjornstad (1990) presented the results of petrographic analyses on sand- to gravel-sized particles (larger than 62 microns) and clay mineral analyses (using the X-ray diffraction on particles smaller than 
four microns) for samples from a number of wells in the 200 West Area of the Hanford Site. Bjornstad (1990, p.3.21) states that within the coarse-grained Ringold deposits (Ringold unit E, u5) of those sediments, quartz $\left(\rho_{s}=2.65 \mathrm{~g} / \mathrm{cm}^{3}\right)$ is the predominant mineral (up to $53 \%$ by volume). The second-most abundant mineral was feldspar, which accounted for up to $29 \%$ of the volume of the Ringold sediments (Bjornstad 1990), with plagioclase (Na-Ca) feldspar $\left(\rho_{s}=2.62-2.76\right)$ being significantly more abundant than potassium feldspar $\left(\rho_{s}=2.55-2.63 \mathrm{~g} / \mathrm{cm}^{3}\right)$. In contrast, the Hanford formation sediments contained large quantities (up to 64\% by volume) of mafic (i.e., basalt) clasts (Bjornstad 1990), whose essential components are plagioclase and pyroxene (but which also contain accessory minerals such as magnetite $\left[\rho_{s}=5.2 \mathrm{~g} / \mathrm{cm}^{3}\right]$, hematite, ilmenite, apatite, quartz and olivine). In general, the mineralogical compositions of the sediments from the 200 West Area reported by Bjornstad (1990) are consistent with the differences in the average particle densities for the Hanford formation and Ringold Formation in the 300 Area (reported in Table A.2). However, there has been no systematic study of particle densities for different size fractions of Hanford or Ringold Formation sediments.

Bulk-density statistics are given in Table A.3. The average bulk densities for the Hanford formation (u1) and the combined Ringold Formation units (u4, u5, u8, and u9) are 2.08 and 1.86, respectively. Figure A.2 shows the distribution of bulk-density data with elevation. From this figure and from Table A.3, it is clear there are also significant differences between the bulk densities of the different Ringold Formation subunits. The average bulk densities of $\mathrm{u} 4$, $\mathrm{u} 5$, and $\mathrm{u} 8+\mathrm{u} 9$ are $1.56,2.04$, and $1.42 \mathrm{~g} / \mathrm{cm}^{3}$, respectively. Although not readily apparent from the statistics given in Table A.3, from Figure A.2 it appears there may be less variability in the bulk-density data for units $u 4$ and $u 8+u 9$ than for units $u 1$ and $\mathrm{u} 5$, possibly as a result of misclassification of some samples. Lower variability of units $\mathrm{u} 4$ and $\mathrm{u} 8+\mathrm{u} 9$ may be a result of these units being finer textured, and lacking any significant gravel- or cobbled-sized material. More representative samples can probably be obtained from these units relative to the coarser, gravel- and cobble-dominated units $\mathrm{u} 1$ and u5. Some of the apparent variability in the bulk density (and porosity) data for $\mathrm{u} 1$ and $\mathrm{u} 5$ may result from sample disturbance caused from the use of core barrels that are small, relative to the mean grain sizes of the gravel- and cobble-dominated portions of these hydrostratigraphic units.

The average particle densities for the Hanford u1 unit $\left(\rho_{s}=2.76 \mathrm{~g} / \mathrm{cm}^{3}\right)$ and for the combined Ringold units $\left(\rho_{s}=2.65 \mathrm{~g} / \mathrm{cm}^{3}\right)$ were used in conjunction with the measured bulk densities for the LFI core samples to calculate porosities for those samples, since the particle densities of those samples were not measured. Table A.4 provides descriptive statistics for the pooled, total-porosity data from all 16 wells shown in Figure A.1 -including the data from the four LFI wells. Figure A.3 shows a histogram of the pooled total porosity data. The histogram of the total porosity data shown in Figure A.3 appears to be at least bimodal with modes at approximately 0.20 and 0.48 . 

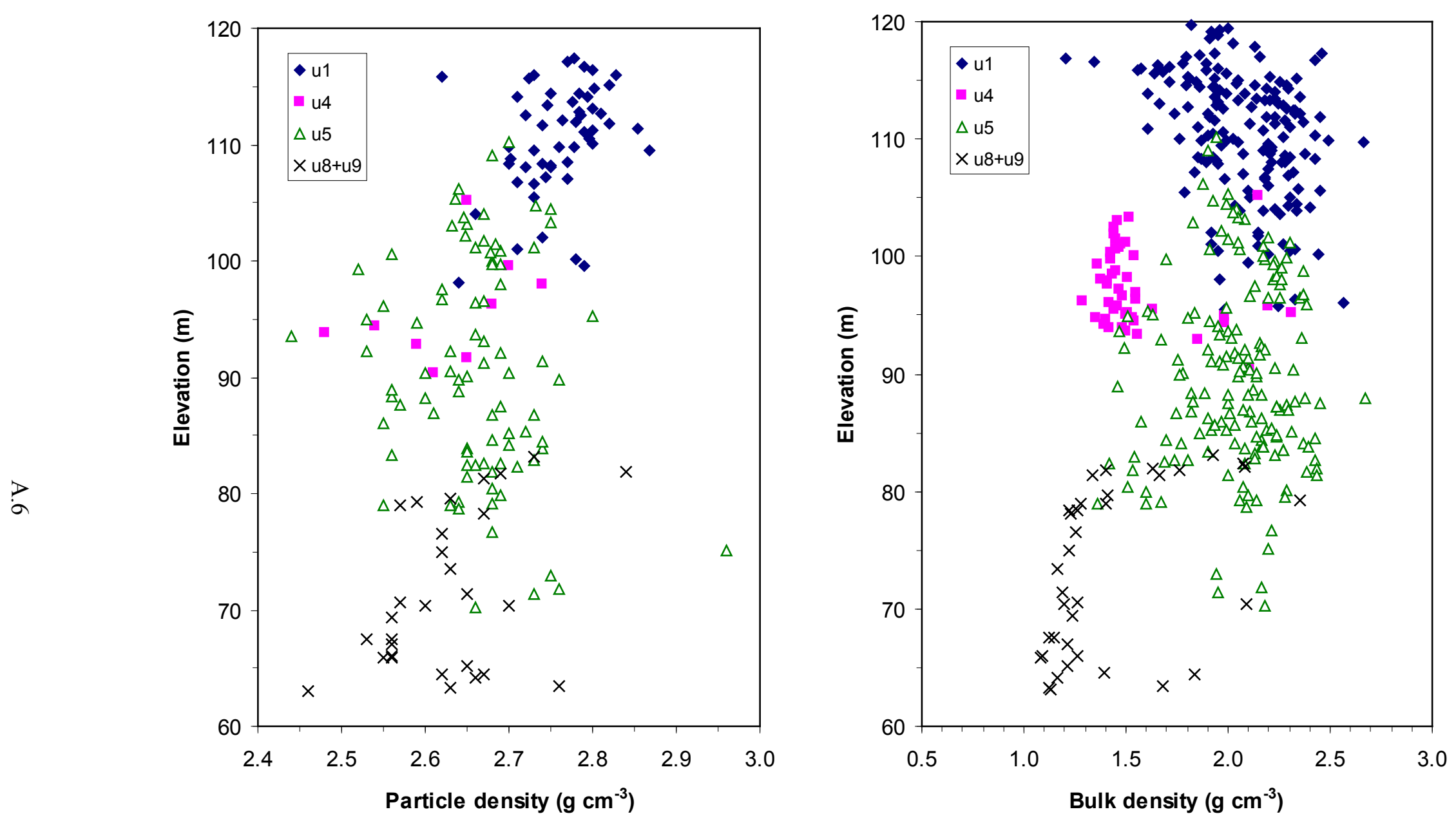

Figure A.2. Distributions of Particle Density (left plot) and Bulk Density (right plot) with Elevation for Hanford Site 300 Area Core Samples 
Table A.4. Descriptive Statistics for Pooled, Total-Porosity Data (units u1, u4, u5, u8, and u9 combined) from Hanford Site 300 Area Core Samples for 16 Wells

\begin{tabular}{lc}
\hline \multicolumn{2}{c}{ Total Porosity Statistics - Combined Units } \\
\hline Statistic & All wells \\
\hline Mean & 0.280 \\
Standard error & 0.006 \\
Median & 0.256 \\
Mode & 0.212 \\
Standard deviation & 0.121 \\
Sample variance & 0.015 \\
Kurtosis & -0.536 \\
Skewness & 0.598 \\
Range & 0.505 \\
Minimum & 0.072 \\
Maximum & 0.576 \\
Sum & 113.013 \\
Number of samples & 404 \\
Confidence interval for the & \pm 0.012 \\
mean at a 95\% confidence & \\
level & \\
\hline
\end{tabular}

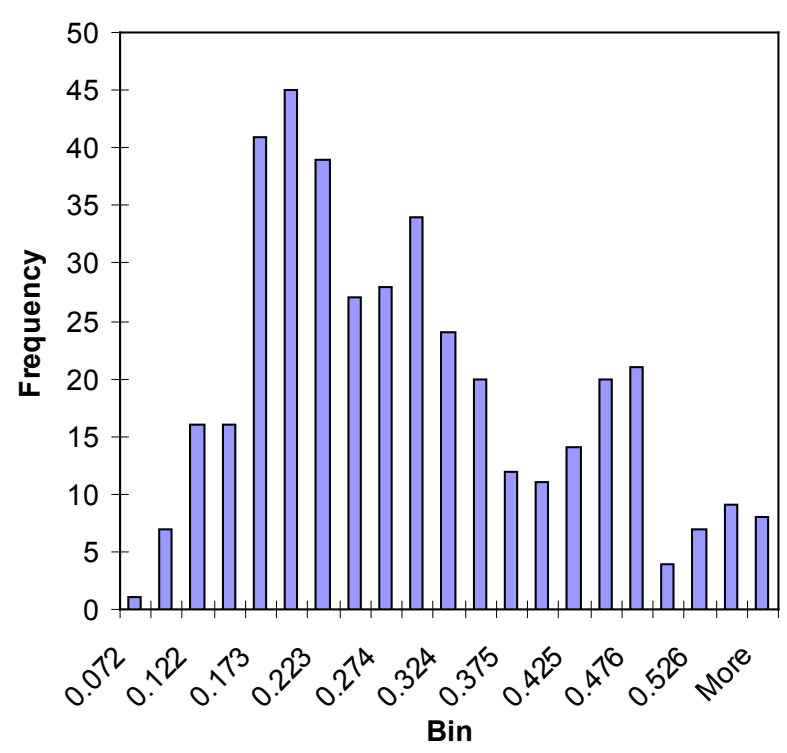

Figure A.3. Histogram of Pooled Total Porosity Data for Hanford Site 300 Area Core Samples

Figure A. 4 shows the distribution of total porosity with depth for the different hydrostratigraphic units. The higher total porosity values (greater than 0.4 ) are primarily from three sources: 1) from elevations below $80 \mathrm{~m}$ (corresponding with Ringold Formation overbank flood deposits and lower mud units, u8 and u9); 2) from clusters between the 90- to 105-m elevation interval (corresponding with the 
discontinuous and previously unrecognized/undesignated fine-grained Ringold sand unit, which overlies the top of Ringold unit E, u5 [Williams et al. 2007] and is tentatively classified as unit u4); and 3) from several samples above the 115-m elevation (representing finer-grained sediments at the top of or overlying the Hanford formation sediments, $\mathrm{u} 1$, near the ground surface). Note that most samples with high total porosity values within the 90 - to $105-\mathrm{m}$ elevation interval (Figure A.4) are also from a single well, 399-3-18, which was one of the four LFI wells.

Table A.5 shows the descriptive statistics for the total porosity data grouped by individual units (e.g., $\mathrm{u} 1, \mathrm{u} 4, \mathrm{u} 5, \mathrm{u} 8+\mathrm{u} 9$ ). Note that unit $\mathrm{u} 8$ and $\mathrm{u} 9$ are grouped together due to similar properties and the reduced number of samples available for these two units. The average total porosities of units $u 1$ (undifferentiated Hanford formation) and u5 (Ringold Formation unit E) are similar, with values of 0.249 and 0.233 , respectively. However, the average permeability of unit u5 appears to be two to three orders of magnitude lower than the average permeability of the Hanford formation in the 300 Area (see Figure 2.1). This difference in average permeabilities for similar total porosities suggests one or both of the following: 1) the effective porosity of unit $\mathrm{u} 5$ is significantly lower than that of unit $\mathrm{u} 1$, possibly due to cementation and partial diagenesis; or 2) the mean grain diameter of $u 5$ is smaller than that of $u 1$. Additionally, if $\mathrm{u} 5$ were more poorly sorted on average than $\mathrm{u} 1$, it would result in lower permeabilitiesbut it would also likely result in a significantly reduced average total porosity for u5 relative to u1, which is not the case. Therefore the decreased permeability of $\mathrm{u} 5$ relative to $\mathrm{u} 1$ probably stems from a smaller mean grain diameter and/or lower effective porosity.

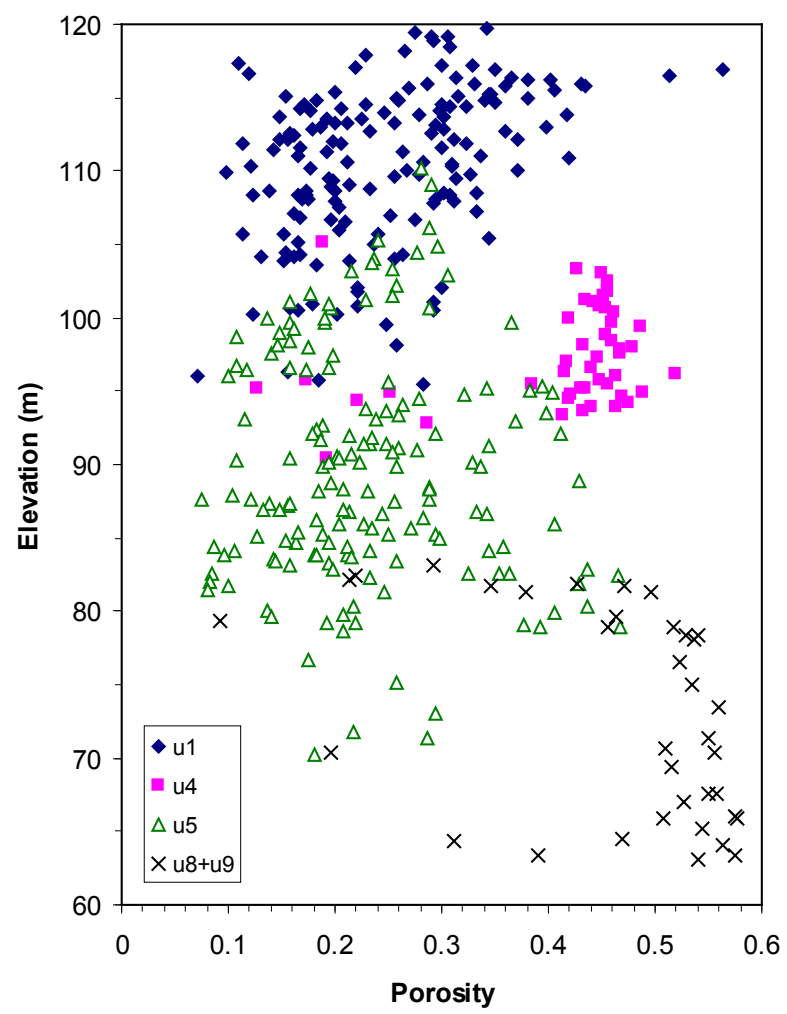

Figure A.4. Distribution of Total Porosity with Depth for Hanford Site 300 Area Core Samples. Symbols represent different hydrogeologic units $-\mathrm{u} 1, \mathrm{u} 4, \mathrm{u} 5$, and $\mathrm{u} 8+\mathrm{u} 9$. 
Table A.5. Descriptive Statistics for Total Porosity of 300 Area Core Samples Grouped by Individual Units (u1, u4, u5, and u8) for 16 Wells

\begin{tabular}{lcccc}
\hline \multicolumn{4}{c}{ Total Porosity Statistics - Individual Units } \\
\hline \multicolumn{1}{c}{ Statistic } & $\begin{array}{c}\text { Hanford } \\
(\mathrm{u} 1)\end{array}$ & $\begin{array}{c}\text { Ringold } \\
(\mathrm{u} 4)\end{array}$ & $\begin{array}{c}\text { Ringold } \\
(\mathrm{u} 5)\end{array}$ & $\begin{array}{c}\text { Ringold } \\
(\mathrm{u} 8+\mathrm{u} 9)\end{array}$ \\
\hline Mean & 0.249 & 0.411 & 0.233 & 0.461 \\
Standard error & 0.007 & 0.014 & 0.007 & 0.021 \\
Median & 0.243 & 0.445 & 0.217 & 0.516 \\
Mode & $\mathrm{N} / \mathrm{A}$ & $\mathrm{N} / \mathrm{A}$ & 0.212 & $\mathrm{~N} / \mathrm{A}$ \\
Standard deviation & 0.087 & 0.093 & 0.089 & 0.126 \\
Variance & 0.008 & 0.009 & 0.008 & 0.016 \\
Kurtosis & 0.362 & 2.591 & -0.120 & 1.298 \\
Skewness & 0.574 & -1.919 & 0.587 & -1.462 \\
Range & 0.493 & 0.392 & 0.391 & 0.484 \\
Minimum & 0.072 & 0.126 & 0.075 & 0.093 \\
Maximum & 0.564 & 0.519 & 0.467 & 0.576 \\
Sum & 39.333 & 18.926 & 38.146 & 16.608 \\
Number of samples & 158 & 46 & 164 & 36 \\
Confidence interval for & \pm 0.014 & \pm 0.028 & \pm 0.014 & \pm 0.042 \\
the mean at a 95 \% & & & & \\
confidence level & & & & \\
\hline
\end{tabular}

The total porosity of the saturated portion of the Hanford formation, which generally lies below the 106-m elevation, is generally lower than the total porosity of the upper, unsaturated (vadose zone) section (Figure A.4). This difference between the vadose and saturated zone porosities of the Hanford formation is presumably due to a higher mass fraction of gravel- and cobble-sized sediments in the lower part of the Hanford formation. Using data from all 16 wells for samples designated as $\mathrm{u} 1$ from elevations less than or equal to $106 \mathrm{~m}$, the average total porosity is 0.203 . For samples designated as $\mathrm{u} 1$ from elevations greater than $106 \mathrm{~m}$, the average total porosity is calculated to be 0.261 . The lower portion of the Hanford formation is the most transmissive zone of the unconfined aquifer system in the 300 Area, so this distinction between the upper and lower parts of the Hanford formation is potentially important.

The average total porosities of $\mathrm{u} 4$ and $\mathrm{u} 5$ (Ringold unit E) are significantly different, with values of 0.411 and 0.233 , respectively. However, the average permeabilities of these two units are within one order of magnitude (Williams et al. 2007) of each other. The average total porosities of $u 4$ and $u 8+u 9$ (combined) are 0.411 and 0.461 , respectively. Calculated porosities for units $\mathrm{u} 4$ and $\mathrm{u} 8+\mathrm{u} 9$ span a large range, with relatively denser clusters of data points at higher porosity values (Figure A.4). There is a potential that some samples that were designated as $u 4$ or $u 8+u 9$ may have been misclassified, which would result in a calculated average porosity that is lower than it should be.

Williams et al. (2007) previously reported total porosity values for 20 LFI core samples (five from each borehole/well) for which whole sediment grain-size distribution data were also available. All but two of the samples appeared to be from the Hanford formation (u1). The average total porosity of those 20 samples was 0.207 , noticeably smaller than the average total porosity value of 0.249 shown for $u 1$ in Table A.5. The statistics in Table A.5 represent samples from 12 additional wells. 
There is some concern regarding representative measurements of porosity and grain-size distributions for 300 Area sediments; this concern specifically relates to the very coarse nature of the Hanford formation in this area and the tendency for standard cable-tool drilling methods to pulverize larger grains in cobble- and gravel-dominated sediments. LFI core samples were collected in 5-ft core barrels containing 1-ft-long, 5-in.-diameter Lexan liners. Drilling was performed with a sonic drilling method. The combination of these factors - sonic drilling and larger-diameter cores - led to what appeared to be more representative, higher-quality cores than are typically obtained from 300 Area sediments using standard 4-in.-diameter Lexan liners and cable-tool drilling. ${ }^{1}$ Therefore, the total porosity data for the LFI core samples may be more representative of the site than the total porosity data from the other cores that were obtained using traditional drilling and sampling methods. In order to determine the presence of significant differences between the average total porosity values for the LFI cores versus the other cores, the samples were split into two groups: one consisting only of LFI core data, and the other consisting of the data from the 12 other wells. Descriptive statistics were computed separately for the pooled data from all units in each group, and for the individual units in each group.

Table A.6 shows the descriptive statistics for the pooled total porosity data for each well group (LFI wells vs. other wells). The average total porosities for all units from the LFI wells and for all units from the other 12 wells are 0.262 and 0.308 , respectively. This difference in average total porosities of 0.046 may be due, in part, to the use of the larger-diameter core barrel and sonic drilling for the LFI wells. However, the area bounded by the 4 LFI wells is much smaller than the area bounded by the 12 other wells, so differences in average total porosity for the LFI wells versus other wells may also correspond to regional differences over the sampled domains.

Table A.6. Descriptive Statistics for Pooled Total Porosity Data (units u1, u4, u5, u8, and u9 combined) from Hanford Site 300 Area Core Samples for LFI wells and Non-LFI Wells

\begin{tabular}{lcc}
\hline \multicolumn{3}{c}{ Total Porosity Statistics - Combined Units } \\
\hline Statistic & 4 LFI Wells & 12 Non-LFI Wells \\
\hline Mean & 0.262 & 0.307 \\
Standard error & 0.008 & 0.009 \\
Median & 0.224 & 0.290 \\
Mode & N/A & 0.212 \\
Standard deviation & 0.120 & 0.118 \\
Sample variance & 0.014 & 0.014 \\
Kurtosis & -0.774 & -0.255 \\
Skewness & 0.613 & 0.683 \\
Range & 0.493 & 0.484 \\
Minimum & 0.072 & 0.093 \\
Maximum & 0.564 & 0.576 \\
Sum & 63.817 & 49.196 \\
Count & 244 & 160 \\
Confidence interval for the mean at a & \pm 0.015 & \pm 0.018 \\
95\% confidence level & & \\
\hline
\end{tabular}

Table A.7 shows the descriptive statistics for the individual units in each well group (LFI wells versus non-LFI wells). The average total porosities of $\mathrm{u} 1$ for the LFI and the non-LFI well groups are 0.236 and

\footnotetext{
${ }^{1}$ Personal communication with Bruce Bjornstad (PNNL) and Bruce Williams (Fluor Hanford, Inc.).
} 
0.282, respectively. This is a statistically significant difference (see Appendix D). For u5, Table A.7 indicates the average total porosities for the LFI and the non-LFI well groups are 0.202 and 0.265 , respectively — which is again a significant difference (see Appendix D). Units $\mathrm{u} 1$ and $\mathrm{u} 5$ can both contain significant mass fractions of gravel- and cobble-sized materials that tend to get pulverized to varying degrees by cable-tool drilling. For $\mathrm{u} 4$, the average total porosities for the LFI well group and for the other well group are 0.427 and 0.281 , respectively. Although this appears to be a significant difference, it may be due, in part, to misclassification of several samples from the non-LFI well group. Also note that there are only five samples identified as $\mathrm{u} 4$ in the non-LFI well group. The average total porosities of the combined $\mathrm{u} 8+\mathrm{u} 9$ units for the LFI and non-LFI well groups are 0.428 and 0.469 , respectively - but only seven samples represent $u 8+u 9$ from the LFI well group.

Table A.7. Descriptive Statistics for Total Porosity of 300 Area Core Samples Grouped by Individual Units (u1, u4, u5, and u8+u9) and Wells (LFI wells vs. non-LFI wells) Using Data from all 16 Wells

\begin{tabular}{|c|c|c|c|c|c|c|c|c|}
\hline \multicolumn{9}{|c|}{ Total Porosity Statistics - Individual Units } \\
\hline \multirow[b]{2}{*}{ Statistic } & \multicolumn{2}{|c|}{$\mathrm{u} 1$} & \multicolumn{2}{|c|}{$\mathrm{u} 4^{(\mathrm{a})}$} & \multicolumn{2}{|c|}{ u5 } & \multicolumn{2}{|c|}{$\mathrm{u} 8+\mathrm{u} 9$} \\
\hline & $\mathrm{LFI}^{(\mathrm{b})}$ & $\begin{array}{l}\text { Non- } \\
\text { LFI }^{(\mathrm{c})}\end{array}$ & LFI & $\begin{array}{l}\text { Non- } \\
\text { LFI }\end{array}$ & LFI & Non-LFI & LFI & Non-LFI \\
\hline Mean & 0.236 & 0.282 & 0.427 & 0.281 & 0.201 & 0.265 & 0.428 & 0.469 \\
\hline Standard error & 0.009 & 0.010 & 0.012 & 0.062 & 0.009 & 0.010 & 0.055 & 0.023 \\
\hline Median & 0.212 & 0.301 & 0.447 & 0.220 & 0.192 & 0.251 & 0.496 & 0.523 \\
\hline Mode & N/A & $\mathrm{N} / \mathrm{A}$ & N/A & N/A & N/A & 0.212 & $\mathrm{~N} / \mathrm{A}$ & $\mathrm{N} / \mathrm{A}$ \\
\hline Standard deviation & 0.091 & 0.065 & 0.074 & 0.138 & 0.079 & 0.087 & 0.146 & 0.121 \\
\hline Sample variance & 0.008 & 0.004 & 0.005 & 0.019 & 0.006 & 0.008 & 0.021 & 0.015 \\
\hline Kurtosis & 1.139 & -0.241 & 9.828 & 3.356 & 0.018 & -0.334 & -0.933 & 2.449 \\
\hline Skewness & 1.026 & -0.809 & -3.124 & 1.836 & 0.666 & 0.581 & -1.123 & -1.656 \\
\hline Range & 0.493 & 0.249 & 0.363 & 0.330 & 0.330 & 0.359 & 0.327 & 0.484 \\
\hline Minimum & 0.072 & 0.122 & 0.126 & 0.189 & 0.075 & 0.108 & 0.213 & 0.093 \\
\hline Maximum & 0.564 & 0.371 & 0.489 & 0.519 & 0.406 & 0.467 & 0.540 & 0.576 \\
\hline Sum & 26.378 & 12.955 & 17.521 & 1.405 & 16.926 & 21.220 & 2.993 & 13.615 \\
\hline Count & 112 & 46 & 41 & 5 & 84 & 80 & 7 & 29 \\
\hline $\begin{array}{l}\text { Confidence interval } \\
\text { for the mean at a } \\
95 \% \text { confidence } \\
\text { level }\end{array}$ & \pm 0.017 & \pm 0.019 & \pm 0.023 & \pm 0.172 & \pm 0.017 & \pm 0.019 & \pm 0.135 & \pm 0.046 \\
\hline
\end{tabular}

(a) Differences in the mean total porosity of $u 4$ for the LFI and other well groups are attributed primarily to misclassification of some of the samples in the other well group.

(b) LFI core samples were collected in 5-in.-diameter Lexan liners, and drilling was performed using a sonic drilling method.

(c) Core samples in the non-LFI well group were generally collected in standard 4-in.-diameter Lexan liners and most of the wells were drilled using a cable-tool drilling method.

As noted earlier, the Hanford formation (u1) is the most transmissive part of the unconfined aquifer system in the 300 Area. For saturated zone modeling, it was also of interest to know how the average 
total porosities of the lower (lower than, or equal to a 106-m elevation) and upper (higher than a 106-m elevation) parts of $\mathrm{u} 1 \mathrm{might}$ differ for the two well groups (LFI well vs. non-LFI wells). Therefore, the $\mathrm{u} 1$ samples were segregated by well group and sample elevation, and descriptive statistics were computed for each, which are shown in Table A.8.

Table A.8 Descriptive Statistics for Total Porosity of Unit $\mathrm{u} 1$ for LFI and Non-LFI Wells Above and Below the 106-m Elevation Using Data from all 16 Wells

\begin{tabular}{|c|c|c|c|c|}
\hline \multicolumn{5}{|c|}{ Total Porosity Statistics - Unit u1 } \\
\hline \multirow[b]{2}{*}{ Statistic } & \multicolumn{2}{|c|}{$\mathrm{u} 1 \leq 106 \mathrm{~m}$ Elevation } & \multicolumn{2}{|c|}{$\mathrm{u} 1>106 \mathrm{~m}$ Elevation } \\
\hline & LFI Wells $^{(a)}$ & $\begin{array}{l}\text { Non-LFI } \\
\text { Wells }^{(b)}\end{array}$ & LFI Wells & Non-LFI Wells \\
\hline Mean & 0.191 & 0.246 & 0.248 & 0.288 \\
\hline Standard error & 0.011 & 0.030 & 0.010 & 0.010 \\
\hline Median & 0.183 & 0.258 & 0.219 & 0.307 \\
\hline Mode & N/A & N/A & N/A & N/A \\
\hline Standard deviation & 0.054 & 0.079 & 0.096 & 0.061 \\
\hline Sample variance & 0.003 & 0.006 & 0.009 & 0.004 \\
\hline Kurtosis & -0.184 & -0.622 & 0.605 & -0.324 \\
\hline Skewness & 0.006 & -0.636 & 0.887 & -0.802 \\
\hline Range & 0.221 & 0.222 & 0.466 & 0.213 \\
\hline Minimum & 0.072 & 0.122 & 0.098 & 0.158 \\
\hline Maximum & 0.292 & 0.344 & 0.564 & 0.371 \\
\hline Sum & 4.778 & 1.724 & 21.600 & 11.231 \\
\hline Count & 25 & 7 & 87 & 39 \\
\hline $\begin{array}{l}\text { Confidence interval for the mean } \\
\text { at a } 95 \% \text { confidence level }\end{array}$ & \pm 0.022 & \pm 0.073 & \pm 0.020 & \pm 0.020 \\
\hline
\end{tabular}

(a) LFI core samples were collected in 5-in.-diameter Lexan liners; drilling was performed using a sonic drilling method.

(b) Core samples in the other well group were generally collected in standard 4-in.-diameter Lexan liners and most of the wells were drilled using a cable-tool drilling method.

The average total porosities of the LFI and non-LFI well groups (Table A.8) for u1 core samples collected at or below the 106-m elevation using data from all 16 wells are 0.191 and 0.246 , respectively. The average total porosities of the LFI and non-LFI well groups for core samples collected above the 106-m elevation using data from all 16 wells are 0.248 and 0.288 , respectively. Both differences appear to be statistically significant (Appendix D), although only seven samples were available for the non-LFI, less-than-106-m-elevation group.

In addition to the potential for sampling bias associated with the drilling method and core diameter, there is a possibility that sediments located farther from the river may actually have different properties than those located closer to the river, owing to differences in depositional environment at different locations. Also, some wells have more data in certain regions of the domain (such as higher than a 106-m elevation) and thus might dominate the statistics for those regions. For example, most of the samples from well 699-S20-E10 are from the Hanford formation (u1) and are located above the 106-m elevation; 
therefore, it is likely that data from this particular well, located $\sim 1.2 \mathrm{~km}$ from the river, may dominate the statistics for the non-LFI u1 core samples for elevations above $106 \mathrm{~m}$ (last column of Table A.8).

The areas immediately surrounding the former liquid waste disposal facilities are of greatest interest for ongoing 300 Area basic research and remedial action investigations. In an attempt to reduce the influence of data on the sample statistics from wells that are located far from the river and from the former liquid waste disposal areas, total porosity data exclusively from the eight wells closest to and surrounding the former liquid waste disposal sites were used. Data from these wells were further separated into LFI and non-LFI well groups, each consisting of data from four wells. Descriptive statistics were computed using the data from the separate LFI and non-LFI well groups, and from the combined data of all eight wells. The non-LFI well group consists of wells 399-1-10B, 399-1-13B, 3991-14B, and 399-1-21B (wells 1-4 in Table A.1), and the LFI well group consists of wells 399-1-23, 3993-18, 399-3-19, and 399-3-20 (wells 5-8 in Table A.1). Table A.9 shows the descriptive statistics for the total porosity data of all units combined for the eight wells closest to the former liquid waste disposal facilities and for those wells broken out into the non-LFI and LFI well groups.

Table A.9. Descriptive Statistics for Total Porosity of 300 Area Core Samples for the Eight Wells Closest to the Former Liquid Waste Disposal Areas for all Hydrogeologic Units Combined

\begin{tabular}{lccc}
\hline \multicolumn{4}{c}{ Total Porosity Statistics - Subset of 8 Wells, All Units Combined } \\
\hline \multicolumn{1}{c}{ Statistic } & 8 Wells & 4 LFI Wells & 4 Other Wells \\
\hline Mean & 0.262 & 0.262 & 0.262 \\
Standard error & 0.007 & 0.008 & 0.012 \\
Median & 0.229 & 0.224 & 0.248 \\
Mode & 0.212 & N/A & 0.212 \\
Standard deviation & 0.115 & 0.120 & 0.084 \\
Sample variance & 0.013 & 0.014 & 0.007 \\
Kurtosis & -0.653 & -0.774 & -0.085 \\
Skewness & 0.628 & 0.613 & 0.722 \\
Range & 0.493 & 0.493 & 0.344 \\
Minimum & 0.072 & 0.072 & 0.122 \\
Maximum & 0.564 & 0.564 & 0.466 \\
Sum & 75.853 & 63.817 & 12.035 \\
Count & 290 & 244 & 46 \\
Confidence interval for the mean & \pm 0.013 & \pm 0.015 & \pm 0.025 \\
at a 95\% confidence level & & & \\
\hline
\end{tabular}

The mean total porosities for all the samples from the LFI and non-LFI well groups in this subset of eight wells are 0.262 and 0.262 , respectively. The total number of samples available from the group of four non-LFI wells is only 46, whereas the total number of samples available from the LFI well group is 230. Thus, there are five times as many samples for the LFI wells as there are for this subset of non-LFI wells. Nevertheless, there is essentially no difference between the mean total porosity values for the data in each well group. 
Table A.10 shows the descriptive statistics for the total porosity data from the four LFI wells and from the four other wells in the eight-well near-the-former-liquid-waste-disposal-facilities group for the individual hydrostratigraphic units. The mean total porosities of the LFI and non-LFI well groups for $\mathrm{u} 1$ are 0.236 and 0.231 , respectively. This difference is insufficient to reject the null hypothesis that the sample means are the same (Appendix D). Despite the limited sample size (11) for the non-LFI well group, this small difference in mean values is in sharp contrast to the large difference in mean values shown previously for u1 (Table A.7) in the LFI and non-LFI well groups (when data from all 12 non-LFI wells was considered). These differences in mean values for the subset of four non-LFI wells versus the whole set of 12 non-LFI wells may be interpreted as evidence of non-stationary and/or sample clustering effects for this sparse data set. For $\mathrm{u} 4$, the mean total porosities for the LFI and non-LFI well groups in this subset of eight wells are 0.427 and 0.233 , respectively. However, there are only three samples in the non-LFI well group and, as noted earlier, it is possible that some of these samples may have been misclassified. The mean total porosities for the LFI and non-LFI well groups for u5 are 0.202 and 0.258 , respectively, which is a statistically significant difference (Appendix D). The mean total porosities for the LFI and non-LFI well groups for $\mathrm{u} 8+\mathrm{u} 9$ are 0.428 and 0.349 .

Table A.10. Descriptive Statistics for Total Porosity of 300 Area Core Samples for the Eight Wells Closest to the Former Liquid Waste Disposal Areas Grouped by Individual Units (u1, u4, u5, and u8) and Wells (LFI wells vs. non-LFI wells)

\begin{tabular}{|c|c|c|c|c|c|c|c|c|}
\hline \multicolumn{9}{|c|}{ Total Porosity Statistics - Subset of 8 Wells, Individual Units } \\
\hline \multirow[b]{2}{*}{ Statistic } & \multicolumn{2}{|c|}{$\mathrm{u} 1$} & \multicolumn{2}{|c|}{$\mathrm{u} 4^{(\mathrm{a})}$} & \multicolumn{2}{|c|}{ u5 } & \multicolumn{2}{|c|}{$\mathrm{u} 8+\mathrm{u} 9$} \\
\hline & $\mathrm{LFI}^{(\mathrm{b})}$ & Other ${ }^{(\mathrm{c})}$ & LFI & Other & LFI & Other & LFI & Other \\
\hline Mean & 0.236 & 0.231 & 0.427 & 0.233 & 0.201 & 0.258 & 0.428 & 0.349 \\
\hline Standard error & 0.009 & 0.022 & 0.012 & 0.028 & 0.009 & 0.016 & 0.055 & 0.039 \\
\hline Median & 0.212 & 0.247 & 0.447 & 0.220 & 0.192 & 0.239 & 0.496 & 0.362 \\
\hline Mode & N/A & N/A & N/A & N/A & N/A & 0.212 & N/A & $\mathrm{N} / \mathrm{A}$ \\
\hline Standard deviation & 0.091 & 0.072 & 0.074 & 0.048 & 0.079 & 0.079 & 0.146 & 0.094 \\
\hline Sample variance & 0.008 & 0.005 & 0.005 & 0.002 & 0.006 & 0.006 & 0.021 & 0.009 \\
\hline Kurtosis & 1.139 & -0.757 & 9.828 & N/A & 0.018 & 0.625 & -0.933 & 0.085 \\
\hline Skewness & 1.026 & 0.185 & -3.124 & 1.059 & 0.666 & 0.997 & -1.123 & -0.739 \\
\hline Range & 0.493 & 0.236 & 0.363 & 0.094 & 0.330 & 0.325 & 0.327 & 0.259 \\
\hline Minimum & 0.072 & 0.122 & 0.126 & 0.192 & 0.075 & 0.141 & 0.213 & 0.196 \\
\hline Maximum & 0.564 & 0.359 & 0.489 & 0.286 & 0.406 & 0.466 & 0.540 & 0.455 \\
\hline Sum & 26.378 & 2.537 & 17.521 & 0.698 & 16.926 & 6.706 & 2.993 & 2.095 \\
\hline Count & 112 & 11 & 41 & 3 & 84 & 26 & 7 & 6 \\
\hline $\begin{array}{l}\text { Confidence interval } \\
\text { for the mean at a } 95 \\
\% \text { confidence level }\end{array}$ & \pm 0.017 & \pm 0.048 & \pm 0.023 & \pm 0.120 & \pm 0.017 & \pm 0.032 & \pm 0.135 & \pm 0.099 \\
\hline \multicolumn{9}{|c|}{$\begin{array}{l}\text { (a) Differences in the mean total porosity of } u 4 \text { for the LFI and other well groups are attributed primarily to the } \\
\text { misclassification of samples in the other well group. }\end{array}$} \\
\hline $\begin{array}{l}\text { (b) LFI core sample } \\
\text { method. }\end{array}$ & were colle & ed in 5-in. & ameter Le & an liners; & illing was & erformed & sing a soni & drilling \\
\hline $\begin{array}{l}\text { (c) Core samples in } \\
\text { liners and most } \mathrm{c}\end{array}$ & $\begin{array}{l}\text { e other }(\mathrm{n} \\
\text { the wells }\end{array}$ & $\begin{array}{l}\text {-LFI) wel } \\
\text { ere drilled }\end{array}$ & $\begin{array}{l}\text { roup were } \\
\text { ing a cabl }\end{array}$ & $\begin{array}{l}\text { senerally } \\
\text { tool drilli }\end{array}$ & $\begin{array}{l}\text { llected in } \\
\text { method. }\end{array}$ & andard 4-1 & -diameter & exan \\
\hline
\end{tabular}


Descriptive statistics of total porosity were computed for the $\mathrm{u} 1$ samples from the subset of eight wells closest to the former liquid waste disposal facilities for elevations at or below $106 \mathrm{~m}$, and for elevations above $106 \mathrm{~m}$; results are shown in Table A.11. The mean total porosity of $\mathrm{u} 1$ for elevations less than or equal to $106 \mathrm{~m}$ for the four LFI wells and for the subset of four non-LFI wells are 0.191 and 0.232 , respectively. For elevations above $106 \mathrm{~m}$, the mean total porosity of $\mathrm{u} 1$ for the LFI and subset of non-LFI wells are 0.248 and 0.230 , respectively.

Table A.11. Descriptive Statistics for Total Porosity of Unit u1 for LFI and non-LFI Wells Above and Below the 106-m Elevation for a Subset of Eight Wells Closest to the Former Liquid Waste Disposal Areas

\begin{tabular}{lcccc}
\hline & \multicolumn{2}{c}{ Total Porosity Statistics - Unit u1 } & \multicolumn{2}{c}{$\mathrm{u} 1>106$ m Elevation } \\
\cline { 2 - 5 } \multicolumn{1}{c}{ Statistic } & 4 LFI wells ${ }^{(\text {a) }}$ & 4 non-LFI wells ${ }^{(\mathrm{b})}$ & 4 LFI wells & 4 non-LFI wells \\
\hline Mean & 0.191 & 0.232 & 0.248 & 0.230 \\
Standard error & 0.011 & 0.038 & 0.010 & 0.028 \\
Median & 0.183 & 0.252 & 0.219 & 0.194 \\
Mode & $\mathrm{N} / \mathrm{A}$ & $\mathrm{N} / \mathrm{A}$ & $\mathrm{N} / \mathrm{A}$ & $\mathrm{N} / \mathrm{A}$ \\
Standard deviation & 0.054 & 0.076 & 0.096 & 0.075 \\
Sample variance & 0.003 & 0.006 & 0.009 & 0.006 \\
Kurtosis & -0.184 & 2.688 & 0.605 & -0.531 \\
Skewness & 0.006 & -1.466 & 0.887 & 0.843 \\
Range & 0.221 & 0.177 & 0.466 & 0.201 \\
Minimum & 0.072 & 0.122 & 0.098 & 0.158 \\
Maximum & 0.292 & 0.299 & 0.564 & 0.359 \\
Sum & 4.778 & 0.926 & 21.600 & 1.611 \\
Count & 25 & 4 & 87 & 7 \\
Confidence interval for the & \pm 0.022 & \pm 0.121 & \pm 0.020 & \pm 0.070 \\
mean at a 95 \% confidence & & & & \\
level & & & & \\
\hline
\end{tabular}

(a) LFI core samples were collected in 5-in.-diameter Lexan liners; drilling was performed using a sonic drilling method.

(b) Core samples in the other well group were generally collected in standard 4-in.-diameter Lexan liners, and most of the wells were drilled using a cable-tool drilling method.

In summary, statistical analyses of the pooled set of total porosity data from 16 wells in and around the 300 Area suggest that the larger-diameter, sonic-drilled cores collected during the LFI have lower average total porosities than the smaller-diameter, non-LFI core samples collected (typically by cable-tool drilling) for the gravel- and cobble-dominated sediments ( $\mathrm{u} 1$ and $\mathrm{u} 5$ ). However, further analyses of data from a subset of eight wells located in the immediate vicinity of the former liquid waste disposal facilities suggest that the differences in mean total porosity values for the LFI and non-LFI wells may actually be due, at least in part, to spatial variability, sample clustering effects, and non-stationarity over the sampled domain. For example, although the difference between the mean total porosities for the LFI wells $(0.236)$ and the non-LFI wells (0.282) wells was statistically significant (see Appendix D) for u1 samples when data from all 16 wells was considered, this difference was much smaller when data from only a subset of four non-LFI wells (0.231) closest to the former liquid waste disposal facilities (and closest to the LFI wells) was considered (see Tables A.7 and A.10). 
We tentatively conclude the total porosity data from the standard 4-in. diameter, cable-tooled cores are valid (unbiased), since we do not have convincing evidence to the contrary, based on this limited data set. This conclusion is also tentative because there are five times more LFI than non-LFI well core samples for the subset of eight wells closest to the former liquid waste disposal facilities. However, this conclusion does not necessarily apply to the grain-size distribution data, for which we do expect a more significant sampling bias in the gravel- and cobble-dominated sediments (i.e., u1 and u5) when smaller diameter cores (4 in.) are collected using cable-tool drilling. The relative contribution of drilling method versus core barrel size on potential sample bias is currently unknown.

The average total porosity of $\mathrm{u} 1$ also appears to vary significantly with elevation. Average total porosity values in the lower section (lower than, or equal to $106 \mathrm{~m}$ elevation) of the Hanford formation, the most transmissive section of the unconfined aquifer system in the 300 Area, were approximately 5\% lower than in the upper part of the formation (higher than $106 \mathrm{~m}$ ) for the LFI cores. For strictly saturated zone modeling in the vicinity of the former liquid waste disposal facilities, we recommend using a total porosity value near 0.2 for the Hanford formation (u1), and the average total porosity values reported for the LFI cores in Table A.5 (or Table A.8) for the other hydrostratigraphic units. It is important to note these mean values represent total porosity, which is not necessarily the same as the effective porosity available for solute transport. 
Appendix B

\section{Hanford Site 300 Area Gamma Log Data}





\section{Appendix B}

\section{Hanford Site 300 Area Gamma Log Data}

\section{B.1 Introduction}

Hard copy records in PNNL's well log library (Sigma 5 Building, Richland, Washington; contact George Last) indicate that borehole geophysical logging in the 300 Area began in 1963 on wells that were completed as early as April 1948. Several types of borehole geophysical logging data have been collected in the 300 Area, including gross and spectral gamma, density, neutron-porosity, neutron-moisture, and sonic logs. Gross gamma logs have been collected for the majority of the wells, while the other types of logs have only been collected for some of the wells. Because the domain of interest in the 300 Area covers both the vadose zone and the shallow unconfined aquifer, it is important to distinguish between neutron-porosity and neutron-moisture logs. Neutron-porosity tools use a sealed radioactive source designed to measure the porosity of liquid-saturated sediments below the water table. Neutron-porosity logs were collected in the 300 Area in 1987 to 1988 for the boreholes and wells described by Schalla et al. (1988). The neutron-porosity tool is not useful, however, for measuring the water content of unsaturated (vadose zone) sediments. This is in contrast to the neutron-moisture probe used by the current site geophysical logging contractor (S.M. Stoller Corp., Richland, Washington), which is specifically designed for measuring water or moisture content of unsaturated porous media (Williams et al. 2006, 2007). Neutron-moisture probes typically cannot be used below the water table because they are not designed to be submerged. Depending on the strength of the source, the neutron-moisture probe may not provide reliable water-content data when used in large-diameter (i.e., greater than 8 in.), steel-cased wells because of signal attenuation. No calibration standards are currently available for Stoller's neutronmoisture probe in steel cased wells with inside diameters exceeding 8 in. ${ }^{1}$

Although many of the basic principles are the same, the configuration of the geophysical logging tools and the electronics used in the early 1960s are different than those used more recently (Hallenberg 1984). Therefore, the borehole geophysical data for the 300 Area wells were separated into distinct groups representing different time periods, during which the same logging tools and casings (e.g., 8-in. diameter carbon steel) would likely have been used. Separating the wells and associated borehole geophysical logging data into distinct groups was necessary to standardize the data, and to develop crosscorrelation equations needed for expressing the data from all the wells on a common basis. These groupings were selected based on the time periods during which well logging was conducted, the well drilling and completion records that specify the types of casings used in the processes, and the magnitude of the natural- or gross-gamma log count data that were recorded. The data described in this appendix are limited to natural- or gross-gamma log data (gross gamma logs measure the total gamma radiation emissions in a borehole), principally because this type of data was collected during all drilling and well logging campaigns conducted in the 300 Area, and thus comprises a data set with the most complete spatial coverage for the area.

Natural gamma rays in the subsurface originate primarily from three sources: potassium-40, uranium-238 daughter products, and thorium-233 daughters (Hallenburg 1984). Spectral gamma logging

\footnotetext{
${ }^{1}$ Personal communication with Alan Pearson, Stoller, Inc., Richland, Washington.
} 
distinguishes between these three sources of gamma emissions. Unfortunately, spectral gamma logs are only available for a small subset of the wells in the 300 Area. During a recent limited field investigation (LFI) in the 300 Area, longer-than-typical counting times (200 s) were used with a spectral gamma logging system (SGLS) in four boreholes in an attempt to detect process uranium. However, the SGLS was not sensitive enough to reliably detect process uranium through the large-diameter, temporary steel casing in the boreholes (Williams et al. 2007).

Natural- or gross-gamma log data have been shown to be correlated with shale or clay content and grain size (Serra and Sulpice 1975, Rider 1990). In petroleum and engineering applications, gross gamma logs are used as a cased-hole substitute for the spontaneous potential (SP) curve, which is used primarily for delineating sand and shale sequences in uncased boreholes (Hallenburg 1984). At the Hanford Site, hydraulic and sorption parameters have been shown to be strongly correlated with sediment grain-size distribution data (Rockhold et al. 1988, Gee et al. 1989, Ward et al. 2005). Therefore, gross gamma log data can potentially be used in conjunction with so-called petrophysical relationships and pedotransfer functions (Guber et al. 2006) to estimate hydraulic and sorption parameters. We assume changes in gross gamma log signals in 300 Area sediments are due primarily to differences in mass fractions of silt- and clay-size particles and their associated differences in potassium- 40 content. Where higher concentrations of process uranium are present, they may also be preferentially associated with finer-grained sediments due to the increased surface area available for adsorption. Therefore, regardless of the source(s) of gamma emissions, higher gross gamma log readings will likely be found in the finer-textured 300 Area sediments.

The following section describes the criteria used for data grouping, casing corrections, within-group standardization, and cross-correlation procedures applied to the gross gamma log data from the 300 Area. Section B.3 presents descriptive statistics for these data. Correlations between gross gamma log data and grain-size distribution data (see Appendix C) from LFI core samples are given in the Section 3 of this report.

\section{B.2 Gamma Log Well Groups, Standardization, and Cross Correlation}

Table B.1 lists the 45 wells from which gross gamma log data were compiled and analyzed for this report. In addition to well names and coordinates, Table B.1 provides information on casing corrections applied to the gamma log data for each well, comments regarding cross calibrations for different well groups, and whether aquifer tests were performed (and if so, the formation(s) in which they were performed). Figure B.1 shows the locations of these wells. Also shown in Figure B.1 are outlines of the 300 Area (purple outline) and the four primary uranium liquid waste disposal sites (red outlines).

Although the well coverage for the gamma log data is more extensive than for the total porosity data (see Appendix A), the data are still quite sparse. In particular, until recently (2007) there were no wells within the footprints of either the former north or south process ponds. Nevertheless, the gross gamma $\log$ data currently represent the geophysical log data set with the highest density coverage for the 300 Area, in terms of vertical measurement frequency, vertical extent, and area encompassed. As noted previously, gamma log data were separated into distinct groups representing different periods during which the same logging tools and casing strings (e.g., 8-in. diameter carbon steel) would likely have been used. These well groups are described below. 
Table B.1. Summary of Wells with Gross Gamma Log Data that were Used in the Development of PNNL's 300-FF-5 Groundwater Flow and Transport Model (heterogeneous model case)

\begin{tabular}{|c|c|c|c|c|c|c|c|c|c|}
\hline $\begin{array}{l}\text { Well } \\
\text { No. }\end{array}$ & Well ID & $\begin{array}{l}\text { Easting }^{(e)} \\
\quad(\mathrm{m})\end{array}$ & $\begin{array}{l}\text { Northing }{ }^{(e)} \\
\quad(\mathrm{m})\end{array}$ & $\begin{array}{c}\text { Surface } \\
\text { Elev. }{ }^{(\mathrm{f})} \\
(\mathrm{m})\end{array}$ & Reference & Group & $\begin{array}{c}\text { Casing } \\
\text { Correction }^{(a)}\end{array}$ & $\begin{array}{l}\text { Well(s)/Group(s) with Which } \\
\text { Cross Correlated }\end{array}$ & $\begin{array}{c}\text { Pump or Slug } \\
\text { Test/Unit }\end{array}$ \\
\hline 1 & $399-3-18$ & 594464.71 & 116019.98 & 117.68 & Williams (2007) & 1 & By Stoller ${ }^{(b)}$ & N/A (reference group) & Slug/Ringold \\
\hline 2 & 399-3-19 & 594071.94 & 116030.22 & 120.65 & Williams (2007) & 1 & By Stoller & N/A (reference group) & Slug/Hanford \\
\hline 3 & $399-3-20$ & 594375.42 & 115849.70 & 120.45 & Williams (2007) & 1 & By Stoller & N/A (reference group) & Slug/H\&R \\
\hline 4 & $399-1-23$ & 594113.52 & 116453.04 & 115.47 & Williams (2007) & 1 & By Stoller & N/A (reference group) & Slug/Ringold \\
\hline 5 & 699-S20-E10 & 593124.37 & 117366.18 & 119.73 & Williams (2006) & 1 & By Stoller & N/A (reference group) & \\
\hline 6 & $399-1-1$ & 594359.96 & 116588.84 & 115.06 & $\mathrm{PNNL}^{(\mathrm{c})}$ & $2^{(\mathrm{d})}$ & N/A & Group 1 & \\
\hline 7 & $399-1-2$ & 594082.36 & 116329.53 & 118.19 & PNNL & 2 & N/A & Group 1 & Pump/Hanford \\
\hline 8 & $399-1-3$ & 594254.20 & 116334.91 & 117.71 & PNNL & 2 & N/A & Group 1 & \\
\hline 9 & $399-1-4$ & 594020.60 & 116699.55 & 116.70 & PNNL & 2 & N/A & Group 1 & Pump/Hanford \\
\hline 10 & $399-3-1$ & 594481.30 & 116008.03 & 117.46 & PNNL & 2 & N/A & 399-3-18 (Group 1) & \\
\hline 11 & $399-4-1$ & 594274.10 & 115537.35 & 120.83 & PNNL & 2 & $\mathrm{~N} / \mathrm{A}$ & Group 1 & \\
\hline 12 & $399-4-7$ & 594603.24 & 115492.60 & 115.64 & PNNL & 2 & N/A & Group 1 & \\
\hline 13 & $399-5-1$ & 593750.74 & 115525.32 & 120.97 & PNNL & 2 & N/A & Group 1 & \\
\hline 14 & $399-5-2$ & 592814.46 & 115454.69 & 119.71 & PNNL & 2 & $\mathrm{~N} / \mathrm{A}$ & Group 1 & \\
\hline 15 & $399-6-1$ & 593527.18 & 115807.14 & 118.74 & PNNL & 2 & $\mathrm{~N} / \mathrm{A}$ & Group 1 & \\
\hline 16 & $399-8-1$ & 593632.23 & 116331.96 & 121.00 & PNNL & 2 & N/A & Group 1 & Pump/Hanford \\
\hline 17 & $399-8-2$ & 593202.39 & 116300.42 & 121.55 & PNNL & 2 & $\mathrm{~N} / \mathrm{A}$ & Group 1 & \\
\hline 18 & $399-8-3$ & 593626.12 & 116683.65 & 120.57 & PNNL & 2 & N/A & Group 1 & \\
\hline 19 & 699-S27-E14 & 594114.14 & 115212.74 & 122.58 & PNNL & 2 & N/A & Group 1 & \\
\hline 20 & 699-S30-E14 & 594368.04 & 114270.31 & 122.88 & PNNL & 2 & N/A & Group 1 & \\
\hline 21 & $399-1-9$ & 594253.99 & 116330.37 & 117.80 & Schalla (1988) & 3 & $12 \mathrm{CS}, 10 \mathrm{CS}$ & 399-1-3 (Group 2) \& Group 1 & \\
\hline 22 & $399-1-10 \mathrm{~A}$ & 594346.53 & 116733.99 & 114.37 & Schalla (1988) & 3 & $10 \mathrm{CS}$ & Group $2 \&$ Group 1 & Pump/Hanford \\
\hline 23 & $399-1-10 \mathrm{~B}$ & 594350.85 & 116728.79 & 114.53 & Swanson (1992) & 3 & $10 \mathrm{CS}, 8 \mathrm{CS}$ & Group 2 \& Group 1 & \\
\hline 24 & $399-1-11$ & 594109.81 & 116660.16 & 115.66 & Schalla (1988) & 3 & $10 \mathrm{CS}$ & Group 2 \& Group 1 & \\
\hline 25 & $399-1-12$ & 594040.22 & 116548.51 & 117.45 & Schalla (1988) & 3 & $10 \mathrm{CS}$ & Group 2 \& Group 1 & \\
\hline
\end{tabular}


Table B.1. (contd)

\begin{tabular}{|c|c|c|c|c|c|c|c|c|c|}
\hline $\begin{array}{l}\text { Well } \\
\text { No. }\end{array}$ & Well ID & $\begin{array}{l}\text { Easting } \\
(\mathrm{m})\end{array}$ & $\begin{array}{l}\text { Northing } \\
(\mathrm{m})\end{array}$ & $\begin{array}{c}\text { Surface } \\
\text { Elev. } \\
(\mathrm{m})\end{array}$ & Reference & Group & $\begin{array}{c}\text { Casing } \\
\text { Correction }^{(a)}\end{array}$ & Cross Correlation Comments & $\begin{array}{c}\text { Pump or Slug } \\
\text { Test/Unit }\end{array}$ \\
\hline 26 & $399-1-13 \mathrm{~A}$ & 593910.41 & 116557.26 & 118.60 & Schalla (1988) & 3 & $10 \mathrm{CS}$ & Group 2 \& Group 1 & Pump/Hanford \\
\hline 27 & 399-1-13B & 593909.59 & 116549.20 & 118.59 & Swanson (1992) & 3 & $10 \mathrm{CS}, 8 \mathrm{CS}$ & Group 2 \& Group 1 & \\
\hline 28 & $399-1-14 \mathrm{~A}$ & 593901.13 & 116778.22 & 116.95 & Schalla (1988) & 3 & $10 \mathrm{CS}$ & Group 2 \& Group 1 & Pump/Hanford \\
\hline 29 & $399-1-15$ & 593988.33 & 116964.24 & 116.16 & Schalla (1988) & 3 & $10 \mathrm{CS}$ & Group 2 \& Group 1 & \\
\hline 30 & $399-1-16 A$ & 594318.11 & 116414.16 & 116.89 & Schalla (1988) & 3 & $10 \mathrm{CS}$ & Group 2 \& Group 1 & Pump/Hanford \\
\hline 31 & $399-1-16 B$ & 594324.69 & 116411.62 & 116.83 & Swanson (1992) & 3 & $12 \mathrm{CS}, 10 \mathrm{CS}$ & Group 2 \& Group 1 & \\
\hline 32 & 399-1-17A & 594112.87 & 116413.79 & 115.34 & Schalla (1988) & 3 & $10 \mathrm{CS}$ & Group 2 \& Group 1 & \\
\hline 33 & 399-1-17B & 594104.82 & 116417.72 & 115.45 & Swanson (1992) & 3 & $12 \mathrm{CS}, 10 \mathrm{CS}$ & Group 2 \& Group 1 & \\
\hline 34 & $399-1-18 \mathrm{~A}$ & 593870.64 & 117301.57 & 119.19 & Schalla (1988) & 3 & $10 \mathrm{CS}$ & Group 2 \& Group 1 & \\
\hline 35 & $399-1-18 B$ & 593866.06 & 117297.23 & 119.03 & Swanson (1992) & 3 & $10 \mathrm{CS}$ & Group 2 \& Group 1 & \\
\hline 36 & $399-1-21 B$ & 594157.21 & 116176.80 & 116.96 & Swanson (1992) & 3 & $10 \mathrm{CS}, 8 \mathrm{CS}$ & Group 2 \& Group 1 & \\
\hline 37 & $399-3-9$ & 594504.51 & 115917.93 & 118.54 & $\mathrm{RLS}^{(\mathrm{g})}$ & 3 & $12 \mathrm{CS}, 8 \mathrm{CS}$ & Group $2 \&$ Group 1 & \\
\hline 38 & $399-3-10$ & 594530.12 & 115832.27 & 117.65 & RLS & 3 & $12 \mathrm{CS}, 8 \mathrm{CS}$ & Group 2 \& Group 1 & \\
\hline 39 & $399-3-12$ & 594213.75 & 115946.79 & 118.52 & RLS & 3 & 6CS & Group 2 \& Group 1 & \\
\hline 40 & $399-4-9$ & 594537.85 & 115741.45 & 116.73 & RLS & 3 & $12 \mathrm{CS}, 8 \mathrm{CS}$ & Group 2 \& Group 1 & \\
\hline 41 & $399-4-10$ & 594566.44 & 115655.80 & 115.64 & RLS & 3 & $12 \mathrm{CS}, 8 \mathrm{CS}$ & Group 2 \& Group 1 & \\
\hline 42 & $399-4-11$ & 594087.93 & 115709.19 & 123.78 & Schalla (1988) & 3 & $10 \mathrm{CS}$ & Group 2 \& Group 1 & \\
\hline 43 & 399-8-5C & 593386.06 & 116573.58 & 122.19 & Swanson (1992) & 3 & $16 \mathrm{CS}, 12 \mathrm{CS}$ & Group 2 \& Group 1 & \\
\hline 44 & 699-S29-E16B & 594746.91 & 114738.76 & 115.97 & Swanson (1992) & 3 & $10 \mathrm{CS}$ & Group 2 \& Group 1 & \\
\hline 45 & 699-S29-E16C & 594742.36 & 114730.53 & 115.92 & Swanson (1992) & 3 & $16 \mathrm{CS}, 12 \mathrm{CS}$ & Group $2 \&$ Group 1 & \\
\hline \multicolumn{10}{|c|}{$\begin{array}{l}\text { (a) Casing correction refers to the adjustment of the raw gross gamma log count data to account for signal attenuation caused by the type and thickness of the temporary casing } \\
\text { string(s) used during drilling prior to the completion of a well. } 10 \mathrm{CS} \text { refers to } 10 \text {-in diameter carbons steel casing. See Table B. } 2 \text { and related discussion. }\end{array}$} \\
\hline (b) & \multicolumn{9}{|c|}{ Casing corrections were applied by S.M. Stoller Corp., Richland, Washington. } \\
\hline (c) & \multicolumn{9}{|c|}{$\begin{array}{l}\text { All wells logs referenced as PNNL were obtained from PNNL's well log library (Sigma } 5 \text { Building, Richland, Washington; contact George Last), and were scanned } \\
\text { and digitized from hard copy using ArcView. }\end{array}$} \\
\hline (d) $\mathrm{l}$ (a & \multicolumn{9}{|c|}{ Wells in Group 2 used 8-in. diameter perforated carbon steel casings. The number of perforations or cuts/ft varied by well. } \\
\hline (e) $\mathrm{E}$ & \multicolumn{9}{|c|}{ Easting and Northing are Washington State Plane coordinates, NAD83. } \\
\hline $\begin{array}{ll}\text { (f) } & \mathrm{E} \\
\text { (g) } & \mathrm{h}\end{array}$ & \multicolumn{9}{|c|}{ Elevation datum is NAVD88. } \\
\hline
\end{tabular}




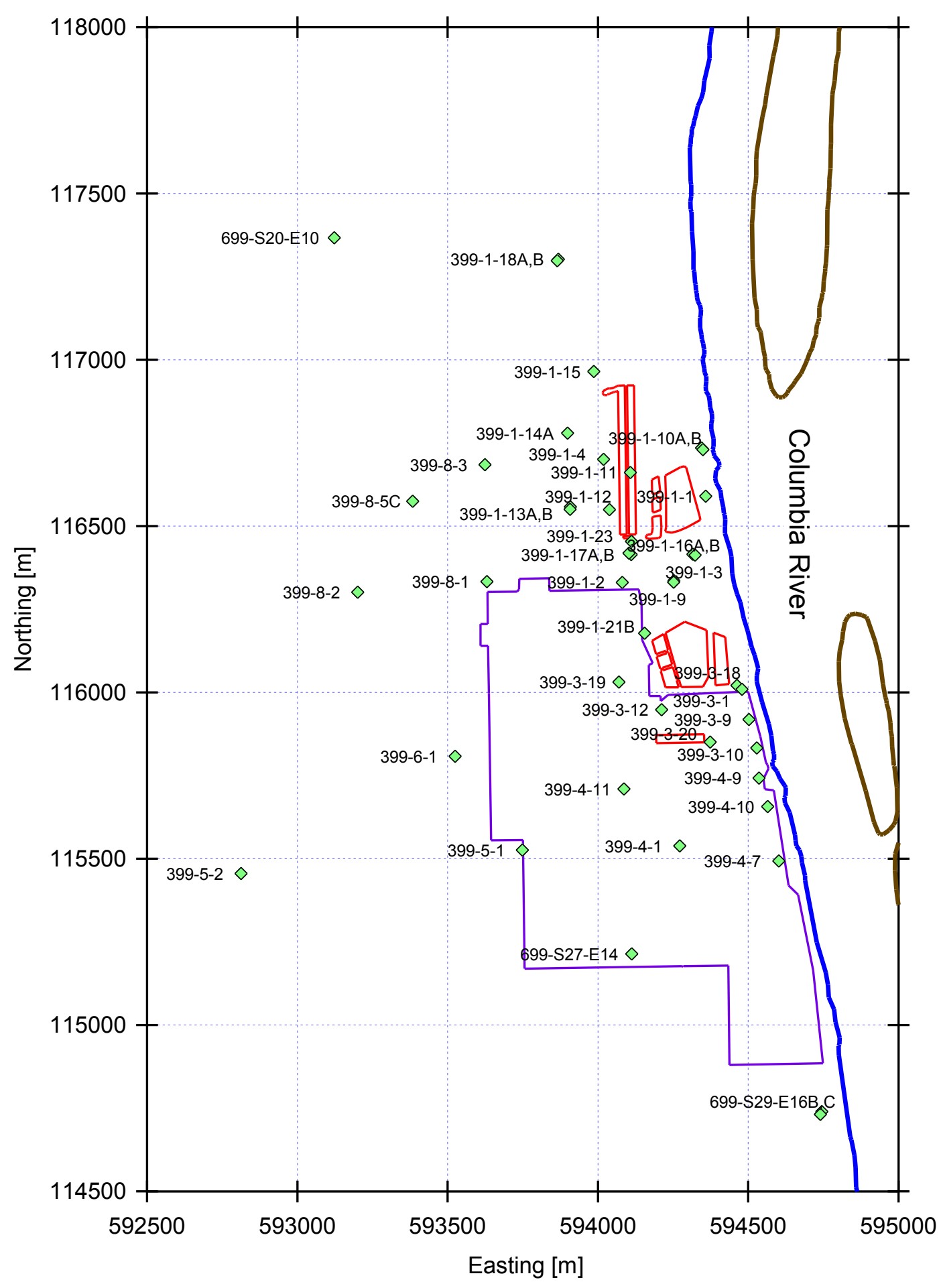

Figure B.1. Hanford Site 300 Area Wells (green diamonds) from Which Gross Gamma Log Data Were Compiled and Analyzed. Also shown are the outline of the 300 Area (purple lines), the former liquid waste disposal facilities (red outlines), and the Columbia River shoreline (blue line). 


\section{B.2.1 Group 1 Wells}

All geophysical logs from the Group 1 wells were obtained in electronic form from S.M. Stoller Corp. Four of the five wells listed in Table B.1 for Group 1 were installed as part of a limited field investigation (LFI) for the 300 Area (Williams et al. 2007). These wells were installed by sonic drilling. Continuous, 1-ft long, 5-in. diameter, split-spoon cores were collected in Lexan liners from each borehole. Selected cores were analyzed for various physical and chemical properties, including bulk density, porosity (see Appendix A), whole-sediment grain-size distribution (see Appendix C), and uranium concentrations. Geophysical logging was performed in the temporary well casing using neutron-moisture, gross-gamma, and spectral-gamma logging tools. Casing corrections were performed on the gross- and spectral-gamma logging data for all Group 1 wells by S.M. Stoller Corp. As noted earlier, longer-than-typical counting times (200 s) were used during logging of these four boreholes with the spectral gamma logging system (SGLS, S.M. Stoller Corp.) in an attempt to measure process uranium. The sensitivity of the SGLS through the large-diameter steel casing was insufficient to reliably identify or quantify process uranium (Williams et al. 2007). However, the combination of the gross gamma logging and the whole-sediment, grain-size analyses for selected samples produced data that allowed for development of correlations between the gamma log data and various grain-size distribution metrics (Appendix C).

The fifth well listed in Table B.1 for Group 1, 699-S20-E10, was installed in a previously undisturbed area to the northwest of the 300 Area, to provide upgradient hydraulic head and groundwater concentration data in support of CERCLA monitoring, and groundwater flow and transport modeling for the 300-FF-5 Operable Unit (Williams et al. 2006). Well 699-S20-E10 was installed using the standard cable tool drilling method. Continuous 1-ft long, 4-in. diameter, split-spoon cores in Lexan liners were collected from the borehole. Selected samples were analyzed for total porosity (Appendix A), wholesediment grain-size distribution, and various chemical constituents, including chloride.

The chloride mass balance method was used to estimate the long-term average natural groundwater recharge rate (also known as net infiltration) to be about $2 \mathrm{~mm} / \mathrm{yr}$ for the vegetated, undisturbed area in the vicinity of well 699-S20-E10 (Williams et al. 2006). In contrast, an 8-year record (1985-1993) of drainage data for a bare (unvegetated), 7.6-m deep, sand-filled lysimeter in the $300-\mathrm{N}$ Area $(\sim 1.8 \mathrm{~km}$ west-northwest of the 300 Area) yielded an average annual recharge rate of $\sim 55 \mathrm{~mm} / \mathrm{yr}$ (Rockhold et al. 1995). The average annual precipitation rate at the Hanford Site has increased since the period when the lysimeter data were collected, so a value of $\sim 60 \mathrm{~mm} / \mathrm{yr}$ is considered to be more representative of the average annual recharge rate through unvegetated sand for recent climatic conditions ${ }^{2}$. These two estimates ( 2 and $60 \mathrm{~mm} / \mathrm{yr}$ ) provide approximate lower and upper bounds on the expected range of longterm average annual natural groundwater recharge rates for the 300 Area. It is important to note, however, that these bounds do not account for locally elevated, episodic recharge rates that may result from runoff/run-on events in parts of the 300 Area adjacent to low permeability or impermeable features, such as buildings or parking lots.

Figure B.2 shows the gross (total) gamma log data for the five wells in Group 1. Wells 399-3-18, 399-1-23, 399-3-19, and 399-3-20 are the LFI wells, located around the vicinity of the former north and south process ponds, shown in Figure B.1. Well 699-S20-E10 is located in the far northeast corner of the map shown in Figure B.1.

\footnotetext{
${ }^{2}$ Personal communication with Glendon Gee, PNNL.
} 


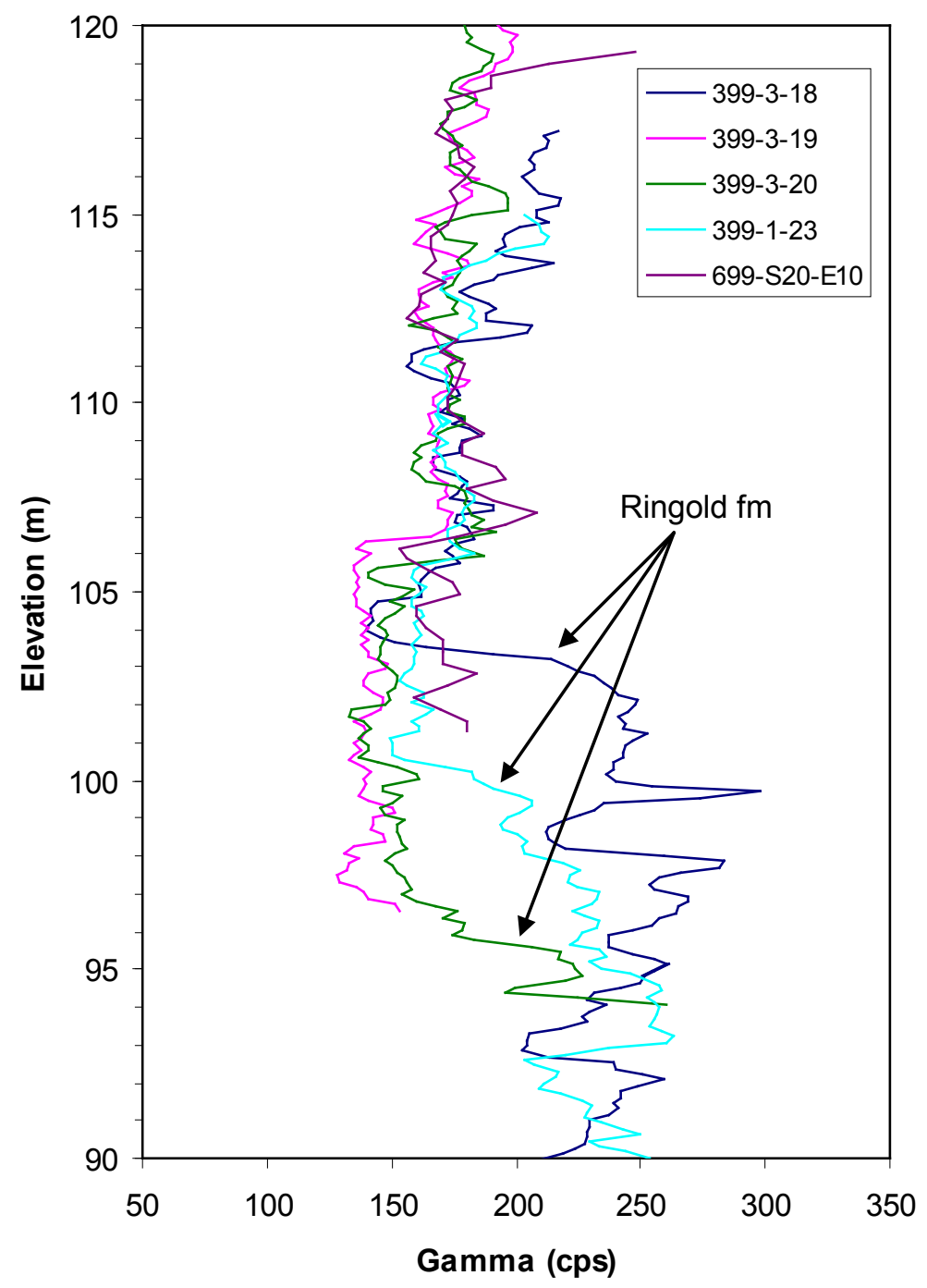

Figure B.2. Gross Gamma Logs for 300 Area Group 1 Wells. The LFI wells are 399-3-18, 399-1-23, 399-3-19, and 399-3-20.

In Figure B.2, the higher gross gamma log readings in the lower parts of the profiles, below the 104-m elevation, are indicative of Ringold Formation sediments, which typically have larger-mass fractions of silt and clay-sized material, and hence have higher gamma log readings. The elevation at which this increase in gross gamma log readings occurs varies between wells because of different depths of scouring of the surface of the Ringold Formation sediments by the cataclysmic floods that were responsible for deposition of the Hanford formation sediments. In Figure B.2, it may be of interest to note the relatively small variability and consistency of the gamma log readings within the lower to middle portion of the Hanford formation, for elevations above approximately $106 \mathrm{~m}$, even though the wells represented in this figure are up to $2 \mathrm{~km}$ apart.

Figure B.3 shows split-core photographs of samples from well 399-3-18 and the gross and spectral gamma logs in this well for the same depth interval. Spectral gamma logging was used by Stoller, Corp. to estimate the activities of the three primary gamma emitters: K-40, U-238, and Th-232 (collectively known as K-U-T logs). 

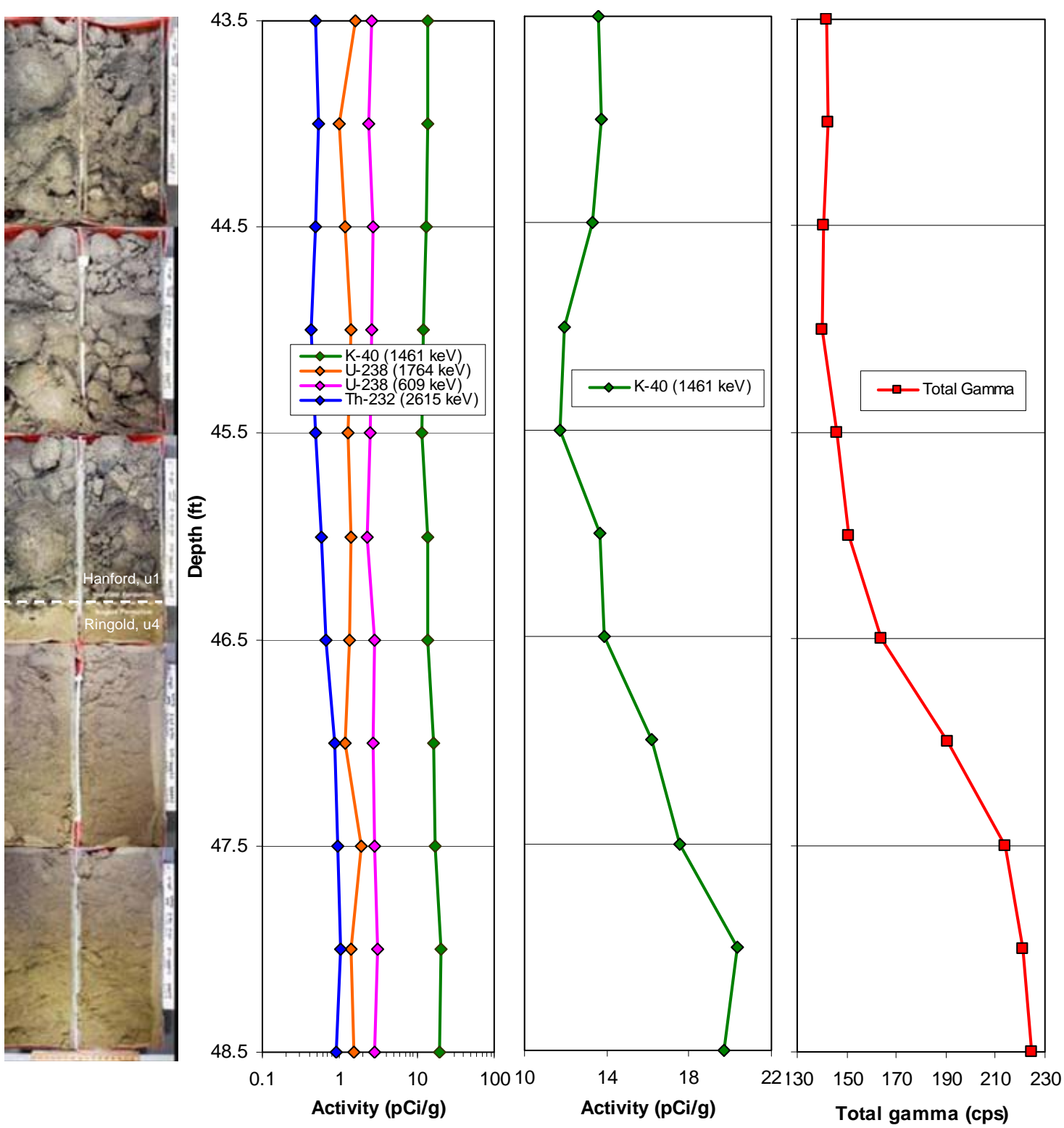

Figure B.3. Split-Core Photographs of Sediments Collected from a Single, 5-ft long Core Barrel During Drilling of Well 399-3-18 and K-40, U-238, Th-232 Activities (pCi/g) Determined by Spectral Gamma and Total Gamma (cps) Logging Over the Same Depth Interval.

As shown by Figure B.3, the estimated activities of K-40 are roughly one order of magnitude greater than U-238, and the estimated activities of Th-232 are roughly one-half those of U-238 over this depth interval. Comparing the total or gross gamma log readings with textural differences evident from the splitcore photographs in Figure B.3 clearly illustrates the strong relationship between sediment texture and total gamma log readings, with the higher gamma log readings corresponding to the finer-textured Ringold Formation sediments located below a depth of 46.3-ft. Grain-size, gamma-log correlation functions are given in Section 3.0 of this report. 
Although the split-core photographs in Figure B.3 indicate a sharp break between the gravel- and cobble-dominated Hanford formation sediments, and the underlying Ringold Formation sediments, the total gamma log response varies smoothly. This is a direct result of the volume of interrogation of the gamma probe. Rider (1996) indicates the volume of a typical gamma log measurement is $\sim 20 \mathrm{~cm}(\sim 8 \mathrm{in}$.) vertically above and below the detector (along the borehole), for a total of $\sim 40 \mathrm{~cm}$ and penetration of about $10 \mathrm{~cm} \mathrm{(} 4 \mathrm{in}$.) into the formation. However, this volume of interrogation varies with formation density.

\section{B.2.2 Group 2 Wells}

The gross gamma log data for the 15 wells listed in Table B.1 for Group 2 represent 1963-vintage data collected using a gamma scintillation probe. These data were available only in hard copy, in PNNL's well log library - so they were digitized and transferred to a Microsoft ${ }^{\mathbb{R}}$ Excel $^{\mathbb{R}}$ spreadsheet to facilitate further analysis. For well Group 2, all gross gamma logging was performed in single, 8-in.diameter perforated carbon steel (CS) casing. Reviews of the well summary and completion reports for these wells indicated that the number of perforations or cuts per unit length of casing varied between wells, which required the data to be standardized. The following standardization procedure was used.

For each well in Group 2, the average gross gamma log reading within the 106- to 114-m elevation interval was computed from

$$
\overline{g_{i}^{r}}=\frac{1}{m} \sum_{j=1}^{m} g_{i j}^{r}
$$

where $m$ is the number of digitized data values within the specified elevation interval; $i$ and $j$ are indices for the well and elevation of the data point, respectively; and $r$ denotes the raw, digitized gross gamma log count data. The 106- to 114-m elevation interval was selected to avoid the region of the Hanford-Ringold Formation contact where large inflections in gamma log readings can occur (Figure B.2). This elevation interval was also selected so that data from a common elevation interval were used for all wells. Data from near the ground surface were omitted, since the surface elevations for wells in this group are quite variable, ranging from 115.06 to $122.88 \mathrm{~m}$ (Table B.1). A grand average gross gamma log count value in the 106- to 114-m elevation interval for the Group 2 wells was computed from

$$
\bar{g}=\frac{1}{n} \sum_{i=1}^{n} \overline{g_{i}^{r}}
$$

where $n$ is the number of wells in Group 2. Standardized gamma log values were then computed from the equation given in Equation (B.3).

$$
g_{i j}^{s}=g_{i j}^{r}\left(\frac{\bar{g}}{\overline{g_{i}^{r}}}\right)
$$

Plots of the raw digitized and the standardized gross gamma log count data for the Group 2 wells are shown in Figure B.4. 

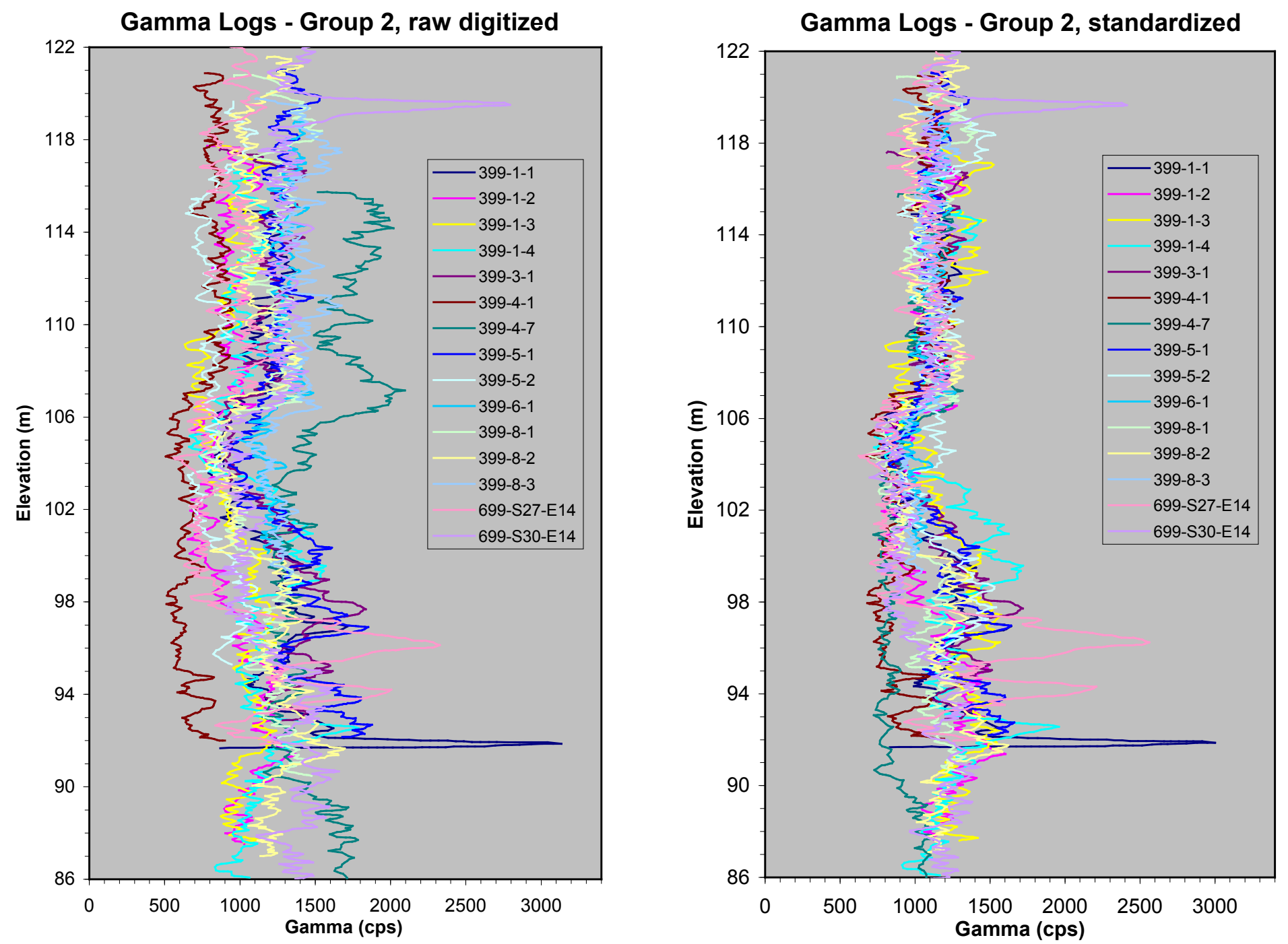

Figure B.4. Raw (Left Panel) and Standardized (Right Panel) Gross Gamma Log Data for 300 Area Group 2 Wells 
The magnitude of the gross gamma log readings for the Group 2 wells (Figure B.4) is much larger than for the Group 1 wells (Figure B.2). Multiple casing strings were not used in any of the Group 2 wells. Therefore, the standardized gamma logs for all wells in this group were converted directly to Group-1-equivalent gamma log counts, without casing corrections.

The Group-1-equivalent gamma log counts for the Group 2 well data were determined using a crosscorrelation equation developed by linear regression of data from elevations below $99 \mathrm{~m}$ and above $107 \mathrm{~m}$ for wells 399-3-1 (Group 2) and 399-3-18 (Group 1), linearly interpolated to common elevations (Figure B.5). Wells 399-3-1 and 399-3-18 are 20.2-m apart, located just southeast of the former south process pond (see Figure B.1 for locations). Data from the region between the 99- and 107-m elevations were not used in this cross-correlation because the elevation of the Hanford/Ringold Formation contact appeared to slightly differ for these two well locations. The cross-correlation was performed to generate a regression equation that translated the standardized gross gamma log data from all wells in Group 2 into similar magnitude and range data gathered from the wells in Group 1. Figure B.6 shows the gross gamma log data for well 399-3-18 and the cross-correlated gross gamma log data for well 399-3-1.

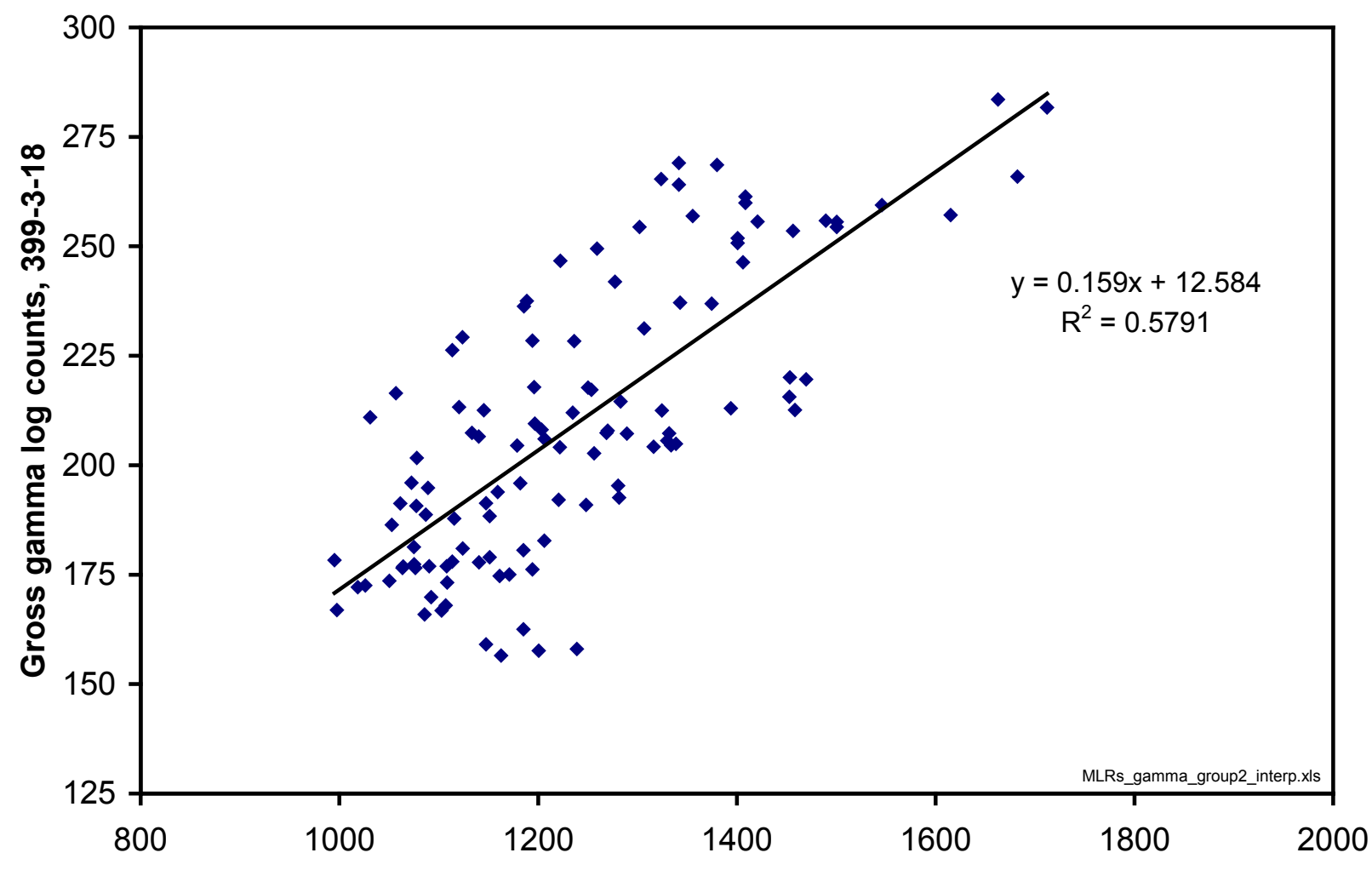

\section{Gross gamma log counts, 399-3-1 (Group 2 standardized)}

Figure B.5. Cross-Correlation Equation for Group 2 and Group 1 Wells 


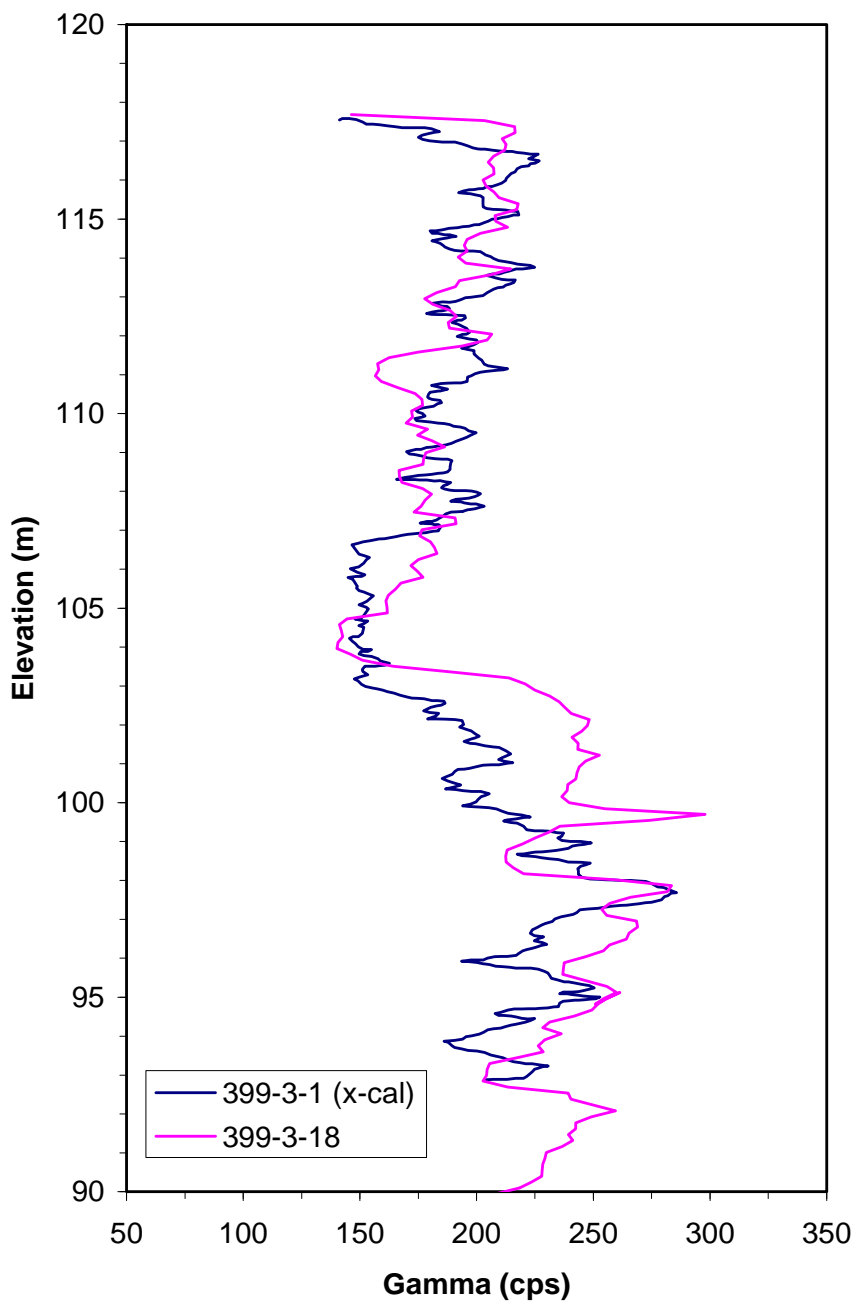

Figure B.6. Gross Gamma Log for Well 399-3-18 (Group 1) and Cross-Correlated, Group 1-Equivalent Gross Gamma Log for Well 399-3-1 (Group 2). These two wells are located 20.2-m apart.

\section{B.2.3 Group 3 Wells}

Wells in Group 3 were drilled and logged from the early 1980s through the early to mid 1990s. The wells in this group were installed at different depths using casings with variable diameters and thicknesses to access different parts of the unconfined and confined aquifer. The well names in Group 3 that end in the letter "A", or that have no letter at the end of the name, usually represent wells that were completed (screened) near the top of the unconfined aquifer, generally in the lower (coarsest) portion of the Hanford formation. Well names that end in the letter " $\mathrm{B}$ " usually represent wells that were completed in the lower portion of the unconfined aquifer, generally in Ringold unit E. Well names that end in the letter "C" usually represent wells that were completed in the confined aquifer, generally in the lower Ringold mud unit or below.

Generally, wells whose names contain the letters B and C used multiple casing strings, so that multiple casing corrections were required for the gamma log data. With the exception of wells whose 
source is indicated as "RLS" in Table B.1, gross gamma log data for most of the wells in Group 3 were not available electronically. Therefore, most of the gamma log data for Group 3 wells were digitized from hard copy records obtained from PNNL's well log library (Sigma 5 building, Richland, Washington; contact George Last) using ArcView $^{\circledR}$ (ESRI, Redlands, California). The digitized data were then transferred to Microsoft $^{\mathbb{R}}$ Excel $^{\mathbb{R}}$ spreadsheets for further analysis.

In general, the gross-gamma log data available for wells in Group 3 represent raw data without any casing corrections. The well summary and completion reports for all wells in Group 3 were reviewed to determine the diameter of the casing strings used in each logged interval. For example, in Table B.1, the code "10CS, 8CS" indicates that both 10-in.- and 8-in. diameter carbon steel (CS) casing was used. After the casing types were determined, casing corrections were applied to the data.

The gross gamma log data from the Group 3 wells were corrected by multiplying them by a casing correction factor, $F_{c}$, using the formula given by Hallenberg (1984)

$$
F_{C}=\exp (\mu \times \rho \times t)
$$

where $\mu$ is "linear absorption coefficient for average $\gamma$ energy" (assume 0.065 ), $\rho$ is the density of the pipe material (assume $7.8 \mathrm{~g} / \mathrm{cm}^{3}$ for steel), and $t$ is the casing thickness $(\mathrm{cm}){ }^{3}$

Table B.2 lists the typical well casings that are used at the Hanford Site and their nominal diameters and thicknesses. For larger-diameter casings (e.g., 16-in. schedule 40 carbon steel $=16 \mathrm{CS}$ ), thickness was estimated by extrapolation of a linear-regression equation [thickness $(\mathrm{cm})=0.0512 \times$ diameter(in.) + $\left.0.4135 ; r^{2}=0.998\right]$ generated from the values given in Table B.2. After casing corrections were performed on the raw gamma log data, the casing-corrected data were standardized using the same procedure described previously, but using only the gamma log data from the Group 3 wells. The casingcorrected and standardized gross gamma log data for the Group 3 wells are shown in Figure B.7.

Although the casing-corrected and standardized gross gamma log data for the Group 3 wells (Figure B.7) are more similar in magnitude to the data from Group 1 (Figure B.2) than are the data from Group 2 (Figure B.3), cross-correlation was also performed for the Group 3 wells to insure the data from all three well groups were comparable.

The standardized Group 3 gamma log data were first converted to standardized Group-2-equivalent gamma log counts using a regression equation (Figure B.8) developed for data from wells 399-1-3 (Group 2) and 399-1-9 (Group 3), which were linearly interpolated to common elevations within the 96to 106-elevation interval. Wells 399-1-9 and 399-1-3 are located only 5.3 m apart, roughly halfway between the north and south process ponds (see Figure B.1). Figure B.9 shows the standardized gamma $\log$ data for well 399-1-3 and the cross-correlated data for well 399-1-9. The Group-2-equivalent gamma $\log$ count data for the Group 3 wells were then converted to Group-1-equivalent count data using the regression equation for the data from wells 399-3-1 (Group 2) and 399-3-18 (Group 1), as previously described.

\footnotetext{
${ }^{3}$ Personal communication with Rick McCain, S.M. Stoller Corp., Richland, Washington.
} 
Table B.2. Specifications for Typical Well Casings Used at the Hanford Site ${ }^{a}$

\begin{tabular}{|c|c|c|c|c|c|}
\hline Type & $\begin{array}{l}\text { Nom. Diam. } \\
\text { (in.) }\end{array}$ & $\begin{array}{l}\text { OD } \\
\text { (in.) }\end{array}$ & $\begin{array}{l}\text { ID } \\
\text { (in.) }\end{array}$ & $\begin{array}{c}\text { Wall Thick. } \\
\text { (in.) }\end{array}$ & Comments \\
\hline \multicolumn{6}{|c|}{ Typical cable tool drill casing } \\
\hline \multirow{5}{*}{$\begin{array}{l}\text { Schedule } 40 \\
\text { carbon steel } \\
(\mathrm{CS}) \text { pipe }\end{array}$} & 4 & 4.500 & 4.026 & 0.237 & \multirow{9}{*}{$\begin{array}{l}\text { Much of the casing used at the } \\
\text { Hanford Site was ASTM schedule } \\
40 \text { pipe; however, other gauges } \\
\text { may also exist }\end{array}$} \\
\hline & 6 & 6.625 & 6.065 & 0.280 & \\
\hline & 8 & 8.625 & 7.981 & 0.322 & \\
\hline & 10 & 10.75 & 10.02 & 0.365 & \\
\hline & 12 & 12.75 & 11.938 & 0.406 & \\
\hline \multirow{4}{*}{$\begin{array}{l}\text { DPT Push } \\
\text { Casing }\end{array}$} & 6 & $71 / 16$ & $61 / 16$ & 0.500 & \\
\hline & 6 & $65 / 8$ & $55 / 8$ & 0.500 & \\
\hline & 6 & $65 / 8$ & $51 / 2$ & 0.5625 & \\
\hline & 6 & 7 & $61 / 16$ & 0.469 & \\
\hline \multicolumn{6}{|c|}{ Groundwater monitoring wells - inner tubing } \\
\hline \multirow{4}{*}{$\begin{array}{l}\text { Schedule } 5 \mathrm{~S} \\
\text { stainless-steel } \\
(\mathrm{SS}) \text { tubing }\end{array}$} & $3 \frac{1}{2}$ & 4.000 & 3.834 & 0.083 & \\
\hline & 4 & 4.500 & 4.334 & 0.083 & \\
\hline & 6 & 6.625 & 6.407 & 0.109 & \\
\hline & 8 & 8.625 & 8.407 & 0.109 & \\
\hline \multicolumn{6}{|c|}{ Groundwater monitoring wells - stainless-steel screen ${ }^{(b)}$} \\
\hline Telescoping & 6 & 5.5 & 4.875 & 0.22 & $12 \mathrm{lb} / \mathrm{ft}$ \\
\hline screen & 8 & 7.5 & 6.75 & 0.22 & $16 \mathrm{lb} / \mathrm{ft}$ \\
\hline Pipe size & 6 & N/A & 6 & 0.22 & $14 \mathrm{lb} / \mathrm{ft}$ \\
\hline screens & 8 & $\mathrm{~N} / \mathrm{A}$ & 8 & 0.22 & $19 \mathrm{lb} / \mathrm{ft}$ \\
\hline \multicolumn{6}{|c|}{ Becker dual-wall casing } \\
\hline outer & 9 & 9.000 & 8.000 & 0.500 & 0.875 at joint \\
\hline inner & 6 & 6.240 & 6.000 & 0.120 & 0.240 at joint \\
\hline total & $\mathrm{N} / \mathrm{A}$ & $\mathrm{N} / \mathrm{A}$ & $\mathrm{N} / \mathrm{A}$ & 0.620 & 1.115 at joint \\
\hline
\end{tabular}

(a) Courtesy of Rick McCain, S.M. Stoller Corp.

(b) Equivalent thickness for stainless-steel screen is calculated from weight per unit length. 
Gamma Logs - Group 3, casing-corrected

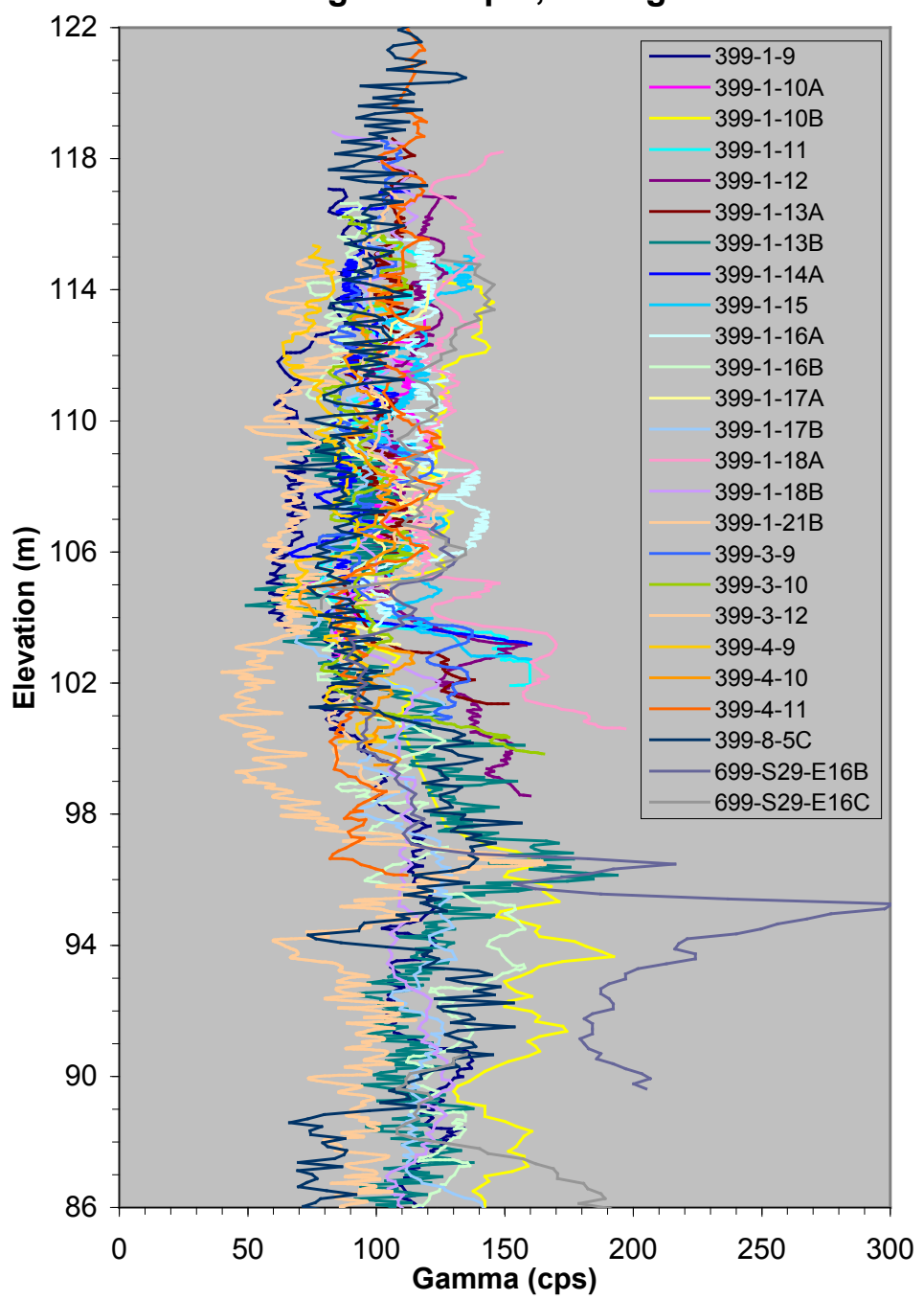

Gamma Logs - Group 3, standardized

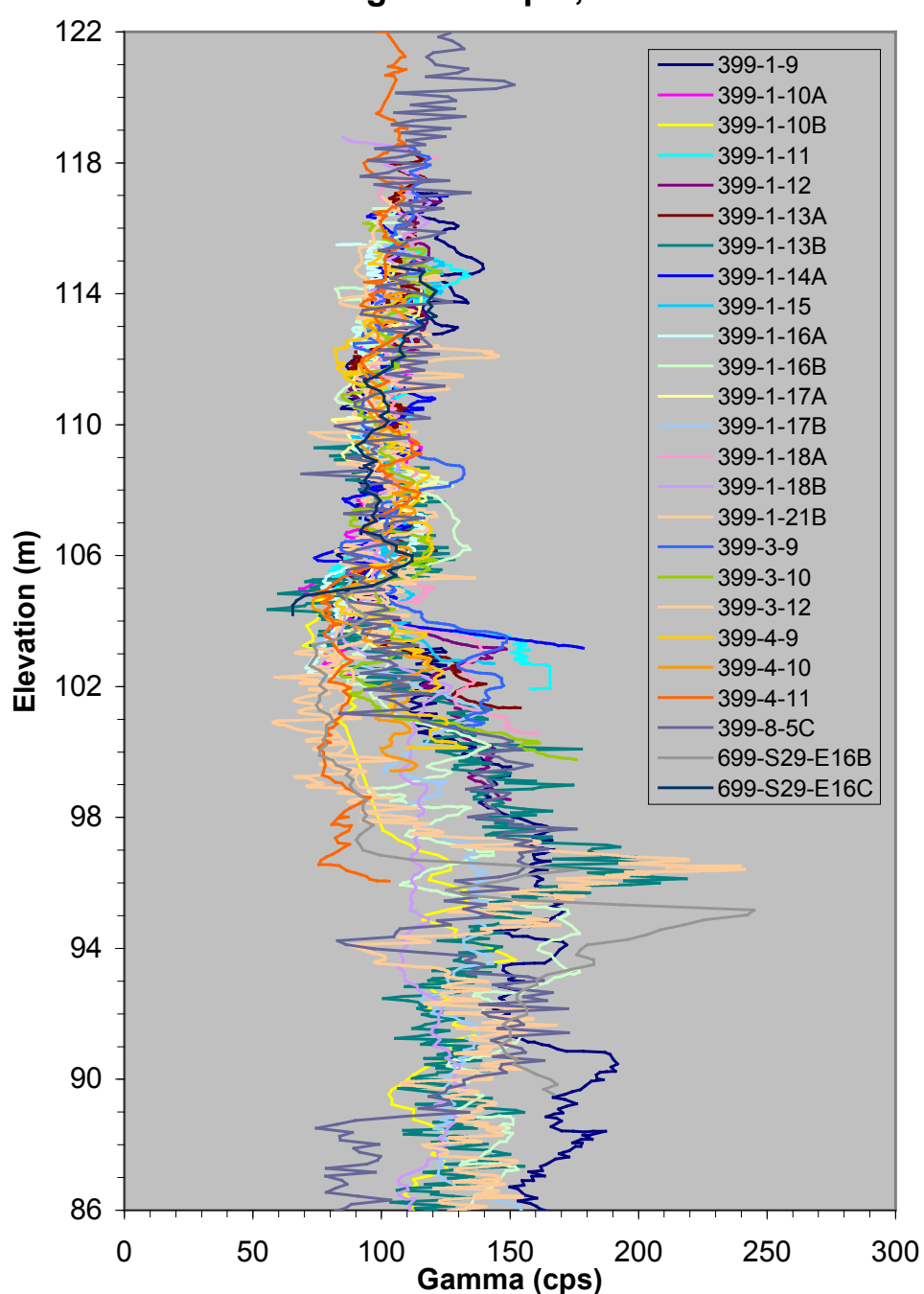

Figure B.7. Casing-Corrected (Left Panel) and Standardized (Right Panel) Gross Gamma Log Data for 300 Area Group 3 Wells 


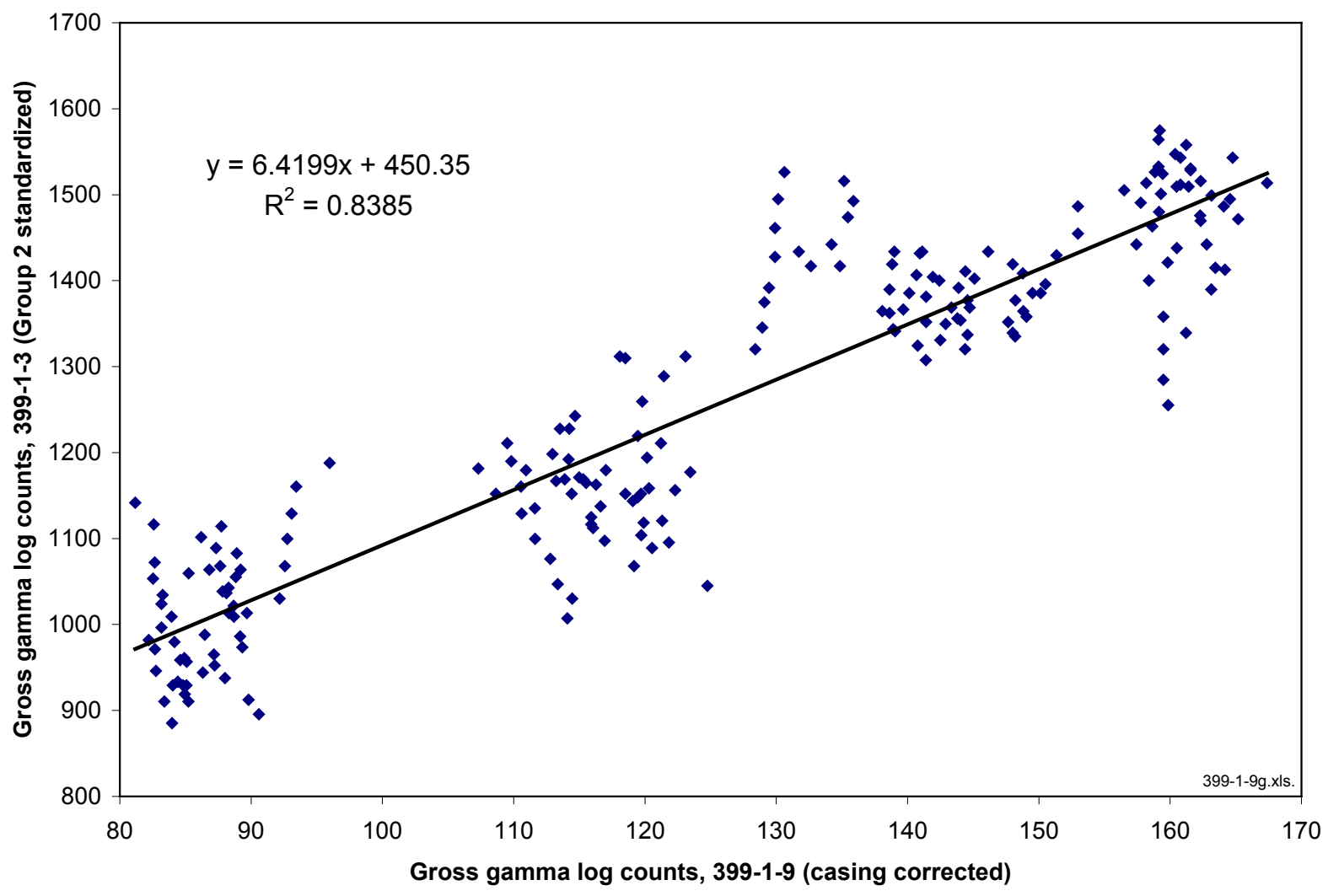

Figure B.8. Cross-Correlation of Group 3 and Group 2 Wells

Most gamma log data for wells in Groups 2 and 3 were digitized from hard copy. This resulted in an excessive number of data points for most of these wells (up to several thousand), irregular spacing of points along the y-axis, and in some cases, multiple gamma log readings with the same elevations for a given well. Data from some of these wells also exhibited more high-frequency variability than other wells, which was attributed to instrument noise. To mitigate the problems caused by multiple data points with the same elevations in any given well, and to eliminate some of the high-frequency noise, digitized data sets from Groups 2 and 3 with these characteristics were smoothed using two passes of a 3-, 5-, or 7point moving average filter. The filter size was determined on a well-by-well basis, depending on the maximum number of digitized data points that had common elevations for a well. 


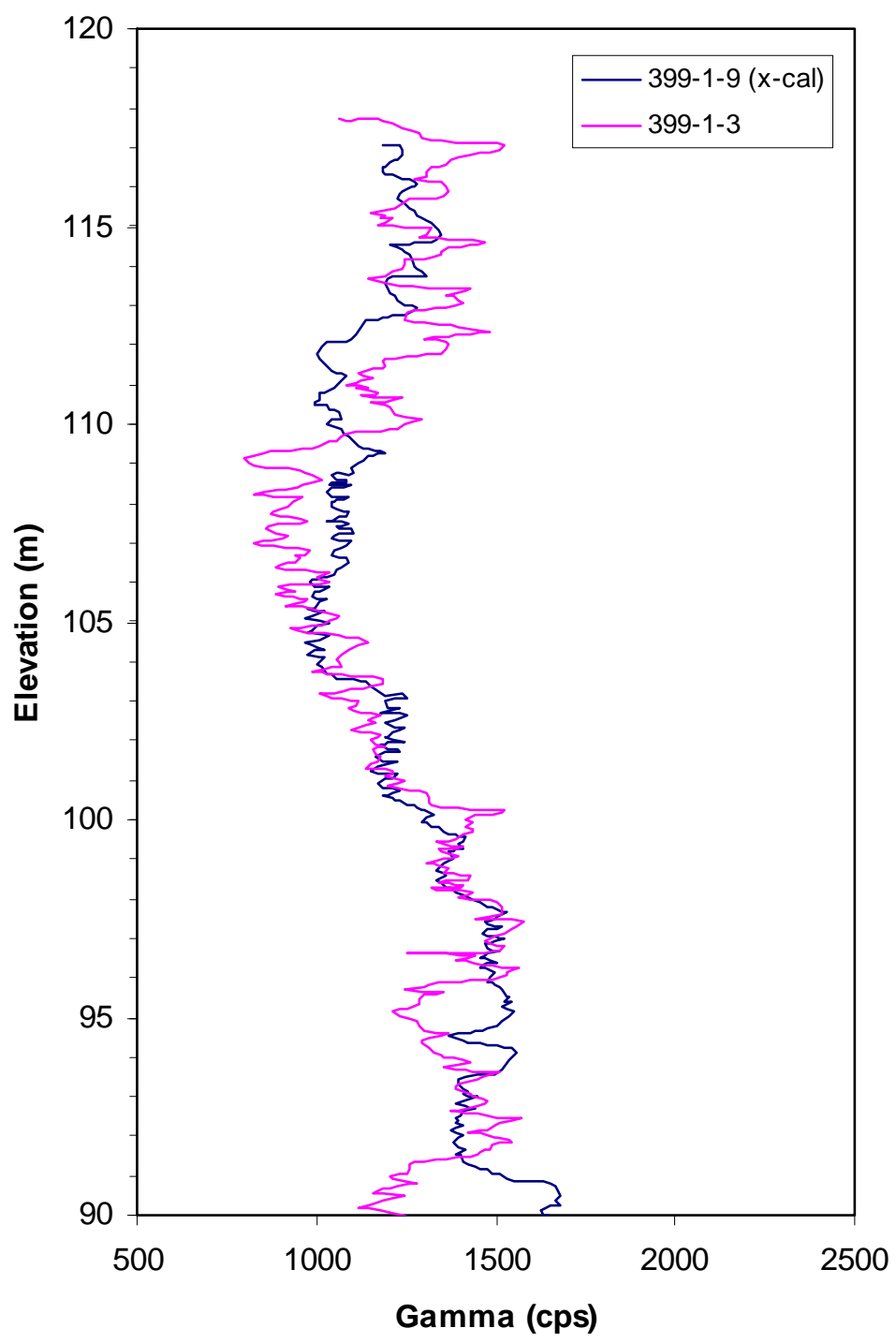

Figure B.9. Gross Gamma Log for Well 399-1-3 (Group 2 Standardized) and Gross Gamma Log for Well 399-1-9 (Group 3 standardized and cross-calibrated to Group 2). These two wells are located $5.3 \mathrm{~m}$ apart.

Figure B.10 shows the Group-3-standardized and digitized gross gamma log data for well 399-1-9, and a curve connecting the smoothed data values that were obtained using two passes of a 5-point moving average filter. Note that the larger-scale structural features are preserved, while the smaller-scale fluctuations (e.g., between the 109- to 104-m and 103-to 101-m elevation intervals), which are presumably noise, are reduced by the smoothing process. 


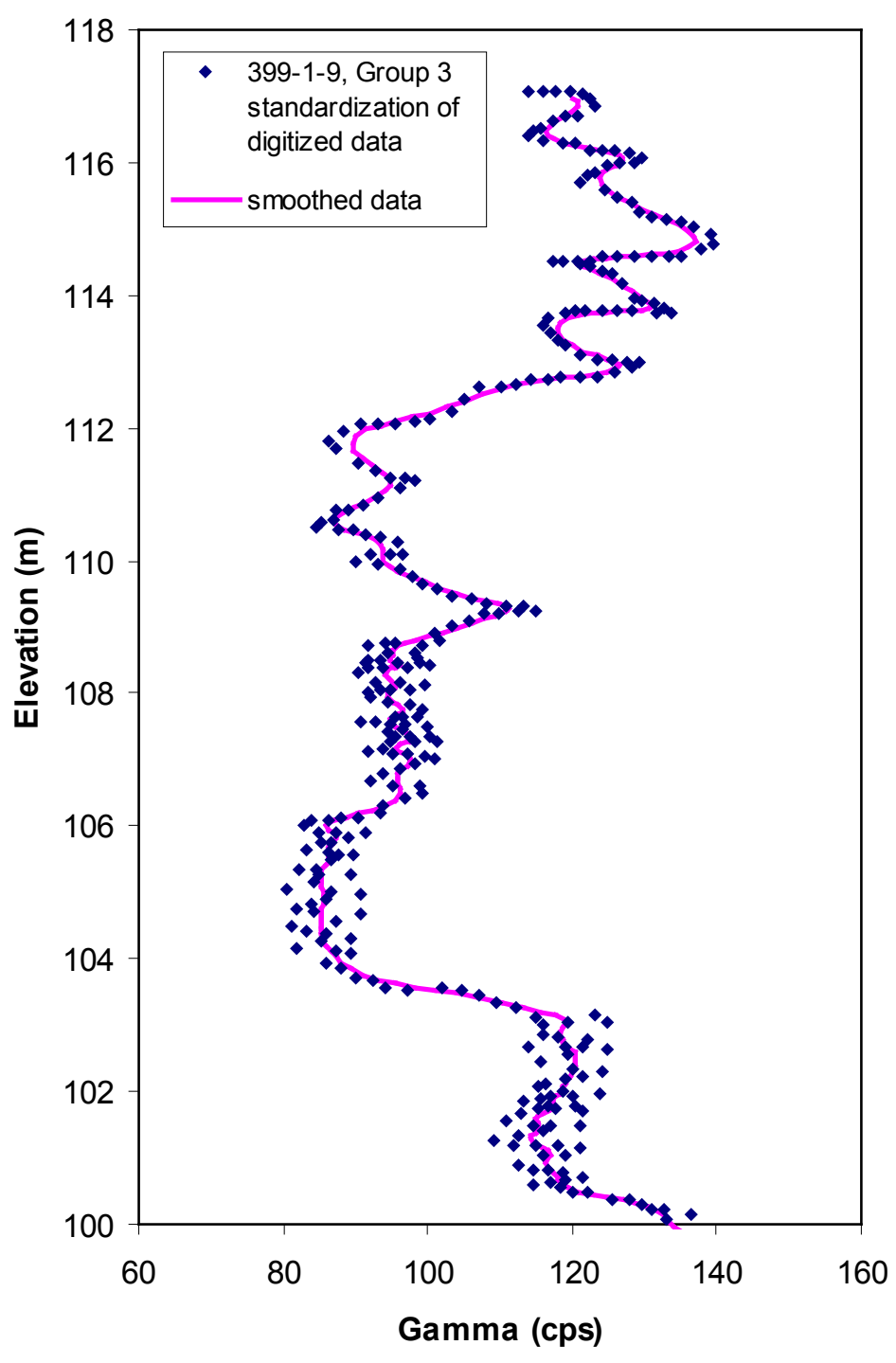

Figure B.10. Group-3-Standardized Gross Gamma Log Data for Well 399-1-9 and Smoothed Data

The smoothed gamma log data for well Groups 2 and 3 were interpolated to a common set of elevations from 124.0 to $69.8980 \mathrm{~m}$, with uniform 0.1524-m (6-in.) spacing. Some wells did not have gamma log data over this entire elevation interval, so values were only interpolated between elevations for which data were available. The gamma log data for the LFI (Group 1) wells, which were not smoothed or interpolated, were logged with 0.1524-m measurement spacing (Figure B.2). The gamma log data for well 699-S20-E10 (also Group 1), which were also not smoothed or interpolated, were logged with $0.3048-\mathrm{m}$ measurement spacing.

The gross gamma logs show distinct characteristics that can be related to sediment type, and possibly to depositional environment in the 300 Area. The lowest gamma log counts typically occur between elevations of 103 to $109 \mathrm{~m}$. This elevation interval generally corresponds with the coarsest sediments in the profile in the lower portion of the Hanford formation. This region frequently (but not always) includes sections of open framework gravel and cobble that are indicative of a very high-energy 
depositional environment. These very coarse sediments are the most permeable in the profile, presumably with the lowest specific surface area and hence the lowest adsorption capacity. In general, the coarsegrained sequence in the lower portion of the Hanford formation overlies sediments that typically have significantly higher gross gamma log counts, indicative of the finer-grained, semi-consolidated Ringold Formation. The open framework gravel and cobble section is typically overlain by sediments with progressively higher gross gamma log counts, representing fining-upward sequences, or alternating fining- and coarsening-upward sequences of sandy gravel and finer textured sediments of the Hanford formation. The shapes of the gamma logs for some wells for this part of the sediment profile could be interpreted as multiple flood and scouring events that periodically truncate the older, underlying sediments. Holocene-age aeolian sand and silt, which also have higher gamma log counts, occupy the top 0 to $4 \mathrm{~m}$ of the sediment profile at some locations (see Figure 9 of Williams et al. 2006).

Some caveats about these interpretations of gamma logs should also be made. Like all types of geophysical logs, gamma log data are susceptible to misinterpretations resulting from, for example, the caving of boreholes during drilling and core sampling activities, accumulation of fines or drilling mud in the borehole or temporary casing below the water table, etc. Such events may affect the gamma log signal but may not be representative of actual changes in formation properties. According to Hallenburg (1984), borehole conditions generally have only a minor effect on gross gamma log curves and can usually be corrected. Other factors to consider include the vertical resolution of the gamma log measurement and the depth of penetration of the measurement into the formation, which depend on well casing, source strength, source-detector configurations, logging speed, etc. These factors may vary between wells, logging campaigns, and geophysical logging contractor. With the exception of casing specifications, information about most of these factors was not available for the historical data (well Groups 2 and 3).

The standardization and cross-correlation procedures that were used here were developed to mitigate the influence of some of the factors noted above so that the gross gamma log data could be used quantitatively. The gross gamma log data for the Group 1 wells, to which no standardization procedures or cross-calibration was applied, are remarkably consistent and of similar magnitude above the 106-m elevation (Figure B.2) — even though these five wells range from $\sim 200 \mathrm{~m}$ to $\sim 2000 \mathrm{~m}$ apart (Figure B.1). The standardization procedures and cross-calibrations applied to the Group 2 and 3 wells yield consistent Group-1-equivalent results. However, it is possible that these procedures may also have eliminated some real characteristics in the data, such as areal trends between well locations.

\section{B.3 Descriptive Statistics}

Descriptive statistics for the standardized and cross-calibrated (Group 1 LFI well equivalent) gamma $\log$ data are presented in Table B.3. Figure B.11 shows box plots representing the gamma log data for each hydrostratigraphic unit. The average gross gamma ( $g g) \log$ count in unit 1 (gg=182) represents the undifferentiated Hanford formation, is significantly lower than in unit 4 ( $g g=217)$, unit 5 ( $g g=216$ ), or unit 8 ( $g g=226$ ), which are all Ringold Formation units. The average gamma log counts are nearly the same in units 4 and 5, and the average gamma log count in unit 8 is a bit larger. 
Table B.3. Descriptive Statistics for Gamma Log Data from 45 Wells in the 300 Area

\begin{tabular}{llllll}
\hline \multicolumn{1}{c}{ Gamma } & All Units & \multicolumn{1}{c}{ Unit 1 } & \multicolumn{1}{c}{ Unit 4 } & \multicolumn{1}{c}{ Unit 5 } & \multicolumn{1}{c}{ Unit 8 } \\
\hline Number of wells & 45 & 45 & 19 & 32 & 10 \\
Mean & 195.689 & 182.288 & 216.842 & 215.832 & 226.249 \\
Standard error & 0.367 & 0.310 & 1.308 & 0.734 & 2.446 \\
Median & 191.316 & 184.327 & 220.890 & 213.173 & 239.757 \\
Standard deviation & 31.630 & 20.947 & 28.933 & 33.418 & 42.639 \\
Sample variance & 1000.466 & 438.773 & 837.141 & 116.768 & 1818.121 \\
Kurtosis & 2.515 & 3.859 & 0.188 & 3.176 & -1.302 \\
Skewness & 0.933 & 0.257 & -0.525 & 0.870 & -0.283 \\
Range & 342.156 & 267.279 & 167.162 & 331.930 & 150.883 \\
Minimum & 114.595 & 114.595 & 130.758 & 124.820 & 152.785 \\
Maximum & 456.750 & 381.874 & 297.920 & 456.750 & 303.668 \\
Count & 7442 & 4578 & 489 & 2071 & 304 \\
Confidence interval & & & & & \\
for the mean at a & 0.719 & 0.607 & 2.571 & 1.440 & 4.812 \\
95\% confidence & & & & & \\
level & & & & & \\
\hline
\end{tabular}

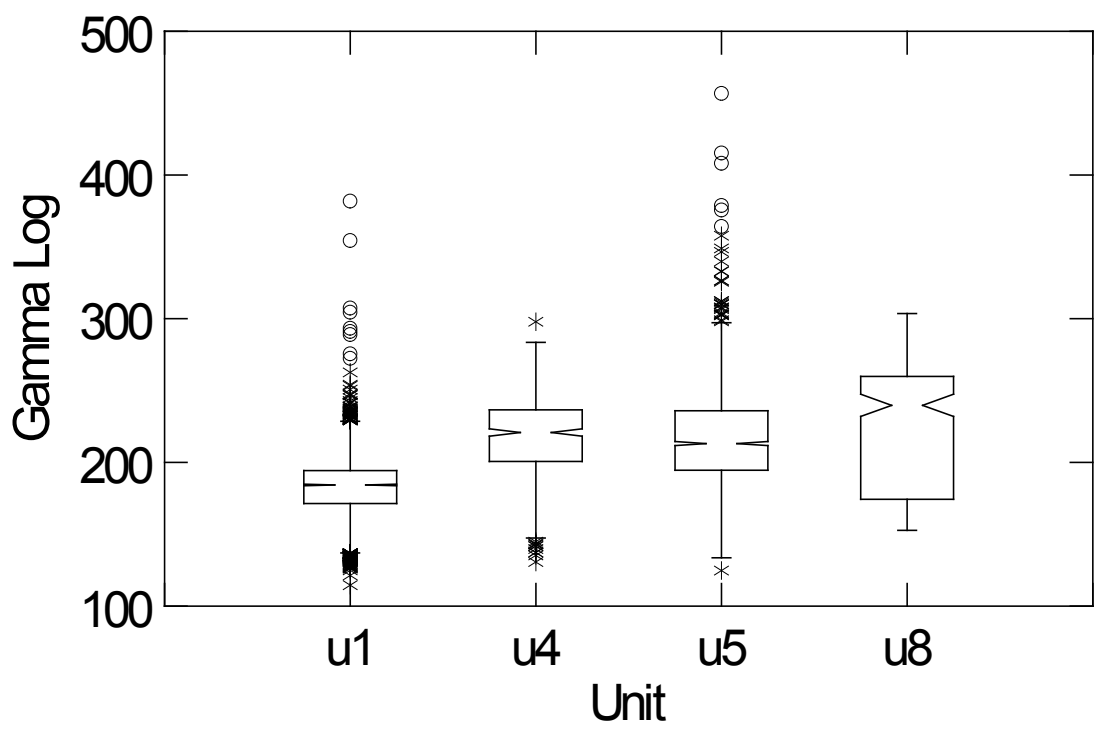

Figure B.11. Box Plots of Gamma Log Data by Hydrostratigraphic Unit 


\section{Appendix C}

\section{Whole Sediment Grain-Size Distribution Data and Metrics for Selected LFI Core Samples}





\section{Appendix C}

\section{Whole Sediment Grain-Size Distribution Data and Metrics for Selected LFI Core Samples}

Williams et al. (2007) describe various analyses that were performed on sediment samples collected from four boreholes as part of a limited field investigation (LFI) for characterization of uranium contamination in the 300 Area. Whole-sediment, grain-size distribution analyses were performed on a limited number of these LFI samples using sieve and hydrometer methods (Gee and Orr 2002). The data were fit with continuous analytic functions to generate different grain-size distribution metrics. Data from selected samples were then used to develop gamma log grain size correlation functions that are presented in Section 3 of this report. This appendix provides a description of the grain-size metrics and data that were used for developing these correlation functions.

Selected LFI core samples' grain-size metrics and data used for developing the gamma log grain size correlation functions are presented in Figures C.1 through C.13. Grain size metrics were computed using both $\mathrm{mm}$ and $\phi$ scales, where $\phi$ is defined as (Folk 1980) described in Equation (C.1).

$$
\phi=-\log _{2}(\mathrm{~mm})
$$

One of the metrics reported in Figures C.1 through C.13 is the inclusive graphic standard deviation, $\sigma_{I G}$, defined as (Folk 1980)

$$
\sigma_{I G}=\frac{d_{16}-d_{84}}{4}+\frac{d_{5}-d_{95}}{6.6}
$$

where $d$ is the grain diameter (in $\phi$ units), and the subscripts (such as 16,84 , and so on) refer to the weight percent of the bulk sample with grain sizes smaller than the given diameter. The inclusive graphic standard deviation is a measure of the uniformity or sorting of the grain size distribution.

Also reported in Figures C.1 through C.13 are the geometric mean diameter, $d_{\text {geom }}$, and the geometric standard deviation, $\sigma_{\text {geom }}$ (both in units of $\mathrm{mm}$ ) which were computed as follows (Campbell 1985)

$$
d_{\text {geom }}=\exp \left\{\sum m_{i} \ln d_{i}\right\}
$$

and

$$
\sigma_{\text {geom }}=\exp \left\{\left[\sum m_{i}\left(\ln d_{i}\right)^{2}-\left(\sum m_{i} \ln d_{i}\right)^{2}\right]^{1 / 2}\right\}
$$

and where $m_{i}$ is the mass fraction of size class $i$, and $d_{i}$ is the arithmetic mean diameter (mm) of size class $i$. The metrics $d_{\text {geom }}$ and $\sigma_{\text {geom }}$ were used by Campbell (1985) to predict moisture retention characteristics of soils from texture data. The ratio of $d_{\text {geom }} / \sigma_{\text {geom }}$ has also been used recently by Ward et al. (2006) to develop pedotransfer functions (PTFs) that relate hydraulic and sorption parameters to soil texture. 
The grain size metrics reported in Figures C.1 through C.13 were generated by fitting a continuous analytic function to each set of discrete grain size data. The analytic functions were evaluated at 500 different values of the fraction passing a given size, from a range of 0.001 to 0.999 , to generate the discrete size classes used to calculate $d_{\text {geom }}$ and $\sigma_{\text {geom }}$ from Equations (C.3) and (C.4). 


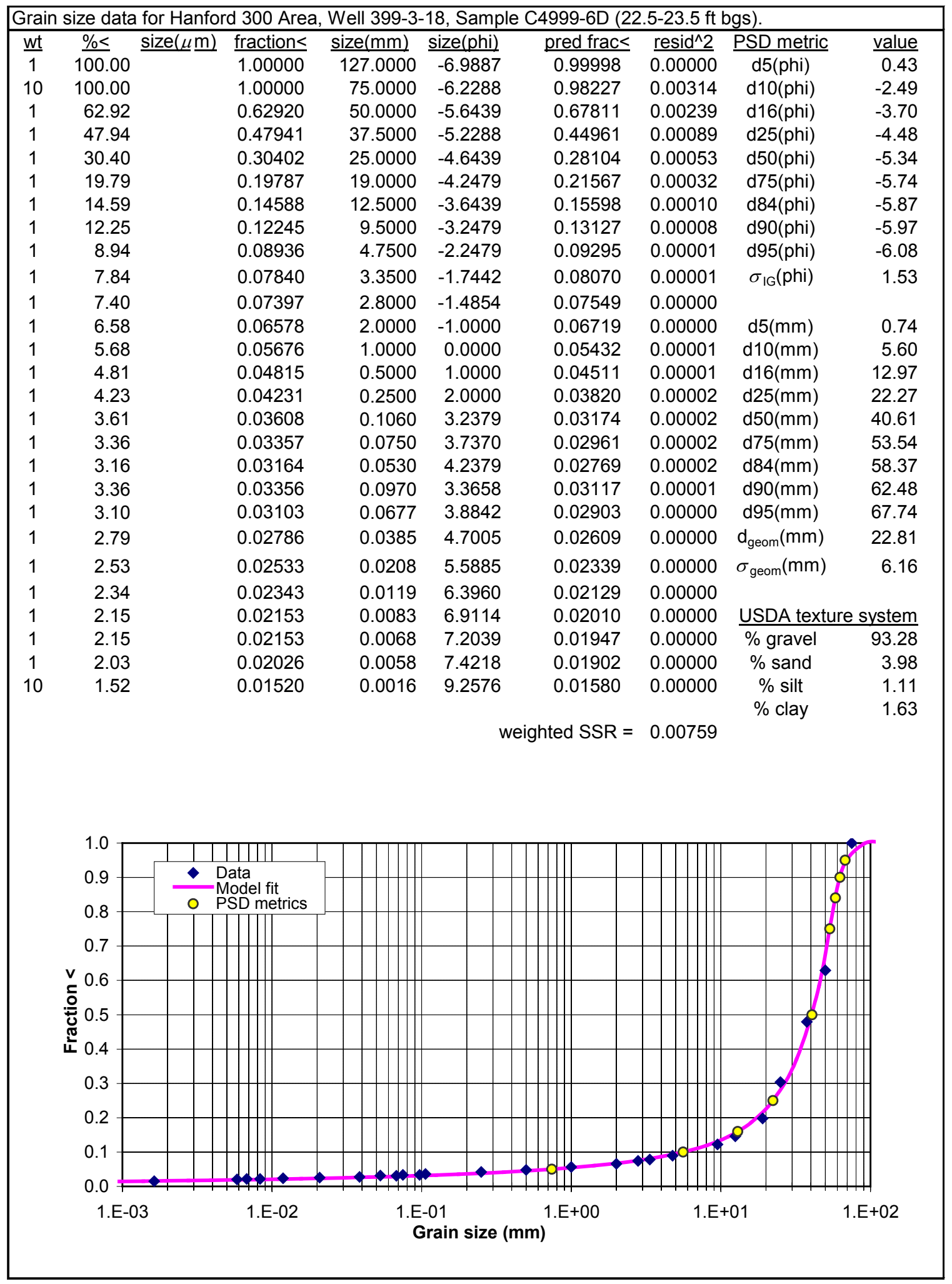

Figure C.1. Grain-Size Data for Hanford Site 300 Area, Well 399-3-18, Sample C4999-6D (Depth Interval 22.5 to $23.5 \mathrm{ft}$ ) 


\begin{tabular}{|c|c|c|c|c|c|c|c|c|c|}
\hline \multicolumn{10}{|c|}{ Grain size data for Hanford 300 Area, Well 399-3-18, Sample C4999-9C (31-32 ft bgs). } \\
\hline$\underline{\mathrm{wt}}$ & $\%<$ & \multirow{2}{*}{$\underline{\operatorname{size}(\mu} \underline{\mathrm{m}})$} & \multirow{2}{*}{ fraction< } & $\underline{\text { size }(\mathrm{mm})}$ & $\underline{\text { size(phi) }}$ & pred frac< & resid^2 & PSD metric & $\underline{\text { value }}$ \\
\hline$\overline{1}$ & $\overline{100.00}$ & & & 127.0000 & -6.9887 & 0.99974 & $\overline{0.00000}$ & d5(phi) & 2.95 \\
\hline 10 & \multicolumn{2}{|l|}{100.00} & 1.00000 & 75.0000 & -6.2288 & 0.99033 & 0.00094 & d10(phi) & 0.24 \\
\hline 1 & 85.44 & & 0.85441 & 50.0000 & -5.6439 & 0.89992 & 0.00207 & d16(phi) & -1.99 \\
\hline 1 & 74.83 & & 0.74832 & 37.5000 & -5.2288 & 0.71872 & 0.00088 & d25(phi) & -3.54 \\
\hline 1 & 45.43 & & 0.45425 & 25.0000 & -4.6439 & 0.46441 & 0.00010 & d50(phi) & -4.74 \\
\hline 1 & 34.56 & & 0.34561 & 19.0000 & -4.2479 & 0.35667 & 0.00012 & d75(phi) & -5.29 \\
\hline 1 & 27.21 & & 0.27206 & 12.5000 & -3.6439 & 0.26105 & 0.00012 & d84(phi) & -5.48 \\
\hline 1 & 22.75 & & 0.22748 & 9.5000 & -3.2479 & 0.22380 & 0.00001 & d90(phi) & -5.64 \\
\hline 1 & 17.15 & & 0.17150 & 4.7500 & -2.2479 & 0.16947 & 0.00000 & d95(phi) & -5.84 \\
\hline 1 & 15.14 & & 0.15143 & 3.3500 & -1.7442 & 0.15195 & 0.00000 & $\sigma_{\mathrm{IG}}(\mathrm{phi})$ & 2.21 \\
\hline 1 & 14.15 & & 0.14154 & 2.8000 & -1.4854 & 0.14409 & 0.00001 & & \\
\hline 1 & 12.75 & & 0.12753 & 2.0000 & -1.0000 & 0.13057 & 0.00001 & $\mathrm{~d} 5(\mathrm{~mm})$ & 0.13 \\
\hline 1 & 10.69 & & 0.10691 & 1.0000 & 0.0000 & 0.10558 & 0.00000 & $\mathrm{~d} 10(\mathrm{~mm})$ & 0.85 \\
\hline 1 & 7.75 & & 0.07749 & 0.5000 & 1.0000 & 0.08341 & 0.00004 & $\mathrm{~d} 16(\mathrm{~mm})$ & 3.97 \\
\hline 1 & 6.11 & & 0.06112 & 0.2500 & 2.0000 & 0.06454 & 0.00001 & $\mathrm{~d} 25(\mathrm{~mm})$ & 11.64 \\
\hline 1 & 4.91 & & 0.04905 & 0.1060 & 3.2379 & 0.04626 & 0.00001 & $\mathrm{~d} 50(\mathrm{~mm})$ & 26.80 \\
\hline 1 & 4.46 & & 0.04458 & 0.0750 & 3.7370 & 0.04039 & 0.00002 & $\mathrm{~d} 75(\mathrm{~mm})$ & 39.17 \\
\hline 1 & 4.07 & & 0.04072 & 0.0530 & 4.2379 & 0.03527 & 0.00003 & $\mathrm{~d} 84(\mathrm{~mm})$ & 44.77 \\
\hline 1 & 4.40 & & 0.04402 & 0.0855 & 3.5487 & 0.04251 & 0.00000 & $\mathrm{~d} 90(\mathrm{~mm})$ & 50.01 \\
\hline 1 & 3.67 & & 0.03668 & 0.0599 & 4.0611 & 0.03699 & 0.00000 & $\mathrm{~d} 95(\mathrm{~mm})$ & 57.30 \\
\hline 1 & 3.30 & & 0.03302 & 0.0344 & 4.8598 & 0.02985 & 0.00001 & $\mathrm{~d}_{\text {geom }}(\mathrm{mm})$ & 12.56 \\
\hline 1 & 2.57 & & 0.02568 & 0.0187 & 5.7410 & 0.02367 & 0.00000 & $\sigma_{\text {geom }}(\mathrm{mm})$ & 8.15 \\
\hline 1 & 2.20 & & 0.02201 & 0.0107 & 6.5400 & 0.01930 & 0.00001 & & \\
\hline 1 & 1.83 & & 0.01834 & 0.0076 & 7.0465 & 0.01701 & 0.00000 & USDA textu & system \\
\hline 1 & 1.83 & & 0.01834 & 0.0062 & 7.3389 & 0.01584 & 0.00001 & $\%$ gravel & 86.94 \\
\hline 1 & 1.47 & & 0.01467 & 0.0053 & 7.5530 & 0.01503 & 0.00000 & $\%$ sand & 9.61 \\
\hline 10 & 0.73 & & 0.00734 & 0.0015 & 9.3521 & 0.00990 & 0.00007 & $\%$ silt & 2.37 \\
\hline & & & & & & & & $\%$ clay & 1.08 \\
\hline & & & & & & ghted SSR = & 0.00446 & & \\
\hline & 1.0 & & & & & & & & \\
\hline & 0.9 & $\diamond$ & Jata & & & & & & \\
\hline & 0.8 & 0 & SD metrics & & & & & & \\
\hline & 0.7 & & & & & & & 8 & \\
\hline & $v 06$ & & & & & & & 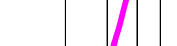 & \\
\hline & 둥 & & & & & & & & \\
\hline & 歾 0.4 & & & & & & & 5 & \\
\hline & 03 & & & & & & & & \\
\hline & 02 & & & & & & & & \\
\hline & 0.1 & & & & & & & & \\
\hline & 0.0 & & & & & & & & \\
\hline & 1.E- & & 1.E-02 & & Grain size & 1. $E+00$ & & & $E+02$ \\
\hline
\end{tabular}

Figure C.2. Grain-Size Data for Hanford Site 300 Area, Well 399-3-18, Sample C4999-9C (Depth Interval 31 to $32 \mathrm{ft}$.) 


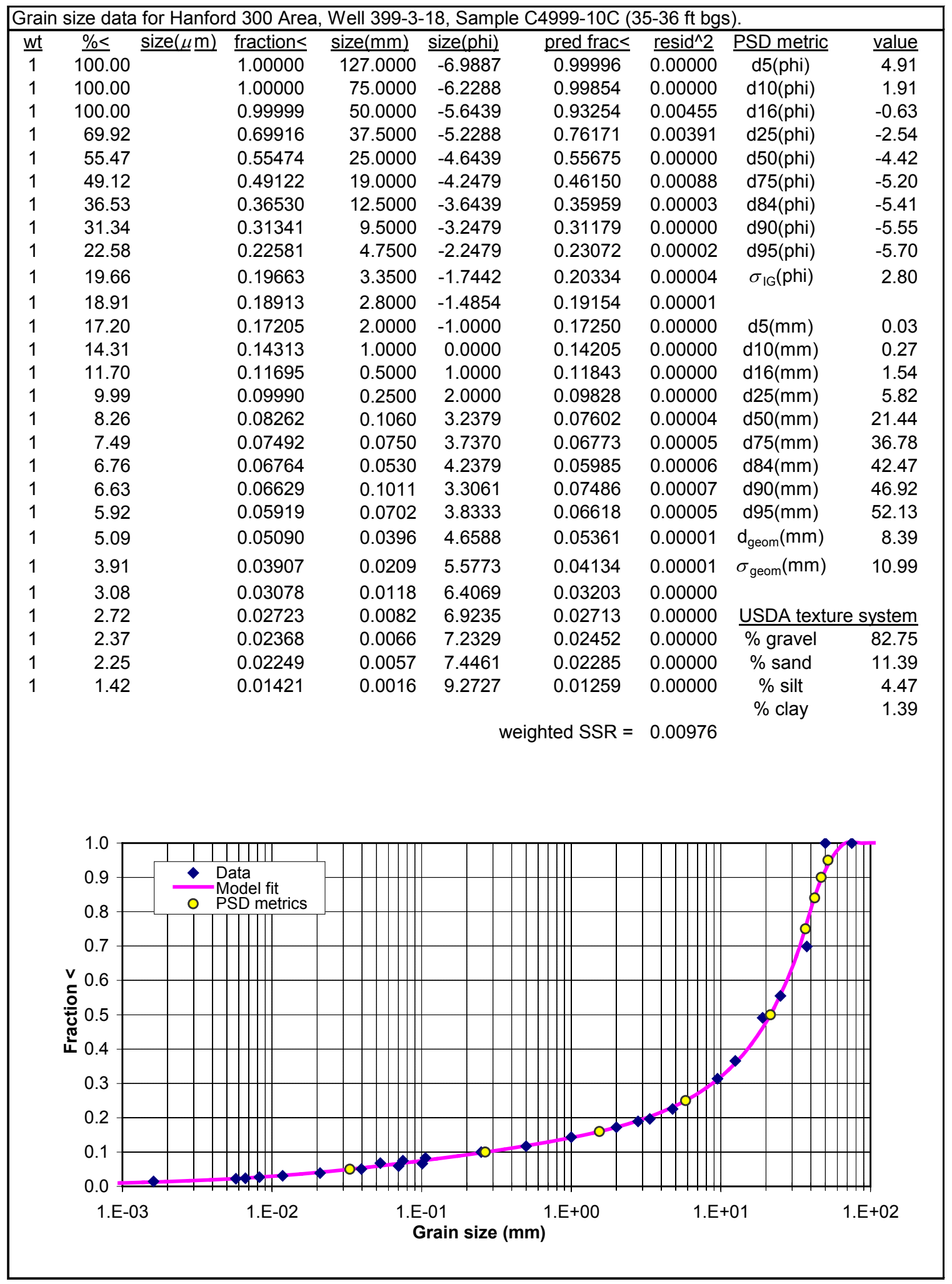

Figure C.3. Grain-Size Data for Hanford Site 300 Area, Well 399-3-18, Sample C4999-10C (Depth Interval 35 to $36 \mathrm{ft}$ ) 


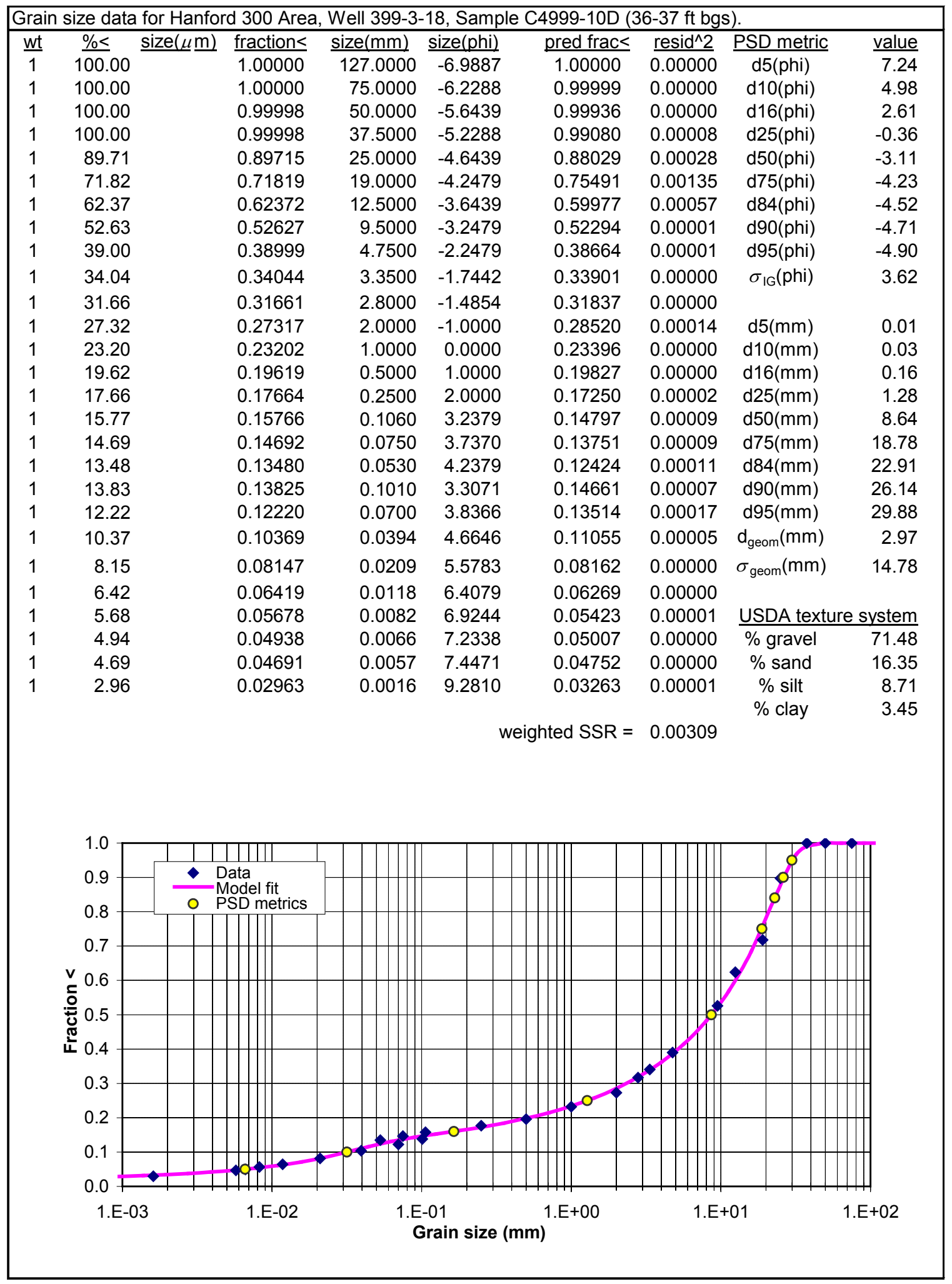

Figure C.4. Grain-Size Data for Hanford Site 300 Area, Well 399-3-18, Sample C4999-10D (Depth Interval 36 to $37 \mathrm{ft}$ ) 


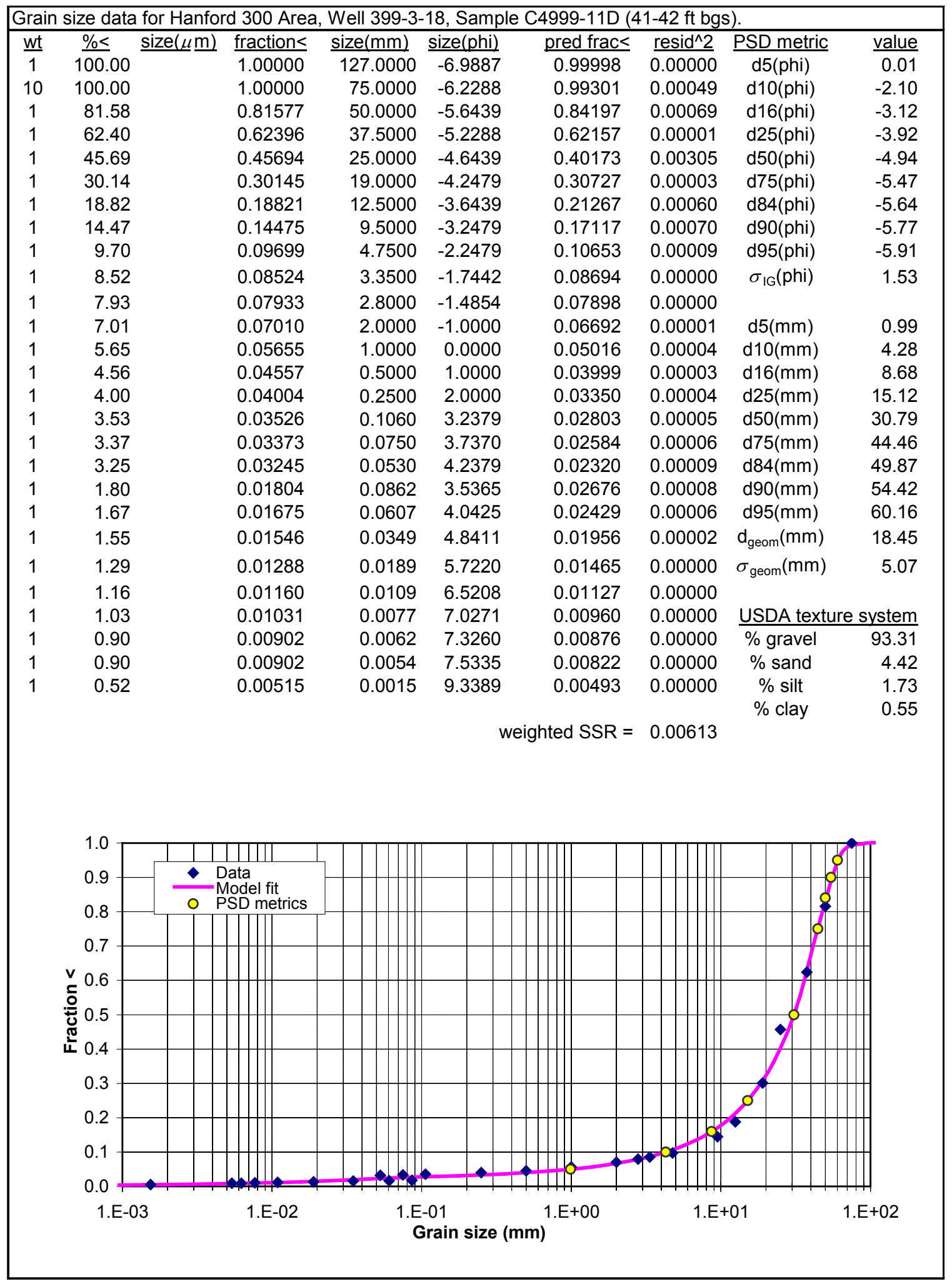

Figure C.5. Grain-Size Data for Hanford Site 300 Area, Well 399-3-18, Sample C4999-11D (Depth Interval 41 to $42 \mathrm{ft}$ ) 


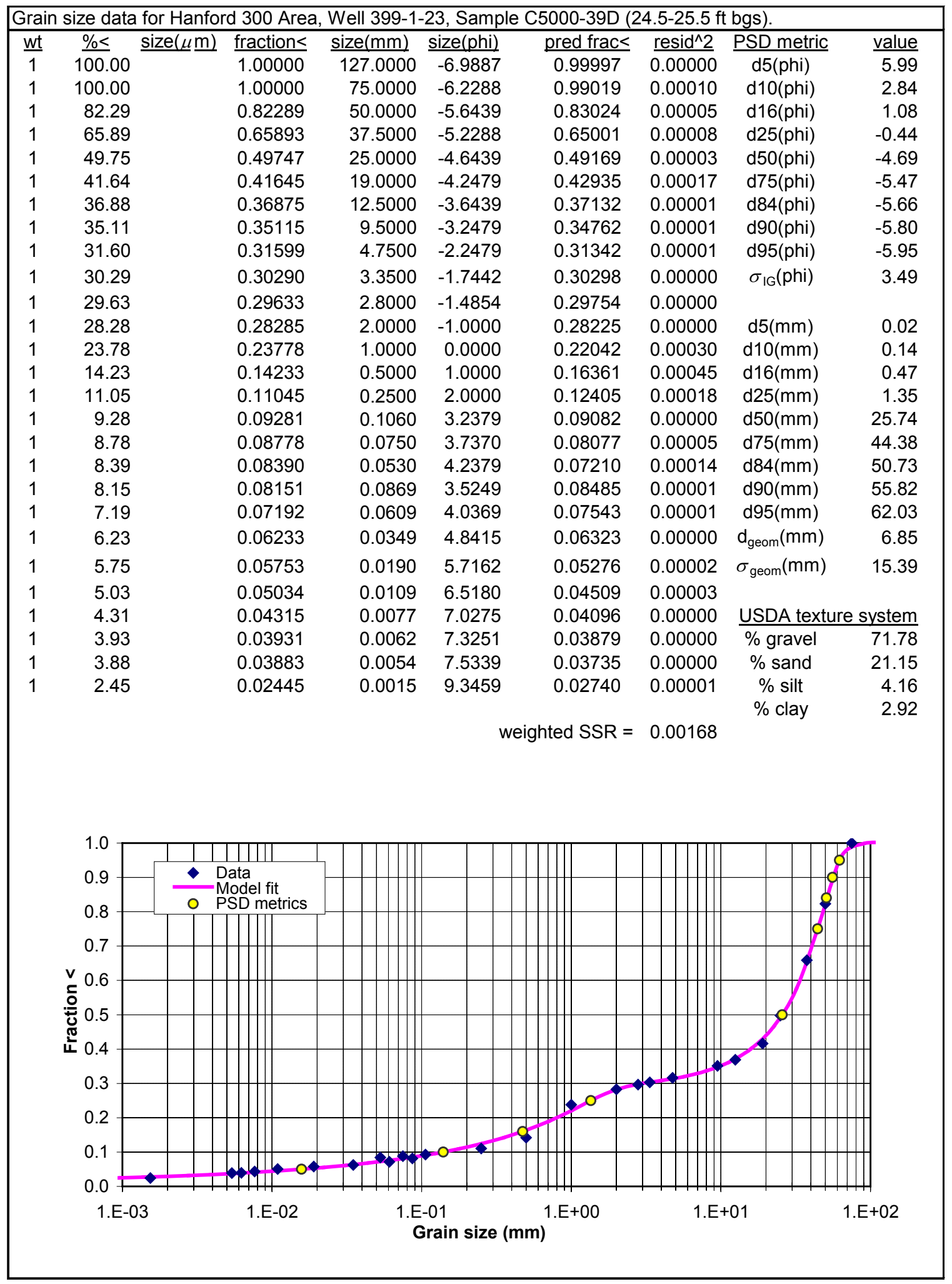

Figure C.6. Grain-Size Data for Hanford Site 300 Area, Well 399-1-23, Sample C5000-39D (Depth Interval 24.5 to $25.5 \mathrm{ft}$ ) 


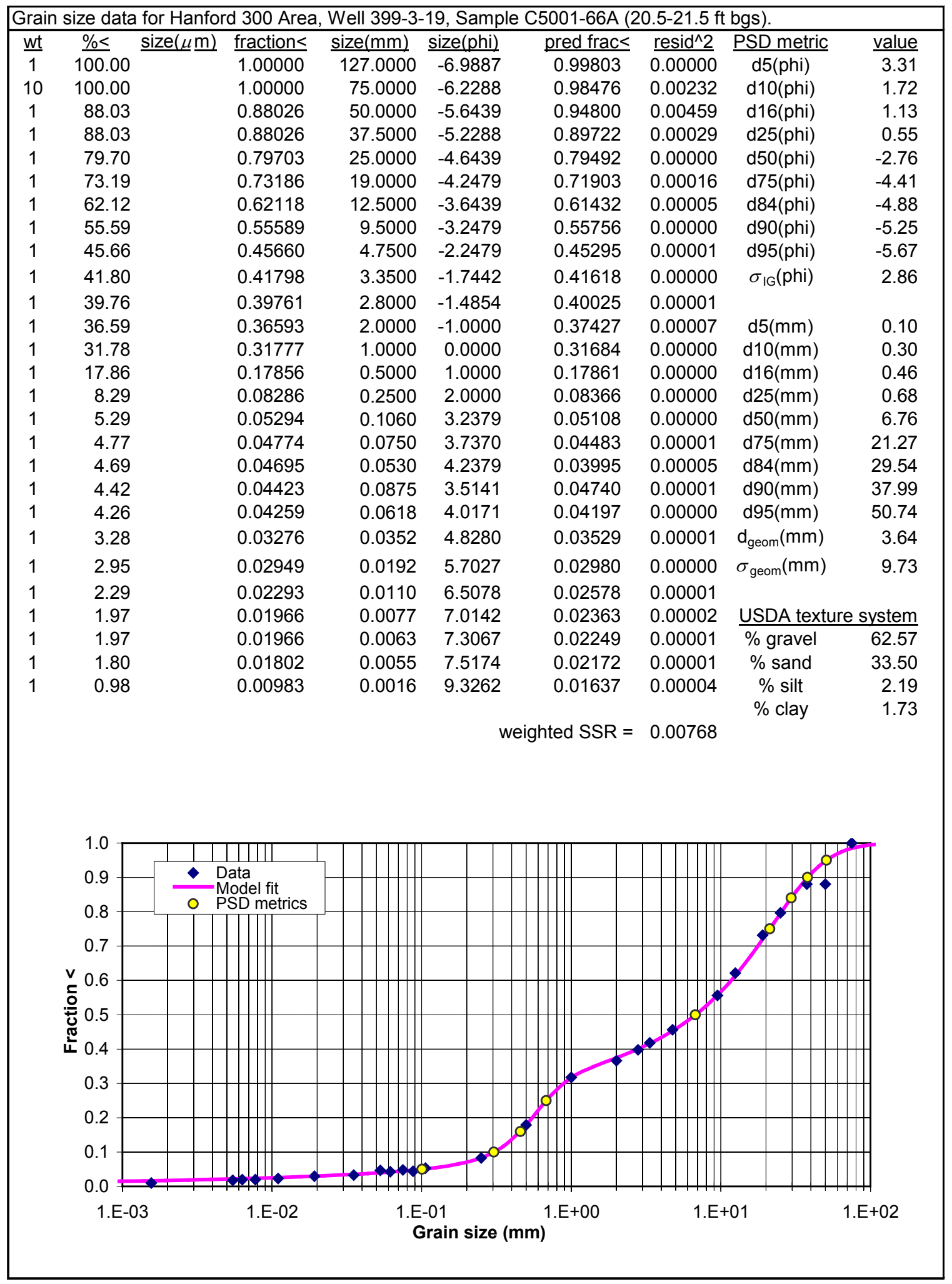

Figure C.7. Grain-Size Data for Hanford Site 300 Area, Well 399-3-19, Sample C5001-66A (Depth Interval 20.5 to $21.5 \mathrm{ft}$ ) 


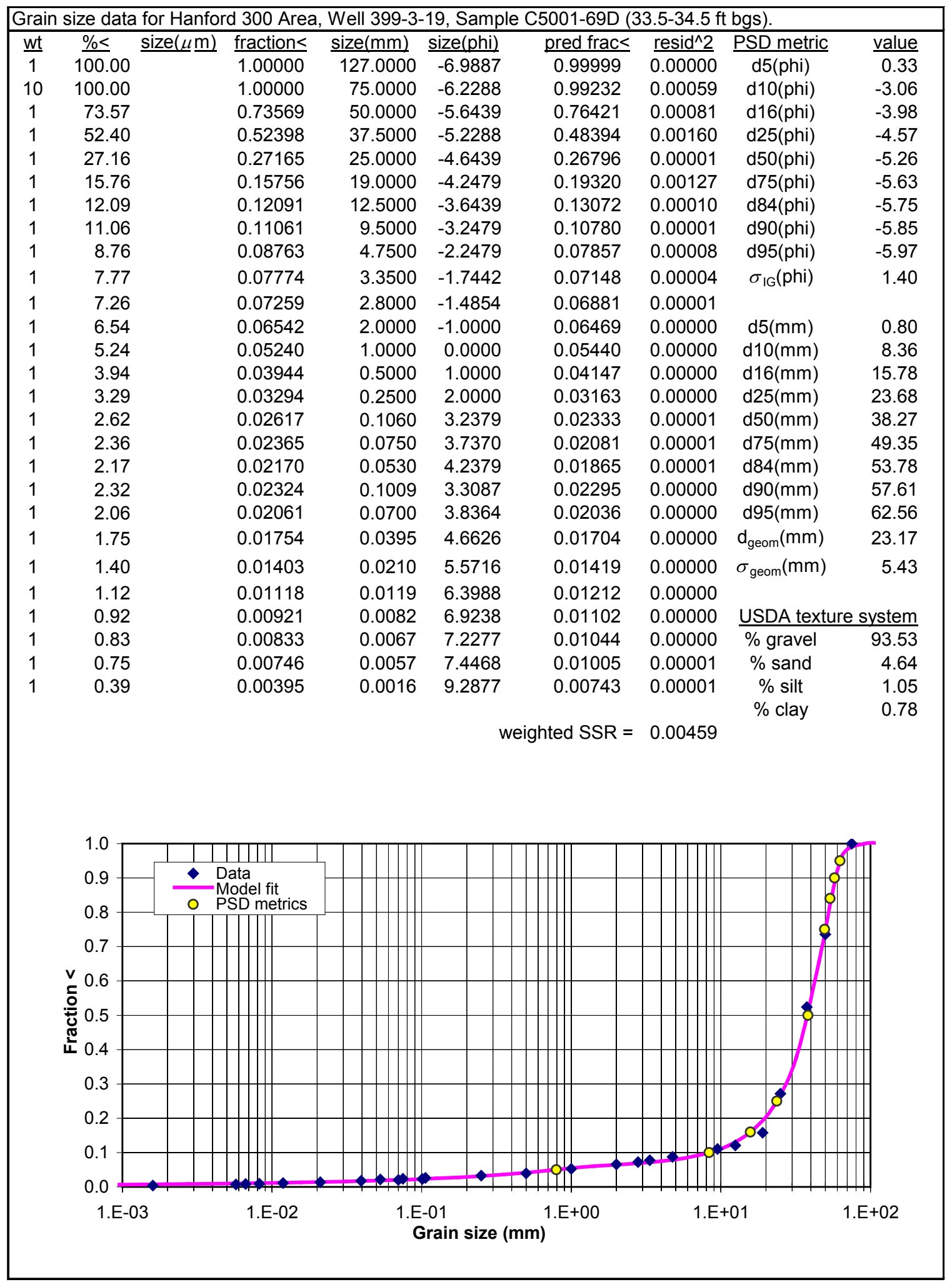

Figure C.8. Grain-Size Data for Hanford Site 300 Area, Well 399-3-19, Sample C5001-69D (Depth Interval 33.5 to $34.5 \mathrm{ft}$ ) 


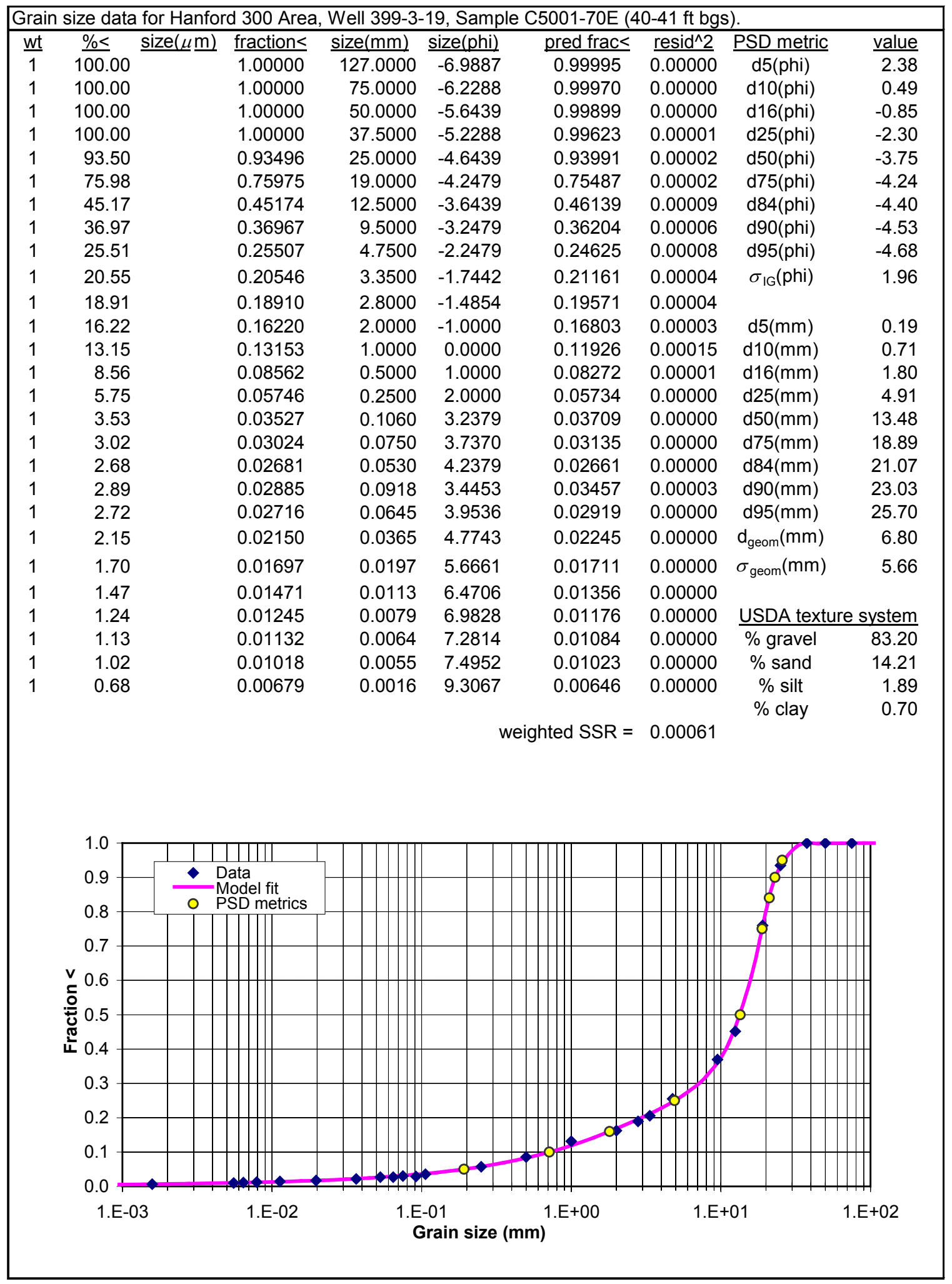

Figure C.9. Grain-Size Data for Hanford Site 300 Area, Well 399-3-19, Sample C5001-70E (Depth Interval 40 to $41 \mathrm{ft}$ ) 


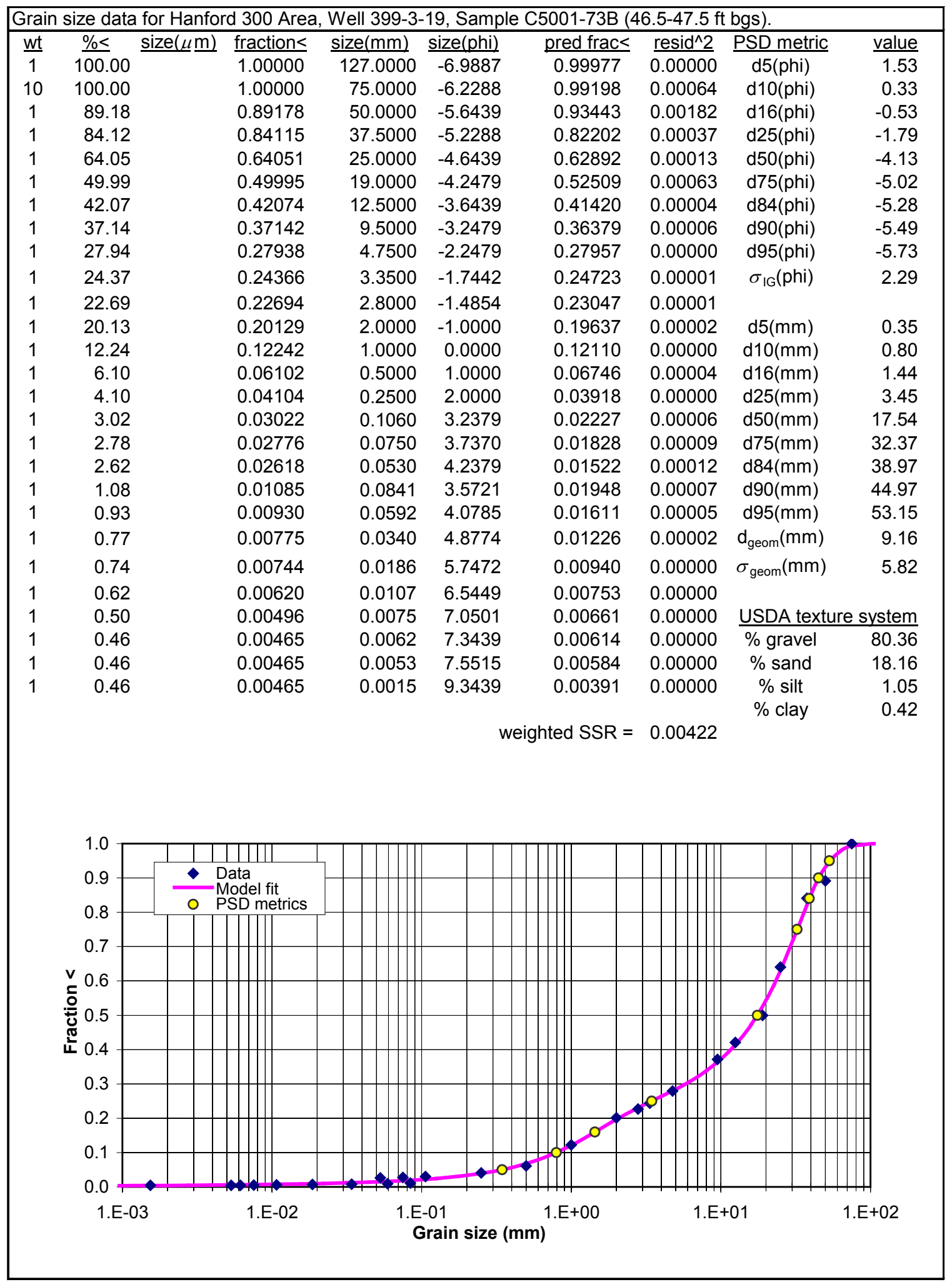

Figure C.10. Grain Size Data for Hanford Site 300 Area, Well 399-3-19, Sample C5001-73B (Depth Interval 46.5 to $47.5 \mathrm{ft}$ ) 


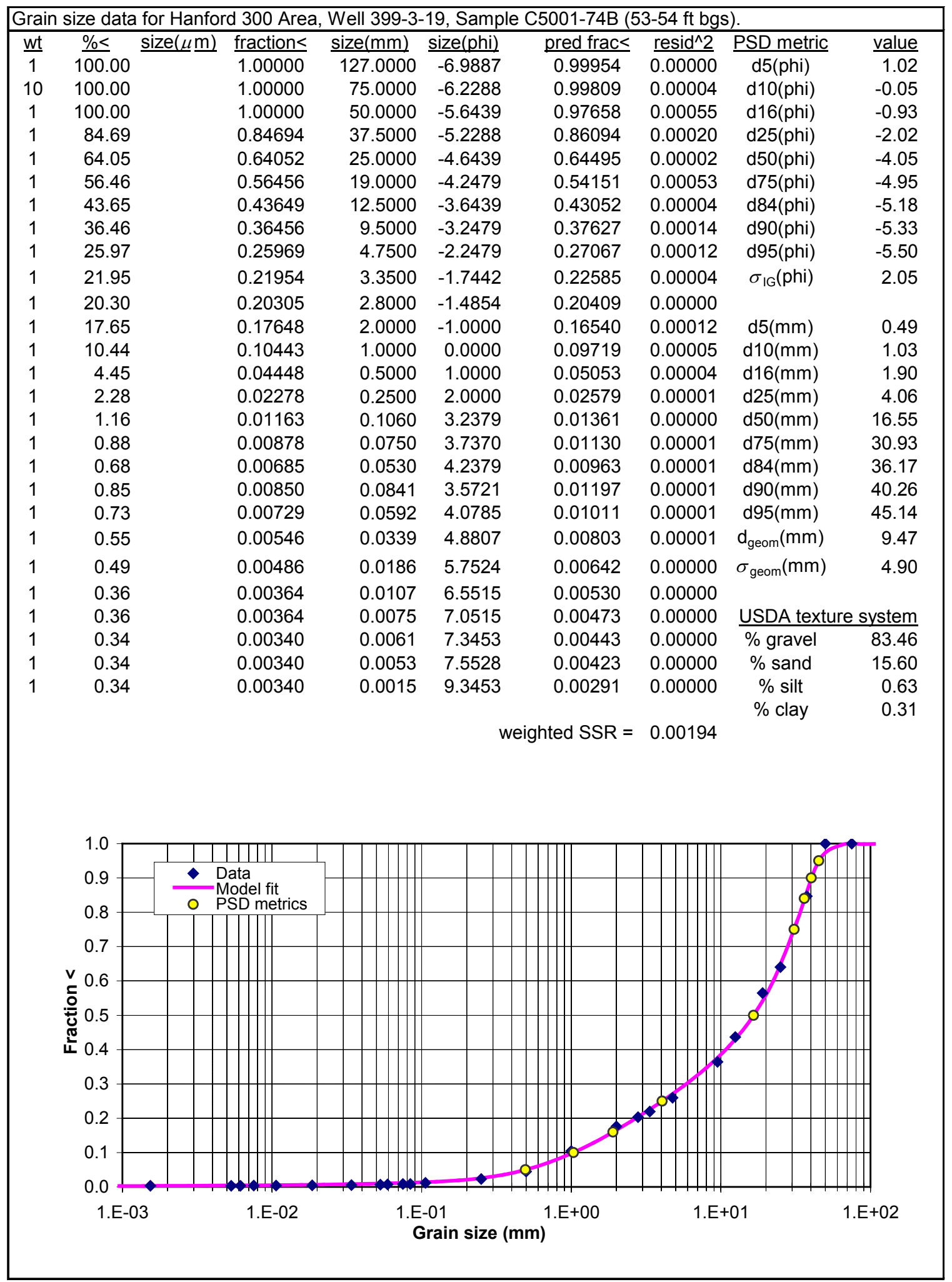

Figure C.11. Grain-Size Data for Hanford Site 300 Area, Well 399-3-19, Sample C5001-74B (Depth Interval 53 to $54 \mathrm{ft}$ ) 


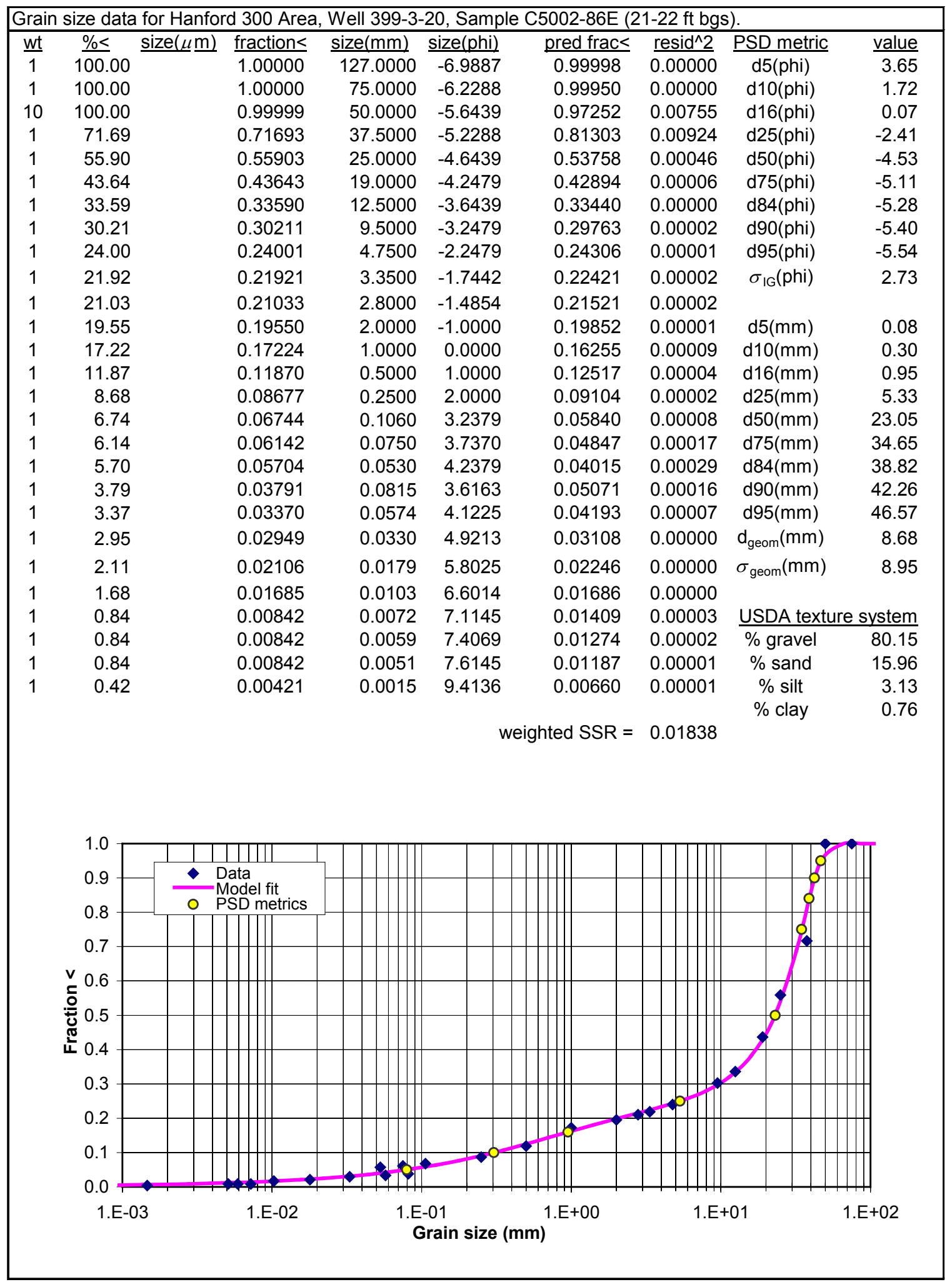

Figure C.12. Grain-Size Data for Hanford Site 300 Area, Well 399-3-20, Sample C5002-86E (Depth Interval 21 to $22 \mathrm{ft}$ ) 


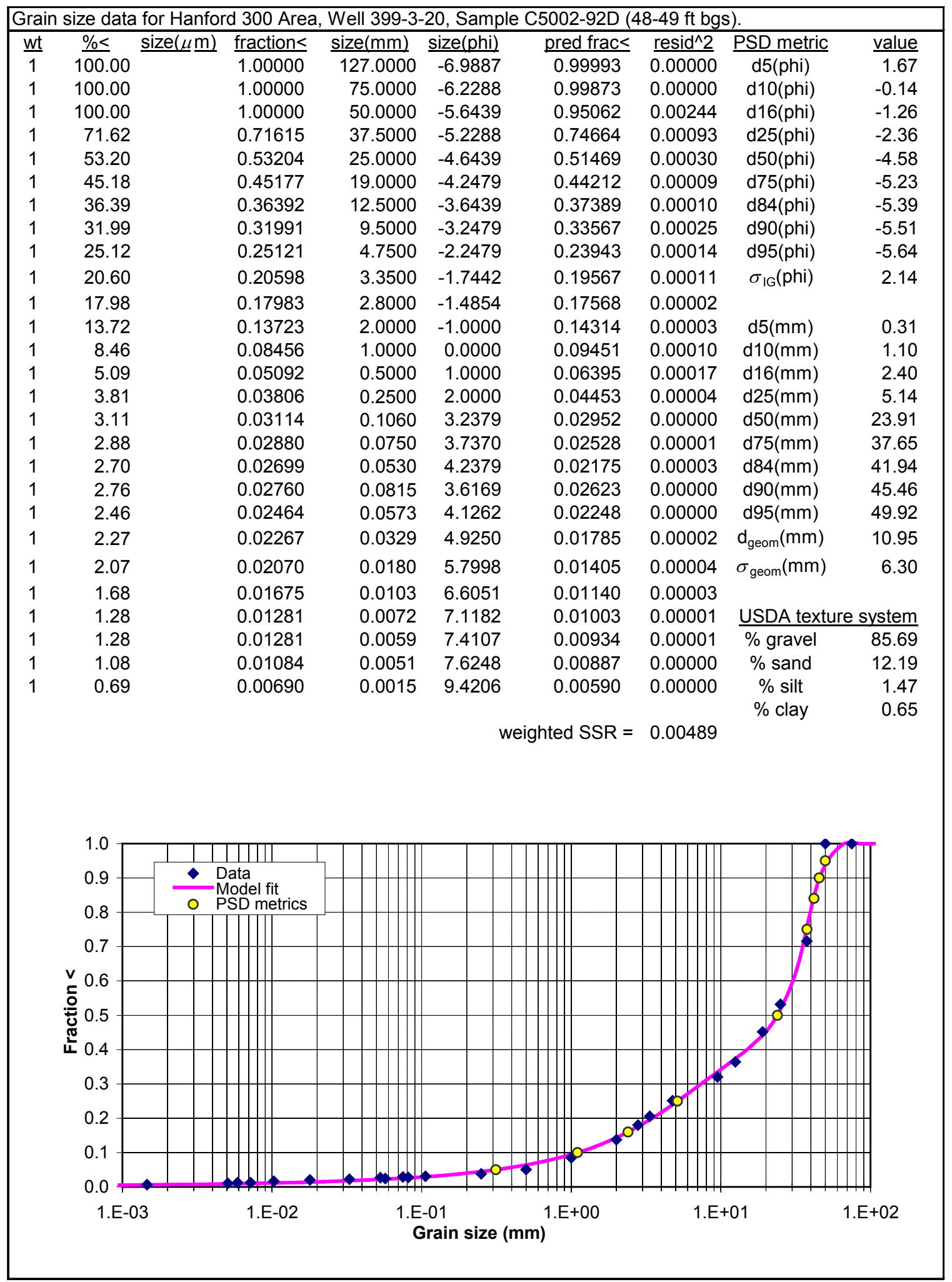

Figure C.13. Grain-Size Data for Hanford Site 300 Area, Well 399-3-20, Sample C5002-92D (Depth Interval 48 to $49 \mathrm{ft}$ ) 



\section{Appendix D}

Tests for Statistical Significance of Differences Between Mean Values 



\section{Appendix D}

\section{Tests for Statistical Significance of Differences Between Mean Values}

To test the statistical significance of differences between the mean values of a variable or parameter for two sample populations, the following test statistics and assumptions are used. The data are assumed to be independent random samples of size $n_{1}$ and $n_{2}$ from normal populations with means $\mu_{1}$ and $\mu_{2}$ and known variances $\sigma_{1}^{2}$ and $\sigma_{2}^{2}$. The null hypothesis, $\mathrm{H}_{0}$, is that $\mu_{1}-\mu_{2}=\delta$, where $\delta$ is a given constant. The alternative hypotheses are that $\mu_{1}-\mu_{2} \neq \delta, \mu_{1}-\mu_{2}>\delta$, or $\mu_{1}-\mu_{2}<\delta$.

For large sample sizes $\left(n_{1,2} \geq 30\right)$, critical regions are defined as $|z| \geq z_{\alpha / 2}, z \geq z_{\alpha}$, and $z \leq-z_{\alpha}$, where $\alpha$ is the level of significance,

$$
z=\frac{\bar{x}_{1}-\bar{x}_{2}-\delta}{\sqrt{\frac{\sigma_{1}^{2}}{n_{1}}+\frac{\sigma_{2}^{2}}{n_{2}}}}
$$

and $\bar{x}_{1}$ and $\bar{x}_{2}$ are the sample means (Freund and Walpole, 1987). For $\alpha=0.05$, the null hypothesis is rejected if $z \leq-1.96$ or $z \geq 1.96$. If $z$ falls between -1.96 and 1.96 , the null hypothesis cannot be rejected. In this case the null hypothesis is either accepted, or it is said that the difference between the sample means is not significant, or else that the difference between the sample means is not large enough to reject the null hypothesis.

If $n_{1}$ or $n_{2}$ (or both) are small $(<30)$ and $\sigma_{1}$ and $\sigma_{2}$ are unknown, a different test statistic is used. For independent random samples from two normal distributions having the (assumed) same but unknown variance, $\sigma^{2}$, the following test statistic is applicable

$$
t=\frac{\bar{x}_{1}-\bar{x}_{2}-\delta}{s_{p} \sqrt{\frac{1}{n_{1}}+\frac{1}{n_{2}}}}
$$

where

$$
s_{p}^{2}=\frac{\left(n_{1}-1\right) s_{1}^{2}+\left(n_{2}-1\right) s_{2}^{2}}{n_{1}+n_{2}-2}
$$

and where the quantity $n_{1}+n_{2}-2$ represents the degrees of freedom (Freund and Walpole, 1987). Critical regions are then defined by $|t| \geq t_{\alpha / 2, n_{1}+n_{2}-2}, t \geq t_{\alpha, n_{1}+n_{2}-2}$, and $t \leq-t_{\alpha, n_{1}+n_{2}-2}$. Since the critical $t$ value depends on the degrees of freedom, it must be determined from standard statistical tables (c.f. Freund and 
Walpole, 1987). For $\alpha=0.05$, and $\left(n_{1}+n_{2}-2\right) \geq 30$, the critical $t$ value is 1.96 . All tests for differences in mean values reported here assume $\alpha=0.05$ and $\delta=0$.

Table D.1 summarizes the $\mathrm{z}$ - and t-test statistics for the mean value comparisons for various combinations of sample populations. Comparisons for which the computed test statistics indicate that the

difference between the sample means is not large enough to reject the null hypothesis (that the difference between the mean values is zero) are given in bold print.

\section{Reference}

Freund, J.E, and R.E. Walpole. 1987. Mathematical Statistics, $4^{\text {th }}$ edition. Prentice-Hall, Inc., Englewood Cliffs, New Jersey. 
Table D.1. Statistical Significance of Differences in Mean Values for Density, Porosity, and Gamma Log Data. If $|z|<1.96$ or $|t|<1.96$ then the difference between the mean values is not large enough to reject the null hypothesis (that the difference in mean values is zero).

\begin{tabular}{|c|c|c|c|c|c|c|c|c|c|c|}
\hline Variable 1 & Variable 2 & $\bar{x}_{1}$ & $\bar{x}_{2}$ & $\sigma_{1}^{2}$ & $\sigma_{2}^{2}$ & $\mathrm{n}_{1}$ & $\mathrm{n}_{2}$ & $s_{p}^{2}$ & $z$ & $t$ \\
\hline Particle density, u1 & Particle density, u4 & 2.76 & 2.63 & 0.002 & 0.007 & 53 & 9 & 0.00 & 4.62 & 7.09 \\
\hline Particle density, u1 & Particle density, u5 & 2.76 & 2.66 & 0.002 & 0.005 & 53 & 86 & 0.00 & 9.91 & 8.94 \\
\hline Particle density, u1 & Particle density, u8 \& u9 & 2.76 & 2.62 & 0.002 & 0.006 & 53 & 29 & 0.00 & 8.63 & 10.02 \\
\hline Particle density, u1 & Particle density, all Ring & 2.76 & 2.65 & 0.002 & 0.006 & 53 & 124 & 0.00 & 11.64 & 9.49 \\
\hline Bulk density, u1 & Bulk density, u4 & 2.08 & 1.56 & 0.058 & 0.058 & 159 & 46 & 0.06 & 12.87 & 12.87 \\
\hline Bulk density, u1 & Bulk density, u5 & 2.08 & 2.04 & 0.058 & 0.059 & 159 & 165 & 0.06 & 1.19 & 1.19 \\
\hline Bulk density, u1 & Bulk density, u8 \& u9 & 2.08 & 1.42 & 0.058 & 0.116 & 159 & 36 & 0.07 & 10.97 & 13.60 \\
\hline Bulk density, u1 & Bulk density, all Ring & 2.08 & 1.86 & 0.058 & 0.135 & 159 & 247 & 0.10 & 7.09 & 6.50 \\
\hline Poros, u1 & Poros, u4 & 0.249 & 0.411 & 0.0075 & 0.0087 & 158 & 46 & 0.01 & -10.56 & -11.01 \\
\hline Poros, u1 & Poros, u5 & 0.249 & 0.233 & 0.0075 & 0.0079 & 158 & 164 & 0.01 & 1.67 & 1.67 \\
\hline Poros, u1 & Poros, u8 \& u9 & 0.249 & 0.461 & 0.0075 & 0.0158 & 158 & 36 & 0.01 & -9.63 & -12.11 \\
\hline Poros, u1 - LFI wells & Poros, u1 - non-LFI wells & 0.236 & 0.282 & 0.0083 & 0.0042 & 112 & 46 & 0.01 & -3.58 & -3.12 \\
\hline Poros, u4 - LFI wells & Poros, u4 - non-LFI wells & 0.428 & 0.281 & 0.0055 & 0.0192 & 41 & 5 & 0.01 & 2.32 & 3.77 \\
\hline Poros, u5 - LFI wells & Poros, u5 - non-LFI wells & 0.202 & 0.265 & 0.0063 & 0.0075 & 84 & 80 & 0.01 & -4.91 & -4.92 \\
\hline Poros, u8 \& u9 - LFI & Poros, u8 \& u9 - non-LFI & 0.428 & 0.470 & 0.0214 & 0.0148 & 7 & 29 & 0.02 & -0.70 & -0.79 \\
\hline Poros, u1 - LFI < 106m & Poros, u1 - non-LFI < 106m & 0.191 & 0.246 & 0.0029 & 0.0062 & 25 & 7 & 0.00 & -1.74 & -2.16 \\
\hline Poros, u1 - LFI > 106m & Poros, u1 - non-LFI > 106m & 0.248 & 0.288 & 0.0092 & 0.0037 & 87 & 39 & 0.01 & -2.80 & -2.38 \\
\hline Poros, 4 LFI wells, all units & Poros, 4 non-LFI wells, all units & 0.262 & 0.262 & 0.0144 & 0.007 & 244 & 46 & 0.01 & -0.01 & -0.01 \\
\hline Poros, 4 LFI wells, u1 & Poros, 4 non-LFI wells, u1 & 0.236 & 0.231 & 0.0083 & 0.0051 & 112 & 11 & 0.01 & 0.21 & 0.17 \\
\hline Poros, 4 LFI wells, u4 & Poros, 4 non-LFI wells, u4 & 0.427 & 0.233 & 0.0055 & 0.0023 & 41 & 3 & 0.01 & 6.49 & 4.45 \\
\hline Poros, 4 LFI wells, u5 & Poros, 4 non-LFI wells, u5 & 0.202 & 0.258 & 0.0063 & 0.0062 & 84 & 26 & 0.01 & -3.19 & -3.17 \\
\hline Poros, 4 LFI wells, u8 \& u9 & Poros, 4 non-LFI wells, u8 \& u9 & 0.428 & 0.349 & 0.0214 & 0.0089 & 7 & 6 & 0.02 & 1.16 & 1.12 \\
\hline Poros, 4 LFI, u1 < 106m & Poros, 4 non-LFI, u1 < 106m & 0.191 & 0.232 & 0.0029 & 0.0058 & 25 & 4 & 0.00 & -1.02 & -1.32 \\
\hline Poros, 4 LFI, u1 > 106m & Poros, 4 non-LFI, u1 > 106m & 0.248 & 0.230 & 0.0091 & 0.0057 & 87 & 7 & 0.01 & 0.60 & 0.49 \\
\hline Gross gamma, u1 & Gross gamma, u4 & 182 & 217 & 439 & 837 & 4578 & 489 & 477 & -25.70 & -33.25 \\
\hline Gross gamma, u1 & Gross gamma, u5 & 182 & 216 & 439 & 1117 & 4578 & 2071 & 650 & -42.09 & -49.69 \\
\hline Gross gamma, u1 & Gross gamma, u8 & 182 & 226 & 439 & 1818 & 4578 & 304 & 524 & -17.83 & -32.41 \\
\hline Gross gamma, u4 & Gross gamma, u5 & 217 & 216 & 837 & 1117 & 489 & 2071 & 1063 & 0.67 & 0.62 \\
\hline Gross gamma, u4 & Gross gamma, u8 & 217 & 226 & 837 & 1818 & 489 & 304 & 1213 & -3.39 & -3.70 \\
\hline Gross gamma, u5 & Gross gamma, u8 & 216 & 226 & 1117 & 1818 & 2071 & 304 & 1206 & -4.08 & -4.88 \\
\hline
\end{tabular}





\section{Distribution}

No. of

Copies

\section{OFFSITE}

Mark Conrad

Lawrence Berkeley National Laboratory

1 Cyclotron Rd.

MS 70A-4418

Berkeley, CA 94720

John N. Christensen

Lawrence Berkeley National Laboratory

1 Cyclotron Rd.

MS 70A-4418

Berkeley, CA 94720

James A. Davis

U.S. Geological Survey

Bldg. 15, McKelvey Building

Menlo Park, CA 94025

Craig Arola

Vista Engineering

8203 W. Quinault Ave.

Kennewick, WA 99336

Tom Stoops, LPG

Oregon Office of Energy

Nuclear Safety Division

625 Marion Street NE

Salem, OR 97303

\section{ONSITE}

12 DOE Richland Operations Office

B.L. Charboneau

J.P. Hanson

R.D. Hildebrand

J.G. Morse

K.M. Thompson (6)

DOE Public Reading Room (2)

8 Fluor Hanford, Inc.

J.V. Borghese

D.B. Erb

B.H. Ford
E6-44

A6-33

A5-13

A6-38

A6-38

A6-38

$\mathrm{H} 2-53$

E6-44

E6-44
No. of

Copies

J.W. Lindberg E6-44

D.S. Miller E6-44

S.W. Petersen E6-44

J.L. Smoot E6-44

B.A. Williams $\quad$ E6-44

4 U.S. Environmental Protection Agency
A.L. Boyd (3)
B1-46
L.E. Gadbois
B1-46

3 Washington State Department of Ecology

$\begin{array}{ll}\text { J.A. Caggiano } & \mathrm{H} 0-57 \\ \text { A.D. Huckaby } & \mathrm{H} 0-57 \\ \text { J. Price } & \mathrm{H} 0-57\end{array}$

2 Washington Closure Hanford, Inc.

J.W. Darby L6-06

E.T. Feist H4-22

29 Pacific Northwest National Laboratory

Y. Chen

K1-85

B.N. Bjornstad

K6-81

C.F. Brown

P7-22

V.L. Freedman

K9-36

M.D. Freshley

K9-33

B.G. Fritz

K6-75

J.S. Fruchter

K6-96

G.E. Hammond

K9-36

C.D. Johnson

K6-96

M.J. Nimmons

K6-96

R. Mackley

K6-96

G.W. Patton

K6-75

R.E. Peterson

K6-75

M.L. Rockhold K9-36

R.M. Smith K6-96

P.D. Thorne K6-96

V.R. Vermeul K6-96

A.L. Ward K9-33

M.D. Williams (6) K6-96

S.B. Yabusaki K9-36

J.M. Zachara K8-96

F. Zhang K9-33

Hanford Technical Library (2) P8-55 



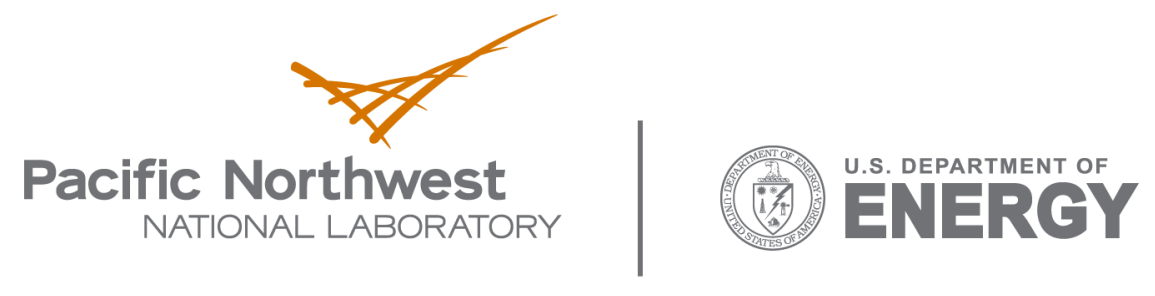

902 Battelle Boulevard

P.O. Box 999

Richland, WA 99352

1-888-375-PNNL (7665)

www.pnl.gov 